\title{
Fast Flux Test Facility Transition Project Plan
}

Prepared for the U.S. Department of Energy Office of Environmental Restoration and Waste Management

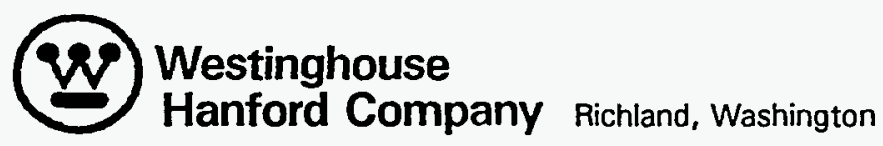




\section{DISCLAIMER}

Portions of this document may be illegible in electronic image products. Images are produced from the best available original document. 


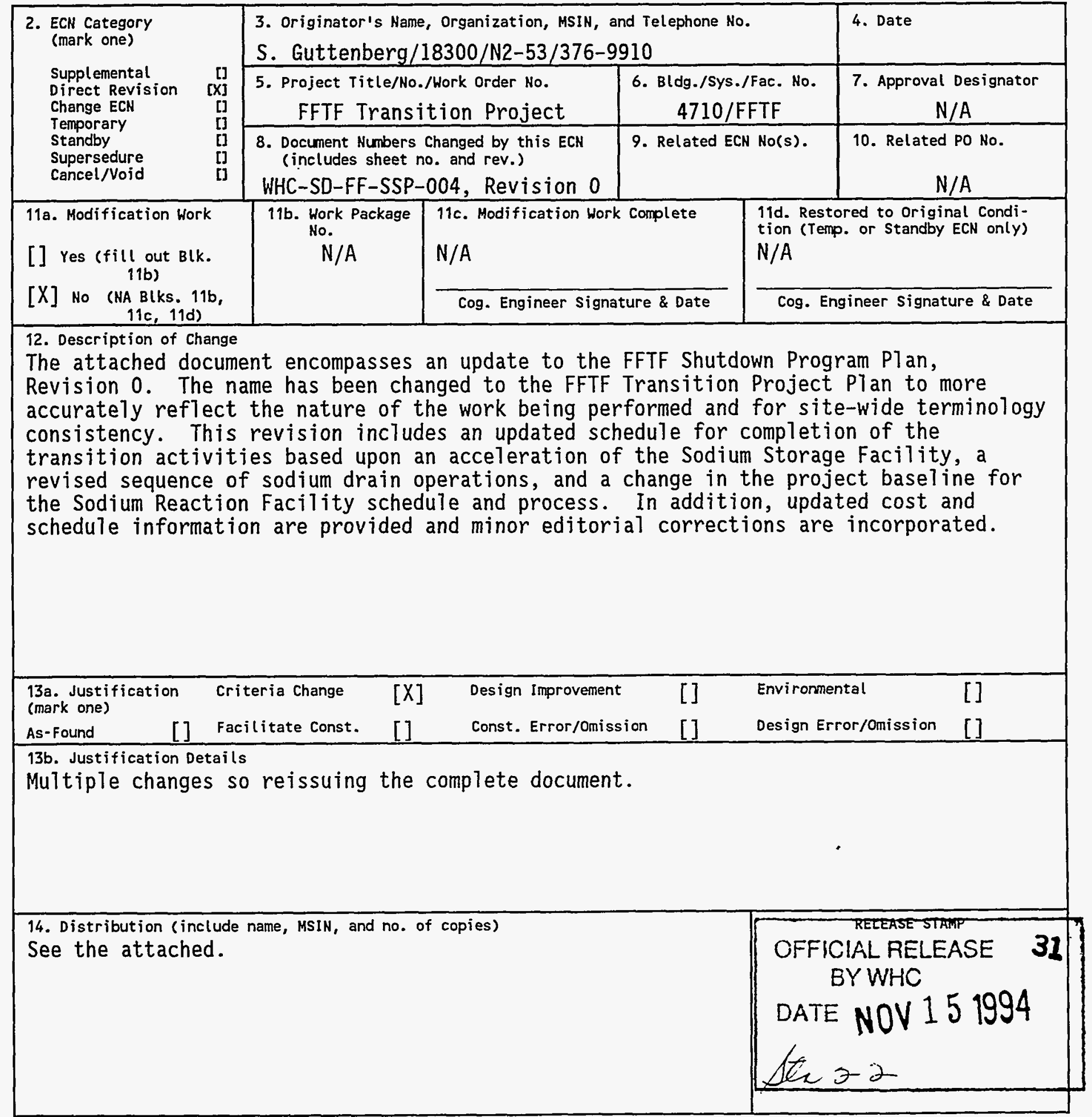

A-7900-013-2 (06/94) GEF095 


\section{ENGINEERING CHANGE NOTICE}

\begin{tabular}{|l|l|} 
Page 2 of 3 & $\begin{array}{l}\text { 1. ECN (use no. from } p g . ~ 1) \\
616245\end{array}$ \\
\hline
\end{tabular}

\begin{tabular}{|l|llllll}
\hline 15. Design & \multicolumn{3}{|c}{ 16. Cost Impact } \\
Verification & \multicolumn{3}{|c}{ ENGINEERING } & \multicolumn{3}{c}{ CONSTRUCTION } \\
Required & Additional & {[]} & $\$$ & Additional & {[]} & $\$$ \\
{[] Yes } & Savings & {[]} & $\$$ & Savings & {[]} & $\$$
\end{tabular}

17. Schedule Impact
Improvement
Delay

18. Change Impact Review: Indicate the related documents (other than the engineering documents identified on side 1) that will be affected by the change described in Block 12 . Enter the affected document number in Block 19.

SDD/DD
Functional Design Criteria
Operating Specification
Criticality Specification
Conceptual Design Report
Equipment Spec.
Const. Spec.
Procurement Spec.
Vendor Information
OM Manual
FSAR/SAR
Safety Equipment List
Radiation Work Permit
Environmental Impact Statement
Environmental Report
Environmental Permit

\begin{tabular}{|c|c|}
\hline Seismic/Stress Analysis & Tank Calibration Manual \\
\hline Stress/Design Report & Health Physics Procedure \\
\hline Interface Control Drawing & Spares Multiple Unit Listing \\
\hline Calibration Procedure & Test Procedures/Specification \\
\hline Installation Procedure & Component index \\
\hline Maintenance Procedure & ASME Coded Item \\
\hline Engineering Procedure & Human Factor Consideration \\
\hline Operating Instruction & Computer Software \\
\hline Operating Procedure & Electric Circuit Schedula \\
\hline Operational Safety Requirement & ICRS Procedure \\
\hline IEFD Drawing' & Process Control Manual/Plan \\
\hline Cell Arrangement Drawing & Process Flow Chart \\
\hline Essential Material Specification & Purchase Requisition \\
\hline Fac. Proc. Samp. Schedule & Tickler File \\
\hline Inspection Plan & \\
\hline Inventory Adjustment Request & \\
\hline
\end{tabular}

19. Other Affected Documents: (NOTE: Documents listed below will not be revised by this ECN.) Signatures below indicate that the signing organization has been notified of other affected documents listed below. Document Number/Revision

Document Number/Revision

Document Number Revision

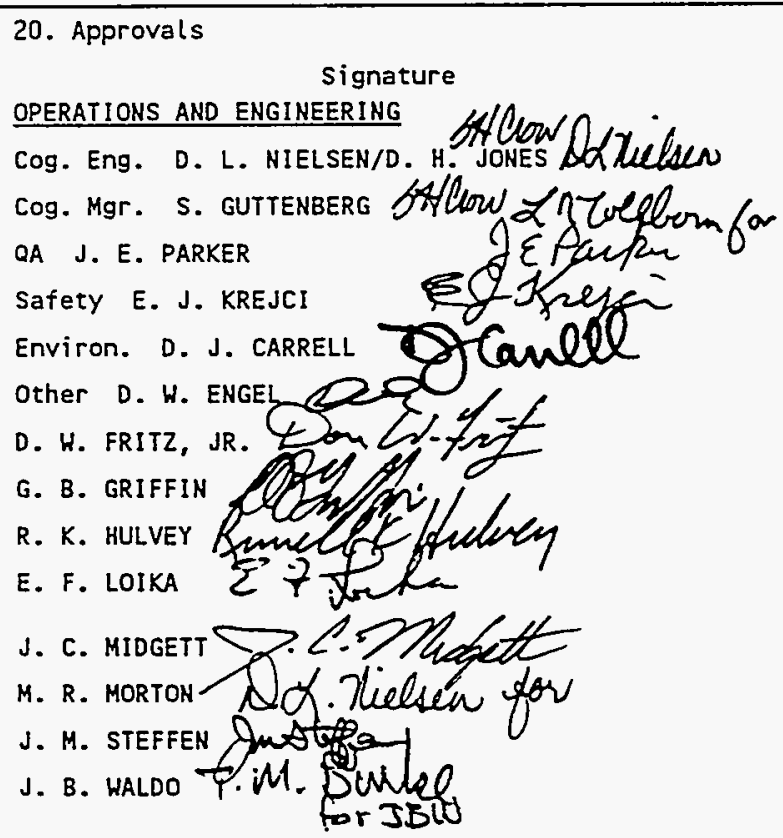

Date

$11 / 14 / 94$ $11114 / 94$ $11 / 14 / 94$ safety $11-14-54$ Design It-14-94 Environ.

$1 / 1464$ other $11 / 14 / 8$ $11 / 1494$ 11/15/44 i1) $15 / 84$ $11 / 15 / 94$ $11 / 14 / 94$ 11 $\mid 15 \div 1$ $11 / 14 / 94$

PE

QA
Signature

Date ARCHITECT-ENGINEER

\section{DEPARTMENT OF ENERGY}

Signature or a Control Number that tracks the Approval Signature

\section{ADDITIONAL}




\section{APPENDIX B}

UNREVIEWED SAFETY QUESTION SCREENING FORM

REFERENCE ITEM \# WHC-SD-FF-SSP-004, REV 1 (ECN \# 616245

TITLE FFTF TRANSITION PROJECT PLAN, REV. 1

\section{QUESTIONS}

Does the referenced item:

A. Make PROPOSED CHANGES to the facility or procedures which differ from conditions described in the FSAR? N/A_ NO\& Yes/Maybe

Basis: This plan is a project planning document. It discusses changes to the plant which are years from implementation and are obviously outside the bounds of the FSAR. The key words in this question are "make proposed changes..." This document makes no changes, and any changes discussed in this document will be implemented by documents which will receive an appropriate USO. Actually, the USO process should not be applied to such planning and budget documents, but this is being done procedurally because the ECN is method of change approval for the plan.

B. Describe an event or condition (DISCOVERY) which differs from those described in the FSAR?

N/A \& NO__ Yes/Maybe

Basis:

C. Describe tests or experiments which differ from those described in the FSAR? N/A $\&$ No__ Yes/Maybe Basis:

QUSQE \#1 H.A. Daute]

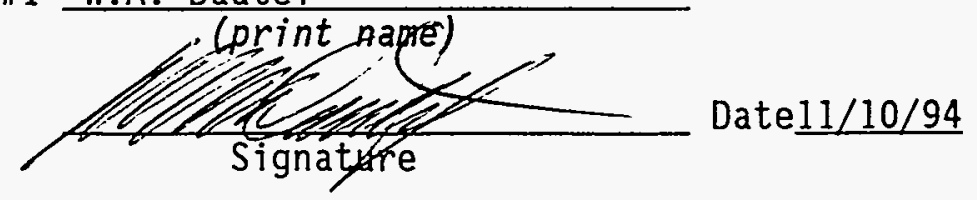

QUSQE \#2 R.L. Strain

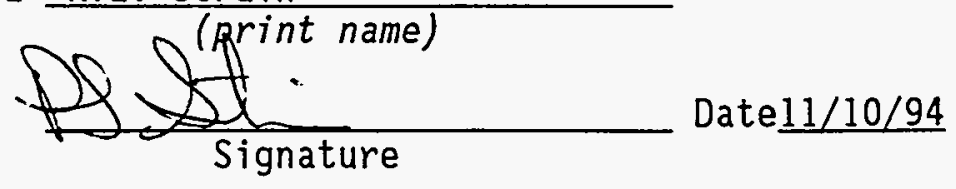




\section{RELEASE AUTHORIZATION}

Document Number: WHC-SD-FF-SSP-004, Rev. I

Document Title:

Fast Flux Test Facility Transition Project Plan

Release Date: $\quad 11 / 15 / 94$

This document was reviewed following the
procedures described in WHC-CM-3-4 and is:

APPROVED FOR PUBLIC RELEASE

WHC Information Release Administration Specialist:

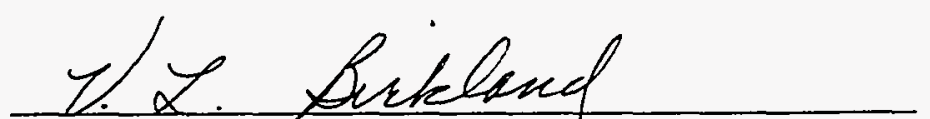

v. L. Birkland

TRADEMARX DISCLAIMER. Reference herein to any specific comercial product, process, or service by trade name, trademark, manufacturer, or otherwise, does not necessarily constitute or imply its endorsement, recomendation, or favoring by the United States Govermment or any agency thereof or its contractors or subcontractors.

This report has been reproduced from the best available copy. Available in paper copy and microfiche. Printed in the United States of America. Available to the U.S. Department of Energy and its contractors from:

U.S. Department of Energy office of Scientific and Technical Information (OSTI) P.O. BoX 62 Oak Ridge, TN 37831

Telephone: (615) 576-8401

Available to the public from:

U.S. Department of Commerce National Technical Information Service (NTIS) 5285 Port Royal Road Springfield, VA 22161

Telephone: '(703) $487-4650$ 


\section{SUPPORTING DOCUMENT}

\begin{tabular}{|l|l|c|}
\hline $\begin{array}{l}\text { 2. ritle } \\
\text { Fast Flux Test Facility Transition Project Plan }\end{array}$ & $\begin{array}{l}\text { 3. Number } \\
\text { WHC-SD-FF-SSP-004 }\end{array}$ & 4. Rev No. \\
\hline 5. Key words & 6. Author \\
Fast Flux Test Facility & Name: S. Guttenberg \\
Sodium & Sodium Storage Facility \\
Sodium Reaction Facility & Bunature \\
Fuel Offload & organization/Charge Code 18300/B171A \\
\hline
\end{tabular}

\section{Abstract}

The FFTF Transition Project Plan, Revision 1, provides changes to the major elements and project baseline for the deactivation activities necessary to transition the FFTF to a radiologically and industrially safe shutdown condition.

\section{DISCLAIMER}

This report was prepared as an account of work sponsored by an agency of the United States Government. Neither the United States Government nor any agency thereof, nor any of their employees, makes any warranty, express or implied, or assumes any legal liability or responsibility for the accuracy, completeness, or usefulness of any information, apparatus, product, or process disclosed, or represents that its use would not infringe privately owned rights. Reference herein to any specific commercial product, process, or service by trade name, trademark, manufacturer, or otherwise does not necessarily constitute or imply its endorsement, recommendation, or favoring by the United States Government or any agency thereof. The views and opinions of authors expressed herein do not necessarily state or reflect those of the United States Government or any agency thereof.

8. RELEASE STAMP

OFFICIAL RELEASE BYWHC

DATE NOV 151994

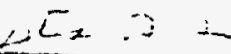

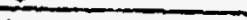




\section{RECORD OF REVISION}

\begin{tabular}{l|l} 
(1) Document Number & \\
WHC-SD-FF-SSP-004 & Page 1 of 1 \\
\hline
\end{tabular}

(2) Title

Fast Flux Test Facility Transition Project Plan

CHANGE CONTROL RECORD

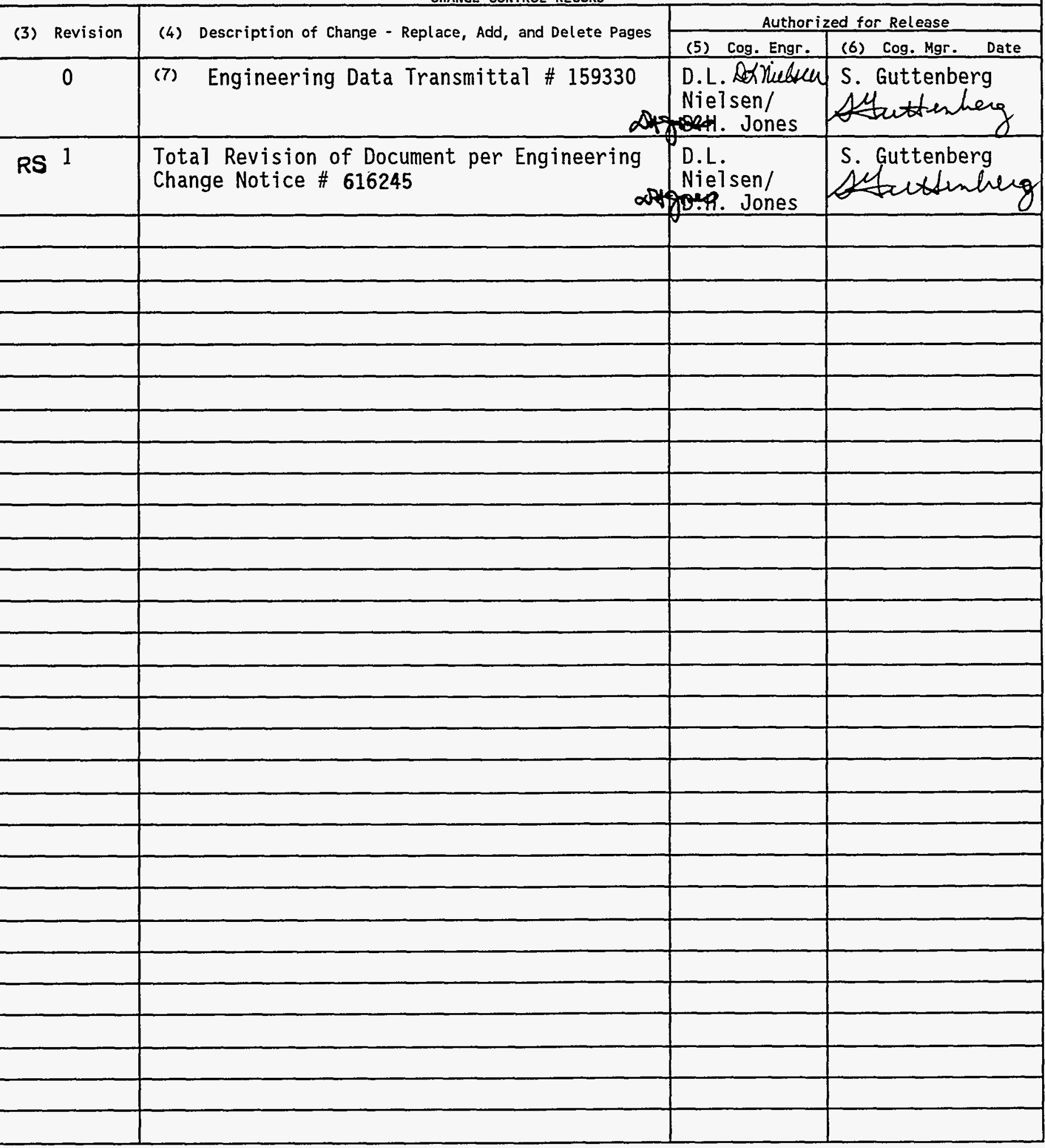




\title{
Fast Flux Test Facility \\ Transition Project Plan
}

\author{
Revision 1
}

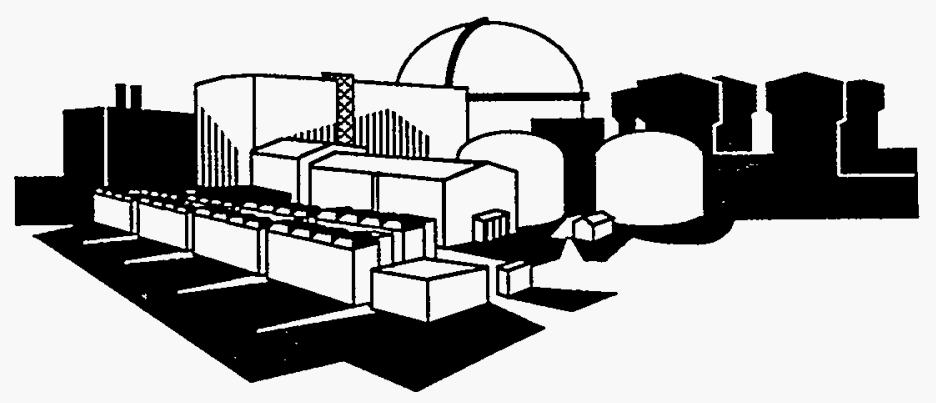

prepared by

Westinghouse Hanford Company

November 15, 1994 
WHC-SD-FF-SSP-004

Rev. 1 Page 2

This page intentionally left blank. 


\title{
FFTF TRANSITION PROJECT PLAN
}

\author{
Table of Contents
}

1.0 EXECUTIVE SUMMARY ....................... . . 7

2.0 INTRODUCTION . . . . . . . . . . . . . . . . . . 11

3.0 PURPOSE AND OBJECTIVES . . . . . . . . . . . . . . . . . . 17

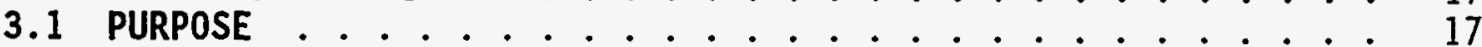

3.2 PLAN OBJECTIVES . . . . . . . . . . . . . . . . . . . 17

3.3 PLANNING STRATEGY . . . . . . . . . . . . . . . . . . 18

4.0 DOE GUIDANCE .......................... . . . 21

5.0 PROJECT MANAGEMENT . . . . . . . . . . . . . . . . . 23

5.1 PLANNING ACTIVITIES . . . . . . . . . . . . . . . . 23

5.2 PROJECT PLAN . . . . . . . . . . . . . . . . . . . . . . . . 24

5.3 PROJECT MANAGEMENT PLANS . . . . . . . . . . . . . . . . . 24

5.4 BASELINE CHANGE CONTROL . . . . . . . . . . . . . . . . . 24

5.5 CONTROLLING DOCUMENTS . . . . . . . . . . . . . . . . . . . 25

5.6 WORK BREAKDOWN STRUCTURE ...................... . . . . . 25

5.7 COST ESTIMATES . . . . . . . . . . . . . . . . . . . 25

5.8 SCHEDULES . . . . . . . . . . . . . . . . . 25

5.9 RESOURCE BREAKDOWN STRUCTURE . . . . . . . . . . . . . . . . 27

5.10 PROJECT CONTROL . . . . . . . . . . . . . . . . . . 27

5.11 PROJECT REPORTING . . . . . . . . . . . . . . . . . . . 27

6.0 COMPLIANCE WITH ORDERS AND REGULATIONS . . . . . . . . . . . . . . 29

6.1 DOE ORDERS . . . . . . . . . . . . . . . . . . . . . . . . . . 29

6.2 REGULATORY COMPLIANCE PLAN . . . . . . . . . . . . . . . . . . 32

6.2.1 National Environmental Policy Act . . . . . . . . . . 32

6.2.1.1 Assumptions/Actions ........... . 33

6.2.1.2 Constraints .............. . 34

6.2.1.3 Schedule................ . . 34

6.2.2 Resource Conservation and Recovery Act . . . . . . . . 34

6.2.2.1 Assumptions/Actions . . . . . . . . . . 34

6.2.2.2 Constraints ............... . 37

6.2.2.3 Schedule ............... . 37

6.2.3 Toxic Substances Controi Act............ . . 37

6.2.3.2 Assumptions/Actions . . . . . . . . . . . 37

6.2.4 Clean Air Act ................... . . 39

6.2.4.1 Assumptions/Actions .......... . 39

6.2.4.2 Constraints .............. . 40

6.2.4.3 Schedule ................. . 40

6.2.5 0ther Regulatory Requirements .......... . 40

6.3 WORKER HEALTH AND SAFETY . . . . . . . . . . . . . . . . . . 41

6.3.1 OSHA Requirements .................. 41

6.3.2 Implementation of Safety Elements . . . . . . . . . . 42

6.3.3 Performance Monitoring . . . . . . . . . . . 43

6.3.4 Fire Protection .................. . 44

6.3.5 Emergency Preparedness .............. 44 
6.3.6 Criticality Safety . . . . . . . . . . 45

7.0 ENVIRONMENTAL RESTORATION CONTRACTOR CRITERIA . . . . . . . . 47

8.0 PLANT CONFIGURATION AT THE END OF TRANSITION . . . . . . . 49

9.0 MAJOR TRANSITION ACTIVITIES . . . . . . . . . . . . 51

9.1 REACTOR DEFUELING . . . . . . . . . . . . . . 51

9.1.1 Reactor Fuel Movement . . . . . . . . . . . . 51

9.1 .2 Key Assumptions . . . . . . . . . . . . . . . . 55

9.2 FUEL DISPOSITION . . . . . . . . . . . . . . . . . . 56

9.2.1 Category IVE Irradiated Fuel . . . . . . . . . . . 56

9.2.2 Category IC/IIID Irradiated Fuel . . . . . . . . . . 57

9.2.3 Category IC Unirradiated Fuel . . . . . . . . . . 57

9.2 .4 Special Fuel ............... . . . 58

9.2.4.1 Delayed Neutron Monitor/Gas Leaker Fue1 . . . 58

9.2.4.2 Sodium Bonded Test Assemblies ... . . . . . 58

9.2.4.3 Lithium Bonded Assemblies . . . . . . . . . 58

9.2.4.4 MFF-8A Prototypic Series III Binary Metal

Fuel Assembly Experiment ......... . 60

9.2.5 Open Test Assembly Instrument Stalks . . . . . . . . . 60

9.3 FUEL OFFLOAD . . . . . . . . . . . . . . 60

9.3.1 Fuel Offload Status . . . . . . . . . . . 60

9.3.2 IEM Cell Fuel Washing/Transfer Logistics . . . . . . 61

9.3.3 Interim Storage Casks ............. . 62

9.3.4 Interim Storage Area . . . . . . . . . . . . . . . 64

9.4 BULK SODIUM AND SYSTEMS DISPOSITION . . . . . . . . . . . 67

9.4.1 Strategy . . . . . . . . . . . . . . . . . 67

9.4 .2 Sodium Drain . . . . . . . . . . . . . . . . . . 72

9.4.2.1 Secondary Loop Drain ....... . . . . 73

9.4.2.2 Primary System Drain .......... . 76

9.4.2.3 Interim Decay Storage Vesse1 . . . . . . . 81

9.4.2.4 Fuel Storage Facility Vessel ....... 81

9.4.3 Liquid Metal Systems Disposition . . . . . . . . . 84

9.4.3.1 Disposition of NaK Loops . . . . . . . . . . . 84

9.4.3.2 Residual Sodium . . . . . . . . . . . 85

9.4.3.3 Passivation/Inerting Considerations . . . . 88

9.4.3.4 Special Components............ 92

9.4.4 Sodium Storage Facility . . . . . . . . . . . . . 96 96

9.4.4.1 Storage Tanks ............ . 99 96

9.4.4.2 Sodium Storage Facility . . . . . . . . . . . 97

9.4.5 Sodium Reaction Facility ............. . 100

9.4.5.1 Process Description ........... 100

9.4.5.2 Facility Description ......... . . 102

9.4.5.3 Packaging and Transportation ........ 102

9.4.5.4 Environmental/Safety Requirements ... . . . 103

9.4.5.5 A1ternative Processes .......... 103

9.4.5.6 Schedules . . . . . . . . . . . . 104

9.4.5.7 Cost and Financing ....... . . 104

9.5 ASME CODE PRESSURE BOUNDARY AND SEISMIC INTEGRITY ..... 105

9.6 GENERAL PLANT SUPPORT/SYSTEM SHUTDOWN ........... 106

9.7 SURVEILLANCE AND MAINTENANCE AFTER TURNOVER . . . . . . . . . 107

9.8 SHUTDOWN CONSTRUCTION MODIFICATIONS . . . . . . . . . 107

9.9 CLINCH RIVER BREEDER REACTOR PROJECT MATERIAL . . . . . . . 108 
9.10 MAINTENANCE AND STORAGE FACILITY . . . . . . . . . . . 109

10.0 ADMINISTRATIVE CONTROLS . . . . . . . . . . . . . . . 110

10.1 TRANSITION PROJECT PLAN . . . . . . . . . . . . . . . . . . 110

10.2 FINAL SAFETY ANALYSIS REPORT . . . . . . . . . . . . . . . 110

10.3 TECHNICAL SPECIFICATIONS . . . . . . . . . . . . . . 111

10.4 CRITICALITY SPECIFICATIONS . . . . . . . . . . . . . 112

10.5 READINESS ASSESSMENTS . . . . . . . . . . . . . . . . . . . 112

10.6 STANDARDS/REQUIREMENTS IDENTIFICATION DOCUMENT . . . . . . . 113

11.0 PUBLIC INVOLVEMENT . . . . . . . . . . . . 114

12.0 FFTF FUEL SUPPLY . . . . . . . . . . . . . . . . 116

12.1 INTRODUCTION ........................ 116

12.2308 BUILDING SHUTDOWN . . . . . . . . . . . . . . . . . 116

12.3 FUELS AND MATERIALS EXAMINATION FACILITY . . . . . . . . . 117

13.0 DATA PRESERVATION . . . . . . . . . . . . 118

14.0 SAFEGUARDS AND SECURITY . . . . . . . . . . 120

$15.0 \mathrm{KEY}$ ASSUMPTIONS/ISSUES AND ACTION ITEMS . . . . . . . . . 122

15.1 KEY ASSUMPTIONS . . . . . . . . . . . . . 122

15.2 ISSUES AND ACTION ITEMS ............. 123

15.2.1 COMPLETED ISSUES/ACTION ITEMS ........ 123

15.2.2 OPEN OR ONGOING ISSUES/ACTION ITEMS . . . . . . 125

16.0 CLOSEOUT OF MISSION DEVELOPMENT ACTIVITIES . . . . . . . 128

17.0 SCHEDULE . . . . . . . . . . . . 130

17.1 PRELIMINARY SUMMARY TRANSITION SCHEDULE . . . . . . . 130

18.0 costs . . . . . . . . . . . . . . . 137

19.0 STAFFING . . . . . . . . . . . . . 140

20.0 REFERENCES . . . . . . . . . . . . . . . 143 
Table of Contents (continued)

\section{FIGURES}

Figure I

Figure 2

Figure 3

Figure 4

Figure 5

Figure 6

Figure 7

Figure 8

Figure 9

Figure 10

Figure 11

Figure 12

Figure 13

Figure 14

Figure 15

Figure 16

Figure 17

Figure 18

Figure 19

Figure 20

Figure 21

Figure 22

Figure 23

Hanford Reservation Area Map

FFTF Complex

FFTF Core Map

FFTF Core Map (Detailed)

Core Component Container

Interim Storage Cask

FFTF Sodium Disposition Logic

Secondary Loop Layout

Intermediate Heat Exchanger

Reactor Vesse 1

Primary Loop Layout

Reactor Vessel Preheat Systems

Interim Decay Storage Vesse1

Fuel Storage Facility NaK Loop

Secondary Cold Trap

Primary Cold Trap

Sodium Storage Facility Layout
FFTF Transition Project Summary Schedule

FFTF Transition Project - Annual costs

FFTF Transition Project Summary Work Breakdown Structure

Fuel Storage Facility Storage Vessel

Sodium Reaction Facility Process Flowsheet

FFTF Transition Project - Full-Time Equivalent Staff
PAGE

9,132

10,139

13

14

26

53

54

65

66

68

74

75

77

78

79

82

83

86

93

94

98

101

142

147

Acronym List

TABLES

PAGE

Table 1

PCB Transformers at FFTF

38

Table 2

Reactor Defuel ing (Phase 1)

55

Table 3

FFTF Breached Fuel Pins

59

Table 4

Approximate FFTF Sodium Volumes

72

Estimated Plant Residual Sodium Volumes

87

Table 6

Shutdown Construction Projects

108

\section{APPENDICES}

Appendix A-1 Appendix A-2 Appendix A-3 Appendix A-4 Appendix $A-5$
FFTF Project Plan

FFTF Status at Completion of Transition Phase

Environmental Restoration Contractor Turnover Criteria

FFTF Irradiated Non-fuel Core Components Disposition

FFTF Reactor Defueling PTan 


\section{FFTF TRANSITION PROJECT PLAN}

\subsection{EXECUTIVE SUMMARY}

The decommissioning process for the Fast Flux Test Facility (FFTF) will be accomplished in three phases: Phase I (Facility Transition), Phase II (Surveillance and Maintenance), and Phase III (Disposition). The FFTF Transition Project Plan (hereafter referred to as the Plan) provides the major elements and project baseline for completing Phase I transition activities. The FFTF Transition Project was established to implement the Plan and complete the transition activities necessary to establish a safe, environmentally secure, and low surveillance and maintenance cost configuration for the FFTF. When this state is achieved, as defined in the FFTF Transition End-Point Criteria Document (see Section 7.0), the facility will be transitioned to Phase II of the decommissioning process for a long-term surveillance and maintenance period pending final disposition (Phase III). The transition activities discussed herein concentrate on preparation of the appropriate environmental and regulatory documentation, reactor defueling, fuel offload to dry cask storage, sodium drain and reaction, management of sodium residuals, and shutdown of the auxiliary systems. During these transition activities, worker health and safety will be maintained.

This document encompasses an update to the FFTF Shutdown Program Plan, Revision 0 . The name has been changed to the FFTF Transition Project Plan to more accurately reflect the nature of the work being performed and for sitewide terminology consistency. This revision includes an updated schedule for completion of the transition activities based upon an acceleration of the Sodium Storage Facility, a revised sequence of sodium drain operations, and a change in the Project baseline for the Sodium Reaction Facility schedule and process.

The original FFTF Shutdown Program Plan provided the basis for the preparation of the FFTF Resource Loaded Schedule. This document provides the details for the major elements, project baseline and cost estimate for the Transition Project. An update to the Resource Loaded Schedule was submitted to the U.S. Department of Energy, Richland Operations Office (RL) on October 31, 1994 (Reference 1). The estimated summary schedule and cost to complete the deactivation of FFTF are depicted in Figures 1 and 2, respectively (see Sections 17.0 and 18.0 for additional detail) which are derived from the updated Resource Loaded ScheduTe.

As indicated, approximately seven years are currently estimated to complete the transition phase of the FFTF decommissioning process. The DOE expectation was to accomplish this effort in approximately five years. To a large extent, the time difference is driven by the logic to shutdown the electrical distribution systems and to dispose of the polychlorinated biphenyl transformers. Future efforts will focus on compressing this logic to improve the schedule. Note, activities will be managed and directed utilizing a projectized approach for control and reporting to achieve the best schedule and cost effectiveness. 
Nevertheless, achievement of an approximate five year transition will depend on many factors and reflects exceedingly aggressive and success oriented planning. Institutional and regulatory barriers, lack of adequate funding, delays in resolving key technical and operational challenges, and the erosion of experienced FFTF staff during this period could impact the schedule. New methods of doing business will be required to streamline approval processes and configuration documentation in order to avoid unnecessary delays and costs. The proactive support of the DOE and other interested stakeholders will also be vital to the success of this project. Thus, attainment of the five year deactivation goal would be a significant accomplishment.

A new purpose for the sodium has been identified by the Tank Waste Remediation Systems Program. The sodium, converted to sodium hydroxide, could be used for caustic washing as part of the high level waste tank sludge pretreatment process. The converted sodium hydroxide from FFTF may not be required until 2008. Therefore, for planning purposes the construction of the Sodium Reaction Facility will likely be deferred. However, in order to maintain visibility in the event the Project baseline changes, Figure 1 shows construction of the Sodium Reaction Facility during Fiscal Years 2001 and 2002, with sodium processing intended to commence in Fiscal year 2003.

Estimated funding for the FFTF deactivation, excluding design and construction of the Sodium Reaction Facility, is $\$ 359$ million (escalated). This corresponds to the point of turnover to the Environmental Restoration Contractor. The estimated cost for the design, construction, operation and deactivation of the Sodium Reaction Facility is $\$ 38$ million. 


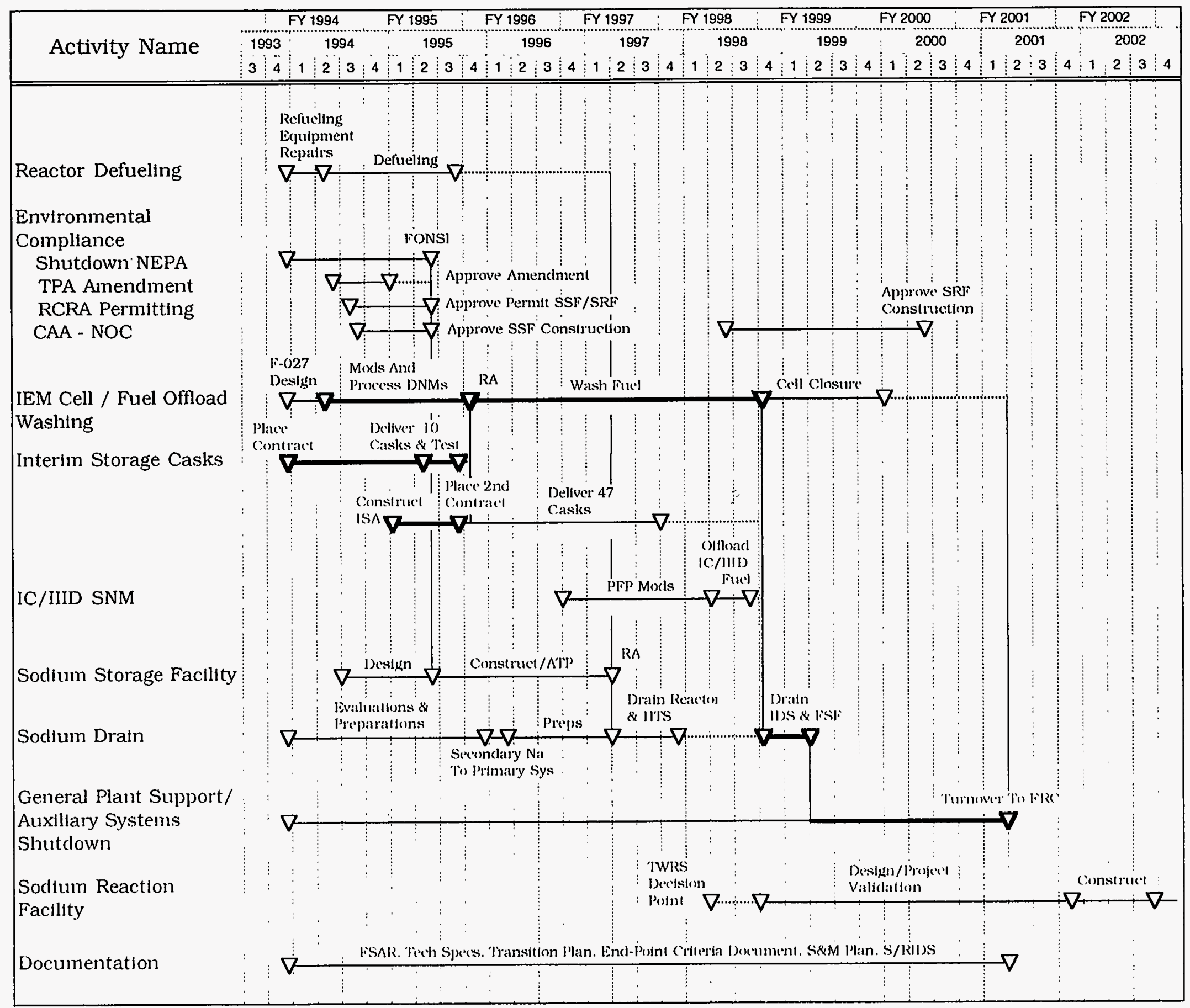




\section{FFTF Transition Project - Annual Costs}

(Escalated Dollars)

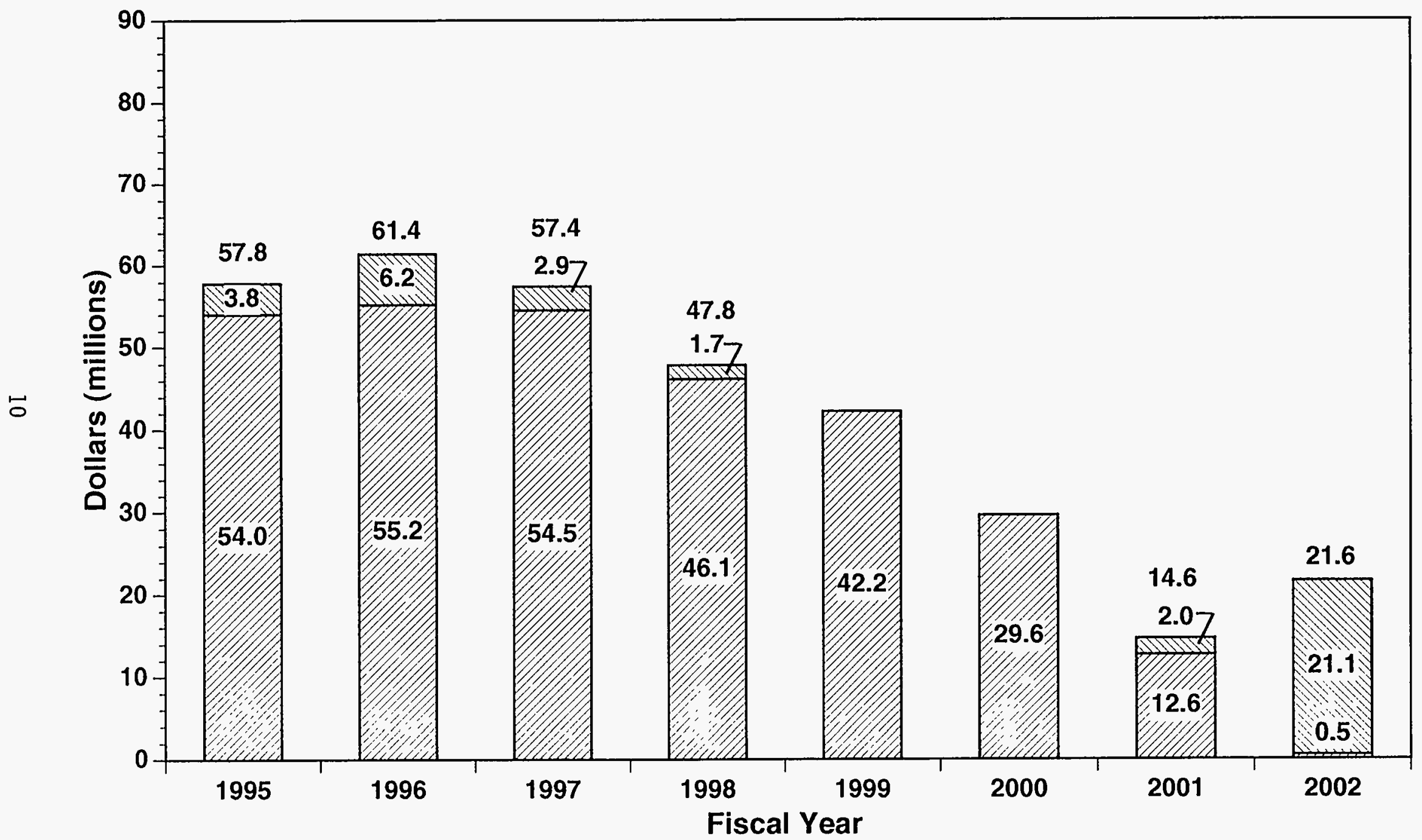

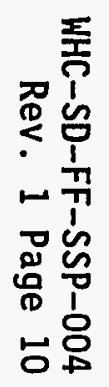

Figure 2. FFTF Transition Project - Annual Costs 


\subsection{INTRODUCTION}

The FFTF, located on the U.S. Department of Energy's Hanford Reservation, is the largest, most modern, liquid metal-cooled test reactor in the world (see Figures 3 and 4 ). Original7y constructed to support the U.S. Liquid Metal Fast Breeder Reactor Program, the FFTF has demonstrated its ability to perform fuel and materials tests in support of both national and international fast breeder reactor programs, produce medical and industrial isotopes, perform materials tests for the fusion and space programs, perform passive safety tests, and provide customized neutron environments to meet customer needs. Detailed studies have also shown the feasibility of producing significant quantities of Plutonium-238, and the capability for producing approximately 100 megawatts of electrical power with the addition of a steam powered turbine generator. In January, 1990, after an evaluation of long term missions for FFTF, the U.S. Department of Energy-Headquarters (DOE-HQ), concluded that justification to support the expense of continued operation did not exist.

The Governor of the State of Washington, in cooperation with the Congressional delegation of the State, and with the endorsement of DOE-HQ, sponsored a marketing initiative to find international support and funding for the continued operation of the FFTF. A survey of potential users identified broad-based support for continued operation, including a long term potential for non-DOE funding which would provide one-half or more of the operating costs. Based on this support, Congress authorized continued FFTF operation and established a deadline of March 31, 1992, for the marketing effort to succeed. The marketing effort identified potential FFTF customers in Europe and Japan and received letters of interest to support FFTF if DOE-HQ wouTd commit to long term operation of the facility. DOE-HQ could not make such a commitment and the marketing effort fell short of the DOE-HQ's operating expense target of $\$ 40$ million annually for Fiscal Year 1992 and 1993.

On March 13, 1992, the Secretary of Energy advised Congress that the FFTF would be placed in an appropriate standby status commensurate with DOE-HQ plans to further evaluate potential missions for the FFTF while conserving Federal funds. Accordingly, on April 1, 1992, RL directed the Westinghouse Hanford Company (WHC), to place the FFTF in standby status with coolant flow maintained in the primary and secondary Heat Transport Systems at $400^{\circ} \mathrm{F}$. The plant achieved a steady state "hot" standby status in December, 1992. On January 11, 1993, the Secretary of Energy announced that the potential missions for FFTF (i.e., Plutonium-238 and tritium production) had not materialized and that the DOE-HQ planned to commence a five-year process to place the FFTF in a cold standby condition. The intent of the cold standby was to permit increased cost savings without losing the option of future operations. Therefore, at the request of RL, WHC prepared and submitted a preliminary FFTF Cold Standby Program Plan (Reference 2) for approval.

Subsequent7y, on February 5, 1993, the Secretary of Energy advised Congress (Reference 3 ) that implementation of the cold standby decision would be deferred pending further discussions with the Washington State Congressional Delegation. This resulted in DOE-HQ commissioning an Independent Review Team 
WHC-SD-FF-SSP-004

Rev. 1 Page 12

This page intentionally left blank. 


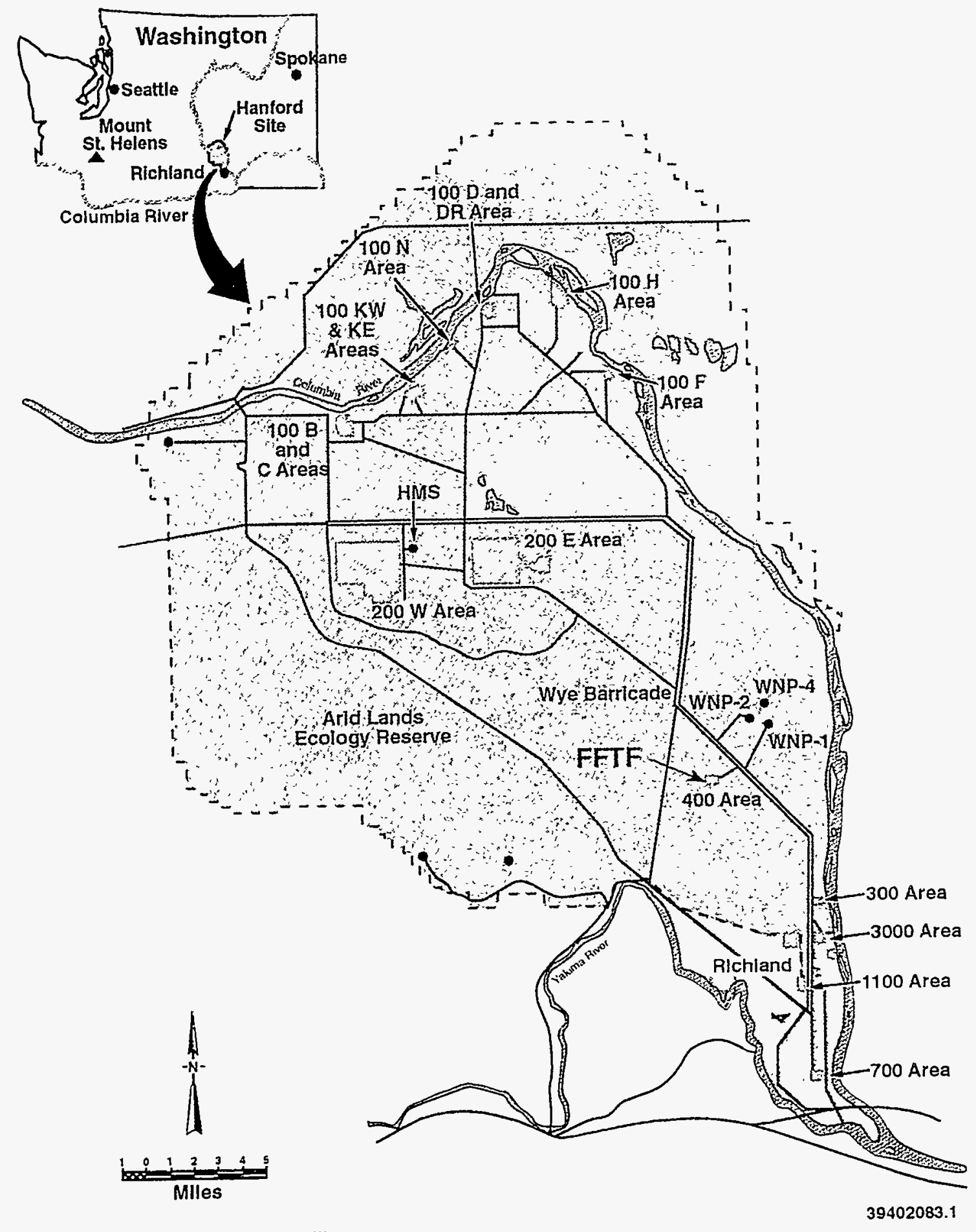

FFTF = Fast Flux Test Facllity

Figure 3. Hanford Reservation Area Map 


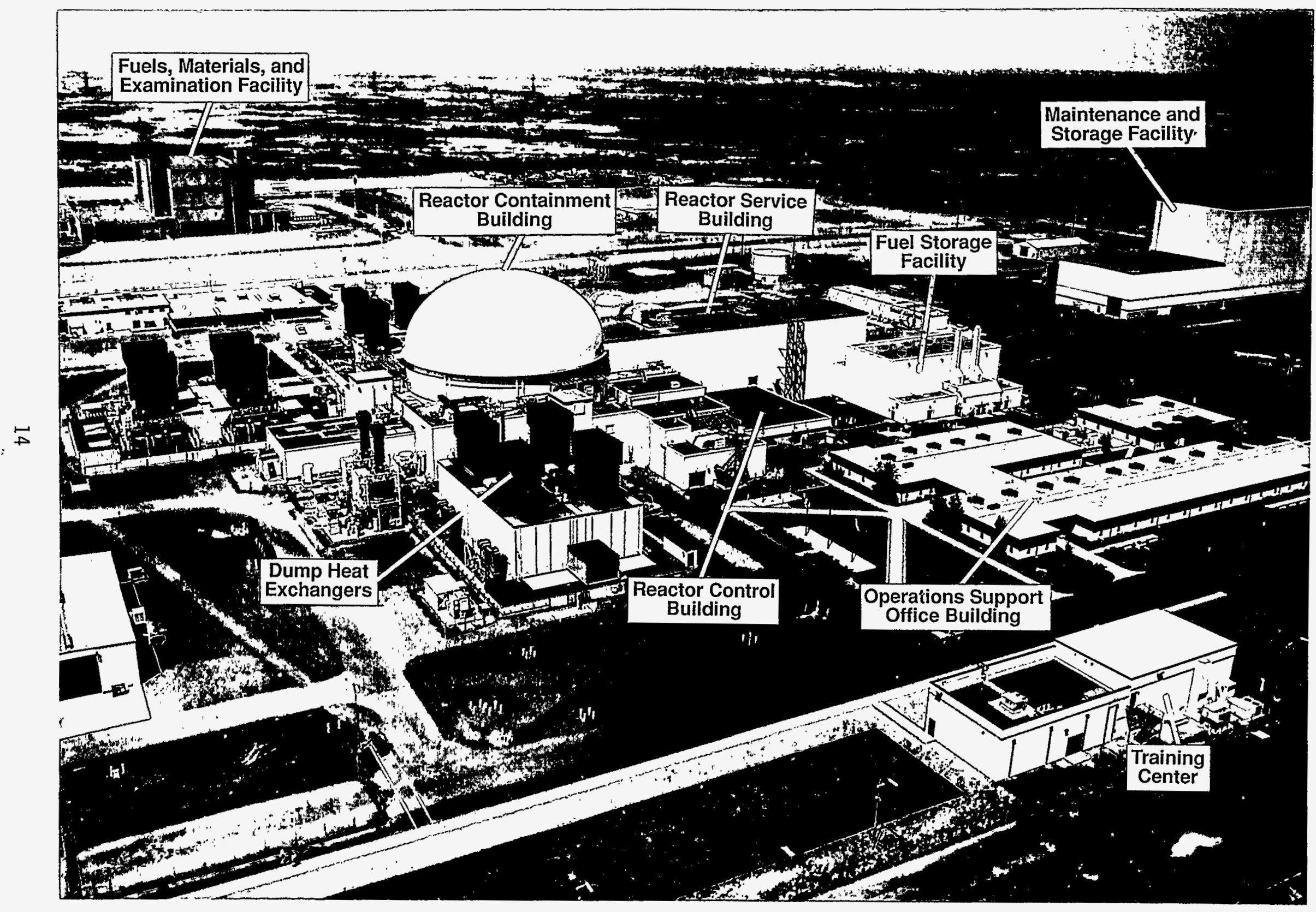

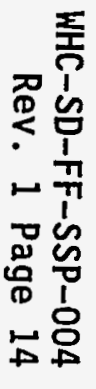

Figure 4. FFTF Complex 
to assess the degree to which FFTF could be made self-supporting by operating as a multi-mission facility, thereby offsetting costs to the Federal government. The findings of this team are documented in Reference 4. This report detailed the business potential, net revenues, policy issues, risks, and benefits associated with a number of current and potential facility missions. The report represented a comprehensive and objective evaluation of the capabilities of the FFTF and potential missions which the facility could successfulty support.

The report concluded that there was no combination of compatible missions for the FFTF with a reasonable probability of making the facility financially viable in the foreseeable future (over the next ten years) and further recommended that the FFTF be shut down, provided DOE-HQ's remaining test reactors have the capability to carry out the various missions they will be expected to perform, including the supply of urgently needed medical radioisotopes. DOE-HQ concluded that the FFTF was not required to support their missions. The Secretary of Energy informed the Washington State Congressional Delegation that DOE-HQ planned to commence a phased process on December 15, 1993, to place the FFTF in a radiologically and industrially safe shutdown condition.

Accordingly, DOE directed the FFTF shutdown in References 5 and 6 . In the latter, RL requested WHC to submit a Program Shutdown Plan and Summary Schedule to RL by March 15, 1994. Revision 0 of the Plan (Reference 7) was issued on March 4, 1994, in response to that request. This Revision 1 of the Plan reflects major changes in the work scope, i.e., an acceleration of the Sodium Storage Facility availability, a revised sequence of the sodium drain operations, a change in the Project baseline for the Sodium Reaction Facility schedule and process, and eliminating potential storage of the Hallam and Sodium Reactor Experimental sodium in the Sodium Storage Facility. 
WHC-SD-FF-SSP-004

Rev. 1 Page 16

This page intentionally left blank. 


\subsection{PURPOSE AND OBJECTIVES}

\subsection{PURPOSE}

The purpose of the Plan is to develop all the major elements and ensuing deactivation activities necessary to transition the FFTF and related facilities to a shutdown state in a safe, environmentaliy sound, and cost effective manner. A projectized approach for managing and directing these activities will be utilized in order to achieve a timely and cost effective completion of the Transition Project. This document is a revision of the original FFTF Shutdown Program Plan (Reference 7 ). The name has been changed to the FFTF Transition Project Plan to more accurately reflect the nature of the work being performed.

\subsection{PLAN OBJECTIVES}

The primary objective of the Plan is to provide the logic/approach and project baseline for the transition of FFTF and related facilities to the

Environmental Restoration Contractor under the guidance of DOE-HQ's Office of Environmental Restoration (EM-40), in a cost effective and quality manner while ensuring safety, security, and environmental compliance. Technical issues and uncertainties associated with the transition activities will be identified and, to the extent possible, resolved. The Plan formed the bases for the development of the Resource Loaded Schedule which was updated and submitted to RL on October 31, 1994 (Reference 1).

This PIan will be updated and revised as the FFTF transition progresses. Portions of the Plan addressing workscope, cost and schedule, and resolution of technical issues and uncertainties will be revised as the detailed supporting documentation and revisions to the Resource Loaded Schedule are developed. It should be recognized that the appropriate level of detail for the multi-year resource loaded summary cost and schedule is dependent on the maturity of the Transition Project. The cost and schedule will be definitive for the short term and will reflect order of magnitude estimates in the out years, recognizing that there are still many issues to be resolved. As the Transition Project matures, the estimates will become more detailed based on more clearly defined scope, documentation, and other program and project data. Therefore, the Resource Loaded Schedule will be managed as a "1iving document" in concert with the Plan and will be modified to reflect the appropriate level of detail as the scope of work changes.

As indicated in Reference 5, DOE-HQ's objective is to achieve transition in approximately five years. However, the current summary schedule indicates approximately seven years to achieve this transition. To a large extent, the time difference is driven by the logic to shut down the electrical distribution systems and to dispose of the polychlorinated bipheny? transformers. Every reasonable effort will be made to compress this logic and to develop other productivity initiatives to improve the schedule and reduce costs. Nevertheless, WHC considers the five year goal to be extremely aggressive, and if successful, would constitute a major accomplishment. However, institutional and regulatory barriers, lack of adequate funding, 
delays in resolving key technical and operational challenges, and the potential erosion of experienced FFTF staff during this period could impact the schedule. These barriers can be surmounted; but would likely require a change in the normal methods of doing business consistent with the "Reinventing Government" philosophy to effectively reduce the Transition Project costs and compress the schedule.

Several of these barriers are addressed in this PIan. Statements of program equivalencies, waivers and exemptions to DOE Orders will be used, which could result in significant cost avoidances. This process is described in Section 6.1. Establishment of enforceable Hanford Federal Facility Agreement and Consent Order (Tri-Party Agreement) milestones to formulate a regulatory compliant approach for the FFTF transition is described in Section 6.2. The Technical Specifications have been condensed to reflect the deactivation status of the plant. This approach is described in Section 10.3. The key assumptions, unresolved issues and action items are described in Section 15.0. The FFTF Plant staff will continue to take a proactive stance to resolve these issues in a safe and cost effective manner. This effort will continue to involve the active cooperation of all the key stakeholders, including RL, DOE$\mathrm{HQ}$, Washington State regulators, WHC and numerous public entities.

\subsection{PLANNING STRATEGY}

The Transition Project encompasses the following deactivation activities: reactor defueling, unirradiated fuel disposition, irradiated fuel washing and dry cask storage, sodium systems drain and management of sodium residuals, auxiliary systems shutdown, and bulk sodium conversion to a form suitable for reuse or disposition. This Plan identifies the work needed to complete the deactivation activities necessary to transition the FFTF to a safe state suitable for long term surveillance and maintenance prior to final decommissioning. The Plan and the Resource Loaded Schedule (Reference 1) are based upon the availability of funding cited in DOE's funding guidance (Reference 8) through Fiscal Year 2000.

Most of the existing plant surveillance and maintenance activities will continue as needed to maintain the FFTF in a safe condition and conform with the requirements that support environmental, worker health and safety, and DOE Order compliance. These plant activities will eventually be phased-out as they are no longer required to support the Transition Project. Resources released from discontinued plant activities will be applied to other transition work, including deactivation of auxiliary systems.

The intent of the Transition Project is to comply with all applicable DOE requirements. These requirements address worker and public health and safety, work conduct and reporting, environmental compliance, configuration control, quality assurance, and record generation, preservation and property protection. Transition activities will be conducted in accordance with these requirements using the existing WHC and FFTF administrative systems wherever applicable. The Transition Project activities will be evaluated by authorized WHC, DOE, and regulatory oversight agencies to ensure that the appropriate level of compliance is maintained. 
The Transition Project will be completed with the turnover of FFTF to the Environmental Restoration Contractor. The final deactivation configuration will be suitable for a long term surveillance and maintenance mode before final decommissioning. Present planning is that the FFTF configuration at turnover will be unoccupied and locked. A minimal amount of lighting, fire protection equipment, and ventilation required to support periodic

surveillance will be maintained. A nitrogen gas blanket will be maintained in all drained sodium systems. The final specific end-point criteria for turnover to the Environmental Restoration Contractor have not been defined. These criteria are being evaluated, and will evolve, reflecting the input of interested stakeholders (see Section 7.0).

Preparation for the surveillance and maintenance phase that follows completion of the Transition Project, record generation and archiving, and the final plant characterization required for eventual decontamination and decommissioning are part of the scope of the Transition Project. Successful deactivation activities and the "Lessons Learned" that are applicable to other DOE reactor facilities (e.g., Experimental Breeder Reactor-II) will be documented. 
WHC-SD-FF-SSP-004

Rev. 1 Page 20

This page intentionally left blank. 


\subsection{DOE GUIDANCE}

RL directed WHC in Reference 6 to place the FFTF in a radiologically and industrially safe shutdown condition commencing December 15, 1993. Shutdown activities were to commence immediately with emphasis on the items delineated in Reference 6. Disposition of these items was described in Revision 0 , of this P]an (Reference 7 ).

A DOE-sponsored panel reviewed the FFTF Shutdown Program P1an, April 11 through April 15, 1994, and produced a series of recommendations (see Reference 9). The Project response to these recommendations was documented in Reference 10. The main recommendation of the panel was to accelerate the construction of the Sodium Storage Facility which would allow earlier draining of the primary and secondary sodium systems. This is consistent with prior WHC recommendations.

A detailed review of the design and construction schedule for the Sodium Storage Facility indicated that a six month acceleration could be achieved, contingent upon availability of appropriate funding, and would culminate in a substantial savings to the Project of approximately $\$ 18$ million. The DOE funding guidance for the Transition Project (Reference 8) supports this baseline acceleration. Therefore, detailed planning is proceeding accordingly, and these changes are reflected in the Resource Loaded Schedule and this document. 
WHC-SD-FF-SSP-004

Rev. I Page 22

This page intentionally left blank. 


\subsection{PROJECT MANAGEMENT}

A Transition Project Office has been established within the FFTF Plant organization to plan, direct, and monitor the FFTF shutdown and turnover to the Environmental Restoration Contractor. Reference 5 directed that the transition to a radiologically and industrially safe shutdown condition be performed using a project approach. The charter of the FFTF Transition Project office is to fulfill this directive in a safe and cost-effective manner.

This office will perform the program integration, including development of the Work Breakdown Structure, Resource Breakdown Structure, logic diagrams and upper tier schedules. This information will be used to establish baselines for the preparation of Resource Loaded Schedules and cost estimates for each element of the Work Breakdown Structure, and make assignments to performing organizations. The Transition Project will be managed utilizing WHC and the U.S. Department of Energy Management Control System procedures.

\subsection{PLANNING ACTIVITIES}

This Plan is a projectized approach to transition of the FFTF to the Environmental Restoration Contractor. The major transition activities are:

- Project management, planning, control, and reporting.

- Support function activities such as safety, security, quality assurance, environmental compliance, and external oversight.

- Reactor defueling, fuel washing, and shutdown of defueling systems and components.

- Transferring irradiated fuel to interim dry storage casks.

- Transferring unirradiated fuel to the Plutonium Finishing Plant.

- Sodium drain and disposition including construction of a storage facility and reaction facility, and shutdown of the liquid metal systems.

- Shutdown of the support systems.

- Shutdown of the electrical, instrument and control systems.

- Surveillance and maintenance which includes all activities needed to maintain safe conditions during the FFTF transition in accordance with applicable DOE Orders.

This Plan defines the technical baselines, and the preliminary cost and schedule baselines. Lower-level, more narrowly defined, in-depth, supporting plans and work packages, cost estimates and schedules will be developed based 
upon this Plan. The technical (scope), cost and schedule baselines will be revised as the Project develops. The FFTF Transition Project Office will prepare the appropriate budgetary planning documentation reflecting these project conditions.

\subsection{PROJECT PLAN}

A Project PIan is provided by Appendix A-1 and defines the overall technical, cost and schedule baselines against which progress and the management

effectiveness can be measured. The Project Plan is based upon the requirements in the DOE Project Management System Procedure (DOE 4700.1) and the WHC Project Management Procedure (WHC-CM-6-2).

\subsection{PROJECT MANAGEMENT PLANS}

A Project Management $\mathrm{Pl}$ an is required for each 1 ine item project requiring Congressional funding, or those specifically identified by RL, and shall be prepared consistent with Appendix A-1. The FFTF Transition Project is one line item project with the following construction sub-projects:

\begin{tabular}{||c|c|c||}
\hline \multicolumn{2}{|c|}{ PROJECT F-028 } & - FFTF TRANSITION CONSTRUCTION SUB-PROJECTS \\
\hline Sub-Project & Description & $\begin{array}{c}\text { Project Management } \\
\text { Plan Required }\end{array}$ \\
\hline $01-F-029$ & Interim Storage Area & No \\
\hline $02-F-030$ & PFP Modifications for FFTF Fuel & Yes \\
\hline $03-F-031$ & Sodium Storage Facility & Yes \\
\hline $04-F-032$ & Sodium Reaction Facility & Yes \\
\hline
\end{tabular}

A Project Management Plan will be prepared for each of the sub-projects consistent with Appendix A-1 with the exception of Project 0I-F-029 (Interim Storage Area) which consists of installing fencing and lighting around an existing concrete slab near the FFTF Plant. There is no cost benefit in preparing a Project Management PIan for the Interim Storage Area.

\subsection{BASELINE CHANGE CONTROL}

Changes to the Plan, Resource Loaded Schedule and technical baselines will be planned, managed and controlled in compliance with the RL Project Management System (RLIP 4700.1A) and the WHC Management Control System (WHC-CM-2-5). The specific baseline change control requirements are included in Appendix A-1. 


\subsection{CONTROLLING DOCUMENTS}

The following documents will be used to manage Project activities. All of the documents are "living documents" and will be used in concert with each other. They will be modified to reflect the appropriate level of detail as the work scope becomes better defined.

- WHC-SD-FF-SSP-052 Advanced Reactors Fiscal Year 1995 Mutti-Year Program Plan

- WHC-SD-FF-SSP-004 FFTF Transition Project PIan

- WHC-SD-FF-SSP-050 FFTF Resource Loaded ScheduTe

\subsection{WORK BREAKDOWN STRUCTURE}

The transition activities have been defined in the Work Breakdown Structure and used by all program participants for work scope definition, budgeting and scheduling. This is shown by the Project Summary Work Breakdown Structure in Figure 5. The more detailed Contractor Work Breakdown Structure has been developed and is provided in the Resource Loaded Schedule.

\subsection{COST ESTIMATES}

Activity based cost estimates were developed for each element of the Work Breakdown Structure and integrated into the overall cost estimate for the FFTF Transition Project. Fiscal year budgeting will be derived from this baseline. Additional information and requirements for preparing cost estimates are given in Appendix $\mathrm{A}-1$.

\subsection{SCHEDULES}

A summary schedule for the Project has been developed from the Project Summary Work Breakdown Structure and is shown in Figure 5. Detailed schedules have been prepared for each element in the Contractor Work Breakdown Structure to provide an integrated and detailed schedule for the FFTF Transition Project. This information is contained in the Resource Loaded Schedule.

As noted in Section 3.2, the level of detail for the multi-year Resource Loaded Schedule and the related cost estimates is dependent upon the maturity of the Transition Project. The cost estimates and schedules will be definitive for the near term, and will reflect order of magnitude estimates for the out-years recognizing there are still many issues to be resolved. As the Transition Project matures, the cost estimates and schedules will become more definitive based upon more clearly defined scope, direction and funding. Therefore, the Resource Loaded Sschedule will be managed as a "living document" in concert with the Plan. The Resource Loaded Schedule will be modified to reflect the appropriate level of detail as the scope the deactivation activities evolves. 


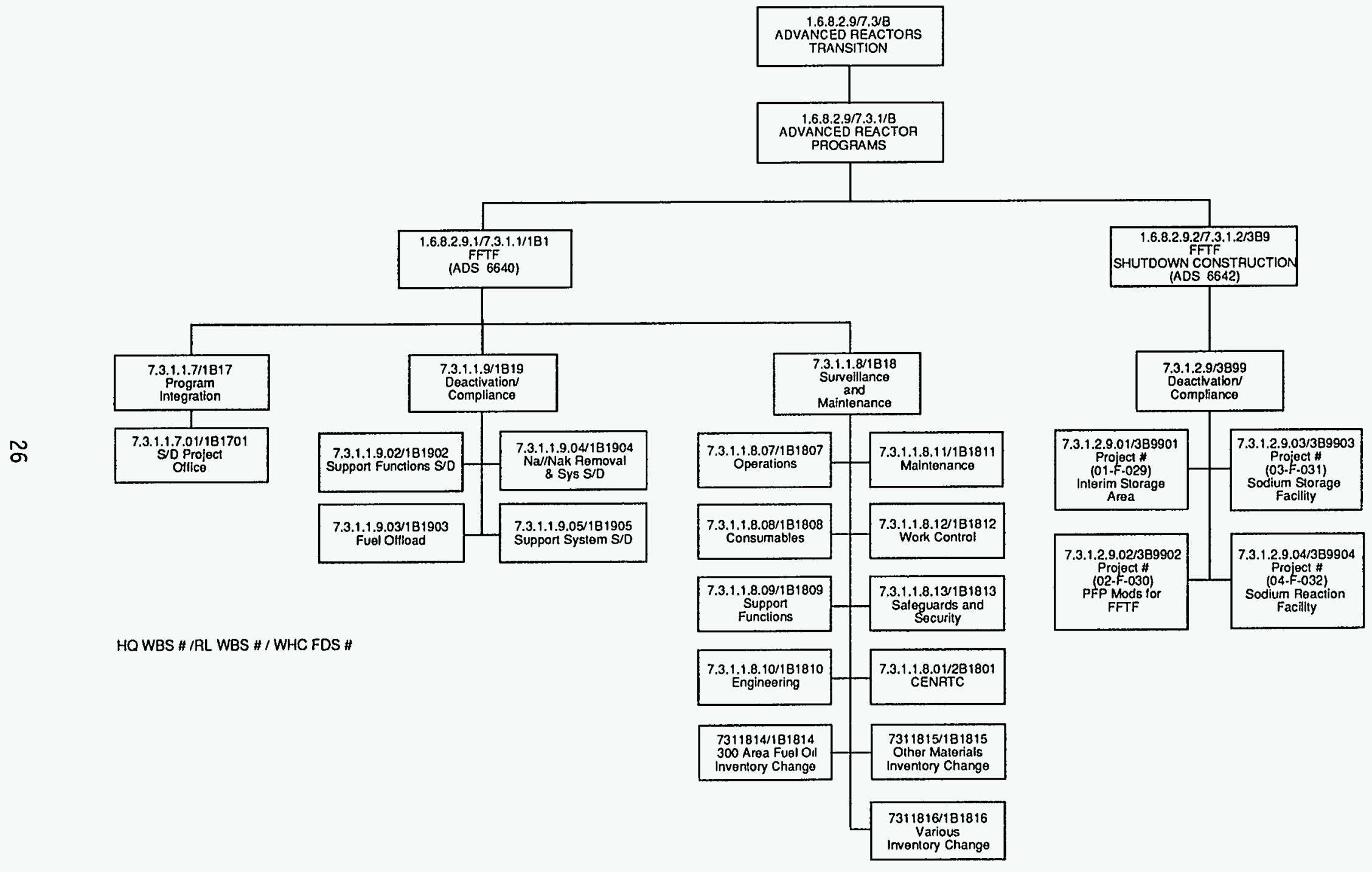

Figure 5 FFTF Transition Project Summary Work Breakdown Structure 


\subsection{RESOURCE BREAKDOHN STRUCTURE}

The Resource Breakdown Structure will be used to organize and summarize resources, personnel and materials needed to complete the Transition Project. The labor portion of the Resource Breakdown Structure has been structured by organization code and the non-labor portion by the Work Breakdown Structure. Activity based cost estimating and deactivation activity priorities have been used to develop the Transition Project budgets.

\subsection{PROJECT CONTROL}

Transition activities will be planned, managed and controlled in compliance with the RL Site Management System and the WHC Management Control System policies and procedures as described in Appendix A-1. Project control will be achieved through management of cost Account Plans which follow the structure of the Project Summary Work Breakdown Structure. Each Cost Account Plan will have a designated Cost Account Manager. The Project Summary Work Breakdown Structure is the basis for development of the in-depth supporting plans, work packages, cost estimates and schedules which have been defined in the Resource Loaded Schedule. They will be reviewed and formally approved by the various program participants as will subsequent changes. The FFTF Transition Project Office will ensure that appropriate coordination occurs between the interested stakeholders to facilitate a safe, timely and cost effective transition to shutdown.

Independent overviews of program plans, procedures and field activities will be provided by WHC QuaTity Assurance, Safety, Security and Environmental organizations within their areas of cognizance. Formal release points have been established and will be satisfied prior to initiating the major transition activities.

\subsection{PROJECT REPORTING}

The reporting requirements for the FFTF Transition Project are given in Appendix $A-1$ which describes the required reports, review meetings and report distribution. Project reporting will follow the RL Site Management System and the WHC Management Control System requirements and procedures. 
WHC-SD-FF-SSP-004

Rev. I Page 28

This page intentionally left blank. 


\subsection{COMPLIANCE WITH ORDERS AND REGULATIONS}

\subsection{DOE ORDERS}

Compliance with all appropriate DOE Orders will continue to be maintained during the FFTF transition. During the transition phase activities, plant conditions will change, and the applicability of a number of the Orders will be affected. A Standards/Requirements Identification Document (S/RIDS) wil1 be developed which will identify the Orders (and Codes and Standards) which apply to FFTF. During the S/RIDS development it is expected that many requirements will be identified which can be satisfied in a cost effective manner using statements of program equivalencies, waivers and exemptions. See Sections 10.5 and 10.6, for additional discussion. Aggressive application of this approach, and subsequent approval by DOE, wiTl be instrumental in accomplishing a cost effective facility deactivation.

Specifically, five DOE Orders should not be implemented. A preliminary assessment and the basis for their exclusion are discussed below:

- DOE Order 5480.18A, "Accreditation of Performance-Based Training for Category A Reactors and Nuclear Facilities"

WHC has applied for an exemption to this Order for all of its training programs. The prohibitive cost (approximately $\$ 11$ million was estimated in the Training Program Accreditation Plan which was submitted to $\mathrm{RL}$ prior to the hot standby directive) makes implementation of this order impractical and unwarranted.

- DOE Order 5480.22, "Technical Safety Requirements" (and RL Implementing Procedure 5480.22, "Technical Safety Requirements")

This Order would require rewriting the existing FFTF Final Safety Analys is Report. Since the current Final Safety Analysis Report contains Technical Specifications which have been approved by DOE, and contain provisions for configuration change control, rewriting them in the form of Technical Safety Requirements would not be cost effective during the transition. Recently, the Technical Specifications were updated with new limits which are appropriate, technically accurate, and consistent with the safety analysis in the Safety Analysis Report. This revision was conducted using approved methods for change control, including DOE approval. The current safety documentation is judged to be adequate to serve the needs of the Transition Project for both DOE and WHC.

- DOE Order 5480.23, "Nuclear Safety Analys is Reports"

As is the case with DOE Order 5480.22, this Order would require rewriting the existing Final Safety Analysis Report in the specified format. Since the current Final Safety Analysis Report is technically sound, received a technical review by the Nuclear Regulatory Commission, and contains provisions for configuration change control, this activity 
is not cost effective during the transition. Additional background on FFTF implementation of DOE Orders 5480.22 and 5480.23 is contained in Reference 11 .

- DOE Order 5480.28, "Natural Phenomena Hazards Mitigation"

Full compliance with this order requires a Probabilistic Risk Assessment. The existing FFTF Final Safety Analysis Report contains an analysis of natural hazards, and design requirements have been implemented to mitigate them for an operating reactor. Natural hazards mitigation is built into the present code compliance in the Final Safety Analysis Report. Additional work on a Probabilistic Risk Assessment is not warranted for a plant undergoing deactivation.

- DOE Order 5480.30, "Nuclear Reactor Safety Design Criteria"

Implementation of this Order requires actions similar to DOE Order 5480.28 above. It is not considered applicable to the FFTF transition based on the logic presented in the discussion for DOE Order 5480.28.

The above discussion is based on the current $C$ lass $A$ reactor classification of the FFTF. Reference 5 directed WHC to "re-evaluate the need to classify the FFTF as a Hazard Category I, Class A reactor since due to the physical changes it can no longer achieve criticality." The results of this evaluation are summarized below:

- $\quad$ Emergency Preparedness:

The DOE Orders in the 5500 series do not differentiate reactors from non-reactors. Instead, they utilize a hazards analysis as the requirements basis. The hazards will be evaluated regardless of the specific facility designation and therefore, this set of orders does not provide a basis for redefining the facility classification.

- Nuclear Safety:

DOE Order 5480.5, "Safety of Nuclear Facilities, "would apply if the FFTF were designated as a non-reactor nuclear facility. DOE Order 5480.6, "Safety of Department of Energy-owned Nuclear Reactors," currently applies and FFTF is in conformance. Some minor differences exist between the Orders, but most of these differences apply to the operational modes in which the plant will no longer be operated. Since DOE Order 5480.6 references the criticality safety requirements of DOE Order 5480.5, these requirements are identical. In addition, the new DOE Order 5480.24, "Nuclear Criticality Safety," requirements are also identical for both types of facilities. Thus, no clear advantage is seen in these Orders for changing from a reactor to a non-reactor nuclear facility designation. Further, DOE Order 5480.6 specifically indicates it is applicable to reactor decommissioning activities.

Note: The above conclusion is from an evaluation of the need to classify the FFTF as a Hazard Category I, Class A reactor. Since that 
evaluation, DOE Order 5480.5 has been replaced. However, the conclusions with respect to reactor versus non-reactor requirements remain valid.

\section{- Reactor Design:}

DOE Orders 5480.28 and 5480.30 provide stringent requirements for reactors. Potentially significant cost avoidances are available if compliance with these Orders can be avoided. Although reclassification as a non-reactor nuclear facility could be done, the Transition Project intends to seek relief from requirements that are deemed not applicable to plants in the transition to shutdown.

- Hazard Category:

An analysis was conducted and transmitted to DOE for approval in Reference 12 which indicated that the facility could be recategorized as Hazard Category 2. DOE Standard 1027 requires Category A reactors to automatically be designated Hazard Category 1. Because FFTF is no longer operated as a power reactor, actual inventories and current conditions would indicate a Hazard Category 2 is more appropriate. These conditions included those used as the basis for the Technical Specification revision, including that the reactor has been defueled to the point it is subcritical under all credible conditions and all fuel assemblies have decayed to the point at which they no longer require forced cooling for safety. The submittal recommends FFTF be designated Hazard Category 2 while retaining the designation of Category A reactor.

\section{- Conclusions:}

There is no cost benefit to reclassifying the facility as a non-reactor. If it were mandated that the facility be reclassified as a non-reactor, then a lengthy analysis would be required to prove that the facility met the non-reactor rules. This would require time and effort with no added benefit, since the present system of procedures and the Final Safety Analysis Report provide adequate flexibility to accommodate plant changes. In summary, changing the reactor designation to a non-reactor nuclear facility would not be beneficial as long as DOE Order compliance using statements of program equivalencies, waivers and exemptions are applied, where appropriate.

Approval of the request for reduction in Hazard Category has potential project benefits. First, this would provide visibility that FFTF does not present an off-site hazard. In addition, reduction in Hazard Category would permit local (RL) approval of plant documents such as Technical Specification changes. This has the potential to reduce turnaround time for project documents and could result in reducing the duration of the project. Verbal feedback to this request indicates that it will not be acted on until all fuel has been removed from the reactor. This is scheduled to occur in September, 1995. 


\subsection{REGULATORY COMPLIANCE PLAN}

A major element in the transition of the FFTF is to ensure compliance with applicable environmental regulations. The decommissioning process for FFTF will be accomplished in three phases: Phase I (Facility Transition), Phase II (Surveillance and Maintenance), and Phase III (Disposition). The Phase I activities (addressed by this Plan) will place the FFTF in a safe and stable end-point condition, as defined in the Transition End-Point Criteria Document (see Section 7.0), such that it can be dispositioned at a later date. This section defines the activities required to achieve compliance with the environmental regulations which impact the Phase I transition activities. These regulations fall under the National Environmental Policy Act of 1969 , the Resource Conservation and Recovery Act of 1976, the Clean Air Act and Amendments of 1990, the Toxic Substances and Control Act of 1976, and the National Historic Preservation Act of 1966.

The January 1994 amendment to Section 3.1 of the Hanford Federal Facility Agreement and Consent Order (Tri-Party Agreement) Action Plan, required DOE to enter into negotiations with the Washington State Department of Ecology and the United States Environmental Protection Agency, Region 10, for the coordination of activities associated with the transition of FFTF in June, 1994. The intent of the negotiations is to establish Tri-Party Agreement milestones and target dates for the transition activities that will result in an expeditious and cost efficient transition of the FFTF to a radiologically and environmentally safe shutdown condition while minimizing impacts to human health and the environment. The milestones and target dates currently being developed will be identified in the M-81-00 and M-20-00 series in the Tri-Party Agreement (Reference 13) and will reflect the actions necessary to achieve FFTF facility transition and initiate the Surveillance and Maintenance Phase. In most cases these milestones were selected based on the critical path schedule for FFTF transition. The goal of the negotiations is to have a finalized agreement approved in Apri1, 1995.

The environmental regulations/approvals discussed below address the Transition Project objectives as delineated in Section 3.0 .

\subsubsection{National Environmental Policy Act}

The National Environmental Policy Act of 1969 (NEPA) requires the scope of the FFTF transition activities to be evaluated to determine if they, or any related activity, meet the criteria for a major Federal action which has the potential for significantly affecting the quality of the human environment. This evaluation is initiated by the preparation and transmittal of an Action Description Memorandum to RL. The preparation of the Action Description Memorandum represents the initial effort required to be in compliance with the NEPA process.

Once the Action Description Memorandum has been evaluated, either an Environmental Assessment is prepared or an Environmental Impact Statement process is initiated. Affected states and Indian Nations are notified of the NEPA process which will be pursued. No action concerning the transition to 
shutdown should take place which would have significant environmental impacts or 1 imit the choice of reasonable alternatives for each major task until this process is completed.

\subsubsection{Assumptions/Actions}

(1) An Action Decision Memorandum was prepared and submitted to RL on January 21, 1994, (see Reference 14) to support a DOE determination regarding the appropriate level of NEPA documentation for the proposed shutdown scope.

(2) Defueling of the FFTF (including replacing the fuel with nonfuel components to maintain configuration of the core structure) is an extension of the refueling/defueling activity described in the FFTF Environmental Statement WASH-1510. Therefore, no additional NEPA review is required for this defueling activity.

Basis: The construction and operation of the FFTF was discussed in a 1972 environmental statement (WASH 1972, Environmental Statement. Fast Flux Test Facility, Richland, Washington, WASH-1510, United States Atomic Energy Commission, Washington, D.C.). The scope of the document included fuel movement in support of reactor operations and core offload as a design condition. This basis reflects concurrence by $\mathrm{RL}$ and $\mathrm{DOE}-\mathrm{HQ}$ Nuclear Energy NEPA Compliance Officers.

(3) Assuming that an Environmental Assessment was the appropriate level of NEPA documentation required for the transition activities, WHC prepared an Environmental Assessment which was submitted to RL on March 31, 1994 (Reference 15). The scope and content of the Environmental Assessment is consistent with the Action Description Memorandum which was submitted in January, 1994. On Apri1 15, 1994, RL provided notification to WHC that, based on the Action Description Memorandum, an Environmental Assessment was the appropriate level of NEPA review for the FFTF transition activities (Reference 16).

The scope of the Environmental Assessment includes: fuel offload to interim dry cask storage; modifications to the Plutonium Finishing Plant for unirradiated Category IC Special Nuclear Material storage; transfer of seven sodium-bonded metal fuel assemblies plus sodium-bonded pins (metal and carbide) to the Idaho National Engineering Laboratory in Idaho Falls, Idaho, for consolidated storage; bulk sodium drain, storage and reaction; inert gas blanketing of the sodium residuals; shutdown of the auxiliary plant systems; and management of resultant waste streams.

On October 7, 1994, a pre-approval authorization committee was convened by $\mathrm{RL}$ to address any final comments on the Environmental Assessment prior to submittal of the document to the affected states and Indian Nations. 
(4) Activities routine in nature, therefore outside the scope of transition, have been identified and were evaluated. These activities involve Tayup of systems which, due to the reduced heat load of the irradiated fuel, are no longer necessary to support plant operations. Most of these activities involve plant reorientation, such as isolating valves and piping, which are not irreversible actions. Resultant materials (e.g., glycols and oils) that may be drained from these systems or equipment would either be reused, recycled, or properly packaged and disposed of as hazardous waste, as appropriate. Only minimal radioactive wastes would be generated as a result of these efforts, and only minor pieces of hardware would be physically removed.

\subsubsection{Constraints}

Those transition activities specifically delineated in the Environmental Assessment cannot commence prior to completion of the NEPA process. The associated constraints are depicted in Figure 1, the most immediate being fuel washing in the Interim Examination and Maintenance Cel1 coupled with Interim Storage Cask utilization.

\subsubsection{ScheduTe}

$\mathrm{RL}$ recently received delegated authority from the DOE-HQ to approve NEPA documentation. This is expected to expedite the Environmental Assessment approval process and remove it from the critical path. Completion of the NEPA review process with issuance of the Finding of No Significant Impact (FONSI) is expected to occur in February, 1995.

\subsubsection{Resource Conservation and Recovery Act}

The Resource Conservation and Recovery Act of 1976 (RCRA) establishes requirements for the management of hazardous waste. The State of Washington Department of Ecology administers the requirements of this Act through the "Dangerous Waste Regulations" contained in Chapter 173-303 of the Washington Administrative Code (WAC). The FFTF sodium coolant will be managed as product material pending a final decision on reuse of the material, as discussed in Section 6.2.2.1(1). However, if a future decision is made to dispose of the sodium as waste, management of the sodium would be regulated pursuant to these requirements. The following assumptions and actions reflect the tentative agreement that has been reached by the State of Washington Department of Ecology, the U.S. Environmental Protection Agency and the U.S. Department of Energy for management of hazardous materials at FFTF during the Tri-Party Agreement negotiations discussed in Section 6.2 .

\subsubsection{Assumptions/Actions}

(1) The approximately 260,000 gallons of FFTF sodium coolant provides cooling for the irradiated fuel components, therefore serving a useful function until the fuel offload is complete. At the completion of reactor defueling, the reactor vessel and heat transport systems could be drained pending availability of the Sodium Storage Facility. 
Although this inventory of sodium will not be needed for cooling after the fuel is removed, a new purpose for the sodium has been identified by the Tank Waste Remediation System (TWRS) Program (Reference 17).

The TWRS Program plans to use the sodium, converted to sodium hydroxide, for caustic washing as part of the high level waste tank sludge pretreatment process. The TWRS Program technical baseline specifies caustic washing as the primary process for tank waste sludge pretreatment. The current TWRS flowsheet, WHC-SD-WM-T1-613, Rev. 0, dated June 29, 1994, requires 21,000 metric tons of sodium hydroxide. Sodium hydroxide produced from the sodium metal at FFTF represents approximately 8 percent of the sodium hydroxide identified in the TWRS flowsheet. The FFTF Transition Project technical baseline includes planning for conversion of the sodium to sodium hydroxide for use in the TWRS Program. The sodium will be managed as product material for use at TWRS until an evaluation is completed in June, 1998, to confirm the final sodium disposition and form (i.e., product or waste). The FFTF evaluation will be conducted in concert with a TWRS evaluation (TriParty Agreement Milestone M-50-03) which wi11 define the TWRS tank waste pretreatment requirements.

In the interim, activities have been initiated, as discussed in Item 2 below, to provide RCRA and WAC 173-303 compliant storage for the sodium in the Sodium Storage Facility and treatment in the Sodium Reaction Facility, in the event the 1998 evaluation determines the sodium use at TWRS is not viable and would have to be managed as dangerous waste.

(2) On September 13, 1994, RL submitted a letter notifying the State of Washington Department of Ecology of their intent to request interim status expansion of the Hanford Facility's Permit for the Sodium Storage Facility and Sodium Reaction Facility (Reference 18). If these facilities cannot be constructed and operated under interim status expansion, the FFTF transition schedule would be significantly delayed and extended because of the three to five years needed to acquire final status for new facilities.

Efforts have been initiated to prepare the necessary documentation to request interim status expansion for the two new facilities. A draft Notice of Intent has been prepared and is expected to be submitted to the State of Washington Department of Ecology by December 20, 1994. Following a 150 day public review/comment period for the Notice of Intent, the Part A Permit application will be submitted to the State.

If the sodium use at TWRS is confirmed in 1998 as expected, the Sodium Storage Facility and Sodium Reaction Facility would undergo procedural closure as defined in Section 6.3.3 of the Tri-Party Agreement. In this event, the Transition End-Point Criteria Document and Surveillance and Maintenance Plan for transitioning the plant to a safe and stable condition, would be provided to the U.S. Environmental Protection Agency and State of Washington Department of Ecology for review, and approval for the hazardous substances proposed to remain in the plant pending Phase III (Disposition) of the decommissioning process. 
(3) When the sodium systems have been drained to the maximum practical extent, sodium residuals will remain in the plant's cooling systems. In addition, there are a number of sodium-wetted equipment [i.e., non-fue] core components, stalks from experimental assemblies (Material Open Test Assemblies, Fuel Open Test Assemblies, etc.), and various fuel handling equipment] that will remain either in the FFTF core to maintain reactor core geometry, or in cells adjacent to the core (i.e., In-vessel Storage, Interim Decay Storage Vessel, Test Assembly Conditioning Station, or Interim Examination and Maintenance Cell). Final disposition of this equipment has not been determined; however it is expected that the majority will be retained in FFTF until the disposition phase of the decommissioning process. The Transition EndPoint Criteria Document and Surveillance and Maintenance Plan will address management of these materials.

(4) As discussed in Item 1 above, the Sodium Storage Facility and the Sodium Reaction Facility will be designed and operated to meet appropriate RCRA requirements. The WAC 173-303 requires sodium storage in a manner equivalent with the Uniform Fire Code. Sodium is classified in the Uniform Fire Code as a flammable solid, pyrophoric and water-reactive material and the rules of $80.305,80.308$ and 80.310 apply, respectively. Due to the large amount of sodium that will be stored in the Sodium Storage Facility in surplus Clinch River Breeder Reactor Project ASME Section III tanks, exact compliance with two Uniform Fire Code rules must be clarified and/or alternate methods concurred with by the authority having jurisdiction over the WAC 173-303. The authority has been established as the Washington State Department of Ecology, who will coordinate with the State Fire Marshall on Uniform Fire Code issues. A letter was submitted on August 16, 1994 (Reference 19), requesting approval of the proposed approach. Following is a brief description of each item:

- Uniform Fire Code Section 80.301 (p) Fire-extinguishing Systems, states "Unless exempted or otherwise provided for in Sections 80.302 through 80.315 , indoor storage areas and storage buildings shall be protected by an automatic sprinkler system."

Basis: Sprinkler systems in a sodium facility are not consistent with current industry practice and are unacceptable because water reacts with sodium to produce violent and uncontrollable reactions. Section 10.509 specifically states that "Sprinklers shall not be installed when the application of water or flame and water to the contents may constitute a serious life or fire hazard, as in the manufacture or storage of quantities of...metallic sodium..." A covered sump is provided as an alternate extinguishing system.

- Uniform Fire Code Section 80.308 (a) 7, Storage Conditions, states "Tanks or containers inside buildings shall not be Targer than 500 gallons." 
Basis: There are approximately 260,000 gallons of FFTF sodium that will be drained from the Plant. Four Clinch River Breeder Reactor vessels will be used to store the FFTF sodium (three with a capacity of 80,000 gallons each and one with a capacity of 52,000 gallons). The safety hazards associated with the transfer and storage of this very large volume of sodium to 500 gallon tanks would be imprudent, increasing the likelihood of a spill/fire and exorbitantly increasing the required size and cost of the facility for no credible technical or safety rationale.

(5) Following conversion of the sodium inventory stored within the Sodium Storage Facility, any residual sodium or chemicals used for the reaction process will be appropriately addressed prior to turnover of the facility to the Environmental Restoration Contractor.

\subsubsection{Constraints}

Approval of the Sodium Storage Facility and Sodium Reaction Facility Part A Permit application for interim status expansion will be required prior to beginning major construction activities. Site preparations (e.g., concrete removal, tank modifications) can commence prior to this approval.

\subsubsection{Schedule}

Preparation of the Notice of Intent is in progress, and submittal to the State of Washington Department of Ecology is expected by December 20, 1994. Following the required 150 day public review period, the Part $A$ Permit application will be submitted to the State on May 20, 1995.

\subsubsection{Toxic Substances Control Act}

The problem of toxic chemicals, including pesticides and especially hazardous wastes, has taken on increased importance with the public realization that thousands of carcinogenic, teratogenic, and mutagenic substances are present in our environment. The Toxic Substances Control Act of 1976 provides

Environmental Protection Agency with authority to require testing of chemical substances, both new and old, entering the environment and to regulate them where necessary. This authority supplements sections of existing toxic substance Taws, such as Section 112 of the Clean Air Act, Section 307 of the Water Act, and Section 6 of the Occupational Safety and Health Act, which already provide regulatory control over toxic substances.

\subsubsection{Assumptions/Actions}

Disposition of the nineteen Polychlorinated Biphenyl (PCB) electrical transformers at FFTF will be required during the transition phase as the transformers are removed from service (see Section 1.2, Appendix A-2). The drain and disposal of the PCB fluids and transformers must be in compliance with applicable PCB disposal requirements as specified in 40 CFR 761 . Table 1 provides a list of the five unique groups of FFTF transformers. The first four groups, which include tweive of the nineteen transformers, will be 
Table 1

FFTF PCB TRANSFORMERS

\begin{tabular}{|c|c|c|}
\hline TRANSFORMER & LOCATION & GALLONS \\
\hline \multicolumn{3}{|c|}{ GROUP I } \\
\hline$\times 28$ & $4621 \mathrm{E}-303$ & 473 \\
\hline$\times 30$ & $491 W-431$ & 473 \\
\hline \multicolumn{3}{|c|}{ GROUP II } \\
\hline$\times 9$ & $\mathrm{R} 00 \mathrm{~F}-4621 \mathrm{~W}$ & 464 \\
\hline$\times 10$ & R00F- $4621 \mathrm{~W}$ & 464 \\
\hline$\times 14$ & ROOF- $-4621 \mathrm{~W}$ & 464 \\
\hline$\times 25$ & R00F-4621W & 362 \\
\hline$\times 26$ & ROOF-4621W & 362 \\
\hline \multicolumn{3}{|c|}{ GROUP III } \\
\hline$x_{6}$ & $4621 W-367$ & 455 \\
\hline$\times 29$ & $4621 W-365$ & 473 \\
\hline$\times 101$ & $4621 W-367$ & 455 \\
\hline \multicolumn{3}{|c|}{ GROUP IV } \\
\hline$\times 5$ & $4621 \mathrm{E}-308$ & 455 \\
\hline$\times 100$ & $4621 \mathrm{E}-308$ & 455 \\
\hline \multicolumn{3}{|c|}{ GROUP V } \\
\hline$\times 7$ & $4621 \mathrm{E}-331$ & 455 \\
\hline $\mathrm{XI1}$ & $491 \mathrm{E}-449$ & 455 \\
\hline $\mathrm{X} 12$ & $491 \mathrm{E}-452$ & 455 \\
\hline$\times 13$ & $491 W-457$ & 464 \\
\hline$\times 59$ & $491 W-457$ & 455 \\
\hline X98 & $491 W-457$ & 455 \\
\hline $\mathrm{X} 117$ & $491 \mathrm{E}-452$ & 455 \\
\hline
\end{tabular}


drained, flushed, and removed within thirty days after being removed from service. The fifth group of seven transformers, which will be more difficult to remove, will be accomplished within nine months of cessation of service.

The proposed disposition for the seven transformers is to drain and flush the units and designate the 570 foot elevation of the Heat Transport Service Building as a storage area for PCB Articles. With the PCB oil removed there will not be a credible danger of a PCB leak; the floor drains in proximity to the transformers have been plugged and berms installed; the floor surface is sealed and impervious to leakage; the FFTF Plant is above the 100-year flood plain; and the transformers are protected from the elements, which would mitigate the consequences even if an improbable leak were assumed to occur. The transformers will be removed within nine months of cessation of service to ensure their disposal within one year from the start of storage. Cessation of service constitutes the start of the storage and the Toxic Substances Control Act limits storage and disposal to a one-year period. Although the 570 foot elevation area containing the transformers does not include a six inch curb to provide a containment volume, the 550 foot elevation does have a curb along its inner wal1, and with the transformers drained and flushed, absorbent material added, and penetrations capped or sealed, the intent of 40 CFR 761.65 (b) (1) will be met and removal of the transformers within nine months will ensure the requirements of 40 CFR 761.65 (a) are also met.

\subsubsection{Clean Air Act}

The role of the Federal government in air pollution control began with amendment of the Clean Air Act in 1970. The 1970 Act provided for the adoption of national air quality standards and required each state to adopt legislation and regulations to assure maintenance of the standards. The state regulations address control of over 600 air pollutants, including air toxins, hazardous air pollutants including radioactive emissions, ozone depleting substances, and pollutants suspected of causing global warming. Since 1970, the Clean Air Act has required Federal facilities to meet all federal, state, and Tocal air emissions regulations.

\subsubsection{Assumptions/Actions}

The planned transition activities which could potentially be impacted by the Clean Air Act are discussed below:

(1) An increase in radionuclide emissions as a result of these planned activities are regulated by the National Emission Standards for Hazardous Air Pollutants (NESHAPs) (radioactive only), 40 CFR 61 subpart $\mathrm{H}$, and Radioactive Air Emissions Program (RAEP), WAC 246-247.

Current7y, a Notice of Construction (NOC) is being prepared according to requirements of the WAC 246-247, Radiation Protection - Air Emissions, and 40 CFR 61 Subpart $H$ for the Sodium Storage Facility. The NOC must receive approval from the State of Washington Department of Hea7th and the U.S. Environmental Protection Agency prior to initiation of construction. An NOC will also be required for the Sodium Reaction Facility prior to construction. An evaluation will be conducted to 
confirm that no significant increases in air emissions will result due to operation of either the Sodium Storage Facility or Sodium Reaction Facility. The evaluation will also determine whether the new sources must be registered per the requirements of WHC-CM-7-5, "Environmental Compliance." If the stack emissions do not meet the criteria for registration, the new facilities will fall under the requirement of periodic confirmatory monitoring.

(2) The Combined Exhaust (registration \#141-001) wi11 continue to be evaluated, per existing practice, to determine whether any transition activities would require a notification to the State of Washington Department of Health.

(3) Fugitive emissions (especially dust) from construction/operational activities associated with the construction of the Interim Storage Area, Sodium Storage Facility and Sodium Reaction Facility will be controlled in accordance with reasonable practices, per WAC 173-400-040(3).

\subsubsection{Constraints}

Construction activities for the Sodium Storage Facility or the Sodium Reaction Facility cannot commence prior to completion of the requisite evaluations and applicable permitting activities discussed in Items 1 and 2 above.

\subsubsection{Schedule}

The Sodium Storage Facility Notice of Construction is scheduled for submittal to the Washington State Department of Health by February 1, 1995. It is expected that the Notice of Construction will be approved by June 1, 1995 . The time necessary to prepare and receive approval of the Notice of Construction for the Sodium Reaction Facility from initiation of the activity until approval from the regulatory authorities is estimated at approximately eighteen months.

\subsubsection{Other Regulatory Requirements}

The Hanford Cultural Resources Laboratory conducted a cultural resources review of the FFTF Transition Project in June, 1994, entailing the deactivation of FFTF and construction of the Interim Storage Area, modifying the PFP fuel storage area, and construction of the Sodium Storage Facility and Sodium Reaction Facility (Reference 20). The review indicated that the new construction sites have previously been highly disturbed by building, road, and utility construction and survey and monitoring by an archaeologist during excavation work is not necessary. However, the review indicated that the FFTF has not been evaluated for eligibility for the National Register of Historic Places. An historical evaluation of the FFTF, in compliance with the National Historic Preservation Act of 1966 , will be conducted during the transition phase.

A biological site assessment was conducted of the project construction sites (e.g., Interim Storage Area, Sodium Storage Facility, Sodium Reaction Facility). The pedestrian survey focused on plant and animal species listed 
as threatened, endangered, candidate, sensitive, or monitored by the State of Washington. The survey concluded that no adverse impacts to such species would occur from the proposed action (Reference 21).

\subsection{WORKER HEALTH AND SAFETY}

The occupational safety and health program for the Transition Project implements the procedures in WHC-CM-4-3, Industrial Safety Manua 7 , and WHC-CM-4-40, Industria7 Hygiene Manua7. These manuals provide the necessary programs and guidance for routine work and conform to the requirements of DOE Order 5483.1A, Occupational Safety and Health Program for DOE Contractor Employees at Government-Owned Contractor-Operated Facilities, DOE Order 5480.4, Environmenta7 Protection, Safety, and Health Protection Standard and DOE Order 5480.10, Contractor Industrial Hygiene Program.

The WHC Program provides instructions and training in the control of physical hazards; hazards identification, surveillance, and communication; asbestos removal operation; hazardous materials handling and emergency response; posting of danger signs and tags or safety instructional materials; storage of pressurized gases; lockout and tagout activities; fall protection; confined space; and explosive or combustible materials handling, processing, storage, transportation, and shipping.

Programs are in existence which ensure worker safety during plant operation and maintenance activities. These programs will continue to function during the transition phase. A general overview of the major programs is given below.

\subsubsection{OSHA Requirements}

Verification of full implementation of Occupational Safety and Health Administration (OSHA) standards is currently underway at FFTF. WHC is in the process of submitting a formal application for Merit Status under the DOE-Voluntary Protection Program. This program has been designated the WHC Worker Protection Program.

This program contains five basic elements: Management Commitment, Employee Involvement, Worksite Analysis, Hazard Prevention and Control, Safety and Health Training. FFTF is currently focusing on Worksite Analysis and Hazard Prevention and Control by performing facility Baseline Hazard Assessments. The Baseline Hazard Assessments:

- Verify that existing administrative programs meet OSHA standards. Any deficiencies that are identified are corrected.

- Establish a hazards baseline document where hazards are identified for the facility and for those that require elimination or mitigation corrective actions are taken.

- Annual verification that the administrative programs continue to meet current requirements and that the facility baseline has not changed. 
The goal of the WHC Worker Protection Program is to ensure a fully compliant worker safety program is in place and functioning to protect the facility worker from accident or injury. The Merit Status signifies that requirements are being properly applied and demonstrates the willingness and ability of the Company to voluntarily comply with the applicable standards. The Baseline Hazard Assessments part of the WHC Worker Protection Program satisfies the DOE requirement for performing periodic compliance inspections.

In addition to the above effort, an annual integrated safety appraisal is conducted by the WHC Safety and Compliance Assurance organizations. A portion of this appraisal has traditionally been a program review and facility inspection to verify compliance with applicable DOE and WHC requirements. In recent years, this has also included an evaluation of the current practices and facility conditions in comparison with the OSHA standards. Discrepancies identified during these appraisals have been documented in the facility's corrective action management system and resolved appropriately.

It is intended that during the transition activities the above programs witl continue. Participation in the WHC Worker Protection Program will not only provide a periodic evaluation of the safety programs in place, but it will al so provide the Environmental Restoration Contractor with an up-to-date listing of the facility hazards present at the time of turnover. Establishing the facility hazards baseline is an important component of the turnover package and will be available as a result of participation in the WHC Worker Protection Program.

\subsubsection{Implementation of Safety Elements}

Incorporation of appropriate safety elements into the procedures used for operation and maintenance is fundamental to the FFTF conduct of operations program. Activities are analyzed for hazards and the results of this analysis are incorporated in the procedure which then receives appropriate safety organization review (industrial, radiological, nuclear, etc.). This process is applied both to the standing operating and preventive maintenance procedures as well as the work instructions which are prepared to support corrective maintenance and plant modifications. This program provides the worker with an integrated procedure which includes the instructions for performing the task as well as specific safety precautions, protective equipment requirements, and exposure controls.

This program will continue to be used to prepare the work packages which will govern the various transition activities. As a result, the same focus on worker safety which marked the operating phase of the plant's operation will continue to be applied to the activities involved in its shutdown. This program is a mature one, which has proven itself effective by having industrial safety, health and fire protection engineers located at the 400 Area for support. This concept is well understood by the plant staff and contributes to the overall team effort. In utilizing this existing program, retraining is precluded, and the errors which generally accompany a change in methods will be avoided. 


\subsubsection{Performance Monitoring}

Several programs for measuring the effectiveness of the plant safety programs are in place. These programs will continue to be followed during transition. Four of these will be described below:

- The plant is routinely inspected by Operations personnel to ensure the plant remains free of safety hazards and that the standards of housekeeping are highly maintained. The plant has been divided into five zones which are each "owned" by a Shift Operations Manager, who inspects the assigned area once per shift cycle and identifies corrective actions to the maintenance organization. Approximately two weeks later, a follow-up inspection is made by the Shift Operations Manager, Operations Manager, a Maintenance Supervisor, an Operations Safety Observer and an Industrial Safety Engineer. Using this process, each area of the plant is visited twice on a five week rotation. The program has proven itself very effective based on the feedback of plant visitors and auditors who consistently praise the absence of safety hazards and the high standards of plant cleanliness.

- In addition to the periodic inspections described above, the Operations Manager conducts a thorough inspection of the plant annually. This manager has received training in the OSHA standards and utilizes a checklist prepared by Industrial Safety which verifies. compliance with all the major elements of the OSHA standards. Plant physical conditions are inspected in addition to a review of the administrative programs in place.

- A multifaceted Self-Assessment program is in place which also conducts field verification of safe plant conditions and conformance to safe work practices. This program involves a team of representatives from the major plant organizations (including oversight functions) which utilizes a set of checklists developed to verify compliance with safety, operations, and maintenance programs. This program also identifies compliant activities which can be optimized. Actions identified by this program are entered into the plant's commitment tracking program. Another activity in this area is the Management Overview Program which utilizes managers who make periodic tours of the plant to insure proper implementation of safe work practices. The managers are briefed by the Plant Manager prior to conducting their tour to receive guidance on areas that are to receive particular focus. Deficiencies identified are also documented and tracked to completion.

- A "Safety First" program is in place which is focused on ensuring safe work practices are being followed by facility workers. This is a behavioral based safety observer program. Volunteers are the participants in this program. The manager of Work Control reviews the scheduled work for each week and determines one or more jobs which warrant observation by one of the "Safety First" volunteers. The observations are documented, as well as good practice and deficiencies. Deficiencies are corrected on the spot whenever possible. 
Deficiencies and good practices are maintained and tracked in a data base and reports are sent to line management for corrective actions. Lessons learned are distributed to appropriate organizations for dissemination to their personnel.

\subsubsection{Fire Protection}

The required Transition Project fire protection features are specified in WHCCM-4-41, Fire Protection Program Manual. The intent is to fulfill the requirements of DOE Order 5480.7A, Fire Protection, and the National Fire Protection Association Standard 101, "Life Safety Code," NFPA (1991). The degree of fire protection is commensurate with the loss risk and risk to human health.

The FFTF has been operating for many years with Final Safety Analysis Report fire analyses that met the requirements of DOE Order 5480.7 of 1980. DOE Order 5480.7A (1993) permits the Final Safety Analysis Report analysis to replace the Fire Hazards Analysis if certain requirements are met. Two of these requirements, calculation of the Maximum Possible Fire Loss and division of the facility into Fire Areas by loss potential, were not addressed in the FFTF Final Safety Analysis Report, but were addressed in a Fire Barrier Study (WHC-SD-FF-ES-020) completed in 1991. This study accomplishes much of the Fire Hazards Analys is requirements, but assumes barriers between fire areas are rated at two hours. A graded approach Fire Hazards Analys is is being prepared that utilizes the existing Final Safety Analysis Report and Fire Barrier Study as a baseline. A new section will have to be prepared that assesses the Maximum Possible Fire Loss, including cleanup costs, that could occur from a sodium fire during the sodium off-load operations.

As the Transition Project activities proceed, a measured reduction in protection is expected to result from the following:

- Systematic reduction in fire loading through removal of flammable liquids and other combustibles.

- Reduction in occupational loading as the workforce is phased out of the plant, leaving it unoccupied.

- Deactivation of plant systems that require fire protection, such as electrical switch gear rooms and the computer rooms.

- Eventual declaration of "no property value" for the plant.

\subsubsection{Emergency Preparedness}

The WHC-CM-4-43, Emergency Management Procedures Manua7, provides the Hanford Site and 400 Area specific procedures for dealing with FFTF Plant emergencies. WHC maintains a building emergency plan, WHC-IP-0263-FFTF, "Emergency P1 an for FFTF Protected Area," for FFTF to provide personne1-specific emergency response actions. These identify lines of authority and the responsibilities of emergency response personnel and organizations. 


\subsubsection{Criticality Safety}

Chapter 20 of the Final Safety Analysis Report and WHC-CM-4-29, Nuclear Criticality Safety Manual, establishes the Nuclear Criticality Safety Program. Deactivation activities with criticality implications will be reviewed by the plant Criticality Safety Representative and overviewed by the FFTF Safety organization to ensure that the proposed work is within the existing criticality prevention specifications. Work outside the previously analyzed and approved criticality prevention envelope will require a new criticality safety evaluation and/or a change to the existing criticality prevention specifications.

A Criticality Safety Evaluation Report will be prepared for the Interim Storage Area which will be a "Fissionable Material Facility, " to identify controls and conditions that must be maintained during the surveillance and maintenance phase. 
WHC-SD-FF-SSP-004

Rev. I Page 46

This page intentionally left blank. 


\subsection{ENVIRONMENTAL RESTORATION CONTRACTOR CRITERIA}

The Plan provides the major elements and project baseline for the transition activities necessary to place FFTF and supporting facilities in a radiologically and industrially safe condition such that they can be turned over for a long term surveillance and maintenance phase pending final disposition at a later date. Although no formal guidance for the appropriate facility turnover criteria has been received from DOE, a set of preliminary generic criteria for facility transfer were developed by the Environmental Restoration Contractor based on the draft DOE guidance provided in Reference 22. These preliminary criteria are shown in Appendix A-3.

The preliminary generic criteria developed by the Environmental Restoration Contractor include a requirement to remove all residual sodium from the plant systems. While this was initially identified as a key issue, subsequent discussions between DOE, Bechtel Hanford Inc., and FFTF personnel have confirmed that sodium residuals will remain in the plant, although the specific quantities and locations have not been finalized. Reference 23 contains an FFTF recommendation and associated technical/programmatic bases for quantifying the sodium residuals. When agreement is reached, it will be formalized in the Transition End-Point Criteria Document.

The Transition End-Point Criteria Document will define exactly what actions are required prior to facility turnover at the end of the transition period. Development of the document for this unique facility will be an evolutionary process requiring extensive interaction between the FFTF, the Environmental Restoration Contractor, DOE, and the regulatory agencies. The content of the Transition End-Point Criteria Document will be specified in the Tri-Party Agreement, Section 14. The process will assure appropriate consideration of the following objectives:

- Protect Public \& Environment

- Facilitate Surveillance and Maintenance (Protect Workers and Reduce Cost)

- Facilitate Decontamination and Decommissioning

- Comply with Regulations \& Requirements

- Meet Commitments to Stakeholders

The specific criteria for all building areas and systems will be agreed to by the FFTF staff and Environmental Restoration Contractor representatives. A preliminary description of the general status of the FFTF systems at turnover is provided in Appendix A-2, and the individual System Shutdown Plans. The Transition End-Point Criteria Document will be developed using: 1) these preliminary descriptions, 2) a formal approach to evaluate the criteria specified above and 3 ) joint walkdowns of systems and spaces with Environmental Restoration Contractor personnel. Once agreed to, these specific criteria will be developed into a checklist for turnover readiness. 
WHC-SD-FF-SSP-004

Rev. 1 Page 48

This page intentionally left blank. 


\subsection{PLANT CONFIGURATION AT THE END OF TRANSITION}

The plant will be placed in an industrially and radiologically safe configuration to comply with the Environmental Restoration Contractor turnover criteria as discussed in Section 7.0. The plant will remain in this state for possibly decades before the start of any final disposition activities. Therefore, the plant will be configured with only a minimal number of operational systems. Appendix A-2 describes the shutdown status of each plant system and all plant buildings. This section will continue to be revised as the system end-point criteria evolve.

As discussed in Section 9.4.3.3, it is expected that approximately 3,555 gallons of frozen sodium residuals will remain in the plant under an inert gas blanket. These residuals will be maintained for Tater disposition by the Environmental Restoration Contractor organization. Although this has been agreed to in principle, it is expected that the details will be developed through negotiations with the Environmental Restoration Contractor organization as well as with various regulatory agencies. The final agreement will be reflected in jointly approved end point criteria. The inert gas blanket will be maintained through use of a simple nitrogen Dewar and pressure regulator system located external to the facility. Minimal system surveillance and maintenance will be required.

A number of modifications will be required to achieve the minimum cost state at the end of the transition phase. Appropriate documentation describing the final deactivated $p$ lant configuration will be turned over to the Environmental Restoration Contractor to establish a baseline for future decontamination and decommissioning activities.

The electrical systems will be configured to provide the minimum necessary power for surveillance. This will involve some electrical bus interconnections and disconnects. Polychlorinated biphenyl oil cooled transformers, will be drained and removed. Minimum lighting will be available for surveillance activities.

A minimum amount of ventilation may be required to meet life safety requirements for periodic access for surveillance and maintenance due to the potential for inert gas leakage and radon buildup. Portable units may be considered for this service. Air operated dampers or valves which fail closed, but need to remain open, will be mechanically blocked in the required position to allow shut down of the instrument air system.

The required fire protection equipment will be identified by a Fire Hazards Analysis that will reflect the final shutdown end state.

Most of the process fluids and lubricating oils used in the plant are hazardous materials (e.g., ethylene-glycol, propylene-glycol, oils, etc.). These fluids will be drained with all heels removed to the maximum extent practical. Any hazardous fluids remaining must comply with environmental regulations. The Recycle Programs office will be notified prior to draining 
in an attempt to find buyers both on and off the Hanford Site. If a buyer cannot be found, the material will be disposed of according to applicable environmental regulations. Some of these systems were not designed to easily facilitate draining, and studies will be performed to determine the most efficient and safe drain methods. The underground fuel oil tanks will either be removed or permanently closed. 


\subsection{MAJOR TRANSITION ACTIVITIES}

The major deactivation activities necessary to transition the FFTF and related facilities to a shutdown state are identified within this section. The overall FFTF fuel offload activity is subdivided into four major phases including: defueling the reactor (Phase 1), disposition of the non-irradiated fuel (Phase 2), disposition of the irradiated fuel (Phase 3 ), and disposition of special fuel (Phase 4) described in Sections 9.1 through 9.3. Portions of these phases may be performed in parallel. The unique and challenging issues associated with the sodium drain and disposition are discussed in Section 9.4.

\subsection{REACTOR DEFUELING}

\subsubsection{Reactor Fuel Movement}

The defueling of the reactor to Interim Decay Storage and the Fuel Storage Facility will use standard FFTF refueling equipment and operating procedures. Fuel in the reactor vessel will be replaced with irradiated non-fuel core components (e.g., reflectors, control rods, etc.) and seventeen new non-fuel core components (Multipurpose Test Assemblies) that would have been excessed. Earlier plans (Revision 0 ) included the use of three Simulated Core Assemblies, because sufficient Multipurpose Test Assemblies had not been identified. The use of Simulated Core Assemblies would have required reprogramming of the In-Vessel Handling Machine computer. Use of the irradiated non-fuel core components, as discussed in Appendix A-4, results in significant cost and schedule advantages and achieves major waste minimization. This approach will reposition the fuel to Interim Decay Storage and the Fuel Storage Facility, and irradiated non-fuel core components to the reactor vessel.

Appendix A-5 provides a detailed description of the defueling logistics. Eighteen non-adjacent core positions will be empty at the end of the defueling evolution. Figure 6 provides a core map for the final reactor configuration following Phase 1 defueling. Figure 7 provides additional detail of this final configuration. At the completion of reactor defueling, there will be 243 non-fueled components (226 irradiated) in the reactor vesse1, 112 fueled components in the Interim Decay Storage, and 258 fueled components in the Fuel Storage Facility. Included in the 226 irradiated non-fueled components are seven Open Test Assembly Instrument Stalks and one 40 foot long Open Test Assembiy.

The total time required to defuel the reactor vessel is shown in Table 2 . The times depicted are actual work days required. This corresponds to 455 calendar days and forms the basis for the defueling activity shown in the FFTF Transition Project Summary ScheduTe (Figure 1). Note, these times do not provide for any major refueling equipment downtime. 
WHC-SD-FF-SSP-004

Rev. 1 Page 52

This page intentionally left blank. 


\section{SHUTDOWN (DEFUELED) CORE CONFIGURATION}
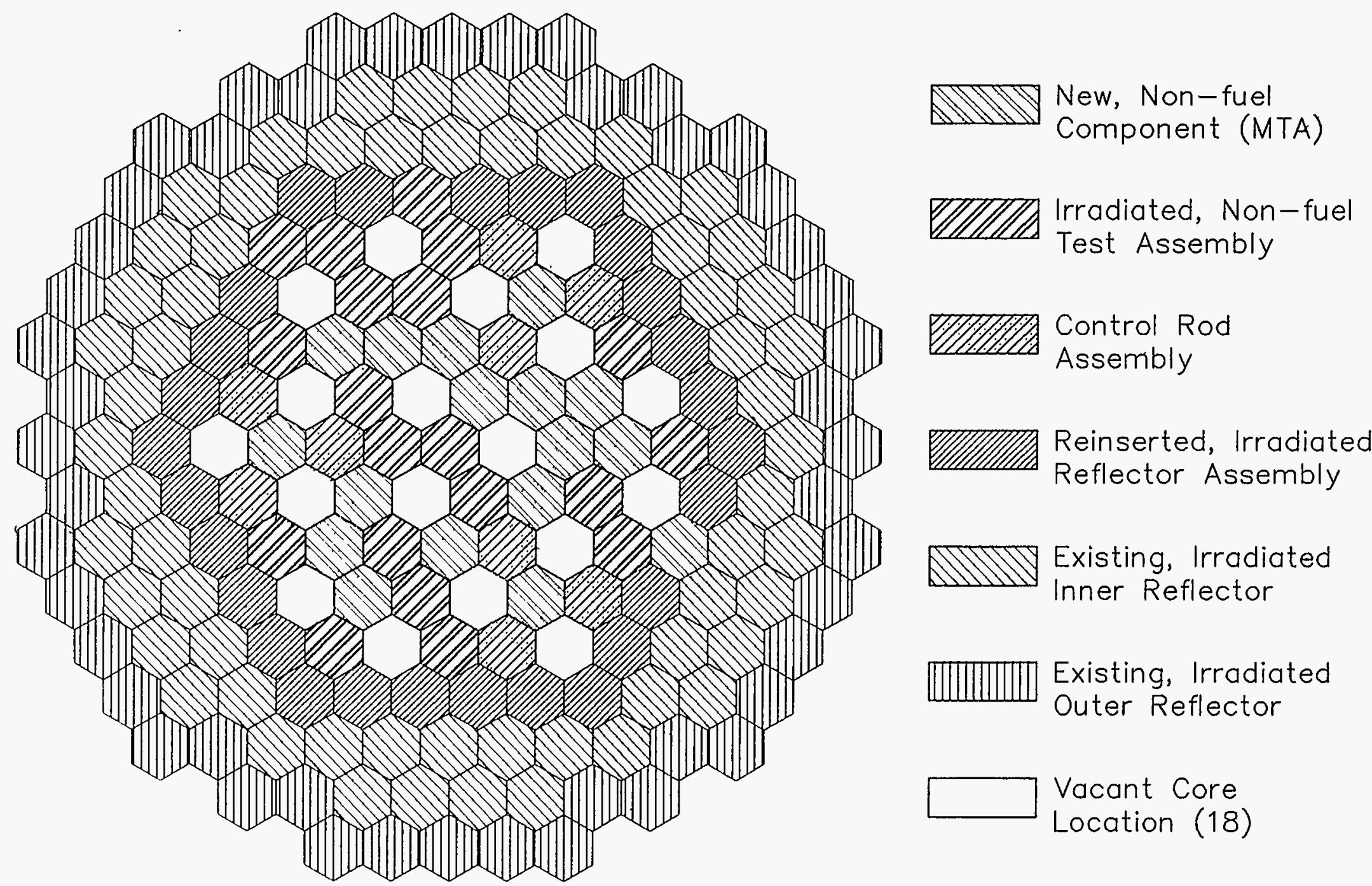

Vacant Core Location (18)

CM.DEFUEL.2

Figure 6. FFTF Core Map 


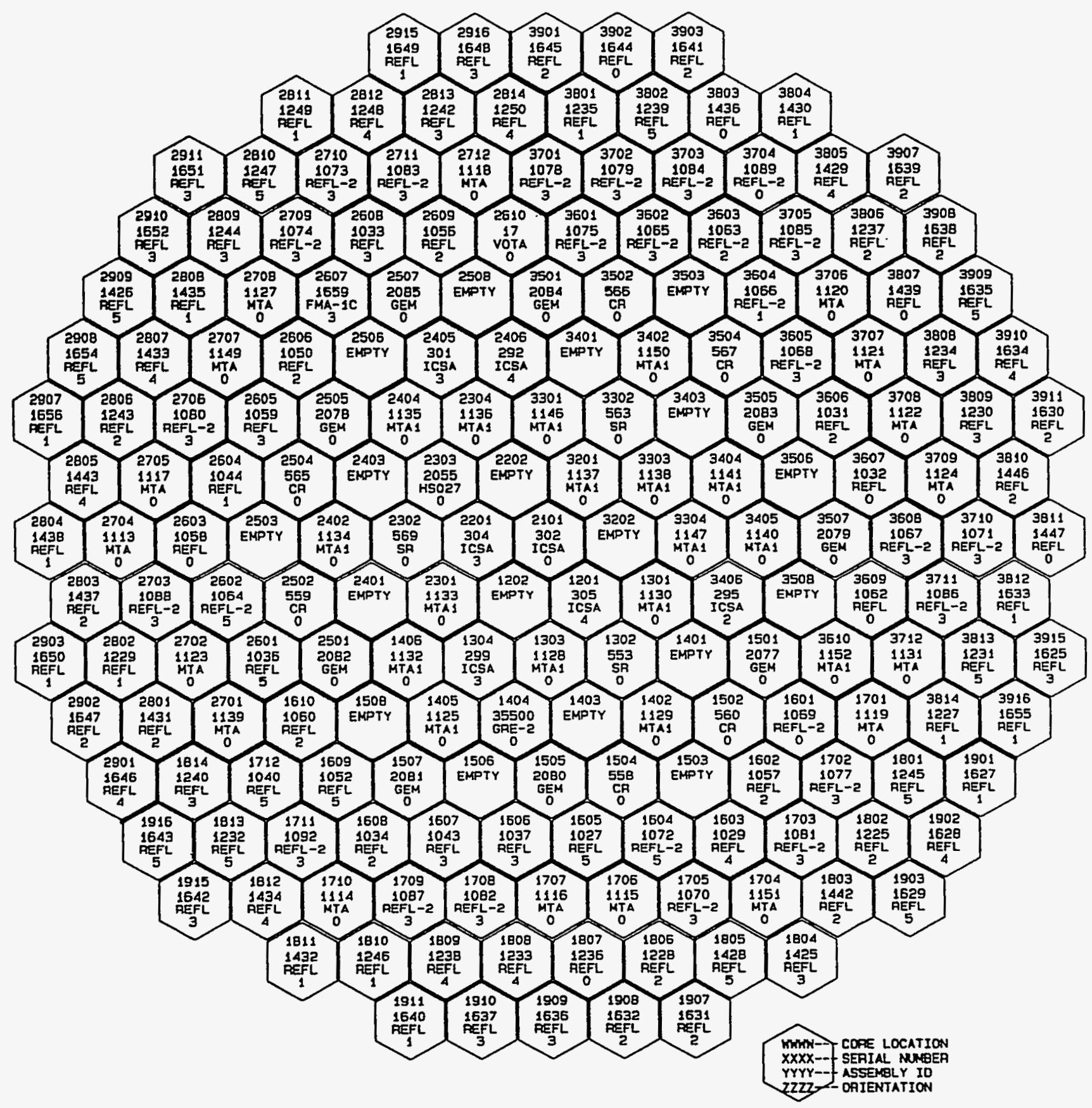

FFTF DEFUELED CORE LOADING - CM.DEFUEL. 2

Figure 7. FFTF Core Map (Detailed) 
WHC-SD-FF-SSP-004

Rev. 1 Page 55

TABLE 2

REACTOR DEFUELING (PHASE 1)

$\begin{array}{lll}\text { STEP } 1 & \text { Offload/load Interim Decay Storage - } 1 & 62 \text { days } \\ \text { STEP } 2 & \text { Core Defuel - Sector 1 } & 40 \text { days } \\ \text { STEP } 3 & \text { Offload/load Interim Decay Storage - } 2 & 80 \text { days } \\ \text { STEP } 4 & \text { Core Defuel - Sector 2 } & 44 \text { days } \\ \text { STEP 5 } & \text { Offload/load Interim Decay Storage - } 3 & 34 \text { days } \\ \text { STEP 6 } & \text { Core Defuel - Sector 3 } & 34 \text { days } \\ \text { STEP 7 } & \text { Final Transfers } & \mathbf{3 1} \text { days } \\ & & 325 \text { DAYS }\end{array}$

The final configuration of the In Vessel Handing Machines and Instrument Trees is to have them in their removal positions (centered under their respective reactor head plug). This is to facilitate removal of the machines at some future time without requiring any additional equipment moves. The Control Rod Drive Mechanisms will not be reconnected to the Control Rod Drive Disconnects, but will be lowered to remove the spring energy on the Control Rod Drive Mechanisms. The Control Rod Drive Mechanisms are removable from the reactor vessel head in this configuration.

Adequate Operations and Health Physics staff are assumed to be available to support 24 hours a day, five days a week operations during defueling evolutions. All planned evolutions requiring maintenance and engineering support are expected to be conducted on day shift only (five days/week).

\subsubsection{Key Assumptions}

The following key assumptions are necessary to conduct the defueling evolutions:

(1) Seventeen modified new Multipurpose Test Assemblies (1" discriminator post) are available for installation into Interim Decay Storage.

(2) Assumed times for planning purposes: (Note that these times do not provide for any major refueling equipment downtime)

- One day (24 hours) to transfer a component between Interim Decay Storage and the Fuel Storage Facility

- One-half day (12 hours) to receive and transfer the Multipurpose Test Assemblies into Interim Decay Storage

- One-third day ( 8 hours) to exchange components between the reactor and Interim Decay Storage

- Three days (72 hours) to replace a center island test position 
(3) The quantity of fueled components being transferred to the Fuel Storage Facility will not require the operation of the Fuel Storage Facility NaK loops as the total decay heat inventory of fueled assemblies will be less than 50 kilowatts by December, 1994 (based on last reactor operation March 19, 1992).

(4) There are 32 unirradiated and three low dose-rate fuel assemblies (Category IC) in Interim Decay Storage. This material requires special security and safeguard measures because of its low dose rate. There is al so one unirradiated metal fueled assembly (Category IIID) in the Test Article Conditioning Station.

(5) A11 Category IC components will remain in Interim Decay Storage until a program has been put into place to remove the Category IC components, wash them of sodium, and place them in appropriate storage as discussed in Sections 9.2.2 and 9.2.3.

(6) Staffing will permit two major defueling activities to occur at any one time (one Health Physics Technician, two Refuelers, and one Refueling Engineer).

(7) This offload will not require opening the three rows at the Fuel Storage Facility that were sealed due to criticality concerns. The currently available locations at the Fuel Storage Facility are sufficient to support defueling.

(8) Maintenance of the core lattice requires that there can be no more than eighteen vacancies in rows one through six in the core after reactor defueling. Of these vacancies, Tocations 1202 and 3202 provide vessel access very near the center and can be accessed through the Center Island spoolpiece at the vessel head penetration. These locations will provide access for the installation of dip tube(s) to facilitate draining the reactor vessel.

(9) Two immersion heaters and a level probe will be inserted into the Fuel Transfer Ports in In-Vessel Storage to provide a redundant heat source for the sodium and to facilitate the drain process.

\subsection{FUEL DISPOSITION}

\subsubsection{Category IVE Irradiated Fuel}

Disposition of the highly-radioactive Category IVE fueled components (332) as defined per DOE Order 5633.3A, Control and Accountability of Nuclear Materials, (DOE 1993) entails interim storage which could last for up to 50 years. The Interim Storage Area (Section 9.3.4) will be located in the northeast corner of the FFTF complex. The fueled components, that are currently stored in a sodium environment, will be washed in the Interim Examination and Maintenance Cell, placed in Interim Storage Casks, and then transferred to the Interim Storage Area. An Interim Storage Cask is expected 
to weigh approximately 60 tons and will contain six or seven fueled components (assemblies or pin containers) that have been sealed in a Core Component Container (Section 9.3.3).

NOTE: By the year 2030, three of the above 332 fueled components will decay to Category IIID status ( $>15 \leq 100 \mathrm{rem} / \mathrm{hr}$ at 1 meter unshielded) and therefore will remain in the 400 Area Interim Storage Area with one existing Category IIID fueled component (an Ident-69) that will continue to have IIID status. The storage arrangement is described in Section 9.2.2.

\subsubsection{Category IC/IIID Irradiated Fuel}

There are 11 irradiated fueled components that by the year 2030 will be either Category IC or IIID special nuclear material as defined per DOE Order 5633.3A, Control and Accountability of Nuclear Materials, (DOE 1993). The planned disposition of the Category IC slightly-radioactive ( $\leq 15 \mathrm{rem} / \mathrm{hr}$ at 1 meter unshielded) and IIID moderately-radioactive $(>15 \leq 100 \mathrm{rem} / \mathrm{hr}$ at 1 meter unshielded) fueled components is to intermix one each of these components with five or six Category IVE highly-radioactive (>100 rem/hr at 1 meter unshielded) fueled components in a single Core Component Container/Interim Storage Cask. This storage concept has been shown, by means of several safeguards and security studies, to provide LOW risk during storage in the 400 Area Interim Storage Area. In order to store fueled components with this inter-mixed approach, a deviation to DOE Orders will be required. The deviation would address pertinent safeguards and security issues.

An alternative to this storage approach is to place the seven future (by the year 2030) Category IC irradiated driver fuel assemblies in a single Interim Storage Cask and ship it to the Plutonium Finishing Plant for storage in their existing protected area. Before the interim storage cask can be shipped to the Plutonium Finishing Plant, it would be necessary to prepare and approve a Safety Analysis Report for Packaging which allows the Interim Storage Cask(s) to be transported across the Hanford Site. This alternative is under evaluation.

\subsubsection{Category IC Unirradiated Fuel}

Planned disposition of the Category IC unirradiated fueled assembiies ( 32 ) as defined per DOE Order 5633.3A, Control and Accountability of Nuclear Materials, (DOE 1993) entails sending the fuel to the Plutonium Finishing Plant for interim storage. These assemblies will be washed in the Interim Examination and Maintenance Cell and transported to the Plutonium Finishing Plant. An engineering study is in progress to determine the best method for fuel storage at the Plutonium Finishing Plant. Possible storage methods include the construction of several storage vault configurations. 


\subsubsection{Special Fuel}

\subsubsection{Delayed Neutron Monitor/Gas Leaker Fuel}

Table 3 identifies the breached fuel assemblies. There are currently two intact assemblies ( $\mathrm{ACN}-1$ and $\mathrm{PO}-4$ ) that produced a delayed neutron monitor signal while in the reactor. $\mathrm{PO}-4$ is scheduled for processing in Fiscal Year 1995, and ACN-1 processing will follow PO-4 late in Fiscal Year 1995, or possibly in Fiscal Year 1996. These assemblies will be processed sodium wetted in the Interim Examination and Maintenance Cell prior to the start of fuel washing activities. The failed pins will be encapsulated and the remaining pins will be washed and placed in Ident-69 pin containers.

There are also several fuel assemblies that are known gas leakers. These will be the last assemblies processed in the Sodium Removal System to minimize the consequences of potential contamination release and resultant deposition in the sodium removal equipment, which would make equipment maintenance more difficult.

\subsubsection{Sodium Bonded Test Assemblies}

The current plans are to ship the six sodium-bonded metal fuel assemblies plus sodium bonded pins from $A C N-1$ and two Ident-69 pin containers from previously disassembled assemblies MFF-1A and IFR-1 to Idaho for consolidation with the Experimental Breeder Reactor-II metal fuel inventory. Experimental Breeder Reactor-II has requested that this fuel be shipped to them in pin form. Therefore, the assemblies will be washed in the Interim Examination and Maintenance Cell, disassembled, the fuel loaded into new pin containers, and transported in Nuclear Regulatory Commission and DOE licensed T-3 casks. These pin containers will require design and fabrication. Utilizing the T-3 casks under the present license would require approximately sixty shipments. It is planned to prepare an addendum to the DOE T-3 license to reduce the number of required shipments.

However, these shipments cannot be made until a favorable Record of Decision is received on the programmatic Environmental Impact Statement for spent nuclear fuel (Reference 27) that would allow this proposed action. The aforementioned Environmental Impact Statement addresses disposition of a 71 DOE spent nuclear fuel. If the shipments are disapproved, the fuel may be washed in the Interim Examination and Maintenance Ce17, and stored with the FFTF irradiated fuel in Interim Storage Casks at the Interim Storage Area. It should be noted that this action could result in substantial costs for future disposition of this material.

\subsubsection{Lithium Bonded Assemblies}

FFTF had one assembly with lithium bonded pins. This assembly (FSP-1R) was washed and disassembled in the Interim Examination and Maintenance Cell, and the pins were sent to the 300 Area for lithium removal. The cleaned pins may be dispositioned in the 300 Area or returned to FFTF for storage in an Interim Storage Cask. 
TABLE 3

FFTF BREACHED FUEL PINS

\begin{tabular}{|c|c|c|c|c|c|c|}
\hline TEST ID & $\begin{array}{c}\text { ASSEMBLY } \\
\text { NUMBER }\end{array}$ & $\begin{array}{l}\text { LEAKER } \\
\text { PINS } \\
\end{array}$ & $\begin{array}{c}\text { FFTF } \\
\text { LOCATION }\end{array}$ & $\begin{array}{l}\text { OFF SITE } \\
\text { LOCATION }\end{array}$ & $\begin{array}{c}\text { CONTAINER } \\
\text { TYPE }\end{array}$ & $\begin{array}{l}\text { No. OF } \\
\text { PINS }\end{array}$ \\
\hline$H F-025^{(1)}$ & CCA-2053 & Unknown & $\begin{array}{l}\text { FSF }^{(2)} \\
U-21\end{array}$ & & & \\
\hline$A B-1$ & FEX-2114 & 1 & FSF $T-15$ & & & \\
\hline $\mathrm{DE}-9$ & $7 \mathrm{EX}-16527$ & 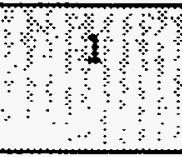 & FSF 1057 & (16ef & $\begin{array}{c}11978 \\
69422 t \\
697126 \mathrm{c} \\
\end{array}$ & $\begin{array}{r}40 \\
46 \\
131 \\
\end{array}$ \\
\hline$A A D-6$ & FEX-8256 & 1 & $\begin{array}{l}\operatorname{IDS}^{(4)} \\
\mathrm{B}-13\end{array}$ & & & \\
\hline F0-1 & FEX-2073 & 1 & $\begin{array}{ll}\text { FSF } & S-54 \\
\text { FSF S- } 08\end{array}$ & & $\begin{array}{l}69 \# 1 C \\
69 \# 8 C\end{array}$ & $\begin{array}{l}91 \\
78\end{array}$ \\
\hline ACN-I & FEX-21II & 2 & FSF $T-14$ & $\because:$ & \&: & \\
\hline$M N-4$ & FEX-16490 & 1 & FSF T-17 & & & \\
\hline RTCB-4 & FEX-2060 & 1 & FSF $T-16$ & & & \\
\hline D9-2 & FEX-16505 & 1 & $\begin{array}{ll}\text { FSF } & \text { U-28 } \\
\text { FSF } & \text { T-19 }\end{array}$ & HFEF & $\begin{array}{c}1578 \\
69 \# 38 \mathrm{C} \\
69 \# 44 \mathrm{C} \\
\end{array}$ & $\begin{array}{r}41 \\
69 \\
107 \\
\end{array}$ \\
\hline$B F A$ & DFA-16392 & & $\begin{array}{l}\text { IEFC } \\
35-3 \\
\text { FSF } S-54 \\
\text { FSF } S-55 \\
\text { IEFC } 16-5\end{array}$ & मै: & $\begin{array}{r}\text { pB19\#6C } \\
69 \# 1 C \\
69 \% 9 C \\
69412 C\end{array}$ & $\begin{array}{r}34 \\
34 \\
118 \\
64\end{array}$ \\
\hline $\mathrm{PO}-2$ & FEX-2066 & 3 & FSF T-33 & & & \\
\hline PO-1 & FEX-2065 & 2 & $\begin{array}{l}\text { FSF } T-40 \\
\text { FSF } T-50\end{array}$ & HFEF & $\begin{array}{c}1578 \\
69 \# 24 C \\
69 \# 39 C\end{array}$ & $\begin{array}{r}17 \\
103 \\
49\end{array}$ \\
\hline$P O-4$ & $F E X-2069$ & 5 & IDS $E-17$ & ४४४। & 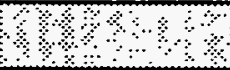 & \%की \\
\hline
\end{tabular}

(1)Failed during storage in Interim Decay Storage

(2) Fuel Storage Facility

(3) Hot Fuel Examination Facility at Argonne National Laboratory-West

(4) Interim Decay Storage

(5) Interim Examination Maintenance $\mathrm{Cell}$

NOTE: Shading indicates a delayed neutron leaker. 


\subsubsection{MFF-8A Prototypic Series III Binary Metal Fuel Assembly Experiment}

There is one unirradiated assembly that contains U-10Zr alloy fuel sodiumbonded to the cladding currently stored in the Test Assembly Conditioning Station. This assembiy will be dispositioned in a similar manner to the irradiated sodium-bonded metal fuel as discussed in Section 9.2.4.2. Because it contains sodium, it will be shipped to Idaho for consolidation with the Experimental Breeder Reactor-II metal fuel inventory, after necessary approvals from the states involved are obtained.

\subsubsection{Open Test Assembly Instrument Stalks}

There are twenty-one Open Test Assembly instrument stalks located in the Test Assembly Conditioning Stations and in Interim Decay Storage. One additional stalk is located in the Interim Examination and Maintenance Cel1. The Materials Open Test Assembly (MOTA) stalks are 40 feet long including the canister tree which contained the material specimens. The Fuel Open Test Assemblies (FOTA) stalks and the Post Irradiation Open Test Assemblies (PIOTA) stalks are 28 feet long. The bottom 30 feet of the MOTA stalks and the bottom 18 feet of the FOTA and PIOTA stalks are radioactive and sodium wetted. A7so, there are two Hanford Engineering Development Laboratory materials assemblies presently in the Fuel Storage Facility. These assemblies will be moved out of the Fuel Storage Facility during deactivation. The ultimate disposition of these assemblies as well as the Open Test Instrument Stalks has not been determined. The Transition Project is developing a recommendation for the handling and disposition of these items.

\subsection{FUEL OFFLOAD}

\subsubsection{Fuel Offload Status}

Plant efforts are currently focused on Phase I defueling, supporting the procurement of Core Component Containers and Interim Storage Casks, and completing the necessary plant modifications required to support washing, cask loading, and interim storage of the fuel. The current status of the FFTF Spent Fuel offload Program activities is summarized below:

- The In-Vessel Handling Machines have had major control system upgrades and the performance during reactor vessel defueling continues to be very good.

- The Closed Loop Ex-Vessel Machine will undergo a minor control system upgrade. This work will be performed as a non-critical path activity.

- The Bottom Loading Transfer Cask has had a major control system upgrade and the performance during reactor vessel defueling continues to be very good.

- The Interim Decay Storage basket rotation control system will be upgraded to enhance reliability. This work will be performed as a non-critical path activity. 
The design and procurement of Core Component Containers and Interim Storage Casks are in progress as discussed in Section 9.3.3.

The definitive design of General Plant Project F-027 is complete and the procurement of the components is in progress. This project will add an ion exchange system to the Interim Examination and Maintenance Cell fuel cleaning system to essentially eliminate the liquid waste that is currently generated during use of the sodium removal system. In addition, the project will provide storage racks on the Interim Examination and Maintenance Cell Maintenance Turntable to store Core Component Containers. The project will also install a new offset adapter plate over the Interim Examination and Maintenance Ce 1710 foot diameter ceiling valve. The adapter plate will position the Solid Waste Cask so that the Core Component Container storage racks can be indexed in line with the Solid Waste Cask. This permits bringing an empty Core Component Container to the cell and retrieving a full one without any in-cell handling of the containers. The Reactor Service Building Cask Loading Station will be modified utilizing the hardware that was procured for the Maintenance and Storage Facility Cask Loading Station and additional interfacing hardware that is presently being fabricated to support loading of the Interim Storage Casks.

- The existing concrete storage pad located in the northeast corner of the FFTF complex will be modified to satisfy security and safety requirements for interim storage of the fue 7 in the Interim Storage Casks.

\subsubsection{IEM Cell Fuel Washing/Transfer Logistics}

Fuel will be transferred from the Fuel Storage Facility and Interim Decay Storage to the Interim Examination and Maintenance Cel1 for sodium removal and subsequent transfer to the Reactor Service Building Cask Loading Station for placement into an Interim Storage Cask for storage at the Interim Storage Area. The Core Component Container accommodates six or seven fuel assemblies or pin containers and is ultimately stored in the Interim Storage Cask with the fuel, thus providing the necessary handiing capability for future removal operations. The Core Component Container size is compatible with the possibility of future overpacking in a Multi-Purpose Canister She 11 . The Multi-Purpose Canister is presently being designed for the transport and burial of commercial nuclear fuel at a future underground repository.

The sodium wetted fuel will be transferred one at a time to the Interim Examination and Maintenance Cell for washing, utilizing both the Closed Loop Ex-vessel Machine and Bottom Loading Transfer Cask. The Bottom Loading Transfer Cask transfers the fuel from either fuel storage location to the Core Component Conditioning Station South. Each assembly is transferred into a dry core component pot which is then moved into the Interim Examination and Maintenance Cell by the Closed Loop Ex-Vessel Machine.

The fuel is washed one at a time in the Interim Examination and Maintenance Cell sodium removal system, dried and placed in a clean Core Component Container and sealed for transfer out of the cell via the Solid Waste Cask. 
The Solid Waste Cask transfers the cleaned fuel to the Reactor Service Building Cask Loading Station where the fuel is placed into an Interim Storage Cask, which is inerted and sealed. The Interim Storage Cask is then transferred to the Interim Storage Area for interim storage of the fuel.

The rate at which fuel can be transferred to the Interim Examination and Maintenance Cell, washed, dried and transferred to the Reactor Service Building Cask Loading Station for placement into an Interim Storage Cask is limited by the time it takes to wash the assemblies. This throughput rate assumes that all refueling equipment and Interim Examination and Maintenance Cell equipment are operated essentially as they do today. Fuel washing operations will be continuous (round-the-clock) seven days per week during the offload period. The definitive design of several enhancements has been completed and the components are being procured. These enhancements are being funded through the General Plant Project F-027 and construction and acceptance testing is scheduled to be completed by September, 1995. Reactor defueling is not a constraint to fuel washing activities.

Eight days are required to complete each cycle of washing and transfer of six components. Since these Interim Examination and Maintenance Cell activities, i.e., transfers, washing, and drying, have been performed routinely as part of the experiment processing cycle, the rate estimates are presented with a high degree of confidence. Assuming a conservative availability factor of $50 \%$, 135 components could be washed each year. At this rate, the current inventory of fuel assemblies and pin containers (37l assemblies and pin containers) can be washed in 2.8 years. Processing of the two delayed neutron monitor signal assemblies discussed in the Section 9.2.4.1 will require four pin containers and thus increase the current inventory by two. Disassembly of the seven sodium-bonded fuel assemblies (see Sections 9.2.4.2 and 9.2.4.4) can be performed one at a time, in parallel with fuel offload sodium removal activities.

The sodium removal process for fuel offload washing will be simplified from that used for experiment processing because of the low ( $<250$ watts) decay heat of the assemblies. No down-flow cooling is required which eliminates cumbersome connections and procedural verification of flow. Another simplification without down flow cooling, is that the system does not have to be thoroughly dried between each wash cycle.

\subsubsection{Interim Storage Casks}

As depicted in the Figure 1 Transition Project Summary ScheduTe, the Interim Storage Cask design and fabrication contract schedule is a critical path element for successful completion of the FFTF transition. Initiation of fuel washing activities is dependent on having storage available. The purchase order for the first ten casks was placed with General Atomics on September 16, 1993. Carryover funding from the Fiscal Year 1993 Advanced Reactor Program budget was obligated to support this procurement, with the balance coming from the Fiscal Year 1995 budget. A Categorical Exclusion for design, testing, and fabrication was also approved for this procurement activity. However, prior to storing irradiated fuel in the Interim Storage 
Casks, the National Environmental Policy Act process must be completed, as discussed in Section 6.2.1. Additional casks will be required to complete the spent fuel offload and a competitive fabrication-only contract, based on the verified and tested design from the current procurement, will be placed by September 1995, with the delivery of the last cask estimated by September 1997. For the present ten cask contract, delivery of the first and the tenth cask is expected in May 1995, and September 1995, respectively.

The Interim Storage Cask is a top loading shielded cask capable of receiving and storing a Core Component Container containing up to seven FFTF irradiated fuel core components or pin containers (see Figure 8). Design and fabrication of the Interim Storage Cask is being performed by General Atomics and Sierra Nuclear Corporation. The FFTF Interim Storage Cask design is modeled after Sierra Nuclear Corporation's Ventilated Storage Cask design which has been licensed under the Nuclear Regulatory Commission general iicensing provisions for storage of commercial fuel. This design is a passively ventilated concrete and steel shielded cask with a stainless steel secondary containment boundary. The final design review was held on August 25, 1994, and Figure 9, provides a sketch of the design. Maximum weight of the cask, with the 5,000 pound Core Component Container payload, will be 114,200 pounds. The internal cavity is 21 inches in diameter and 147 inches in length to accommodate the Core Component Container. An impact limiter located at the bottom of the internal cavity of the Interim Storage Cask will protect the spent fuel if an inadvertent drop of the Core Component Container were to occur during loading. After the fuel is placed in the Interim Storage Cask, the cask will be sealed by bolting down the shielded cover which will then be tested to ensure the redundant metal seals are functional. The Interim Storage Cask will be inerted and contains a provision for intermittent monitoring of the internal cavity. Provisions have also been incorporated into the Interim Storage Cask design to accommodate the possibility of future on-site fuel transfers. For these transfers, an approved Safety Analysis Report for Packaging will be required.

The cost to design and construct the first ten Interim Storage Casks is $\$ 4.7$ million. After the first cask is received and tested, the purchase order for the remaining forty-seven casks will be placed by September 1995, at an estimated cost of $\$ 15.9$ million. (Note: These costs are fully burdened in Fiscal Year 1995 dollars.)

As reported in Revision 0 of the Plan, present planning is to place six assemblies into each Core Component Container. However, an alternate Core Component Container fuel loading configuration is being evaluated in which seven assemblies would be placed in each Core Component Container. The alternative loading being evaluated permits inserting a seventh fuel assembly into the center tube of a Core Component Container after removal of the lower fifteen inches of the assembly. This would be accomplished with special Interim Examination and Maintenance Cell cutting equipment that currently exists but must be modified. If the evaluation of this alternate configuration confirms its acceptability, the total number of Interim Storage Casks required is estimated to be 50 , whereas the configuration with six assemblies per Core Component Container would require 57 Interim Storage Casks. This evaluation is expected to be completed by January 1, 1995. If 
this evaluation is successful, it will result in a substantial cost savings to the Project on the order of $\$ 2.6$ million (for Interim Storage Casks and Core Component Containers). There would be additional cost savings achieved as a result of fewer cask loading/handling operations. This innovative approach and corresponding savings constitute a productivity improvement that will be realized in Fiscal Year 1995 and/or Fiscal Year 1996.

The Core Component Container is a closed container that will provide the primary confinement boundary for the 50 year design life of the dry storage system. It is fabricated from stainless steel and inconel to provide corrosion resistant fuel storage (see Figure 8 ). The Core Component Container provides packaged handling capability and long-term geometry control for the FFTF irradiated fuel assemblies and pin containers. The design provides a separate sealed tube for each fueled assembly with only the upper gas spaces communicating. After each individual fuel assembly or pin container is washed in the Interim Examination and Maintenance Cell Sodium Removal System, it will be loaded in its assigned Core Component Container location.

When either six or seven assemblies have been loaded in the core Component Container, the lid will be installed and a leak test will be performed on the metal seal. After acceptance of the package in the Interim Examination and Maintenance Cel1, the Core Component Container will be transferred in the Solid Waste Cask to the Reactor Service Building Cask Loading Station where the Core Component Container will be loaded into an Interim Storage Cask.

The cost of 57 Core Component Containers required for fuel handling, transfer, and storage in the Interim Storage Casks is estimated at $\$ 3.1 \mathrm{mil1}$ ion in fully burdened Fiscal Year 1995 dollars. The present schedule is to receive the first unit by May, 1995. After successful testing of the first unit by the manufacturer, fabrication of the remaining units will proceed. Nine additional Core Component Containers will be delivered in Fiscal Year 1995 with the remaining Core Component Containers to be delivered at a rate of one per week throughout Fiscal Year 1996. The exact number of Core component Containers required will depend upon the alternate fuel loading configuration being evaluated.

\subsubsection{Interim Storage Area}

The Interim Storage Area will be located at an existing concrete pad approximately 120 feet long by 90 feet wide that is located on the northeast corner of the FFTF complex. The pad will be surrounded by a fence with locked access to permit controlled loading, unloading and inspection of the Interim Storage Casks. There will be gravel in the area between the fence and the concrete pad. There will also be overhead lighting and crash barriers installed, as required. The design and construction of the Interim Storage Area is estimated at $\$ 295,000$ with a construction schedule as depicted in the Figure 1 Transition Project Summary Schedule. This total cost includes $\$ 216,000$ capital construction funds and $\$ 79,000$ expense funds. 


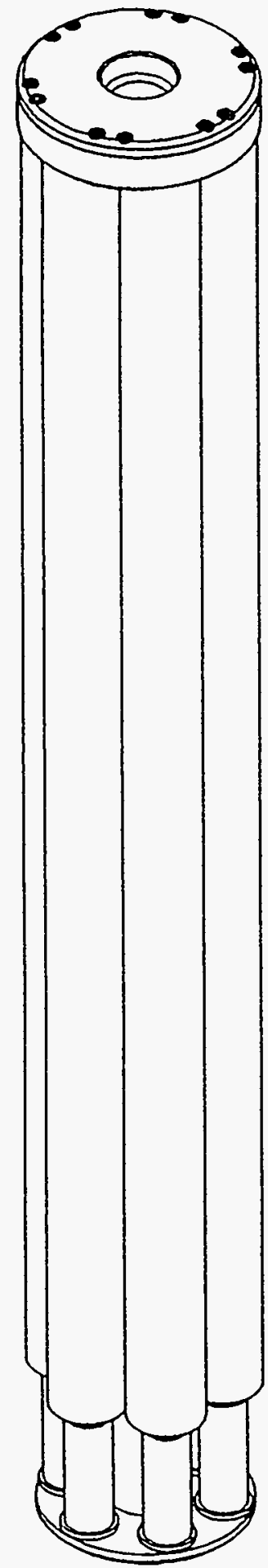

\author{
BOLTED CLOSURE \\ MECHANICAL SEAL \\ HANDLING INTERFACE
}

LOWER STORAGE BASKET

SIX OUTER TUBES

ONE CENTRAL TUBE

Figure 8. Core Component Container 
WHC-SD-FF-SSP-004

Rev. 1 Page 66

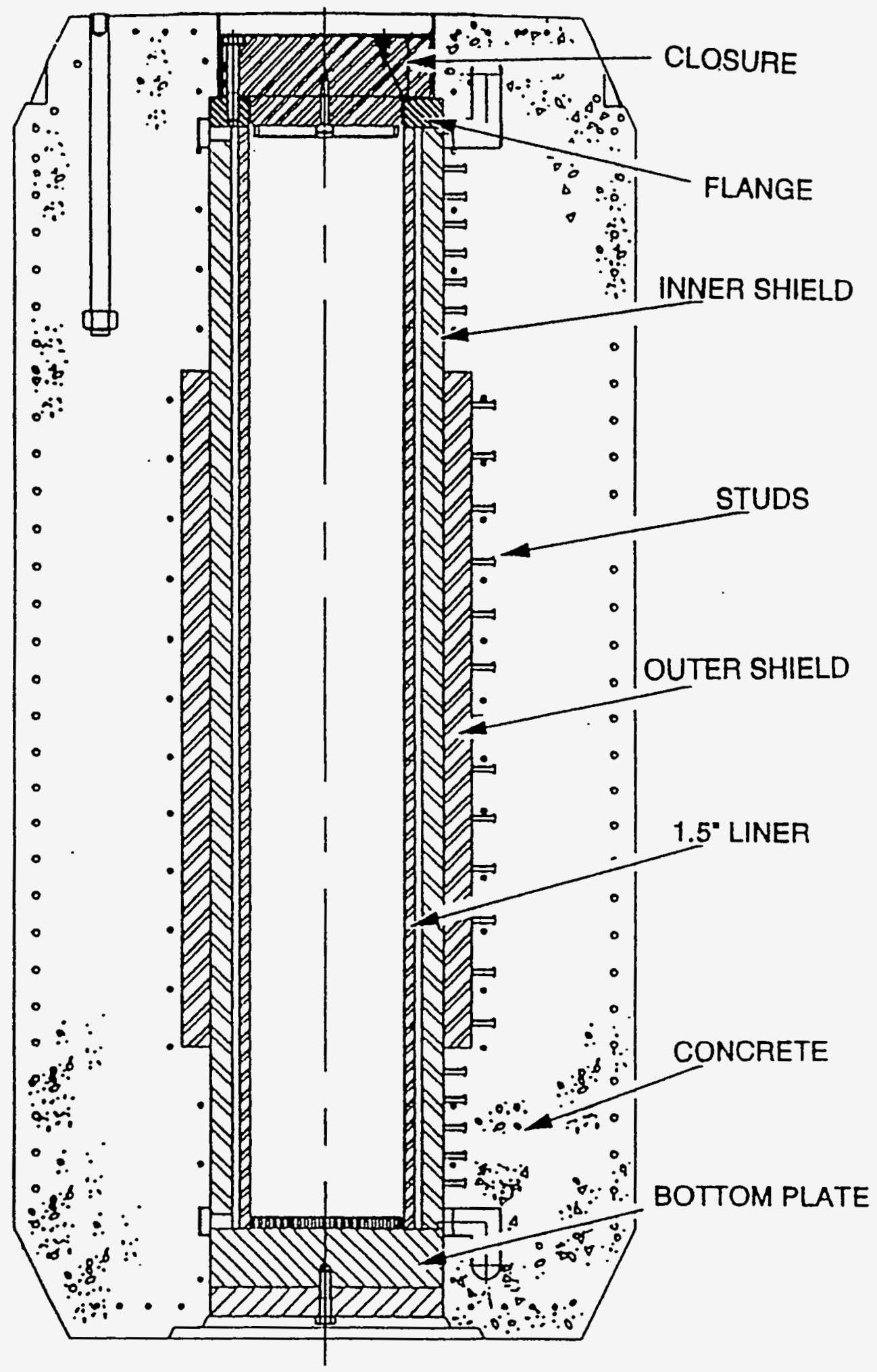

Figure 9. Interim Storage Cask 


\subsection{BULK SODIUM AND SYSTEMS DISPOSITION}

\subsubsection{Strategy}

Figure 10 depicts a decision/logic tree for delineating some of the more significant decisions that will have to be made during the transition process. There is currently no facility available at Hanford for conversion of bulk alkali metal (sodium) to a suitable form for final disposition (e.g., beneficial use or disposal). The figure depicts the options that have been evaluated for disposition of the FFTF bulk sodium, including: long term storage, reaction at a newly constructed sodium conversion facility at Hanford, or shipment to an existing sodium conversion facility at the Argonne National Laboratory-West site in Idaho. The present project basel ine approach is indicated in red. The following paragraphs elaborate on the various options evaluated for bulk sodium disposition in developing this approach.

The initial decision to be made is whether the sodium should be drained or left in the plant. Clearly if the sodium is to be utilized for some purpose, it must be drained. Even if no use can be identified, draining the sodium is the preferred path for the following reasons:

1) Maintaining the systems full of molten sodium clearly does not accomplish the objectives of the transition process. Most plant systems would have to remain in operation and a large staff of people would be required to maintain the facility.

2) If the sodium is to ever be drained from the plant, now is the time to do it. There are two main reasons for this. First, there is currently a highly trained cadre of personnel available who can efficiently and safely perform the drain. Secondly, once the sodium systems freeze, it may be nearly impossible to remelt. In particular, the reactor vesse] has no installed heating system. It is unlikely that the existing trace heat systems on the remainder of the components and piping will function after several years of shutdown. There is also some concern that expansion of the sodium during the meltout process could damage the sodium boundary, possibly leading to sodium leaks. It should al so be noted that if the sodium systems were to be remelted, many of the support systems (e.g., cell cooling and inerting) would probably have to be reactivated.

3) There is no known process for dealing with the large inventory of sodium filled components and piping without first remelting. Dismantling of small sodium filled systems/components is possible, but doing the same with large components such as the reactor vessel, main heat transport system pumps and intermediate heat exchangers is not considered feasible. Although some development work has been done on disposing of small sodium filled components in a molten salt reaction vessel, dealing with large components such as the reactor vessel does not appear to be tenable. 


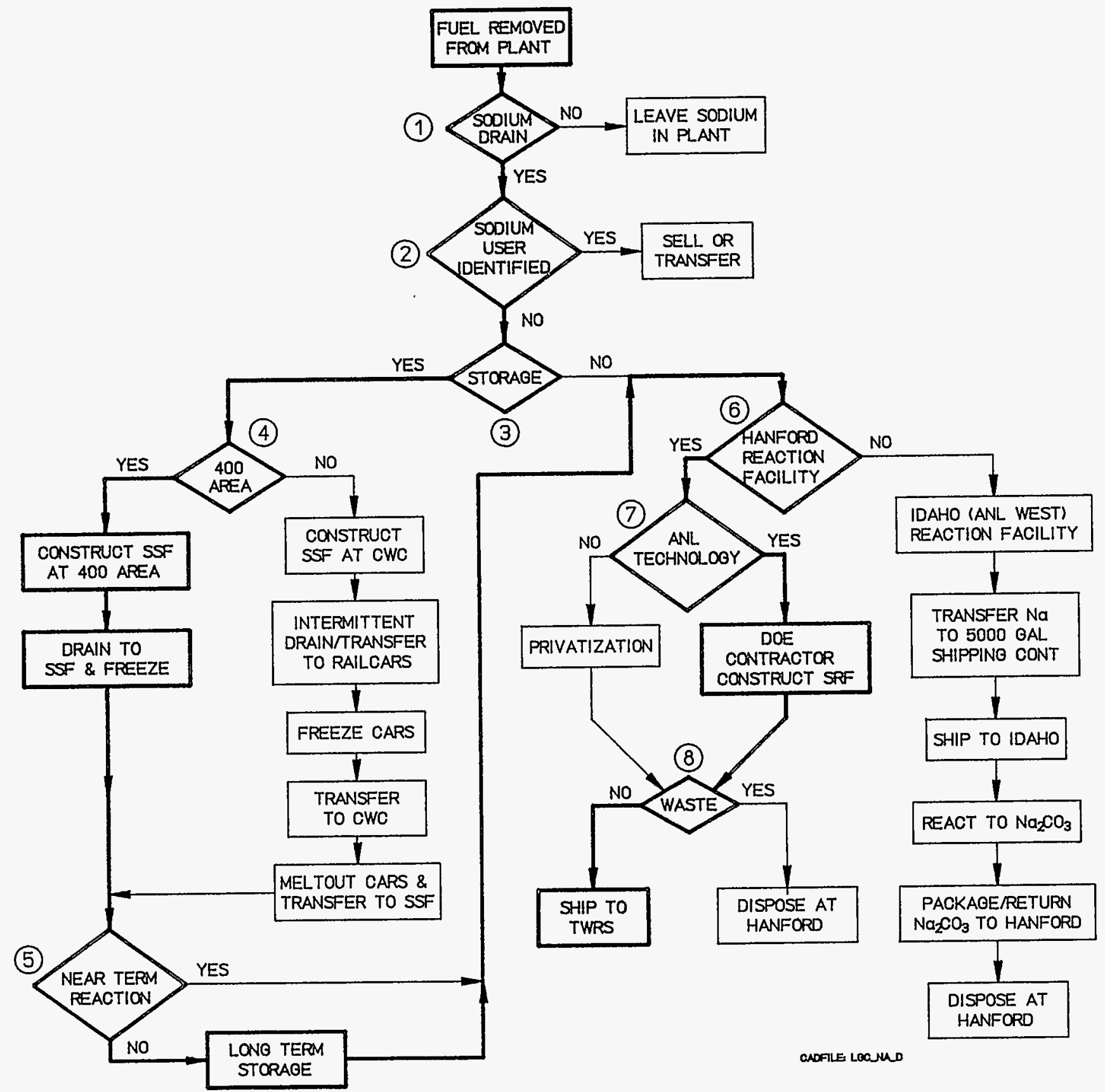

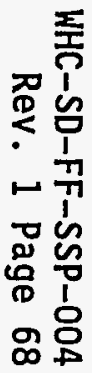

Figure 10. FFTF Sodium Disposition Logic 
4) Leaving the sodium filled systems in place for an indefinite period will likely be unacceptable to regulatory agencies and other stakeholders.

The second decision point represents the potential for some user of the elemental sodium being identified. This is considered highly unlikely considering the radioactive nature of the major portion of the sodium and no uses for the sodium have been identified at this time. Therefore, a storage and/or reaction facility for conversion of the alkali metal to a useful product or to a stable form suitable for disposal will be required. The baseline plan is based on the assumption that the sodium will be converted to hydroxide for use in processing tank waste on the Hanford Site as discussed below.

The third decision point on the logic path addresses whether a sodium storage facility is required, or if the sodium could be directly offloaded to a sodium reaction facility. This offload could consist of a direct pipeline to a reaction facility closely coupled to the FFTF or to transport vehicles (i.e., rail cars or tanker trucks) that could move the sodium to a reaction facility located either at the Central Waste Complex (on the Hanford Site), or to an existing reaction facility located at the Argonne National Laboratory-West. There are several major considerations associated with this decision as discussed below:

1) The Hanford Tank Waste Remediation System (TWRS) baseline process for waste tank sludge disposal includes using a sodium hydroxide solution in a pretreatment process of the feedstream going to the High Level Waste Vitrification facility. Although a final decision on the pretreatment process is not anticipated untif 1998 (TWRS Tri-Party Agreement Milestone M-50-03), on-site use of the FFTF sodium is considered highly likely and is included in the TWRS technical baseline. It is therefore prudent to delay action on final sodium disposition until this decision is made. The activities delayed include final selection of the process for converting the sodium and the design/construction of the Sodium Reaction Facility.

2) Offloading the sodium directly to a sodium reaction facility in lieu of a sodium storage facility has been determined to be imprudent for the following reasons:

- The sodium drain period would be directly linked to the process time in the reaction facility. As discussed in Section 9.4.5, this is expected to be approximately two years. This would delay the shutdown of many of the FFTF systems and extend the transition schedule.

- Any delay in the Sodium Reaction Facility construction or operation would delay completion of the FFTF deactivation. The cost of this delay with the sodium still in the FFTF plant would be approximately $\$ 35$.million per year more than if the sodium was in the Sodium Storage Facility (i.e., a delay of approximately three months would offset the cost of the storage facility). 
- The FFTF drain tank capacity is much less than the sodium systems inventory (this is especially true in the primary system). This means that direct sodium offload to a reaction facility would result in the sodium systems being partially drained for a significant time period. Maintaining the sodium molten in a partially drained system would present a considerable technical challenge with a significant risk of inadvertent freezing.

Offloading the sodium directly to transport vehicles for shipment (offsite or on-site) would be even less viable due to the added costs and complexities. For example, many shipping containers (or many trips) would be required and many connections/disconnections to these containers would lead to a higher risk of spills and fires with radioactive sodium. Further, there would be greater personnel exposure during the process of changing transfer connections. There are also significant issues associated with the shipment of these large quantities of radioactive sodium, especially off-site.

Based upon these considerations, it is concluded that the sodium will be placed in a storage facility for some time period prior to final disposition. The next decision is thus the location of the Sodium Storage Facility (Decision Point \#4). Construction of the Sodium Storage Facility at the Hanford Central Waste Complex to consolidate storage locations for hazardous wastes was considered. This is not the preferred option as discussed later

(Decision Point \#5). The previously discussed issues associated with offloading to transport vehicles and the subsequent shipment of 1 arge quantities of radioactive sodium also eliminate this as a viable alternative.

In conclusion, programmatic considerations coupled with the limitations of the present FFTF storage capability and the draining complexity leads to the second and third decision points: (2) a Sodium Storage Facility is required, and (3) the facility needs to be closely coupled with the FFTF plant to permit safe and efficient drain operations. Decision Point \#5 addresses the issue of whether the sodium should be maintained in the new Sodium Storage Facility for long term storage or whether final disposition of the material should be pursued in the relatively near term. The Sodium Storage Facility will be designed and constructed to meet appropriate Resource Conservation and Recovery Act storage requirements. Therefore, the sodium could be stored within the Sodium Storage Facility for an extended period prior to conversion to a useful product or alternatively converted to a stable material suitable for disposal on the Hanford Site as nonhazardous radioactive waste. As stated previously, the baseline plan is to store the sodium in the Sodium Storage Facility for several years until it is needed by TWRS for waste tank sludge processing. This represents the long term storage option.

Two options are available for conversion of the sodium for use or disposal (Decision Point \#6): construction of a reaction facility at Hanford or utilization of the existing sodium reaction facility at the Argonne National Laboratory-West Site. The Idaho sodium reaction facility was originally 
designed for a sodium hydroxide end product but the design is currently being modified to provide the capability to convert sodium hydroxide to a carbonate which is a stable product that can be buried in the State of Idaho. However, sodium carbonate is currently a regulated material in the State of Washington. Therefore, other waste forms (e.g., sodium sulfate) for the FFTF sodium are also being evaluated. Further, there are significant issues, both technical and institutional, with considering the shipment of this huge volume of sodium. Most of the FFTF sodium inventory is radioactive and due to its specific activity can only be shipped in 5000 gallon maximum increments. The only practical container for this size shipment is a Department of

Transportation MC-312 cargo tank. Since Argonne National Laboratory-West does not have a railroad spur into their facility, all transfers would have to be over public highways. In addition, the radioactive sodium carbonate waste would have to be returned to Hanford for disposal. The weight of the sodium carbonate material would be more than twice the weight of the metallic sodium feed material, due to the conversion process as discussed in Section 9.4.5. The sheer number of transfers, when coupled with the radiation levels, use of public highways, the need to cross state boundaries, the inefficiency and technical problems associated with transferring this amount of sodium, the public perceptions, potential state government issues/expectations, and changing regulations eliminate this as being a practical or economically viable option. Also, as stated previously, there is a high probability that the sodium can be used on the Hanford Site (in the form of sodium hydroxide). Therefore, it is concluded that the Sodium Reaction Facility should be constructed at the Hanford Site.

The Sodium Reaction Facility should be constructed adjacent to the Sodium Storage Facility. Since the facility will have a relatively short lifetime (e.g., approximately two years of operation) there are no apparent incentives for locating the facility elsewhere at Hanford. By locating the Sodium Reaction Facility adjacent to the Sodium Storage Facility, all sodium related operations will occur at a single Hanford Site.

Decision Point \#7 addresses which reaction process should be utilized for the final disposition of the FFTF sodium inventory. The logic path depicted uses the sodium reaction process utilized by the Argonne National Laboratory-West as the baseline process. This process is believed to provide the lowest cost option available since the costs associated with process development, demonstration testing, design, startup, procedural development, safety documentation, etc., will have been completed at the Idaho facility. Duplication of this design at Hanford will provide substantial cost savings and is believed to exemplify the cost reductions that can be achieved by applying the "Savings Through Sharing" concept that is encouraged between the DOE sites. If the sodium is to be used in processing tank waste, the reaction process would proceed only to the hydroxide phase. If the sodium is to be disposed of, a stable waste form must be produced. As discussed earlier, sodium carbonate is a regulated material in the state of Washington. Therefore, further evaluations will be performed to determine whether any new or alternate processes are available that could result in further cost reductions, an improvement in the final waste form, or reduction of 
operational risks for a comparable cost. A request for expressions of interest from the private sector has been solicited and several responses have been received. There clearly are viable commercial vendors available should this option be selected at a later date. Based upon discussions provided earlier in this section, it is expected that final decisions related to the sodium reaction facility will not be made until after completion of TWRS TriParty Agreement Milestone M-50-03 (scheduled for 1998). Decision Point \#8 represents the final conclusion on reaction product form (currently assumed to be sodium hydroxide for use by TWRS).

Sections $9.4 .2,9.4 .4$, and 9.4 .5 provide details on the sodium drain, Sodium Storage Facility and the Sodium Reaction Facility based on the preferred logic discussed herein. Section 9.4.3 discusses the management and associated issues of the sodium residuals that will remain in the $p 1$ ant systems following the sodium drain to the storage facility.

\subsubsection{Sodium Drain}

The transition phase of decommissioning requires the offload and storage of the bulk sodium coolant contained within various systems throughout the FFTF. Table 4 provides the approximate plant sodium volumes. Some sodium containing components are constructed or configured such that they cannot be completely drained without extraordinary effort. It is planned to make every reasonable effort to remove the majority of the sodium from the plant. However, sodium residuals will remain within the systems; locations and quantities will be defined in the Transition End-Point Criteria Document. In addition to the sodium, a small quantity (approximately 600 gallons) of sodium-potassium (NaK) alloy exists in the plant.

The current plan is to mix this small quantity of NaK with the large quantity of sodium, thus resulting in a very small (fraction of a percent) potassium impurity concentration in the sodium. This small impurity will have an insignificant effect on the sodium properties (e.g., melting point). A

TABLE 4

APPROXIMATE FFTF SODIUM VOLUMES

\begin{tabular}{|c|c|}
\hline Secondary Systems & 66,000 gallons \\
\hline Primary System & 140,000 gallons \\
\hline Interim Decay Storage & 23,000 gallons \\
\hline Fuel Storage Facility & 31,000 gallons \\
\hline Tota & 260,000 gall \\
\hline
\end{tabular}

detailed discussion of the planned status of the liquid metal systems at the time of turnover to the Environmental Restoration Contractor is provided in Section 9.4.3. The expected drain sequence is described below. 
The drain sequence will be initiated after the reactor core has been defueled and two immersion heater assemblies have been installed in fuel transfer ports in the reactor vessel in order to maintain a redundant heat input mechanism (primary system heat input will also be available from electrical trace heat and the Nitrogen Blower Heater Unit as described in Section 9.4.2.2). The three secondary loops will be drained to the three in-plant storage/drain vessels, T-42, T-43, and T-44 about two years before the Sodium Storage Facility is availabie. This sequence has been estimated to save approximately $\$ 2.6$ million when compared to waiting for completion of the Sodium Storage Facility (savings result from reduced electrical power costs and elimination of some equipment maintenance and surveillance). This innovative approach and resulting savings constitute a productivity improvement that will be realized in Fiscal Year 1996 and Fiscal Year 1997. The reactor vessel and the primary heat transport system and auxiliary systems will be drained following the transfer of the secondary sodium inventory and the existing inventory from the in-plant vessels to the Sodium Storage Facility. Finally, the Interim Decay Storage and Fuel Storage Facility sodium systems will be drained following completion of the fuel washing/cask storage evolution. Each of these drain processes is described below.

\subsubsection{Secondary Loop Drain}

The first step will be to transfer sodium that currently exists in the secondary sodium storage tank $(T-44)$ to the primary sodium storage tank $T-43$ and the primary sodium overflow tank (T-42) to maximize the tank volume available for secondary system draining. T-44 has sufficient volume to accommodate nearly two secondary loop drains at a time (secondary loops 1, 2, and 3 contain $17,750,18,300$, and 16,900 gallons respectively while the T-44 usable volume is approximately 30,000 gallons). Sodium movement from T-44 to the primary tanks will be via pressure transfer. Two secondary loops will be drained and approximately 32,000 gallons transferred to the primary tanks. The third loop will then be drained resulting in about 29,000 gallons being stored in T-44 in order to minimize the volume of the relatively uncontaminated secondary sodium that is mixed with the radioactive primary sodium.

Due to the relatively simple loop layout and component design (see Figure 11), most of the sodium in the secondary loops, including the auxiliary process loops, will drain by gravity to $T-44$. However, small quantities of sodium residuals will remain in some portions of the piping. More importantly, the sodium cold traps and Intermediate Heat Exchangers will not drain completely. Disposition of the sodium in the cold traps is discussed in Section 9.4.3.4. Each Intermediate Heat Exchanger will have approximately 1500 gallons of sodium remaining in the tube sides of the units following the gravity drain (see Figure 12). This sodium must be removed by cutting into the American Society of Mechanical Engineers (ASME) coded boundary at the top of the inlet pipe of each unit and installing a special dip tube through which the sodium can be transferred to T-44 after the Sodium Storage Facility is available (still leaving a smal1 residual in the Intermediate Heat Exchanger as described in Section 9.4.3.2). This Intermediate Heat Exchanger drain must be performed within the primary Heat Transport System cell inside containment. 


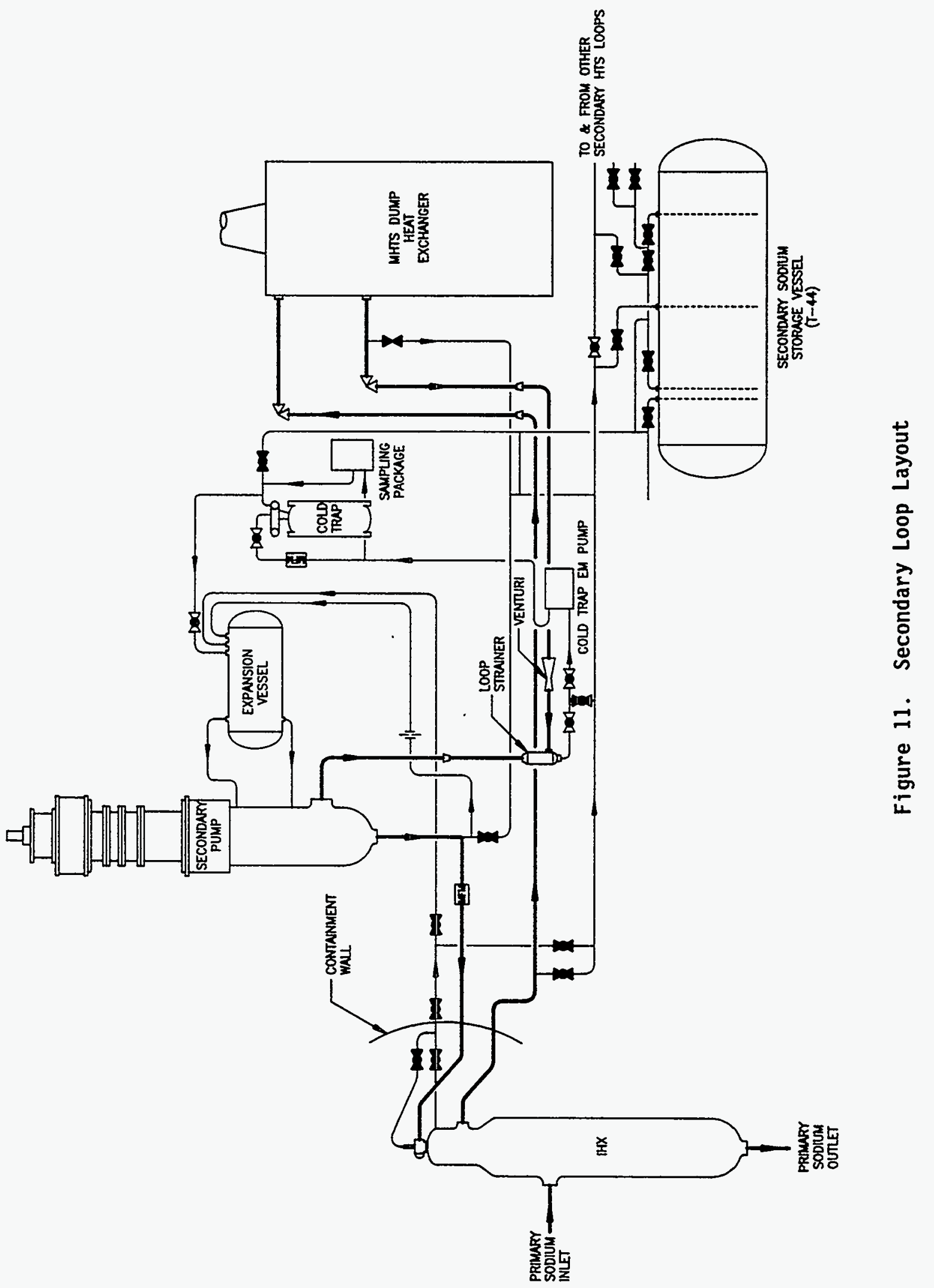


WHC-SD-FF-SSP-004

Rev. I Page 75

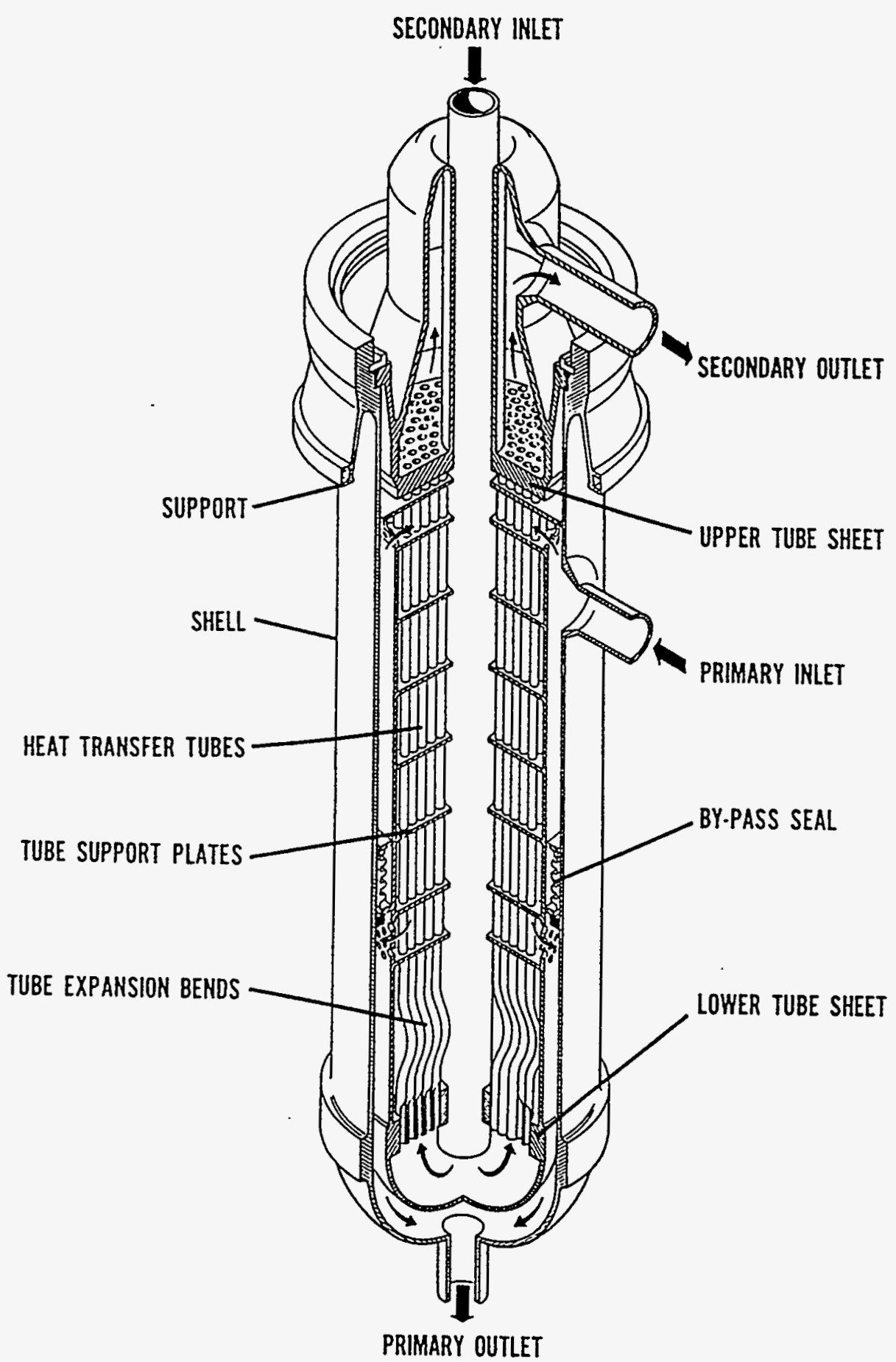

Figure 12. Intermediate Heat Exchanger 


\subsubsection{Primary System Drain}

Following the transfer of the 29,000 gallon T-44 inventory to a dedicated sodium tank in the Sodium Storage Facility for the less contaminated sodium, the more radioactive inventory in T-42 and T-43 will be transferred. In addition, the sodium-potassium alloy in the primary cold trap and Interim Decay Storage cooling loops must be dispositioned (as described in Section 9.4.3.1) before the reactor vessel (see Figure 13) and three primary loops (see Figure 14) can be drained. Drain of the primary system provides a unique challenge. All of the secondary system piping and components are trace-heated, so system temperature can be maintained while draining. However, in the primary system this is not the case. The primary loops, including pumps and Intermediate Heat Exchangers, are a 71 trace-heated but the reactor vessel is not. The reactor vessel is currentiy maintained at temperature by reactor decay heat and by heat transfer into the primary from the secondary loops (which are heated by pump work and/or oil fired preheaters). As soon as the primary flow is stopped, the reactor vessel will start cooling. The reactor has no permanentiy installed heaters and there is virtually no temperature instrumentation on the vessel itself.

During the original preheat for sodium fill, two temporary heating units were utilized to preheat the reactor vessel (see Figure 15). One unit, the Nitrogen Blower Heater Unit, produced heated air which was directed against the bottom of the reactor vessel through a permanently installed piping manifold within the guard vessel. This unit is still available and is the only existing means of maintaining temperature or reheating the reactor vessel (nitrogen would now be circulated through the inerted cells as a closed system rather than using air in a once through mode as was done in preparation for sodium fill). The other unit, the Argon Blower Heater Unit, circulated argon within the empty reactor vessel to limit temperature gradients during preheat. This unit is water-cooled and is therefore not acceptable for use after sodium fill. Thus, the Nitrogen Blower Heater Unit and the installed preheat manifold are the only existing means of maintaining the reactor vessel temperature when primary sodium flow through the loops and vessel is secured. Once the draining operation begins, a single equipment failure could lead to sodium freezing in the reactor vessel. Electrical immersion heaters will therefore be purchased and installed through the fuel transfer ports to provide a redundant heating mechanism for the reactor vessel sodium.

The plant has provisions for draining all three primary loops, the upper portion of the reactor vessel, and the reactor overflow tank (T-42). However, drain of the reactor vessel below the level of the inlet nozzles is precluded by design. Draining of the primary system will be performed in stages. The sodium level will first be lowered in the reactor vessel to the Minimum Safe Level (12 feet below normal operating level) by draining to the primary sodium storage tank (T-43) while circulating sodium with Main Heat Transfer System pumps on pony motor. Approximately two drain cycles with intermediate transfers to the Sodium Storage Facility will be required due to the limited volume of T-43. Further lowering of the level will break syphon on the three loops (at the reactor outlet nozzles) and loop circulation will stop, 


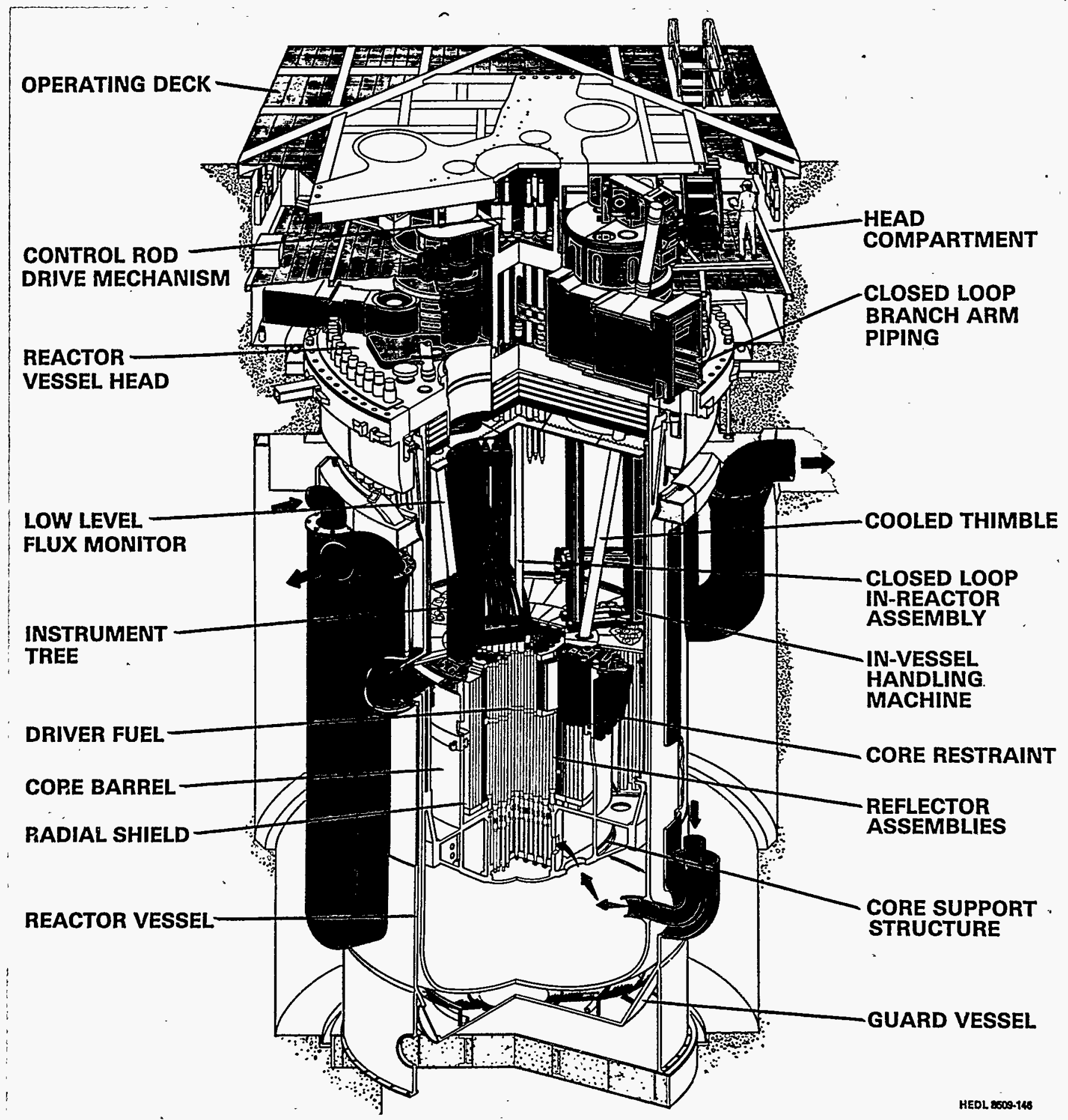

Figure 13. Reactor Vesse] 


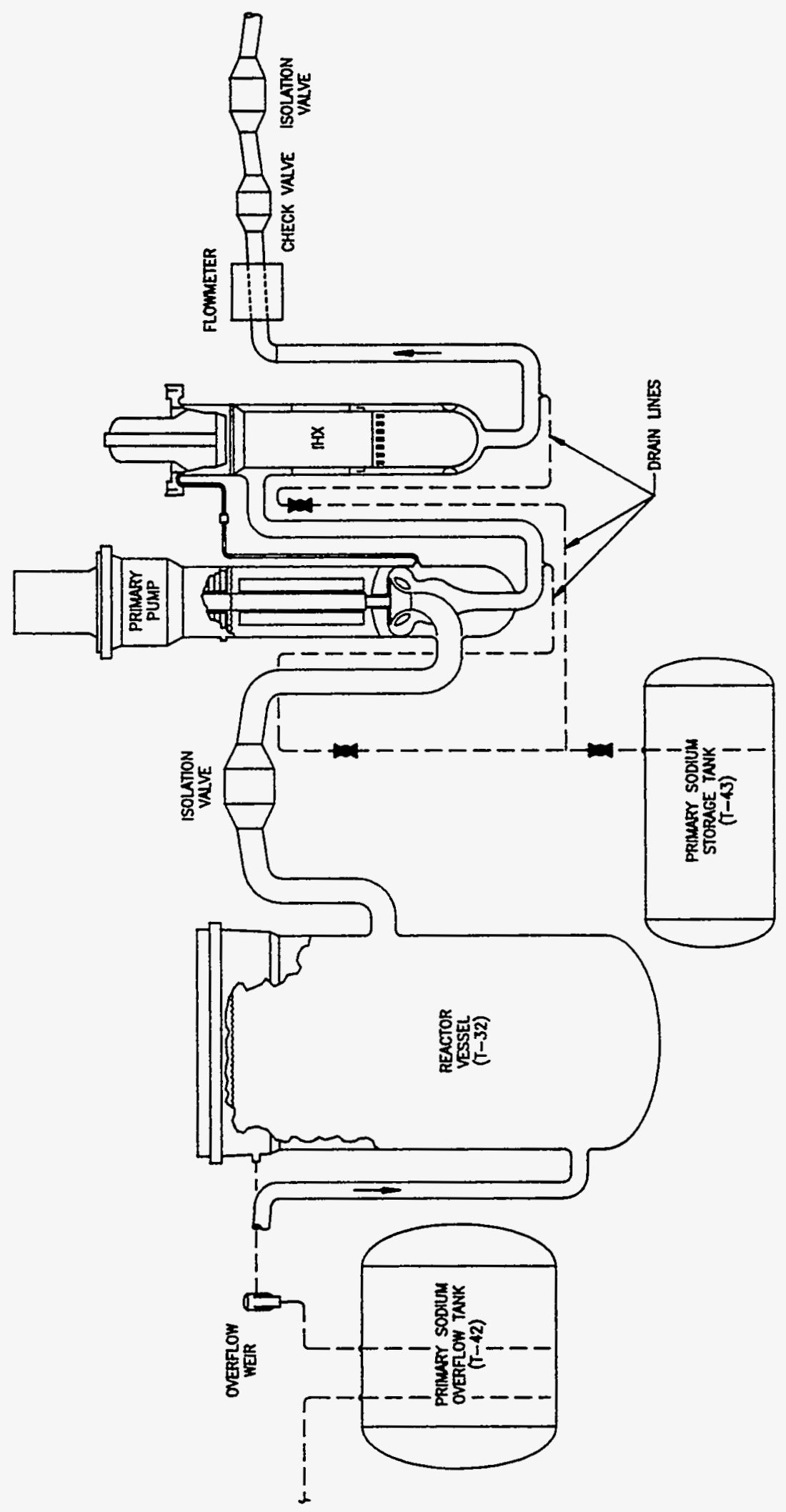

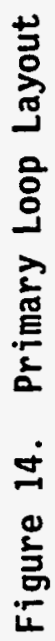


WHC-SD-FF-SSP-004

Rev. I Page 79

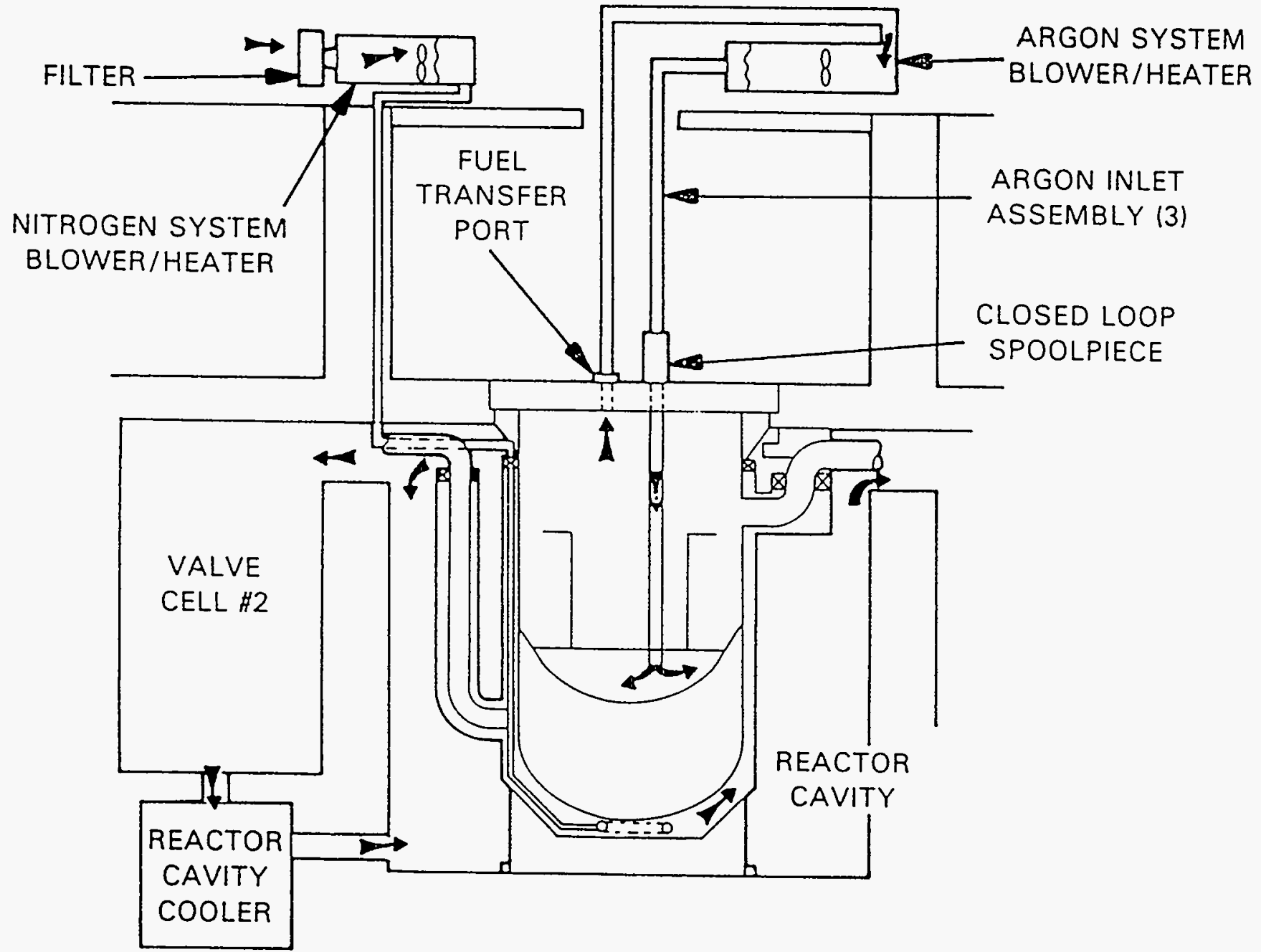

Figure 15. Reactor Vessel Preheat Systems 
effectively isolating all sodium in the reactor vessel from normal plant heat sources. At this point, the reactor vessel and pool sodium will begin a slow cooldown if auxiliary heating is not provided.

At least 51,000 gallons of sodium will now remain in the reactor vessel and all vessel heat must come from the Nitrogen Blower Heater Unit and the immersion heaters. Sodium draining through the drain lines located near the bottoms of the Intermediate Heat Exchangers can continue by syphoning from the reactor vessel through the cold leg piping. Due to the limited size of T-43, several additional drain and transfer (to the Sodium Storage Facility) cycles will be required. This process can continue until the sodium level in the reactor vessel is reduced to the vicinity of the reactor inlet nozzles. The cold leg syphon will then break and additional sodium removal via the drain lines will not be possible.

Approximately 16,000 gallons of sodium will remain in the reactor vessel below the inlet nozzles. Only two means of access to the reactor inlet plenum to drain this sodium heel have been identified:

(1) Cut an access hole in the reactor inlet piping in one of the loop isolation valve cells and insert a specially designed and fabricated "flexible tube" down through the inlet piping to the bottom of the vessel and then use the pressure/vacuum technique for sodium removal.

Drill an access hole through the core basket and the wall of the low pressure inlet plenum to permit a dip tube (approximately 50-feet long) to be inserted directly from the top through the reactor vessel head.

With either option, the temporary drain tube would be connected to the primary drain header, probably by entering one of the shielded Heat Transport systems cells from above. Sodium transfer would be accomplished by pressurizing the primary system and evacuating the storage tank.

The first method of access to the inlet plenum appears very difficult because the nearest access is almost 70 feet away in a primary cell which will have a background radiation level of at least several tens of millirem per hour. The special flexible tube that would be inserted through this opening must:

- Maintain the gas boundary of the existing sodium piping.

- Negotiate at least four right angle bends and two partial elbows.

- Be capable of blind insertion into a $400^{\circ} \mathrm{F}$ argon/sodium vapor environment.

- Be capable of being remotely guided under sodium to position the tube end at the low point of the reactor vesset.

- Transfer $400^{\circ} \mathrm{F}$ sodium under a high vacuum (no through wall leakage acceptable). 
This would be an extremely difficult and costly task requiring a substantial development effort with a low probability of success. This option would also result in a high radiation exposure to personnel.

The second method involves remote drilling, using tooling inserted and operated from the deck above the reactor. There are minimal radiological concerns with this relatively straight forward operation (i.e., as low as reasonably achievable (ALARA) goals are achieved). Based on preliminary studies, some development and testing will be required to establish the specific tooling and machining parameters required for drilling under sodium. Remotely installed drilling equipment over forty feet long will need to be designed and fabricated. It may also be necessary to develop a tool to remove a core basket receptacle prior to drilling through the inlet plenum. It is anticipated however that this work will be less than the development work needed for the first option and it is judged to have a higher probability of success. Based on this and ALARA considerations, the second method is selected as the baseline case for this plan. In either case, some residual sodium will remain in the bottom of the vessel as discussed in Section 9.4.3.2.

After completion of the reactor vessel and primary loop drains, the sodium remaining in the primary processing loop (including the overflow tank, T-42) will be drained to the primary sodium storage tank and then transferred to the Sodium Storage Facility. Residual sodium volumes are discussed in Section 9.4.3.2 and disposition of the cold trap is discussed in Section 9.4.3.4.

\subsubsection{Interim Decay Storage Vessel}

The Interim Decay Storage vessel (see Figure 16) has an installed drain line to the bottom. Using a combination of vacuum on T-43 and pressure in the vessel, it can be drained without difficulty. The drain will probably be interrupted at some intermediate level to siphon or displace the sodium out of each of the Core Component Pots, which will be a complex and time-consuming operation. This evolution will be performed to allow the Core Component Pots to be grappled if required later during decontamination and decommissioning. Some residual sodium will remain in the bottom of the vessel as discussed in Section 9.4.3.2.

\subsubsection{Fuel Storage Facility Vessel}

The Fuel Storage Facility (Figure 17) will be drained after the last fuel-bearing component is removed. The Fuel Storage Facility vessel drain will also utilize a dip tube drain line and a comparable pressure and vacuum technique; it should be drained without difficulty. However, the Fuel Storage Facility is not cross-connected in any way with the rest of the FFTF sodium systems, and as such, approximately 400 feet of sodium line will have to be installed above grade for this drain evolution. It is currently planned to transfer the Fuel Storage Facility sodium directly from the vessel to the Sodium Storage Facility. Some residual sodium will remain in the bottom of the vessel as discussed in Section 9.4.3.2. 


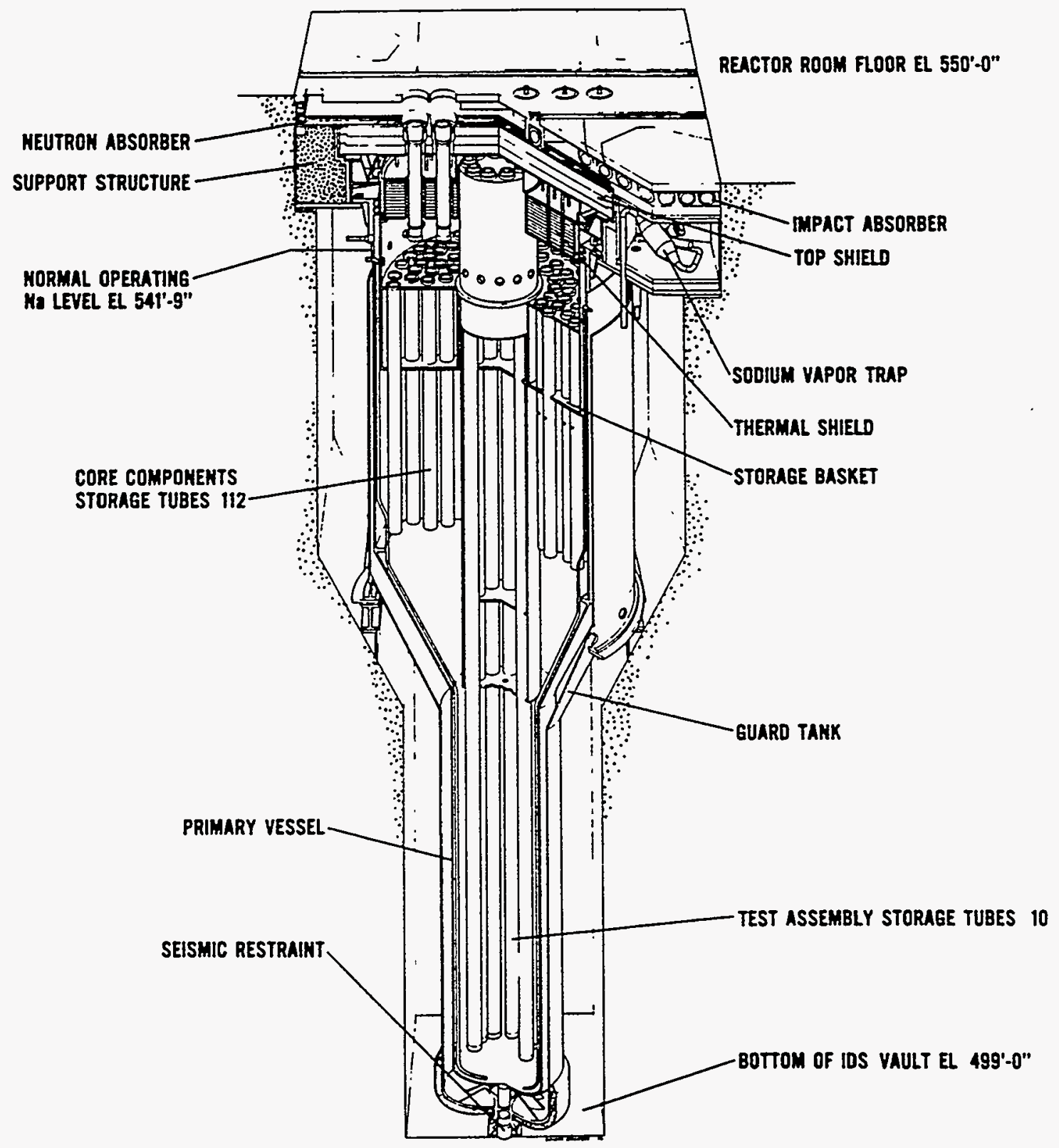

Figure 16. Interim Decay Storage Vessel 


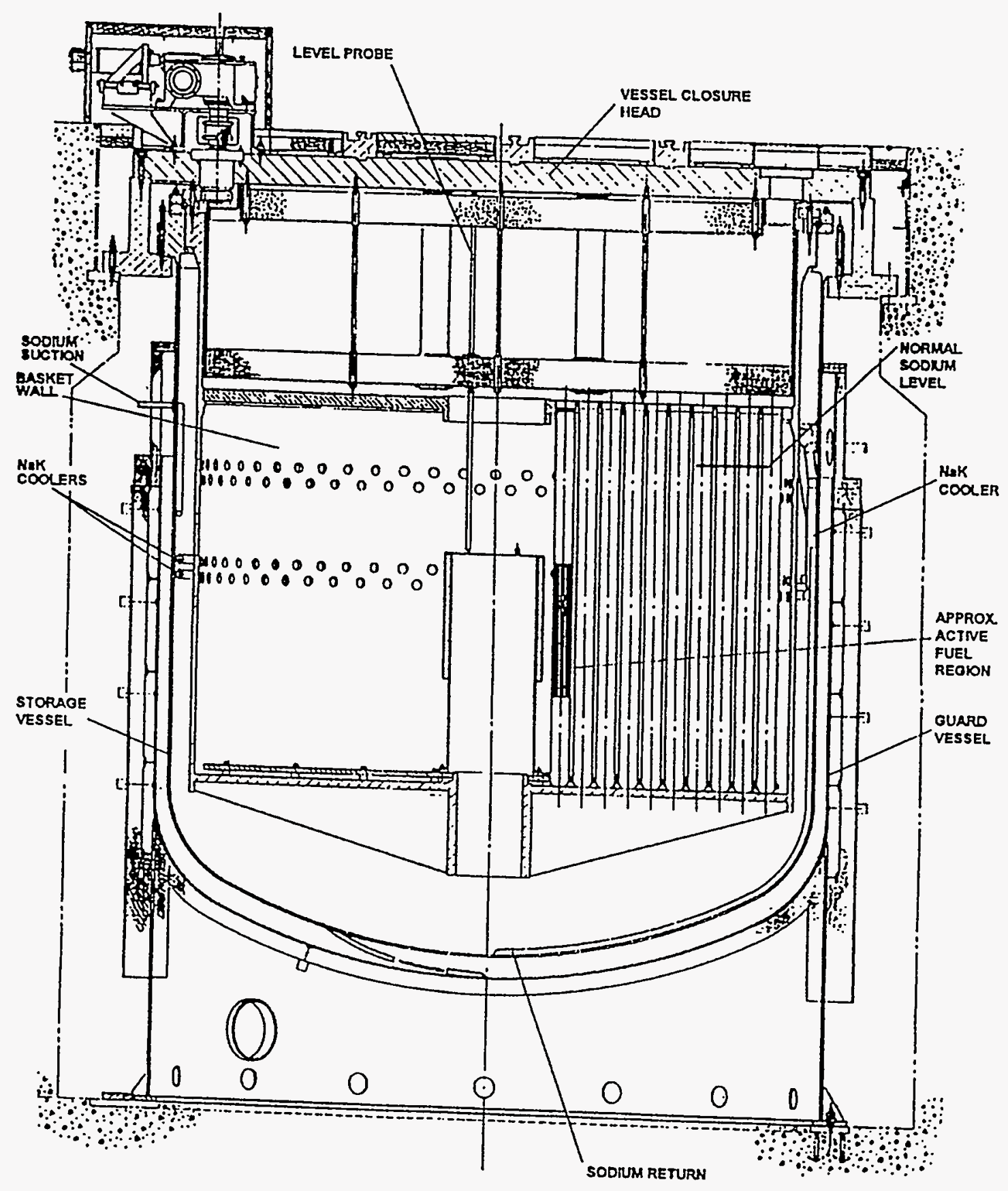

Figure 17. Fuel Storage Facility Storage Vessel 


\subsubsection{Liquid Metal Systems Disposition}

The sodium drain sequence and methods were previously discussed in Section 9.4.2. As described in that section, there are numerous portions of the sodium systems which will not completely drain due to the piping and component configurations. In addition to the sodium loops, there are three sodiumpotassium alloy (NaK) loops that need to be placed in a safe and stable condition. Disposition of the NaK loops is a special challenge since unlike sodium, it remains in the liquid state at normal ambient temperatures and it is more reactive than sodium. The planned process for dealing with the NaK loops is summarized in Section 9.4.3.1. Section 9.4.3.2 discusses the residual sodium volumes that are estimated to remain following the completion of the drain process. Following removal of the bulk of the alkali metal from the loops, there are several options for maintaining the systems and the residual sodium. These options and the current plans are the subject of Section 9.4.3.3. Finally, there are a number of special components associated with the sodium systems that provide unique problems due to their high level of radioactive contamination (attributed primarily to cesium) and/or inability to be drained. The planned disposition of these components is discussed in Section 9.4.3.4.

\subsubsection{Disposition of NaK Loops}

There are three NaK (eutectic of $78 \mathrm{wt} \%$ potassium and $22 \mathrm{wt} \%$ sodium) $100 \mathrm{ps}$ in the FFTF. Two are in containment (primary cold trap and Interim Decay Storage cooling loops) and one is at the Fuel Storage Facility. Dispositioning these loops provides one of the more difficult challenges of transition. Since NaK is more reactive than sodium, especially with air, and some compounds can become shock sensitive, the disposition of these systems in a safe manner must be carefully addressed. The alternatives proposed are based largely on first cut risk assessments specifically answering the question, "What state would result in the least risk to the personnel responsible for maintaining and ultimately dismantling these systems, presumably years from now?"

Current planning is to dispose of the NaK by mixing it into the bulk sodium. The total NaK inventory is a small fraction of a percent of the sodium volume and the sodium properties (e.g., freezing point) will not be measurably affected by the presence of this small quantity of NaK. Three potential processes for transferring the NaK into the sodium and then dispositioning the NaK system were considered:

(1) Transfer the NaK into the sodium (directly or indirectly) and then maintain a nitrogen atmosphere as planned for the sodium systems (see Section 9.4.3.3). This option was el iminated from further consideration due to the concerns related to maintaining NaK residuals in the loops for many years and the required later disposition.

(2) Transfer the NaK into the sodium (directly or indirectly) and then react the NaK residuals (e.g., by flowing moist inert gas through the system). This eliminates the concerns associated with leaving NaK residuals but is not practical for complex, small diameter piping systems or 
components where significant residuals are likely to exist. When cleaning and/or flushing these systems, significant residuals or un-drained piping sections could result in a violent, uncontrolled reaction.

(3) Flush the NaK system with sodium, drain the system to the extent possible, allow the residual sodium to freeze and then maintain a nitrogen atmosphere. This eliminates the concerns associated with leaving NaK residuals but is only practical where both NaK and sodium system piping are available in the same vicinity for cross-connection. It should be noted that this may require removal of existing insulation and the addition of trace heat to some accessible portions of the NaK piping in order to reduce the risk of sodium freezing during the flush.

Due to the piping complexity of the primary cold trap and Interim Decay Storage NaK cooling systems and the inability to drain the NaK filled cold trap cooling jacket, the third option appears appropriate for these systems.

Several possibilities exist for cross-connecting the in-containment NaK systems with the sodium systems they cool. The small bore sodium and NaK systems in containment share a vertical pipeway that starts above the electromagnetic pump cells at the bottom of containment and rises some 40 feet. This vertical pipeway has been entered in the past and could be entered again if necessary. However, a more likely location for cross-connecting the primary sodium to the cold trap cooling NaK is adjacent to the cell where the second primary cold trap was to be installed. The Interim Decay Storage sodium and NaK systems both share a common cell at the 489 foot level of containment and may be cross-connected at this location.

The Fuel Storage Facility NaK cooling loop (see Figure 18) represents a considerably simpler geometry but there is no convenient location to interconnect with a sodium system to allow flushing. Since the in-vessel cooler low point represents a significant un-drainable volume, it is currentiy planned to perforate the in-vessel cooler and thus drain the NaK directly into the sodium storage vessel (probably following partial drain of the vessel). If this is determined not to be feasible, then the Fuel Storage Facility NaK loop could be treated in the same manner as the in-containment cold trap cooling Nak loops. That is, it could be flushed with sodium (probabiy piped from the Fuel Storage Facility sodium process 10op) and the non-drainable portion allowed to freeze.

\subsubsection{Residual Sodium}

As described in Section 9.4.2, residual sodium will remain in portions of the Main Heat Transport System and auxiliary sodium loops following completion of the drain processes. In addition, Section 9.4.3.1 discussed the planned sodium flushing of the two in-containment NaK cooling loops and the residual sodium disposition. Estimates of the plant residual sodium volumes are provided in Table 5; additional indeterminate quantities are likely to remain in other portions of the systems, especially in complex small diameter piping 


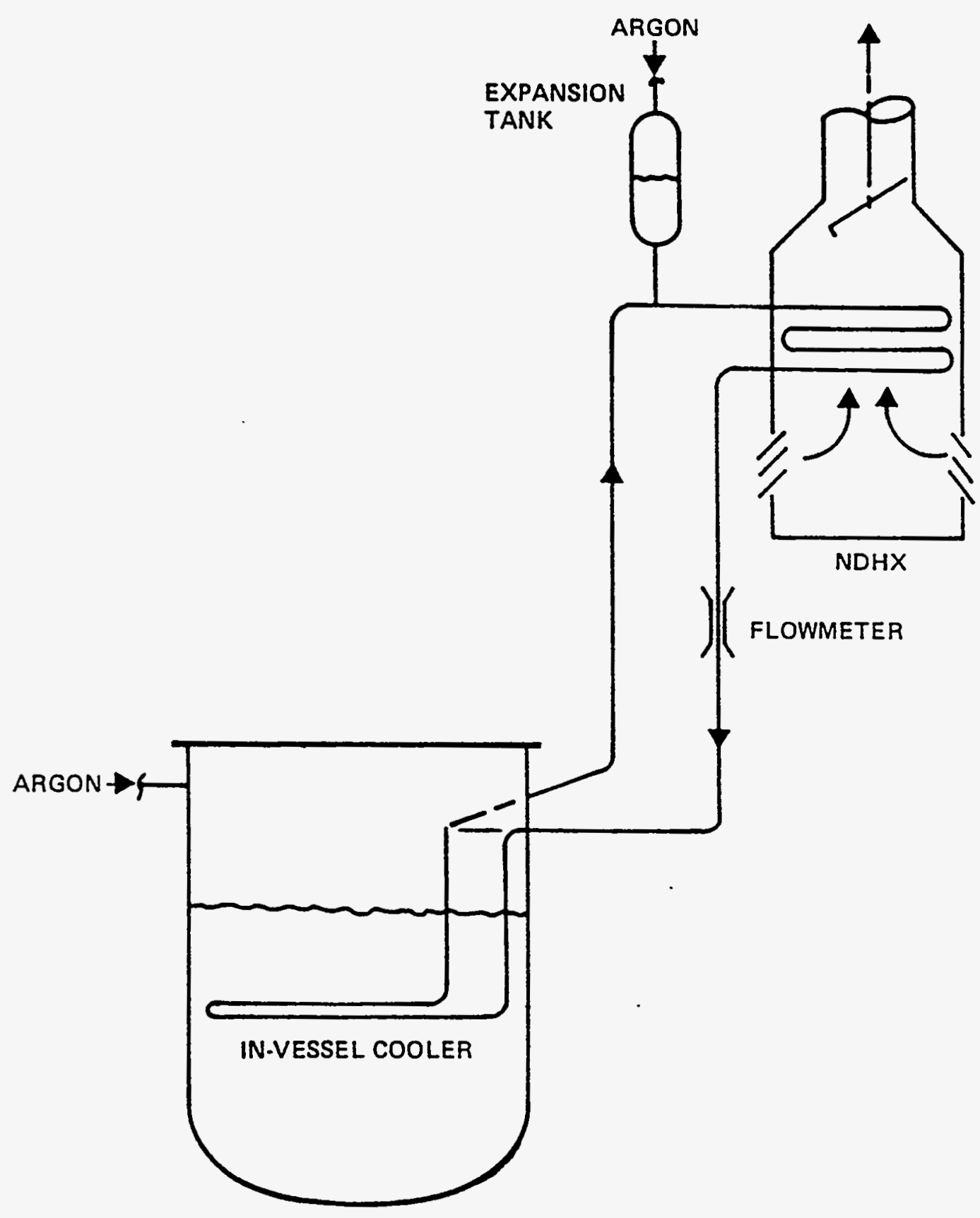

Figure 18. Fuel Storage Facility NaK Loop 


\section{TABLE 5}

\section{ESTIMATED PLANT RESIDUAL SODIUM VOLUMES}

Reactor Vessel Inlet Plenum 100

Primary Pump/Discharge Piping ${ }^{(1)}$ 15

IHX Primary Side/Discharge Piping(1)

Primary Hot Leg Isolation Valve ${ }^{(1)}$ 375

Primary Cold Leg Isolation Valve(1) 210

Primary Cold Leg Check Valve ${ }^{(1)}$ 105

Reactor Overflow Weir 20

Reactor Overflow Tank (T-42) 15

Primary Sodium Storage Tank (T-43) 20

Primary Cold Trap (N-5) ${ }^{(2)}$ 800

- Primary Cesium Trap 80

Interim Decay Storage Vesse1 100

Interim Decay Storage Cold Trap (N-46) 300

Fuel Storage Facility Vessel 100

Fuel Storage Facility Cold Trap 200

IHX Secondary Side(1) 30

Secondary Loop Venturi Flowmeter (1) 120

Secondary Sodium Storage Tank (T-44) 30

Secondary Loop Cold Trap ${ }^{(1)}$ 900

other Small Overflow and Drain Tanks 20

Total Estimated Volume

(1) Residual sodium volume given is for three loops.

(2) Includes residual sodium in the NaK cooling jacket. 
systems. Although retention of sodium residuals was initially identified as a key issue, subsequent discussions between DOE, Bechtel Hanford Inc., and FFTF personnel have confirmed that sodium residuals will be retained in the plant. Specific locations and quantities have not been finalized but will be formalized in the Transition End-Point Criteria Document.

It is currently planned to leave the frozen sodium residuals sealed in place with a nitrogen blanket atmosphere to prevent any significant long term reactions (options considered for dealing with the residuals are discussed in Section 9.4.3.3). This is a safe and stable condition for turnover of the liquid metal systems to the Environmental Restoration Contractor.

It should be noted that a very small portion of the residual sodium in the reactor vessel could potentially remain molten due to decay heat from activation of the reactor structural materials. This residual would consist of sodium films and droplets adhering to components in the immediate core region (such as the non-fueled core assemblies). The residual sodium pool in the bottom of the vessel is expected to freeze. The possible presence of this very small molten residual is considered acceptable since the system will remain inerted. The reactor internal temperatures will not be discernable at the exterior of the vessel.

\subsubsection{Passivation/Inerting Considerations}

There are two issues that must be answered once the sodium has been drained from FFTF. First, recognizing that there will be sodium residuals, when will the residuals be removed, i.e., during the transition or during final decontamination and decommissioning? Second, if the residuals are retained until the final disposition phase, how will they be managed or maintained?

In the "ideal" condition, the residual sodium would be removed and the systems cleaned during transition. Typically, a water vapor-inert gas injection process followed by a water flush is used to clean residual sodium from components such as fuel assemblies prior to experiment disposition, or components/ equipment prior to return to service. These components are well drained and the sodium removal process occurs within a reaction vessel that is carefully monitored and controlled. This technology cannot readily be adapted to clean the FFTF systems because:

- The typical cleaning process discussed above does not lend itself to in situ cleaning of the very complex FFTF systems. Due to the complex geometries and piping arrangements it cannot be assured that sodium blockages will not remain, which could result in severe and uncontrolled reactions when water is introduced.

- In order to assure safe cleaning, it will be necessary to dismantle portions of the systems and/or remove components to obtain direct access and to assure that there are no sodium blockages. At this point, a combination of in situ and direct cleaning of the removed components could be performed. During this cleaning process, hundreds of thousands 
of gallons of radioactive liquid waste would be generated, even with judicious recycle of the rinses. Treatment of this waste may not result in cost effective disposal.

- Portions of the primary sodium and cover gas system piping, components, and vessel are intensely radioactive, either with deposited corrosion and fission products, or induced activity from neutron irradiation. In particular, the reactor vessel, primary cold trap, cesium trap, vapor traps, and cover gas piping will not be approachable for "hands-on" work for several decades. Other areas, while accessible, also have significant radiological source terms which would result in high exposures to personnel working in those areas. This is not consistent with ALARA policies.

Deferring this activity for perhaps several decades pending a final decontamination and decommissioning decision has several advantages:

- Radiation levels will have decayed, perhaps allowing hands-on operations within acceptable ALARA guidelines within most areas.

- Future technical advances (e.g., robotics) may result in significant improvements in methods which could be applied at the FFTF.

- Lessons learned from other liquid metal reactor facilities that are expected to undergo decontamination and decommissioning activities in the upcoming years would provide insight into the preferred final disposition of the plant.

- The scope and technical direction of the decontamination and decommissioning activities may significantly change. It is conceivable that the reactor and primary systems in containment may be left in their current configuration.

- Dismantiing of these systems will generate large quantities of sodium filled or wetted piping and components. Cleaning of this hardware will require a permitted mixed waste treatment facility, which requires a different process than used in the Sodium Reaction Facility discussed in the Plan. Currently there are no mixed waste treatment facjlities either within the DOE complex or that have been identified in industry that can treat this waste.

- Major dismantling and cleaning may require preparation of an Environmental Impact Statement.

Deferring this activity also has some disadvantages:

- The cadre of FFTF personnel highly trained in the operation and maintenance of sodium systems would not be available, requiring the training of a completely new workforce. Further, the legacy of dismantling the sodium systems would be transferred to another organization decades in the future. 
- The sodium residuals will require the maintenance of a nitrogen bianket for the intervening years before final decommissioning. Operation of a nitrogen distribution system will result in slightly increased surveillance and maintenance costs.

- There is a perception, by people unfamiliar with sodium and its properties, of risk associated with maintaining the sodium residuals in the plant for decades. However, this perceived risk is unwarranted. For example, several sodium test loops at Hanford have been in a layup state for ten to fifteen years without any known safety or technical issues. The largest of these facilities is located in the 337 Building highbay, which houses a one-third scale sodium mockup of the FFTF reactor vessel and internals. This system has been maintained under an -inert atmosphere for 17 years with virtually no surveillance effort.

Weighing these advantages and disadvantages, it has been concluded that sodium residuals will be retained in the plant at the time of turnover to the Environmental Restoration Contractor.

The second issue, which is how these sodium residuals can be safely maintained is addressed below.

Three options for post-drain maintenance were considered:

(1) Drain the sodium, fill the piping with dry inert gas, and close the system (an inert gas purge is then required since complete system sealing is not possible).

(2) Drain the sodium, and react the residual sodium with a water vapor-inert gas process while evacuating the hydrogen formed during the sodium reaction. As with Option 1 an inert cover gas (purge) would be maintained on the system when it was closed.

(3) Drain the sodium, react the sodium surfaces with carbon dioxide and close the system. The carbon dioxide reaction step is called "passivation." Following passivation, the system might be sealed or maintained with a carbon dioxide purge (an active carbon dioxide system has been maintained at the deactivated FERMI plant).

Option 1 above would leave unreacted sodium in droplets, films, lumps, and pools in the primary and secondary systems. It is not likely that the closed system would remain hermetically sealed; a small purge of inert gas at slightly higher than atmospheric pressure is anticipated. However, a small amount of air (with moisture) may still enter the system over time and react to form small amounts of sodium hydroxide and hydrogen near the leak point.

Most of the system would not be affected by the inleakage: for small gas leakage the effect would be to produce a small amount of anhydrous sodium hydroxide. The piping system could be dismantled from this condition, using appropriate care, once the radioactivity decreases to safe levels. 
Option 2 would convert most of the film and droplet sodium to moist sodium hydroxide and leave a moist hydroxide film on the surface of any sodium pools. Considerable volumes of hydrogen and possibly airborne sodium and cesium aerosol would be generated and appropriately vented. The hydrogen would contain some amount of tritium. The effect of small air inleakage following this process would be insignificant because more moisture would already be present than would likely leak in as water vapor. The water vapor-inert gas system would have to be designed, installed, and operated. Leaving the plant systems containing moist sodium hydroxide would result in increased risk of corrosion (stress corrosion cracking) of the stainless steel (e.g., at weld locations). In the extreme, this could lead to loss of system integrity and the spread of contamination. For this reason the system would have to be heated and purged with nitrogen to dry the hydroxide. As in Option 1, inerting and maintaining a slightly positive pressure would be required for the surveillance and maintenance period. The difficulty of dismantling the piping system at a later date (if that is to be done) would be complicated by the presence of the hydroxide.

Option 3 would result in most of the residual sodium being covered with a layer of sodium carbonate, with unreacted sodium and perhaps some hydroxide underneath. Air/water vapor inleakage should have no effect on the carbonate crust covering the unreacted sodium. The difficulty of dismantling the piping system would also be comparable. Two disadvantages of the passivation option are: the sodium carbonate surface is nonreactive, and if the decision is made later to rinse away the residual sodium or otherwise react it, the carbonate layer makes that operation more difficult; and some moist hydroxide may be present resulting in the same concerns discussed in Option 2.

For planning purposes, Option 1 (drain, fill with nitrogen, close) was selected for the following reasons:

- It requires the least amount of time and money in the short term, since no water vapor-inert gas system is required during the transition process, and perhaps not at all.

- It eliminates potential corrosion concerns due to the introduction of moisture resulting in the formation of sodium hydroxide which could attack the stainiess steel boundary.

- It allows greater flexibility for future treatment options.

- Nitrogen would be used because it does not react with sodium and is less expensive than argon.

However, a further study will be conducted to confirm these conclusions and will address related experiences at other Liquid Metal Reactor facilities that either have or are undergoing shutdown. As previously indicated, FFTF staff will work closely with the Experimental Breeder Reactor-II personnel to address common shutdown issues. It is also planned to establish dialogue/interaction with foreign reactor plant personnel, where applicable. These technical exchanges will be factored into the study. 


\subsubsection{Special Components}

There are several components that deserve special consideration in the shutdown process due to their high level of radioactive contamination (attributed primarily to cesium) and/or inability to be drained. These components include six sodium cold traps (three secondaries, one primary, one Interim Decay Storage, and one Fuel Storage Facility), a cesium trap, and two sodium vapor traps. Each of these is discussed below:

- Secondary cold Traps:

Each air cooled secondary cold trap (see Figure 19) contains approximately 300 gallons of sodium that cannot be readily drained. Some tritium (in the form of sodium hydride) that diffused through the intermediate heat exchangers from the primary sodium has collected in these cold traps. Tritium emits a very low energy beta particle and poses no health hazard to plant personnel while contained in the cold traps. The current plan is to drain the process loops as much as possible and then allow the remainder (including the cold traps) to freeze and remain in place. There does not appear to be any technical or cost advantage in draining these secondary cold traps during transition. In either case, additional work to remove residual sodium from each cold trap will be required for final disposition. Further, draining the cold traps now may increase the safety hazard during final decommissioning since there is some potential for generation of significant quantities of hydrogen (from sodium compounds which occur in significant quantities only in the cold trap) if the cold trap is opened to the air. Maintaining the trap furl of frozen sodium eliminates this possibility. This issue also applies to the Primary, Interim Decay. Storage, and Fuel Storage Facility cold traps discussed below (additional detail is available in Reference 23).

- Primary Cold Trap:

The primary cold trap (see Figure 20) is cooled by a NaK cooling jacket around the outside of the sodium containing crystallizer tank. As described in Section 9.4.3.1, the current plan is to interconnect the sodium and NaK system piping and flush the NaK into the sodium system, thus eliminating the NaK storage/disposal concern. However, sodjum in both the tank and the cooling jacket is not drainable. More importantly, the cold trap has accumulated considerable quantities of fission and activated corrosion products (e.g., cesium and manganese). The actual level of radioactivity is unknown at this time but it is expected to result in a general dose rate of at least several tens and perhaps several hundreds of rem per hour. This makes it impossible to enter the cold trap cell to do hands-on work. Further, there is probably no safer or more secure location than its current inaccessible cell within the containment building. Therefore, the primary cold trap will be allowed to freeze (following drain of as much as the process loop as possible) and will be left in place. 
WHC-SD-FF-SSP-004

Rev. I Page 93

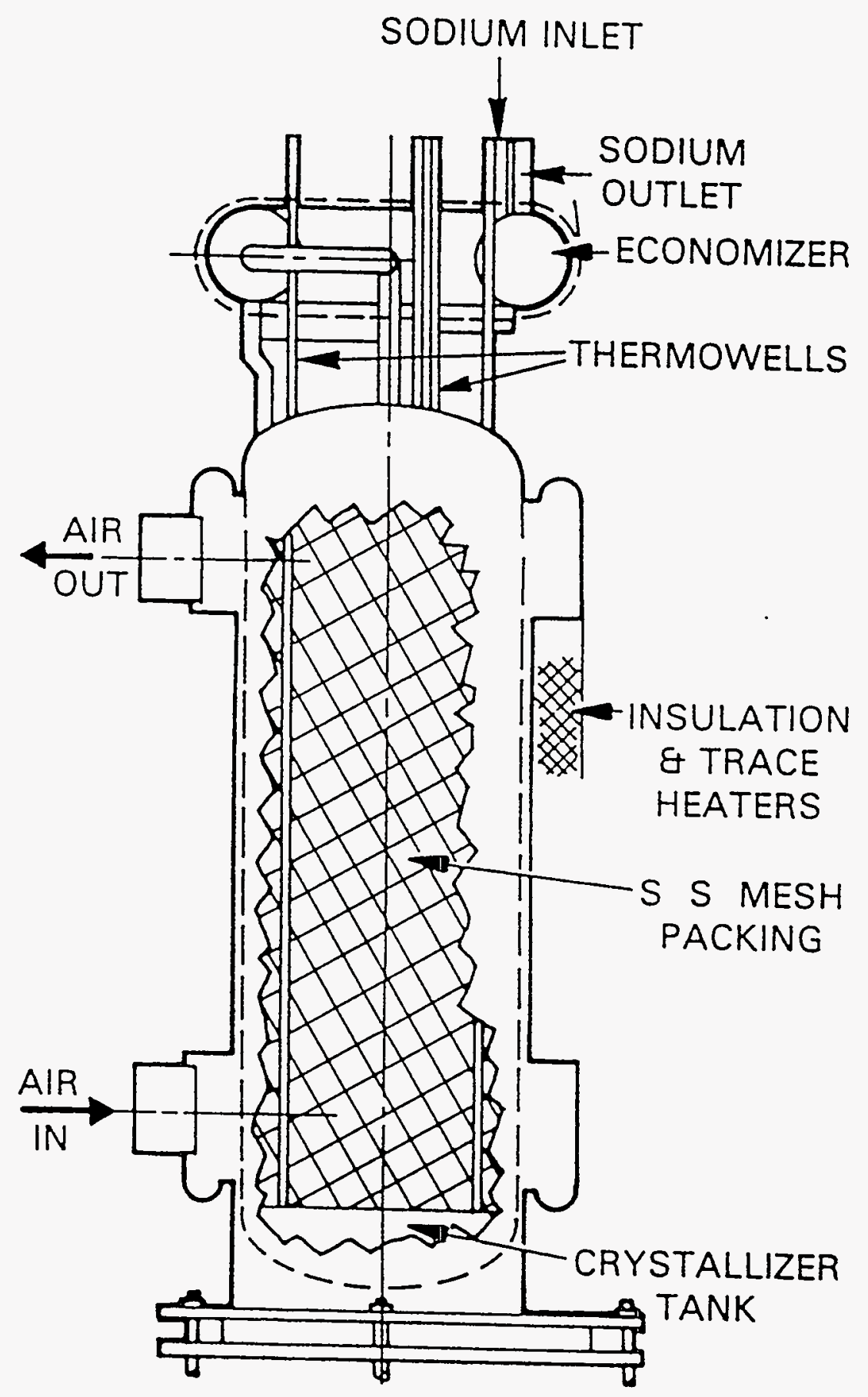

Figure 19. Secondary Cold Trap 


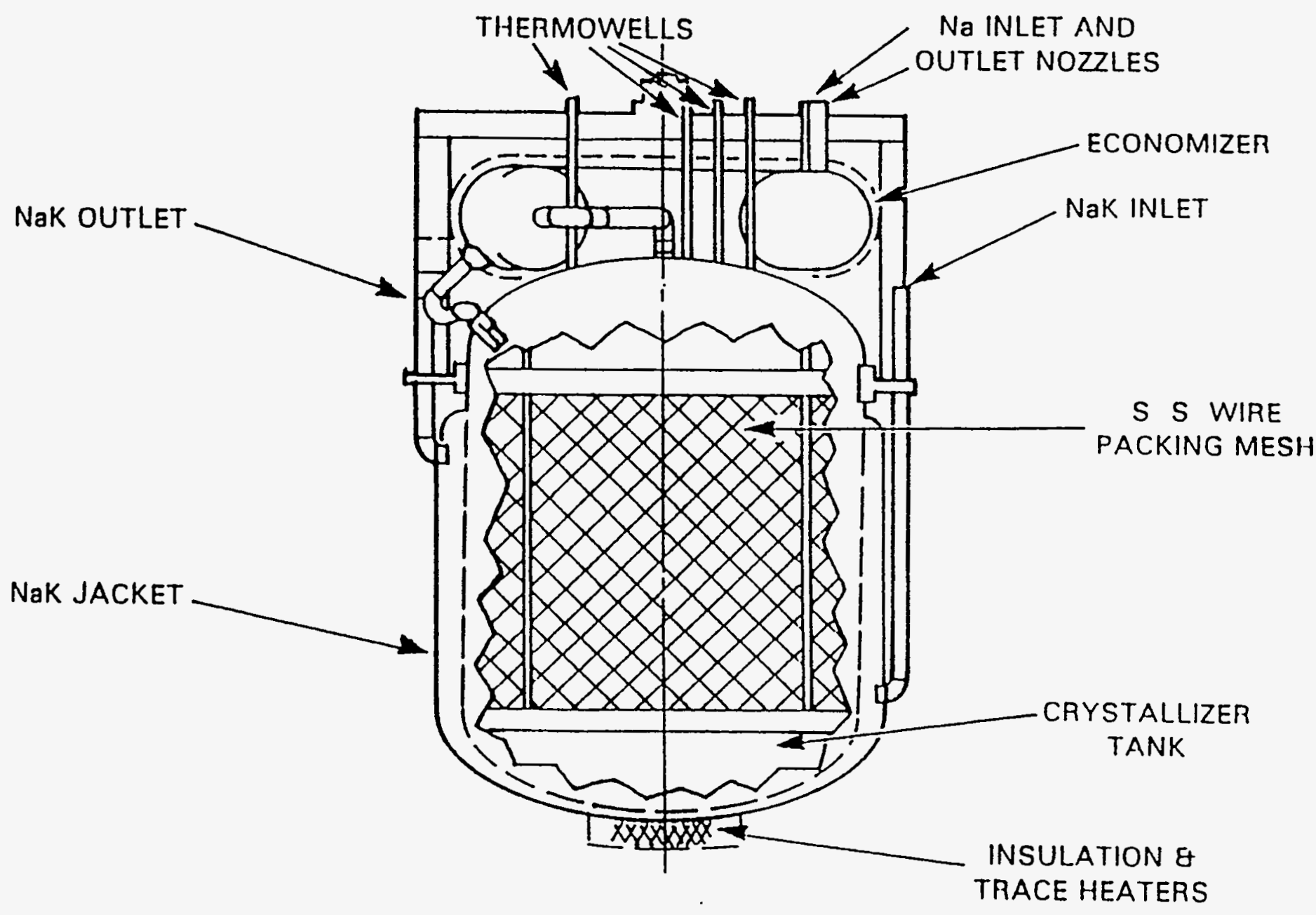

Figure 20. Primary Cold Trap 


\section{Interim Decay Storage Cold Trap:}

The Interim Decay Storage cold trap is similar to the secondary cold traps except it is cooled by nitrogen rather than air. Because it services the relatively clean Interim Decay Storage sodium, the radioactivity level should be considerably lower than the primary cold trap. However, some contamination is expected since failed fuel has been stored in Interim Decay Storage. In addition, the cold trap is located in the same cell as the highly radioactive primary cold trap. Since this component is located in a safe and secure cel1 inside containment, the current $\mathrm{plan}$ is to treat it in the identical manner as the primary cold trap. That is, allow it to freeze and leave it in place.

\section{- Fuel Storage Facility Cold Trap:}

The Fuel Storage Facility cold trap is air cooled and has accumulated fission products resulting in a radiation exposure rate of 85 millirem per hour on contact. The cold trap could be drained. The same rationale discussed for the secondary cold traps would also apply to the FSF cold trap. The Fuel Storage Facility process loop will be drained to the extent possible. The cold trap will then be allowed to freeze and will be left in place.

- Cesium Trap:

The cesium trap is a reticulated vitreous carbon filter designed to remove cesium that enters the primary sodium due to fuel cladding failures. It is Tocated in Heat Transport System South (outside of containment). It is not drainable and is expected to have a very high level of radioactive contamination that makes cell entry impossible. Therefore, as with the primary cold trap, the plan is to freeze the cesium trap and leave it in place.

\section{- Sodium Vapor Traps:}

Two sodium vapor traps are utilized to minimize sodium vapor transport into the primary cover gas system piping systems. These components are located in isolated (currently inaccessible) cells within the containment building. One vapor trap has accumulated significant quantities of cesium-137 and considerable quantities have migrated beyond the vapor trap into the downstream gas piping systems. This has resulted in very high radiation exposure rates in some regions (e.g., a measured 150 rem per hour hot spot exists). It can be expected that the other vapor trap is also contaminated, but this has not been confirmed by measurements (downstream compressors have slight contamination). It is planned to close the isolation valves downstream from the vapor traps and other locations containing significant accumulations of contamination (the 1 ines may be cut and capped). As stated in section 9.4.3.3, the intent is to basically seal the primary system following 
sodium drain. This will minimize the potential for release of contamination during the surveillance and maintenance phase after turnover to the Environmental Restoration Contractor.

\subsubsection{Sodium Storage Facility}

The Sodium Storage Facility will be designed and constructed adjacent to the FFTF Complex for sodium offload. This facility will house the FFTF primary, secondary, Interim Decay Storage and Fuel Storage Facility sodium. For an evaluation of the Sodium Storage Facility site location, see Section 9.4.1 above.

A detailed review of the design and construction schedule for the Sodium Storage Facility indicated that a six month acceleration could be achieved, contingent upon availability of appropriate funding, and would culminate in a substantial savings to the Project of approximately $\$ 20$ million. The DOE funding guidance for the Transition Project (Reference 8) supports this baseline acceleration. Detailed planning and supporting activities are proceeding according $7 y$.

Therefore, the Conceptual Design Report (Reference 24), cost estimate and Preliminary Safety Evaluation (Reference 25) for the Sodium Storage Facility were completed on an expedited basis and transmitted to RL on October 18, 1994. An accelerated design and construction schedule has been developed and shows the Title I definitive design of the Sodium Storage Facility beginning on January 3, 1995. DOE Order 4700.1 requires the funding authorization to be in place before the Title I design is initjated. A Request for Project Authorization was transmitted to RL on October 24, 1994 (Reference 26). If the authorization is approved by January 3, 1995, the design of the facility will begin and plans toward completing the turnover of the facility to WHC Operations by January 30, 1997 will be implemented.

If authorization to begin the design and construction of the Sodium Storage Facility is delayed, additional costs to maintain the Plant in a safe condition will be incurred at an annual rate of $\$ 35$ million.

\subsubsection{Storage Tanks}

Large, carbon steel sodium tanks are available on the Hanford site for storage of the FFTF sodium. These tanks were originally built for the Clinch River Breeder Reactor Project, and have been stored in an outdoor laydown yard near the Hanford 300 Area since 1985. There are three 80,000 gallon tanks, two 52,000 gallon tanks and one 36,000 gallon tank available. Only the three 80,000 gallon tanks and one of the 52,000 gallon tanks are planned to be used.

The four large tanks will be transported from the 300 Area to the FFTF site and then installed into the new Sodium Storage Facility. Each tank is expected to require a separate move, using a crawler type transporter or a rubber-tired platform trailer and prime mover(s). A large, portable crane at each end of the move will be required to handie the tanks. An access route to the final installation site will also need to be cleared (power lines moved, 
fences removed/reinstalled, underground utilities protected from weight, etc.). Each 80,000 gallon tank is vertically mounted, 28 feet in diameter, over 24 feet tall, and weighs approximately 80 tons with the rigging installed. The 52,000 gallon tank is horizontally mounted, 18 feet in diameter, approximately 31 feet long, and weighs about 57 tons.

\subsubsection{Sodium Storage Facility}

The proposed Sodium Storage Facility (Figure 21) is conceptualized as being constructed in the area between the south and west Dump Heat Exchangers. An existing concrete pad, originally constructed to serve as the future mounting location for the Closed Loop Three and Four Dump Heat Exchanger equipment, will be removed. Existing concrete tunnels to the pad may be utilized for routing pipe and utilities from the plant. Any other underground utilities which interfere with construction of the storage facility will be moved to provide the necessary access.

Shielding will be necessary to reduce radiation levels to acceptable limits outside the building walls. An exclusion fence may also provide or contribute to the radiation protection. The sodium drain could begin as early as April 1997 , at which time, the dose rate would be reduced to approximately 12 millirem per hour at the tank surface due to the decay of sodium-22 (the primary dose contributor). Radiation levels at the top of the tanks will be approximately 85 mrem per hour.

Once the storage tanks are in place, electrical trace heaters and insulation will be added so the tanks can be preheated prior to the sodium fill. Temporary level probes will be used in thimbles in each tank for monitoring during initial fill or any subsequent drain operation. Level monitoring will not be required once the sodium in the tanks becomes a solid.

To offload the sodium from the FFTF, piping will be provided from the FFTF systems to the new Sodium Storage Facility. Insulation and trace heat will be added to this piping header in order to maintain a $300^{\circ} \mathrm{F}$ to $400^{\circ} \mathrm{F}$ temperature during the sodium transfer. The tanks will be inerted prior to transfer of the sodium and an inert gas blanket will be maintained over the sodium during storage. Argon will be routed from the FFTF to the storage facility. It is planned to use the existing closed loop tunnels for the pipe routing. Pressure protection will be provided on the gas supply line. Gas venting during the tank fill will be directed through a high efficiency particulate absolute (HEPA) filter. Pressure relief devices will be installed to protect each tank and its radioactive contents during the sodium storage period.

The storage facility will be designed and built to appropriate Resource Conservation and Recovery Act requirements. When a requirement is deemed unsafe or impractical, a waiver or exemption will be pursued. Technical rationale and/or safety equivalence will be used to justify any such request. Two candidate exemptions have been identified to date which are discussed in detail in Section 6.2.2.1 (4). 


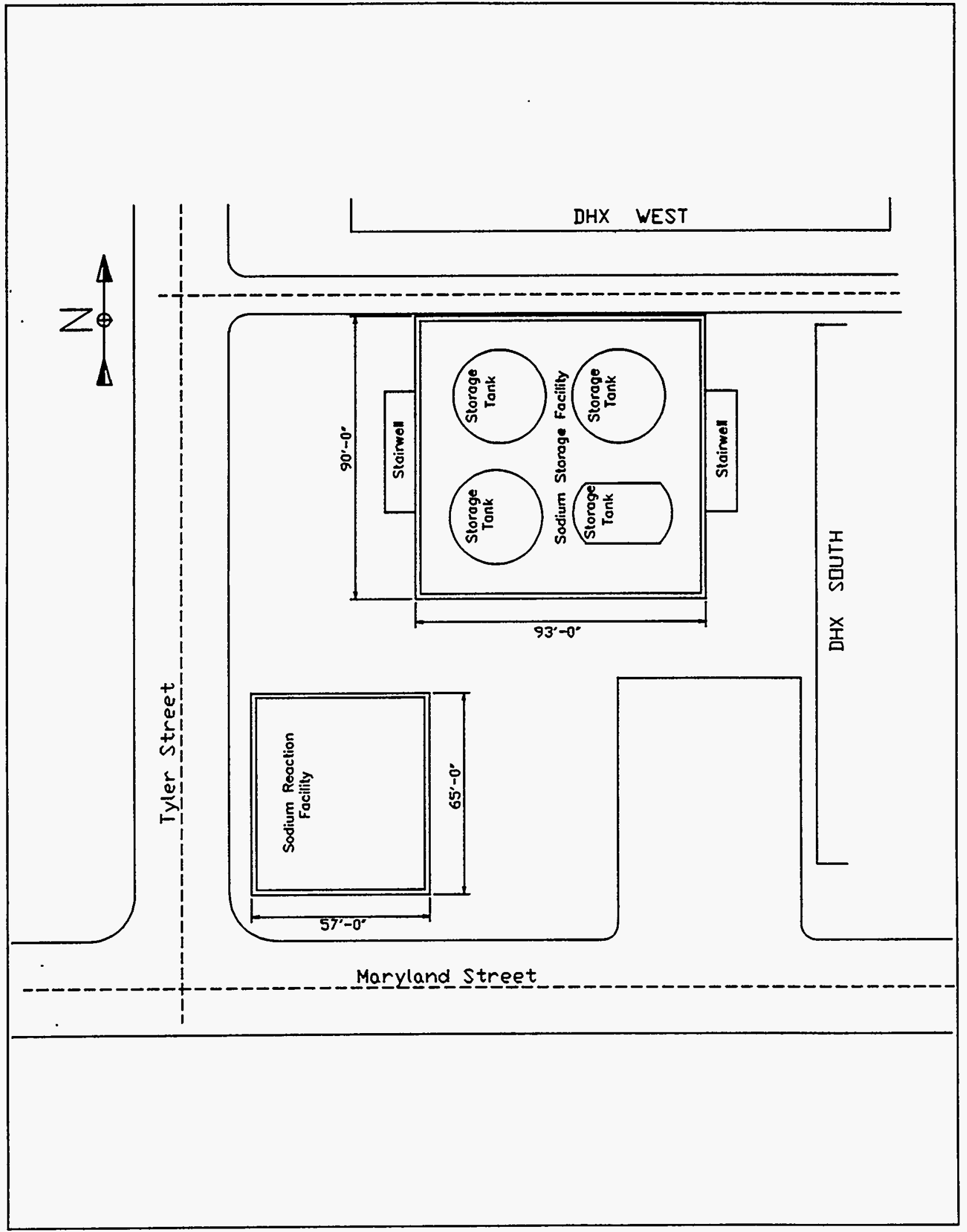

Figure 21. Sodium Storage Facility Layout 
As developed by the conceptual design, the four Clinch River Breeder Reactor Project tanks will be mounted on a two-foot thick concrete floor. The building internal area between the walls will contain a steel-lined sump approximately 2 feet deep, which has sufficient capacity to contain the total contents of one of the larger $(80,000$ gallon) Clinch River Breeder Reactor Project tanks. A metal floor with strategically located openings (holes/annulus) will cover the sump to limit the oxygen available for combustion.

A concern related to piping leaks or ruptures which could siphon the contents of the tanks into the sump was resolved by providing an anti-siphon pipe connection between the sodium 7 ine and the tank gas space. This design improvement will allow the piping design to be reduced to Safety Class 3 .

The walls will be 18-inch thick concrete (for shielding purposes), and will be approximately 40 feet tall. The roof will be sloped to allow for water runoff. An appropriately shielded mezzanine area above the tanks will provide access for operation and maintenance. The facility entry doors will be provided with locks to restrict access.

Smoke type fire detectors will be provided. Design basis fire cleanup costs and risk assessments will be evaluated as part of the Fire Hazards Analysis. Other basic services will be provided such as minimal lighting, heating, ventilation air conditioning, high efficiency filtering of tank vents, oxygen monitoring, trace heat power, 120 volt power outlets, communications, etc.

The Preliminary Safety Evaluation (Reference 25) concluded that the design of the Sodium Storage Facility storage tanks and their foundation will be Safety Class 2. The exterior load bearing walls, roof, and foundations are classified as Safety Class 3 , but will be designed for Safety Class 2 seismic and wind loads. Expected releases during routine and off-normal conditions were evaluated and determined to be within acceptable limits.

The Conceptual Design Report (Reference 24) includes a detailed cost estimate and schedule for the Sodium Storage Facility. This revised estimate reflects a reduction in cost from $\$ 15.8$ million delineated in Revision 0 of the Plan, to a current $\$ 10.4$ million. The decrease is attributed to the following:

- The facility size was reduced because the requirements for storing the Hallam and Sodium Reactor Experiment sodium were deleted.

- The contingency factor was reduced from $30 \%$ to $20 \%$ due to the availability of more detailed engineering and construction data.

- The general safety classification of the total facility was reduced from Safety Class 2 to the safety class configurations described above. This innovative reduction in the safety classification will be evaluated during the definitive design. Any productivity improvements that result will be applied to Fiscal Year 1995 and/or Fiscal Year 1996. 
The Sodium Reaction Facility will be constructed as a separate building, in close proximity to the Sodium Storage Facility, as shown on Figure 21 .

Further details can be found in Section 9.4 .5 below.

\subsubsection{Sodium Reaction Facility}

Sodium is classified as a hazardous substance and must either be converted to a chemical form that can be used as feed stock in some different process, or reacted to a stable material for disposal. This section describes the current planning for this disposition as well as some alternative approaches.

A new purpose for the sodium has been jdentified by the Tank Waste Remediation Systems Program. It is to use the sodium, converted to sodium hydroxide, for caustic washing as part of the high level waste tank sludge pretreatment

process. The converted sodium hydroxide from FFTF may not be required until 2008. Therefore, for planning purposes the construction of the Sodium Reaction Facility is assumed to be deferred. However, in order to maintain schedule visibility in the event the Project baseline changes, construction of the Sodium Reaction Facility is shown in Figure 1 to occur during Fiscal Years 2001 and 2002 .

\subsubsection{Process Description}

The Project baseline is to produce sodium hydroxide solution that can be used by the Hanford Tank Waste Remediation System (TWRS) in the processing of tank sludge deposits. As discussed in Section 9.4.1, the sodium reaction process utilized by Argonne National Laboratory-West will form the basis for the FFTF Sodium Reaction Facility (see Figure 22 flow sheet). Pending operational verification of the Idaho unit, the same processing facility will be constructed at FFTF at the appropriate time, thus reducing development and design costs. Figure 22 shows the entire process to convert sodium to sodium carbonate. However, the process will be truncated by eliminating the steps called "Alternate Process" to produce sodium hydroxide for the TWRS Project baseline application. If the baseline changes the sodium hydroxide could be converted to a solid compound for land disposal. Since sodium carbonate is listed as a toxic substance in Washington State, the Argonne National Laboratory-West process likely would be modified to produce sodium sulfate or sodium-tetraborate. A description of the Argonne National Laboratory-West Sodium conversion process to sodium carbonate is provided below.

The process consists of injecting molten sodium metal and water into a reaction vessel partially filled with $40 \%$ to $50 \%$ sodium hydroxide at about $240^{\circ} \mathrm{F}$. The vigorous reaction produces more sodium hydroxide and hydrogen gas. The gas is swept out of the vessel by a nitrogen cover gas purge and maintained at sufficiently low dilution so as not to be flammable when it is mixed with air. The sodium hydroxide product is collected in adjacent holding tanks (up to 82,300 gallons capacity) and then shipped to the TWRS facilities, as discussed in Section 9.4.5.3. To form solid sodium carbonate, the sodium hydroxide solution is dehydrated and then reacted with carbon dioxide gas. The carbonate is dried, collected into containers and transported to the disposal site or held for future use as possible feed stock for another process on the Hanford Site. Figure 22 shows the approximate flow stream 


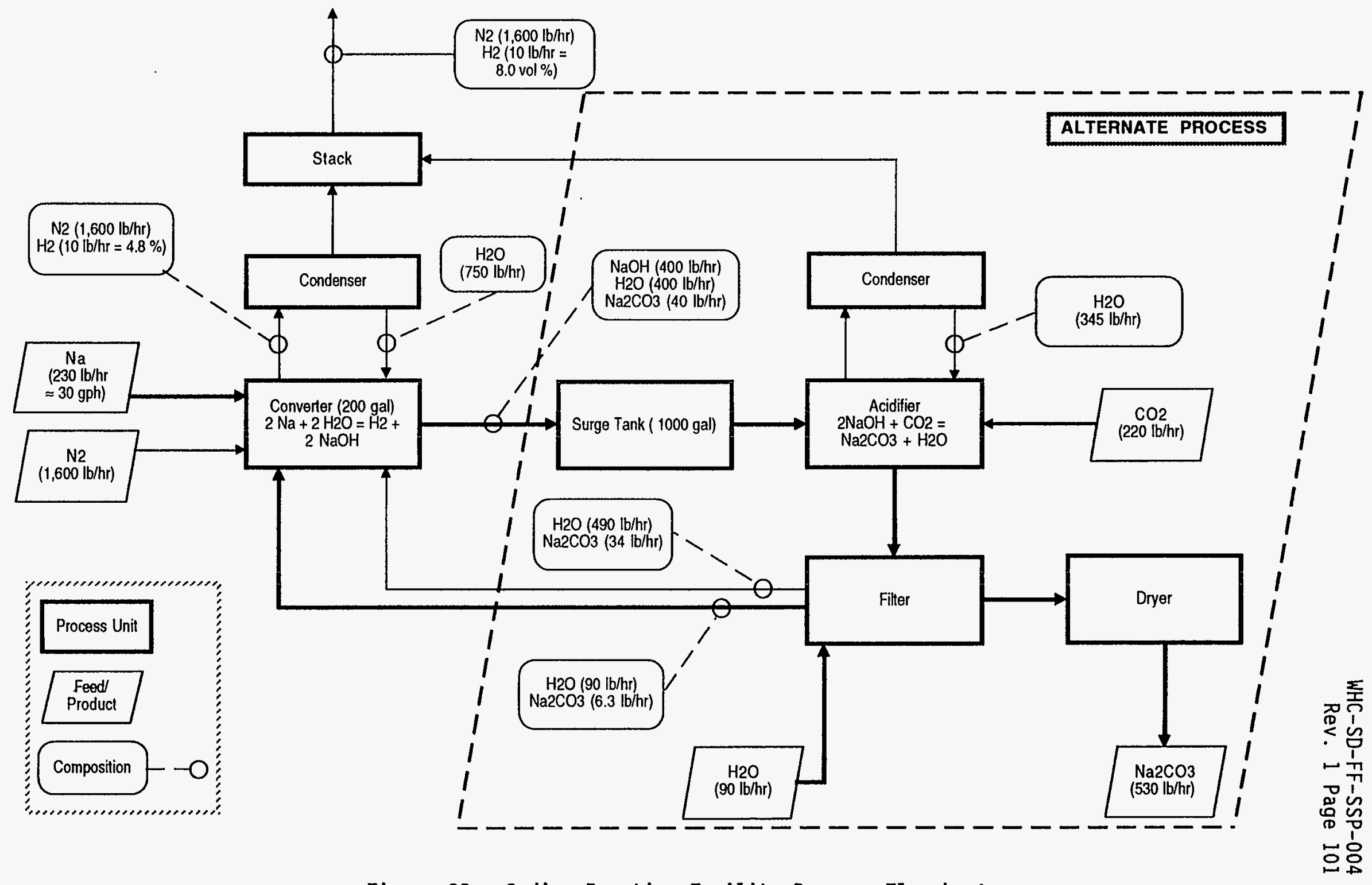

Figure 22. Sodium Reaction Facility Process Flowsheet 
compositions and concentrations of the major components. The radioisotope contaminants from the FFTF sodium are expected to be carried to the end product, e.g., hydroxide or carbonate, except for tritium. Some of the tritium will not remain with the product phase and will be exhausted through an appropriate vent system with in acceptable discharge concentrations. All of the FFTF sodium metal will be processed in two years with a plant efficiency of $70 \%$ at a throughput of 30 gallons/hour.

\subsubsection{Facility Description}

Detailed layout of the facility will await complete determination of the Argonne National Laboratory-West final design. The Idaho facility will be upgraded to produce sodium carbonate from its current sodium hydroxide capability. The general size, shape and location of the expected FFTF Sodium Reaction Facility building is shown in Figure 21 . Since the facility will have a relatively short lifetime, construction is expected to be as inexpensive as possible, consistent with safety and environmental requirements (See Section 9.4.5.7). In addition to the process equipment, storage for supplies, a control room and minimal maintenance space also would be needed. For the production of a solid product such as sodium carbonate or sodium sulfate, additional piping and vessels would be needed for the facility. Keeping the two buildings as separate sub-projects will allow minimum interference with the earlier construction of the Sodium Storage Facility. Delayed construction of the Sodium Reaction Facility will allow full process development and testing by the Argonne National Laboratory-Hest before final design of the Sodium Reaction Facility, and allow costs for the shutdown construction projects to be spread out over several years (see Section 9.8).

\subsubsection{Packaging and Transportation}

For the baseline case, the sodium hydroxide will be pumped into holding tanks located in or near the Sodium Reaction Facility building, adjacent to the chemical processing equipment. Two tanks, 50,300 gallons and 32,000 gallons, have been reserved from CTinch River Breeder Reactor Project surplus equipment for this purpose. The tanks will be located in the facility to preclude freezing of the hydroxide solution. This on-site storage capacity will allow the FFTF to continue production at times when the TWRS is not able to receive the sodium hydroxide. Transport of the product likely will be by tank truck.

For the production of a solid product, such as sodium sulfate or sodium tetraborate, equipment would be needed for packaging the solid powder into acceptable containers for transportation and disposal. This would include personnel and facility protection from dust and residual radioactivity as well as temporary storage of filled containers.

In both cases, the building must allow truck access for shipping the product, for materials delivery, and for emergency vehicles. 


\subsubsection{Environmental/Safety Requirements}

With the exception of those items discussed in Section 6.2 and Section 15.2.2, Item 4, a 11 required safety and environmental compliance regulations will be followed in the design and operation of the Sodium Reaction Facility. The total radioisotope content of the sodium in 1997 is expected to be:

\begin{tabular}{|c|c|}
\hline Isotope & Total Activity (Ci) \\
\hline $\mathrm{Na}-22$ & 120 \\
\hline $\begin{array}{l}\mathrm{Cs}-137 \\
\mathrm{Pu}-239 \\
\mathrm{H}-3\end{array}$ & $\begin{array}{l}0.06 \\
0.0008 \\
96\end{array}$ \\
\hline
\end{tabular}

Al1 radioisotopes except some of the tritium will be retained in the liquid (or solid) product phase. The tritium released will be less than the acceptable limits to insure the safety of the general public and Hanford workers. It is expected that measurements will be taken of the Argonne National Laboratory-West processing operation to confirm this. The radioactive components discharged from the process will be monitored to assure regulatory compliance. Likewise, any radiological or chemical contamination as well as radiation levels will be monitored for personnel safety.

\subsubsection{Alternative Processes}

The baseline process was selected based on its capability to process the FFTF, and possibly other sodium metal, for the lowest cost and in a timely, safe and environmentally compliant manner. The major support for this decision is the assumption that the process and plant will have been designed, tested and operated at Argonne National Laboratory-West prior to construction and operation at the FFTF. There may be other variations or processes that arise that will further reduce the cost or improve the product or reduce some risk for a comparable cost. Such possibilities will be examined.

The alternative of producing a solid product for land disposal has the primary disadvantage of incurring the added cost of land burial. Compounds produced from the FFTF sodium would be, as a minimum, low level radioactive waste. For sodium sulfate, the burial cost is currently estimated to be in the order of $\$ 10$ million in Fiscal Year 1998. Sodium carbonate, classed as hazardous material in the State of Washington, would become a mixed hazardous-low level radioactive waste with a much higher burial cost.

An additional process option that is being developed by Atomics International, in Canoga Park, California, uses molten sodium carbonate as the solvent.

Molten sodium and carbon dioxide are pumped into a chemical reactor containing molten sodium carbonate in the temperature range of $1250^{\circ} \mathrm{F}$ to $1800^{\circ} \mathrm{F}$.

Additional sodium carbonate is formed, cooled and prepared for packaging. The process has been used successfully for the treatment of aqueous and organic mixed waste. However, additional testing has been performed by Atomics International with sodium metal and a proposal based on this process has been 
offered by Atomics International to the United Kingdom for treatment of sodium at the Prototype Fast Reactor, which has recently been directed to shutdown. The process has the advantage that no sodium hydroxide (aqueous) phase is involved and that virtually all of the radioactive elements (except tritium) remain in the solid phase. The process does operate in a large ceramic vessel at high temperature. However, the process selection by the United Kingdom and further work by Atomics International may provide information for further consideration by FFTF. This process may be useful for the disposal of complex structures such as cold traps. As mentioned above, the resulting product would need to be disposed of as a mixed hazardous-low level radioactive waste.

In addition, inquiries will be made as to the experience and planning that may be available in other countries that have sodium cooled reactors. Other processes that may emerge will be reviewed to assure full coverage of alternate possibilities.

However, any such process must first show clear technical or cost advantages to be seriously considered. Such cost considerations must include the extra costs of process development and demonstration.

\subsubsection{Schedules}

The Tank Waste Remediation System milestone M-50-03 under the Tri-Party Agreement is due March 31, 1998, to confirm the adequacy of caustic leach as a process for treatment of TWRS tank sludge material. If the decision is to use sodium hydroxide, production processing will be at the nominal rate of 8 waste tanks per year starting in Fiscal Year 2004. However, sludge washing that uses the concentrated sodium hydroxide will not start before Fiscal Year 2008. If the decision is not to use sodium hydroxide, then the FFTF Sodium Reaction Facility process would be modified to produce a disposable sodium compound at a time to be determined.

FFTF personnel will follow the design, construction, testing and operation of the Argonne National Laboratory-West facility. For planning and schedule visibility purposes, the FFTF Transition Project Summary Schedule (Figure 1) calls for start of the Functional Design Criteria in JuTy 1998, Detailed Design (site specific application of the Argonne National Laboratory-West design), in February 2001, with construction starting in December 2001. However, detailed schedules for the Sodium Reaction Facility based upon TWRS need dates have not been formulated.

\subsubsection{Cost and Financing}

The estimated cost for the Sodium Reaction Facility is $\$ 23$ million dollars (escalated), assuming full conversion to sodium carbonate. However, utilizing an Argonne National Laboratory-West proven design to produce only sodium hydroxide, should significantly reduce this amount. Construction costs can be determined more closely when the final product form and schedule details are established. For planning purposes, estimates of Sodium Reaction Facility startup, operation and transition costs beyond Fiscal Year 2002 are an additional $\$ 13.5$ million in escalated dollars. 


\subsection{ASME CODE PRESSURE BOUNDARY AND SEISHIC INTEGRITY}

The American Society of Mechanical Engineers (ASME) Code pressure boundary and Seismic Category 1 integrity will be maintained on those plant systems and equipment which are required to perform fuel offload and maintain the sodium inventory. In essence, FFTF will become a fuel storage facility until fuel offload is complete and will retain the same pedigree as the existing Fuel Storage Facility and Interim Decay Storage, which are ASME Section III and Seismic Category 1.

Because the reactor has been shut down for an extended period there is no longer any significant radioactive gas species present. For this reason surveillance will no longer be required on a number of reactor cover gas containing components. For example, there is a group of ASME coded check valves known as "refueling check valves" which prevent reactor cover gas leakage in the event non-code inert gas supply lines are damaged. These gas pressure boundary components will no longer be tested and maintained to the code and may be removed. In addition, hardware inserted through the reactor head/cover gas space in support of sodium drain activities (e.g., immersion heaters and level probes) will not be designed to ASME Section III requirements. Gas system components, such as relief valves, which are important to the sodium pressure boundary will be maintained to code requirements until the sodium is drained.

Prior to September 1994, the Technical Specifications contained requirements for leak testing the code boundaries for the Heat Transport System reactor head and the reactor containment building. In September 1994, these requirements were deleted in conjunction with the Technical Specifications Reduction Project (see Section 10.3), since the plant configuration and conditions were such that no credible event could affect public health and safety. Although the leak testing requirements are no longer in effect, the reactor containment building must still meet the requirement of a two hour rated fire barrier.

Appropriate limited portions of the Surveillance and Inservice Inspection program will be continued until sodium drain utilizing the FFTF Surveillance and Inservice Inspection Program PTan (WHC-SD-FF-SISI-006). This document provides the guidelines of ASME Section XI, Division 3 Rules for Inservice Inspection and Testing of Liquid Metal Cooled Plants. The program requirements will be reduced to surveillance of the Heat Transport System via leak detection (reactor vessel/sodium tank level sensors and contact detectors) and smoke detectors. Deferral of surveillances such as visual inspections of primary piping welds to Intermediate Heat Exchanger and pump nozzles, reactor support arm welds, and on-line aerosol leak detection (virtuaily no aerosols are generated at the refueling temperature of $400^{\circ} \mathrm{F}$ ) is permitted by ASME Section XI, Division 3, Section IMA-2400(C), as stated below:

"For plants that are out of service continuously for 6 months or more, the inspection interval during which the outage occurred may be extended for a period equivalent to the outage." 
Additional support for deferral of the surveillances discussed herein is found in the fact that no weld anomalies (cracks or defects) have been found in weld inspections during surveillances over the ten years of FFTF operation (Apri] 1982 - April 1992). Primary piping surveillances were completed for a11 three Heat Transport System 7oops in December 1993. Only minimal snubber movements have been observed throughout the surveillances conducted over the ten year surveillance period indicating piping geometry has been maintained.

Only a limited number of Seismic 1/Active Heat Transport System boundary valves will continue to be tested. Overpressure protection of the Heat Transport System boundary will be assured by continued testing of the cover gas pressure relief valves. Seismic integrity will be maintained by continuing the existing snubber surveillance program until sodium is drained.

During the transition period through fuel offload from the reactor, modifications and repairs to the sodium boundary will continue to be controlled via ASME Section XI Repair Programs, involving DOE and an authorized third party nuclear inspector, to assure that the ASME code boundary integrity is maintained. Subsequent modifications and repairs categorized as temporary for assisting in the drain process, shall be per approved work packages typically used for Safety Class 2 non-nuclear ANSI B31.1 piping systems. Safety Class 2 is the highest classification applied to the approved design of the Sodium Storage Facility which will receive all 260,000 gallons of FFTF and Fuel Storage Facility sodium. The approved design and safety classification are documented in the Conceptual Design Report (Reference 24) and the Preliminary Safety Evaluation (Reference 25).

Upon completion of the sodium drain, ASME Heat Transport System pressure boundary and Seismic 1 integrity surveillance will cease. Long term storage of the systems/components will utilize a dry inert nitrogen cover gas blanket in order to minimize reaction of the residual sodium.

\subsection{GENERAL PLANT SUPPORT/SYSTEM SHUTDOWN}

The level of general plant support for the FFTF during the first four years of transition will be comparable to that required for hot standby. This is because approximately $90 \%$ of the plant systems are required to support hot sodium circulation prior to sodium draining. Some reduction will result from the planned early drain of the secondary sodium systems. As systems become available for shutdown, there will be a corresponding reduction in the need for general maintenance and plant support. The required level of support will be minimal after sodium drain and cooldown to ambient temperature.

Essentially all of the plant systems will be deactivated. Actual facility support will be limited to minimal maintenance, inert gas system positive pressure checks, and facility walkdowns. Similar monitoring will be required for the Sodium Storage Facility up to the time it is drained and the sodium is processed through the Sodium Reaction Facility. Fire detection will be required in the Sodium Storage Facility and Sodium Reaction Facility where storage of sodium and processing will be centralized. Facility support will also be required for cleanup of the sodium residuals in the Sodium Storage Facility and Sodium Reaction Facility. 
As the level of required support decreases, the displaced resources will then be available to assist in configuring the plant for turnover to the Environmental Restoration Contractor. The staffing level during this period is identified in the Resource Loaded Schedule (Reference 1).

\subsection{SURVEILLANCE AND MAINTENANCE AFTER TURNOVER}

A two phase turnover to the Environmental Restoration Contractor is anticipated. The first phase will occur when the FFTF final transition state has been achieved. The second phase would constitute turnover of the sodium storage and reaction facilities after the sodium has been converted and these facilities have been $\mathrm{placed}$ in an appropriate deactivated state.

Resources required to support Surveillance and Maintenance activities are expected to be sma11. Onty minimal amounts of equipment are expected to be operational within the FFTF Plant (e.g., lighting, inert gas capability, and occasional air circulation fans). The FFTF complex will be designated as a Property Protection Area (with fuel stored at the Interim Storage Area) and appropriate Safeguards and Security resources will be required (see Section 14.0).

During the transition phase the FFTF staff will prepare a Surveillance and Maintenance $\mathrm{Pl}$ an for the transitioned facility as required by Tri-Party Agreement negotiated milestones (Reference 13) and by the EM-40 Draft Guidance (Reference 22) to be carried out by the Environmental Restoration Contractor. The configuration of the facility will be as stated in the Transition End-Point Criteria Document. The Surveillance and Maintenance Plan will address the following areas:

- Facility Operations

- Facility Maintenance

- Quality Assurance

- Radiological Controls

- Hazardous Material Protection

- Health and Safety/Emergency Preparedness

- Safeguards and Security

- Cost and Schedule

\subsection{SHUTDOWN CONSTRUCTION MODIFICATIONS}

Significant plant modifications will be required for the FFTF transition phase. These construction projects, preliminary cost estimates, and references to other sections in the Plan for related work scope details are summarized in Table 6 below. The total estimated cost is $\$ 37.7$ million 
(escalated dollars). The DOE Project Management System (DOE Order 4700.1) entails funding authorization before Title I design can be initiated. If authorization to begin the design and construction of the Sodium Storage Facility is delayed, a cost penalty will be incurred as discussed in Section 9.4.4. If funding for construction of the Interim Storage Area is not authorized, fuel washing and transfer of the reactor fuel to the Interim Storage Casks for transfer to the Interim Storage Area also will be delayed.

TABLE 6

Shutdown Construction Projects

Sub-Projects

Interim Storage Area (Section 9.3.4)

Sodium Storage Facility (Section 9.4.4)

PFP Modifications (Section 9.2.3)

Sodium Reaction Facility (Section 9.4.5)

TOTAL

\begin{tabular}{ll}
$\begin{array}{l}\text { Estimated } \\
\text { Cost }\end{array}$ & $\begin{array}{l}\text { Estimated } \\
\text { Completion }\end{array}$ \\
\hline
\end{tabular}

$\$ 0.2 M$

June 27, 1995

$10.4 M$

January 30, 1997

4.OM

April 3, 1998

$\underline{23.1 M}$

September 16, 2002

$\$ 37.7 \mathrm{M}$

\subsection{CLINCH RIVER BREEDER REACTOR PROJECT MATERIAL}

Following the demise of the $\mathrm{Cl}$ inch River Breeder Reactor Project, WHC assumed the responsibility for storage and maintenance of associated equipment and materials that had been procured. Over the years, potential uses were identified for some of the equipment and material. Where no potential use could be identified, the hardware was declared "excess" and sold at a public auction in Apri1, 1990. Due to access problems, some of the large excess hardware stored in an outside laydown yard near the 300 Area were not sold at that time.

WHC received direction from $\mathrm{RL}$ in Reference 28 to proceed with the sale of the remaining $C l$ inch River Breeder Reactor Project hardware, except for the equipment required to support cold standby or shutdown of the FFTF, i.e., onsite sodium storage. This action would also eliminate storage costs of approximately $\$ 200,000$ per year. Subsequently, a temporary "hold" of three to six months was placed on initiating the sale so that the new DOE administration could complete its re-evaluation of potential FFTF missions. Once the shutdown directive was received, most of the Clinch River Breeder Reactor Project hardware (with the exception of the tanks discussed in Section 9.4.4) was designated as excess. Sale of the steam generator material, which had been stored in Pensacola, Florida, was accomplished on April 9, 1994. This sale grossed $\$ 425,122$. Most of the locally stored material was sold on October 27, 1994. Sale of the remaining items is expected to occur later this fiscal year. 


\subsection{MAINTENANCE AND STORAGE FACILITY}

The Maintenance and Storage Facility is located in the 400 Area approximately 500 feet north of the FFTF complex and west of the railroad track serving the FFTF Containment Building. It was designed as a multipurpose service center to support the specialized maintenance and storage requirements of the 400 Area facilities. It is also being used to support equipment modification and assembly, testing, and training for the 200 Area Tank Farms. The Maintenance and Storage Facility will also continue to provide maintenance services for the FFTF during the transition phase.

Current plans for the Maintenance and Storage Facility include support of several long term commitments to the Tank Waste Remediation System organization. No other suitable facility at Hanford is available to provide this support. Operation of the Maintenance and Storage Facility will continue independent of the FFTF shutdown. 


\subsection{ADMINISTRATIVE CONTROLS}

\subsection{TRANSITION PROJECT PLAN}

The primary objective of the $\mathrm{Plan}$ is to provide the logic/approach and project baseline for the transition of FFTF and related facilities to a condition suitable for turnover to the Environmental Restoration Contractor in a cost effective and quality manner while ensuring safety, security, and environmental compliance. The Plan forms the bases for the Resource Loaded Schedule (Reference 1). This Plan is a living document that will be updated as the FFTF transition progresses. Technical issues and uncertainties associated with the transition that will require resolution are identified in Section 15. The portions of the Plan addressing workscope, cost and schedule, and resolution of these technical issues will continue to be revised as the detailed supporting documentation is developed.

\subsection{FINAL SAFETY ANALYSIS REPORT}

The FFTF Final Safety Analysis Report provides the safety basis for operation of the facility. During transition, new operations and conditions being performed must be reviewed to demonstrate conformance with applicable statutes, Federal rules, and DOE directives. In addition, DOE Order 5480.21 (Unreviewed Safety Questions) requires that changes to the operating envelope be evaluated for compliance with the existing Final Safety Analys is Report and where the proposed changes would deviate from the conditions and analyses described in the Final Safety Analysis Report, appropriate revisions must be prepared and submitted for RL approval.

During the transition, some new equipment, operations, and facilities will be put in place. Examples include:

- Sodium offload activities.

- Storage and reaction of bulk sodium.

- Management of sodium residuals.

- Defueting.

- Fuel offload to interim dry storage.

- Shutdown of auxiliary support systems.

The type of safety analyses/Safety Analysis Report for new facilities will depend on the requirements of DOE Order 5480.23 for the Hazard Category of each facility. Although it is currently expected that the safety analysis reports for the Sodium Storage Facility, Sodium Reaction Facility and the Interim Storage Area will be stand-alone (separate from FFTF), the final decision will be based on current order requirements, safety and cost effectiveness. 
In September, 1994, a major revision to the FFTF Technical Specifications was approved (see Section 10.3 below). Rather than making numerous changes throughout the body of the Final Safety Analysis Report, a new Appendix G, "FFTF Operation during the Transition to Shutdown," was provided as an attachment to the Fina] Safety Analysis Report. This new appendix provided:

- The overall safety bases for the FFTF during transition.

- The specific bases for all Limiting Conditions for Operation that were retained and changed in the Technical Specifications.

- The justification for all Limiting Conditions for Operation that were deleted in this revision.

For the Unreviewed Safety Question process, Appendix $G$ is to be used in conjunction with the body of the FSAR. While the body of the FSAR might still state that a system function is important to safety, Appendix G might provide updated information that the function no longer has a safety purpose.

Although Appendix $G$ is now limited to Technical Specification related information, its scope may be expanded in the future. Such information as Safety Class and seismic reductions, system code reclassification or system deactivations could be consolidated in Appendix G.

\subsection{TECHNICAL SPECIFICATIONS}

Immediately after receipt of the Shutdown Order, a Technical Specification Reduction Project was initiated. The purpose was to provide an accurate, up-to-date safety analysis, then to pare down the Technical Specification requirements based on the new analyses. The goal was to end up with a set of Technical Specifications that were all necessary for the current plant conditions, were all mutually consistent and were developed for deactivation rather for reactor operation.

The Technical Specification Reduction Package was transmitted to DOE for approval in May, 1994. This package deleted $79 \%$ of the existing Technical Specification sections and modified an additional 15\%. DOE approved the changes on September 7, 1994. Because the operator training and operating procedure changes were accomplished in parallel with the DOE reviews, the Technical Specification change was implemented in the plant on September 14, 1994.

As a result of the Technical Specification Reduction Project, deactivation will proceed with:

- the operators having an accurate description of the systems and parameters that are still important to safety,

- system and component deactivations not being held up by out of date Technical Specifications requiring their operability and 
- periodic Technical Specification surveillance being minimized based on actual safety requirements.

The Technical Specification Reduction Project not only deleted unnecessary Technical Specifications, but verified that all remaining specifications would automatically become not applicable based on stated plant conditions.

The savings from the Technical Specification Reduction Project have not yet been quantified. However, these savings will constitute a multi-year productivity improvement and will be defined later this Fiscal Year.

\subsection{CRITICALITY SPECIFICATIONS}

Chapter 20 of the Final Safety Analysis Report contains the FFTF Criticality Specifications. Several activities which will be conducted during the transition phase will require changes or additions to these specifications, including:

- Fuel handling at the Solid Waste Transfer Pit and Reactor Service Building Cask Loading Station utilizing the Core Component Containers. Note: The Solid Waste Transfer Pit provides backup flexibility in the fuel offload process.

- Fuel washing in the Interim Examination and Maintenance Cell using the Core Component Containers for transfer.

- Interim Storage Cask fuel storage in the Interim Storage Area.

\subsection{READINESS ASSESSMENTS}

The Plan will be structured to provide Operational Readiness Reviews and/or Readiness Assessments in conformance with DOE Order 5480.31 and WHC guidance. Present policy guidance requires Operational Readiness Reviews or Readiness Assessments the rigor of which are "commensurate with the facilities potential impact on safety, environmental compliance, safeguards and security, and its programmatic importance." The transition phase will involve several major transition activities each of which is judged to require a Readiness

Assessment. These activities are:

- Washing, transfer and storage of fuel at FFTF

- Storage of unirradiated fuel at the Plutonium Finishing Plant

- Draining of sodium to the Sodium Storage Facility

- Startup of the Sodium Reaction Facility

These Readiness Assessments will be initiated sufficiently in advance of need dates to allow for completion without compromising the need dates. Further estimates will be provided and the schedule will be updated as experience with DOE Order 5480.31 is gained. 
In addition to this formal process, additional internal reviews of upcoming operations may be performed using a less formal FFTF Readiness Review process to assure that readiness is complete.

\subsection{STANDARDS/REQUIREMENTS IDENTIFICATION DOCUMENT}

Defense Nuclear Facility Safety Board's recommendation 90-2 suggested that DOE, its Contractors, and the Laboratories should identify adequate standards and requirements to provide protection of the environment and the health and safety of workers and the public for each DOE facility and site. RL directed implementation of this recommendation by all Hanford Facilities.

Phase 1 of this task requires that a Standards/Requirements Identification Document (S/RIDS) be prepared. To aid in drafting S/RIDS, FFTF will utilize a private contractor, experienced in performance of this task. The contractor, with considerable guidance from FFTF personnel, will generate the original S/RIDS. After approval of the S/RIDS, FFTF personnel will perform an assessment of implementing procedures/documentation to ensure that programs are in place to implement the S/RIDS. Phase 1 is expected to be complete in Fiscal Year 1995.

Phase 2 of the S/RIDS assessment is the "Adherence Based" phase. It consists of a continuous process where assessments of compliance with the S/RIDS identified in Phase 1 are performed by FFTF Personnel. These self assessments will be periodically performed in each S/RIDS area, such that all areas will be assessed with a nominal 3 year frequency. This phase will begin in Fiscal Year 1996. 


\subsection{PUBLIC INVOLVEMENT}

The successful transition to a deactivated state will depend on acceptance by the organizations and groups who can impact the decision making process. Impacts can result from existing DOE and WHC organizations, legislators, and public interest groups. A fundamental expectation of the Transition Project is to involve stakeholders early in the transition planning phase.

FFTF is one of several transition facilities at Hanford. Although each facility is unique, many of the deactivation steps are common. Public input from deactivating other facilities is a valuable resource to the FFTF team. As transition planning continues, information about FFTF, its current status and other pertinent facts related to the facility will be widely shared. Stakeholders will be apprised of upcoming activities outlined in the Plan allowing the earliest opportunity to raise concerns and issues.

DOE and WHC will work with stakeholders to develop the best ways to reach decisions and resolve issues as they are identified. This will include sharing information on the deactivation alternatives, end point objectives, constraints, costs and associated timetables. Input from stakeholders will be used as alternatives are evaluated, selected and implemented. The interrelationship of how FFTF deactivation decisions relate to other decisions being made on site will be addressed.

People who are interested in decisions at Hanford vary from project to project. For the FFTF Transition Project, potential stakeholders include those who have supported FFTF and its products; interested and environmental groups concerned about the disposal of radioactive and hazardous materials at Hanford; and Tocal government and economic interest groups.

Specific actions that were taken or will be pursued are:

- Hold small group meetings with interested stakeholders to familiarize them with the FFTF Plant, its history and unique features, and to briefly outline the aims of the Plan. These meetings will enable DOE and WHC to receive early feedback from the stakeholders.

- Participate in the Hanford Site deactivation workshops with stakeholders on the Plutonium Finishing Plant and the Plutonium Uranium Extraction Plant. Consider applicability of concerns/issues and resolution thereof for the FFTF deactivation process.

- Provide copies of the PIan to interested stakeholders and the public for early review and comment. Factor input into studies and selection of options for addressing resolution of specific issues and performance of activities.

- Receive early review and feedback by the Hanford Advisory Board. The charter of the Board is to serve as an independent, non-partisan body to provide informed recommendations and advice to the Tri-Party agencies on major policy issues related to Hanford cleanup. The Hanford Advisory Board has been briefed on the FFTF Transition Project. 
WHC-SD-FF-SSP-004

Rev. I Page 115

This page intentionally left blank. 
WHC-SD-FF-SSP-004

Rev. I Page 116

\subsection{FFTF FUEL SUPPLY}

\subsection{INTRODUCTION}

The major facilities historically associated with FFTF fuels development, fabrication and inspection are the Fuels Development Laboratory (308 Building) and the Fuels and Materials Examination Facility. Although the Fuels and Materials Examination Facility was reconfigured several times to be responsive to several different fuel supply scenarios, the facility has never been operated, and is therefore not radioactively contaminated. Several other 300 Area facilities, principally 306 Building and 3715 Warehouse, have had significant roles in the FFTF fuel supply. The following shutdown planning discussion will address each of these facilities.

FFTF fue 1 in the form of 24 finished unirradiated assemblies and several thousand individual unirradiated fuel pins are stored in a vault at the Plutonium Finishing Plant. No attempt has been made to address the final disposition of these fuel rods and assemblies. It will be a significant task and the subject of future planning.

\subsection{BUILDING SHUTDOWN}

Shutdown of the 308 Building was directed and planned prior to the FFTF standby directive. The impetus for the shutdown was the previous direction to cease fuel fabrication operations in the building, i.e., move to the Fuels and Materials Examination Facility, combined with aggressive efforts to minimize security costs. Shutdown of the 308 Building is progressing well. It is documented by the 308 Building Shutdown PTan, WHC-SD-FL-SSP-001. The scope of the plan addresses the 308 Building and immediately surrounding structures and the 306 Building $\mathrm{UO}_{2}$ labs. Areas directly associated with the 308 Building and its equipment and materials but not included in the plan are the 3715 Warehouse, Room 173 of the 306 Building, and equipment stored at Umatilla. These areas and associated materials and equipment can now be dispositioned due to the FFTF shutdown order. Efforts to remove the equipment and materials for reallocation to other users or excess was recently completed. Room 173 contained primarily assembly and inspection equipment and fabricated components such as cladding or ducts. The 3715 Warehouse housed steel, (e.g., billets), and the Umatilla storage included equipment removed from 308 Building during shutdown that was retained for potential FFTF fuel supply application at the Fuels and Materials Examination Facility.

The 308 Building has two main areas. The original section of the facility contains the gloveboxes and hoods associated with the mixed oxide fuel development and test fabrication. The Annex includes a TRIGA reactor utilized primarily for neutron radiography. The fuel fabrication portion of the facility has been deactivated. All nuclear materials used in the fuel fabrication process have been removed from the building with the exception of relatively small amounts of residual plutonium oxide held up in the gloveboxes and associated exhaust ducting. Decontamination has reduced the material retained in gloveboxes and enclosures to a total of less than 400 grams of 
plutonium. Approximately 20 grams of material remain in the 2100 linear feet of glovebox ventilation exhaust ducting. Contamination in the gloveboxes has been stabilized with a fixative coating. No ventilation systems are operational.

The reactor is currently shut down and fuel has been placed within storage racks in the reactor water pool in preparation for eventual fuel removal. The downloaded TRIGA reactor has been designated as a fuel storage basin and is being monitored under the RL approved shutdown plan and Interim Safety Basis Document. The ultimate disposition of the fuel is uncertain at this time but several options are being considered, including 400 Area storage. Removal of the TRIGA fuel is scheduled for completion in early 1996 with complete shutdown of the 308 Building by July 1996. Preparation of a decontamination and decommissioning file is in progress to allow transfer of the entire 308 Building complex to the decontamination and decommissioning contractor in the July 1996 time period.

Cleanup efforts in the $306 \mathrm{UO}_{2}$ lab continues on schedule for a December 1994 completion. The laboratories will be returned to the 306 landlord upon completion.

\subsection{FUELS AND MATERIALS EXAMINATION FACILITY}

A transition to other primary sponsors was made at the end of Fiscal Year 1994.

The facility will be funded from rental space proceeds and overheads if necessary. A near-term decision on use of the Fuels and Materials Examination Facility to support an expedited K-Basin spent fuel response is expected in early 1995. The plutonium disposition community has shown renewed interest in the facility as well. 


\subsection{DATA PRESERVATION}

Consistent with the intent of DOE Order 1430.1C, "Management of Scientific and Technical Information," technology information related to the performance of the FFTF fuel and plant will be archived. The approach will be to store information currently in document form on compact disks. A limited effort will be undertaken to categorize stored information in order to facilitate retrieval at some future date. It should be noted, however, that the archiving effort will focus on storage rather than ease of retrieval. The cost of this program is estimated to be $\$ 300,000$ and the duration of the program is approximately two years. 
WHC-SD-FF-SSP-004

Rev. 1 Page 119

This page intentionally left blank. 


\subsection{SAFEGUARDS AND SECURITY}

During the transition activities, a continuing emphasis will be to reduce security costs as much as possibie. A proposal to downsize the existing FFTF Protected Area to the top of the Interim Decay Storage vessel located inside the Reactor Containment Building was approved by DOE and implemented on May 2, 1994. The associated annual savings of approximately $\$ 4$ million are reflected in the cost profiles provided in this Plan. When all the FFTF fuel has been removed from within the plant, there will be another substantial cost reduction in the Safeguards and Security budget. Disposition of the FFTF fuel is discussed in Section 9.2.1 through 9.2.4.

In the area of safeguards, a DOE Order deviation was approved (Reference 29) which reduces inventory frequency and saves approximate $7 y \$ 134,000$ over the next three year fuel offload work schedule. This innovative approach and resulting savings constitute a productivity improvement that will be realized in Fiscal Year 1995 through 1997. 
This page intentionally left blank. 


\subsection{KEY ASSUMPTIONS/ISSUES AND ACTION ITEMS}

\subsection{KEY ASSUMPTIONS}

The following assumptions were made in developing the Plan. Assumptions that have become reality are noted.

1. DOE will fully support the Transition Project by providing required funding and timely reviews of appropriate documentation. Any funding shortfalls will create schedule slippages and higher total costs.

2. Funding will be authorized to perform necessary plant construction modifications without constraining schedules.

3. DOE will actively pursue National Environmental Policy Act approval such that the schedule will not be adversely impacted. DOE-HQ has transferred approval authority to RL, which will speed up the approval process.

4. Assemblies that caused a delayed neutron monitor signal will be processed during the first two years of the shutdown schedule, while the Interim Examination and Maintenance Cell is being prepared to support fuel offload washing.

5. Irradiated non-fuel core components, e.g., reflectors and control rods, will be transferred to the reactor and in-vessel storage. Defueling is in progress utilizing these non-fuel core components.

6. Containment integrity will not be required during fuel offload handling operation due to low fuel decay heat and iodine inventory. The containment integrity requirements have been removed from FFTF Technical Specifications.

7. The Maintenance and Storage Facility will remain available to support other Hanford missions and is therefore excluded from shutdown consideration.

8. Experienced staff will be available as needed throughout the transition to shutdown to support the schedule. While this assumption may be unrealistic, it is impossible to reliably forecast the volatility of the experience and availability of staff and the associated impact on shutdown cost and schedule.

9. Electrical transformer polychlorinated biphenyl cooling oils will be dispositioned.

10. Other Nuclear Energy materials and facilities on the Hanford Site are not addressed in this plan. Those facilities are undergoing remediation under the auspices of the Nuclear Energy Legacy Program. 
11. The Sodium Storage Facility and Sodium Reaction Facility will be designed to appropriate Resource Conservation and Recovery Act requirements, as identified in Section 6.2.

12. The Readiness Assessment process will not compromise the transition schedule, as discussed in Section 10.5.

13. The Interim Examination and Maintenance Cell ion exchange system installation (Section 9.3.1) will be in place to support the fuel washing schedule.

14. Delivery of the Interim Storage Casks and Core Component Containers will arrive to support initiation of fuel washing activities in October, 1995.

15. Fire protection requirements are partly dictated by the Maximum Possible Fire Loss and programmatic value of the facility. WHC has assumed the facility has no programmatic value and book replacement values will be zeroed by the time of turnover to the Environmental Restoration Contractor. Therefore, fire protection will be minimized at the time of turnover commensurate with fire protection requirements for $D \& D$ facilities.

16. The Technical Specification Reduction package and the Final Safety Analysis Report Appendix have been approved.

17. Implementation of Price Anderson Amendments Act requirements will not affect cost or schedule.

18. Facilities at the Plutonium Finishing Plant will be available for Category IC unirradiated fuel.

\subsection{ISSUES AND ACTION ITEMS}

Revision 0 of the Plan (Reference 7) contained thirty-seven issues and action items. To date, a number have been completed. The completed issues and action items are listed in Section 15.2.1, while the issues and action items still open or ongoing are listed in Section 15.2.2.

\subsubsection{COMPLETED ISSUES/ACTION ITEMS}

1. Conduct a Systems Engineering approach for determining the final sodium disposition. This should include investigating potential future uses, either commercial or at Hanford, for the sodium or its proposed byproducts (i.e., sodium hydroxide, sodium nitrate, sodium carbonate, etc.). [The Project baseline is to convert sodium to sodium hydroxide for use by THRS.]

2. Evaluate Nitrogen Blower Heater Unit ability to provide sufficient/reliable heat to prevent reactor vessel sodium freeze during drain operations. [Evaluations have confirmed this ability. However, 
as described in Section 9.4.2, immersion heaters will be installed in the reactor vessel as the primary source of heat. The Nitrogen Blower Heater Unit will provide a backup heat source until the final stage of draining, at which point it will be the only source.]

3. Verify if the Clinch River Breeder Reactor Project tanks in the Sodium Storage Facility can withstand a vacuum during sodium offload. [Evaluations have verified vacuum capability.]

4. Develop specific turnover criteria including resolution of the residual sodium issue with the Environmental Restoration Contractor, including potential molten sodium residuals in the reactor vessel. [The issue of residuals has been resolved, although specific criteria are to be developed (see Section 7.0).]

5. Conduct a detailed evaluation of the technical viability for offloading sodium directly to the Sodium Reaction Facility (with interim use of plant storage tanks as appropriate). [Evaluation completed and option not considered viable, see Section 9.4.1.]

6. Determine shielding requirements, if any, for the Sodium Storage Facility. [Conceptual Design Report includes these requirements.]

7. A Cultural Resource Review will be made (by Pacific Northwest Laboratories) prior to initiating any potential surface-disturbing activities on-site, or potential modifications for facilities with potential for inclusion in the National Historical Register. [Review has been completed, see Section 6.2.]

8. Confirm by structural analysis the acceptability of the primary system to sustain adequate gas pressure for direct sodium transfer. [Issue is no longer applicable, since sodium will be transferred to $T-43$, rather than directly to the Sodium Storage Facility.]

9. Evaluate possibility of transfer of Sodium Reactor Experiment sodium into either the Hallam tanks or an FFTF sodium storage vessel. [Issue is no longer applicable, since neither the Sodium Reactor Experiment sodium nor the Hallam sodium will be stored at FFTF.]

10. An evaluation by the FFTF Plant and the Environmental Restoration Contractor based on value engineering principles will be made to address the key issue of whether the sodium residuals remain in the plant at the time of turnover to the Environmental Restoration Contractor (Section 9.4.3.3.). This will require interaction and guidance from DOE-HQ (EM40 and EM-60). [Issue resolved. Sodium residuals wil] be retained in the Plant.]

11. A request will be made for expressions of interest from the private sector for alternate sodium reaction processes. [Eight responses received from solicitation in the Commerce Business Dai]y.] 
12. Examine variations on the sodium reaction process for potential cost reduction, product improvement or risk reduction. [The Project baseline is to convert sodium to sodium hydroxide for use by TWRS.]

\subsubsection{OPEN OR ONGOING ISSUES/ACTION ITEMS}

1. Resolve Uniform Fire Code and Uniform Building Code issues for the Sodium Storage Facility (see Section 6.2.2.1 (4)). [Letter submitted to Ecology requesting approval of proposed approach.]

2. Identify acceptable methods for cleaning sodium residuals from the Sodium Storage Facility and Sodium Reaction Facility (i.e., tankage and piping).

3. If sodium residuals are retained, confirm the method for accommodation (i.e., passivation or inerting). [Project baseline entails inerting with nitrogen.]

4. Resolve Uniform Fire Code and Uniform Building Code issues for the Sodium Reaction Facility.

5. Determine shielding requirements for the Sodium Reaction Facility.

6. During the detailed planning and design activity for the primary system drain, an evaluation will be required to determine the preferred method of access.

7. Determine which organization will assume responsibility for the fuel stored at the Interim Storage Area after turnover of the plant to the Environmental Restoration Contractor.

8. Evaluate the condition of the Clinch River Breeder Reactor Project tanks (internal corrosion/contamination), removal of unnecessary internals, cleanup and logistics for transfer to the Sodium Storage Facility.

9. Identify cross-connect locations and techniques for flushing the NaK systems with sodium.

10. Conduct a Fire Hazards Analysis in accordance with DOE Order 5480.7A.

11. A Deviation to appropriate DOE Orders will be submitted that addresses storage of irradiated fuel material outside a Protected Area.

12. Investigate the experience and planning of foreign and domestic liquid metal reactors expected to undergo shutdown and/or decontamination and decommissioning.

13. During transition activities, plant conditions will change, and the applicability of a number of the DOE Orders will be affected. An assessment of the current Orders will be conducted as a Transition Project activity. 
14. Perform an analysis to determine if there will be any expected increase in the potential for radionuclide emissions as a result of planned activities.

15. Perform an analysis to determine if any new and/or modified sources of radionuclide emissions will be subject to a preconstruction review and approval by the State of Washington Department of Health.

16. The Combined Exhaust (registration \#141-001) will need to be reviewed to determine if a modification is necessary for State of Washington Department of Health registration. The point of exhaust(s) for the Sodium Storage Facility and the Sodium Reaction Facility will 1ikewise require evaluation and possibly registration.

17. An analysis will need to be performed to determine whether any Toxic Air Pollutants are present in any proposed new points of exhaust(s)/emission for the Sodium Reaction Facility.

18. Determine the radionuclide inventory in the facility while knowledgeable staff and computer models are still available. These inventories will be needed prior to decommissioning to establish handling and shielding requirements and disposal methods.

19. Document fueled assembly as-built isotopic masses and irradiation histories so that the material nuclide inventories can be determined at any time in the future. That information is important for material surveillance, handling and shielding requirements, and to determine the ultimate disposition of this material.

20. Confirm from a criticality standpoint that disassembly of special fuel can be performed in paraliel with fuel offload sodium removal activities.

21. The DOE T-3 Cask Ticense will be revised to increase the amount of sodium allowed per shipment.

22. The requirements wil1 be defined for the Safety Assessment document as required by DOE Order 5480.6, paragraph $8 . J$ ("The facility shall be radiologically characterized and a Safety Assessment conducted regarding the existence of hazardous or radioactive material and nuclear fuel"). (These requirements are needed at the time of turnover to the Environmental Restoration Contractor.)

23. Pin containers for the disassembled sodium bonded test assemblies must be designed and fabricated (See Section 9.2.4.2).

24. A criticality safety evaluation report will be prepared for the Interim Storage Area to identify controls and conditions that must be maintained during the post deactivation surveillance period. 
25. Notify the Recycle Programs Office prior to draining process fluids and lubricating oils to find buyers both on and off the Hanford site. Perform a study to determine the most efficient drain methods for these fluids.

26. Categorize technology information related to FFTF fuel and plant performance (see Section 13.0).

27. This Plan is based on funding targets provided for the Fiscal Year 1995 Multi-Year Program Plan. Any reductions in these budget target values will extend the shutdown period and significantly increase the overall cost of shutdown. The Transition Project will re-evaluate these impacts based on future funding guidance.

28. Evaluate relocation of the gas bottle storage area adjacent to the Interim Storage Area to preclude potential accident hazards. The evaluation will also assess any impacts due to radiological dose rate at the gas bottle storage area resulting from its close proximity to the Interim Storage Area.

29. A criticality safety evaluation report will be prepared to assess if seven fueled components (assemblies and pin containers) can be placed in a Core Component Container and hence into an Interim Storage Cask.

30. Evaluate the potential impact on the Interim Examination and Maintenance Cell fuel washing operations of cutting fuel assembly nozzles to support the alternate 7-pack core component container loading configuration.

31. Conduct an historical evaluation of the FFTF in compliance with the National Historic Preservation Act of 1966. 


\subsection{CLOSEOUT OF MISSION DEVELOPMENT ACTIVITIES}

Orderly close-out of the mission development activities began at the time the FFTF shutdown order was received, and all activities are now closed out. The processing and sale of radioisotopes made in MOTA-2B during the final FFTF irradiation cycle in 1992 was completed August 1, 1994. The radioisotopes that were not sold have been transferred to the jurisdiction of the WHC Isotope Program Office.

During the operation of FFTF, experimental assemblies designed by the Power Reactor and Nuclear Fuel Development Corporation of Japan (PNC) were irradiated in the FFTF under the terms of a Specific Memorandum of Agreement between DOE and PNC. Assemblies and pins from these irradiation tests have been stored at the FFTF awaiting a decision by DOE-HQ on the future actions to be taken under the Specific Memorandum of Agreement. Negotiations on the course of these future actions have been held, with no final decisions made. At present, it is envisioned that the only involvement of FFTF in completing this Agreement will be retrieval of fuel pins and sectioning of ducts from assembilies. These operations will be conducted in the Interim Examination and Maintenance Cell, and upon completion, the pins and ducts will be shipped to other off-site facilities for further examination. At present, planning shows that these operations in the Interim Examination and Maintenance Cell can be completed without affecting the FFTF Transition Project critical path. Costs for this work are not included in the funding profile, since PNC will reimburse DOE. 
WHC-SD-FF-SSP-004

Rev. I Page 129

This page intentionally left blank. 


\subsection{SCHEDULE}

\subsection{PRELIMINARY SUMMARY TRANSITION SCHEDULE}

The preliminary summary schedule for transition is depicted in Figure 1 (repeated herein). It graphically demonstrates the integration and interrelationship of the key deactivation activities. The schedule is derived from the Resource Loaded Schedule (Reference 1).

The appropriate level of detail for the multi-year resource loaded cost and schedule is dependent on the maturity of the Transition Project. The cost and schedule are definitive for the short term and will reflect order of magnitude estimates in the out years, recognizing that there are still many issues and uncertainties to be resolved. As the Transition Project matures, the estimates will become more detailed based on more clearly defined scope, documentation, and other program and project data. Therefore, the Resource Loaded Schedule will be managed as a "living document" in concert with the Plan and will be modified to reflect the appropriate level of detail as the scope of work evolves.

Each of the transition activities shown in Figure 1 are briefly discussed below:

\section{Reactor Defueling}

- Reactor defueling commenced on April 20, 1994. Fuel is being relocated to the Interim Decay Storage vessel and the Fuel Storage Facility. This is not a critical path activity (see Section 9.1).

\section{Environmental Compliance}

- A National Environmental Policy Act (NEPA) Environmental Assessment was submitted and a Finding of No Significant Impact (FONSI) is pending.

- Tri-Party Agreement negotiations are in progress to define enforceable milestones for completing the transition of the FFTF (see Section 6.2).

- Submittal of a Notice of Intent/Part A Permit application to the Washington State Department of Ecology requesting Resource Conservation Recovery Act (RCRA) interim status for the Sodium Storage Facility and Sodium Reaction Facility is being prepared (see Section 6.2.2).

- A Notice of Construction is being prepared requesting approval from the State of Washington Department of Health and the U.S. Environmental Protection Agency for the Sodium Storage Facility. A Notice of Construction will likewise be required for the Sodium Reaction Facility (see Section 6.2.4). 
WHC-SD-FF-SSP-004

Rev. I Page 131

This page intentionally left blank. 


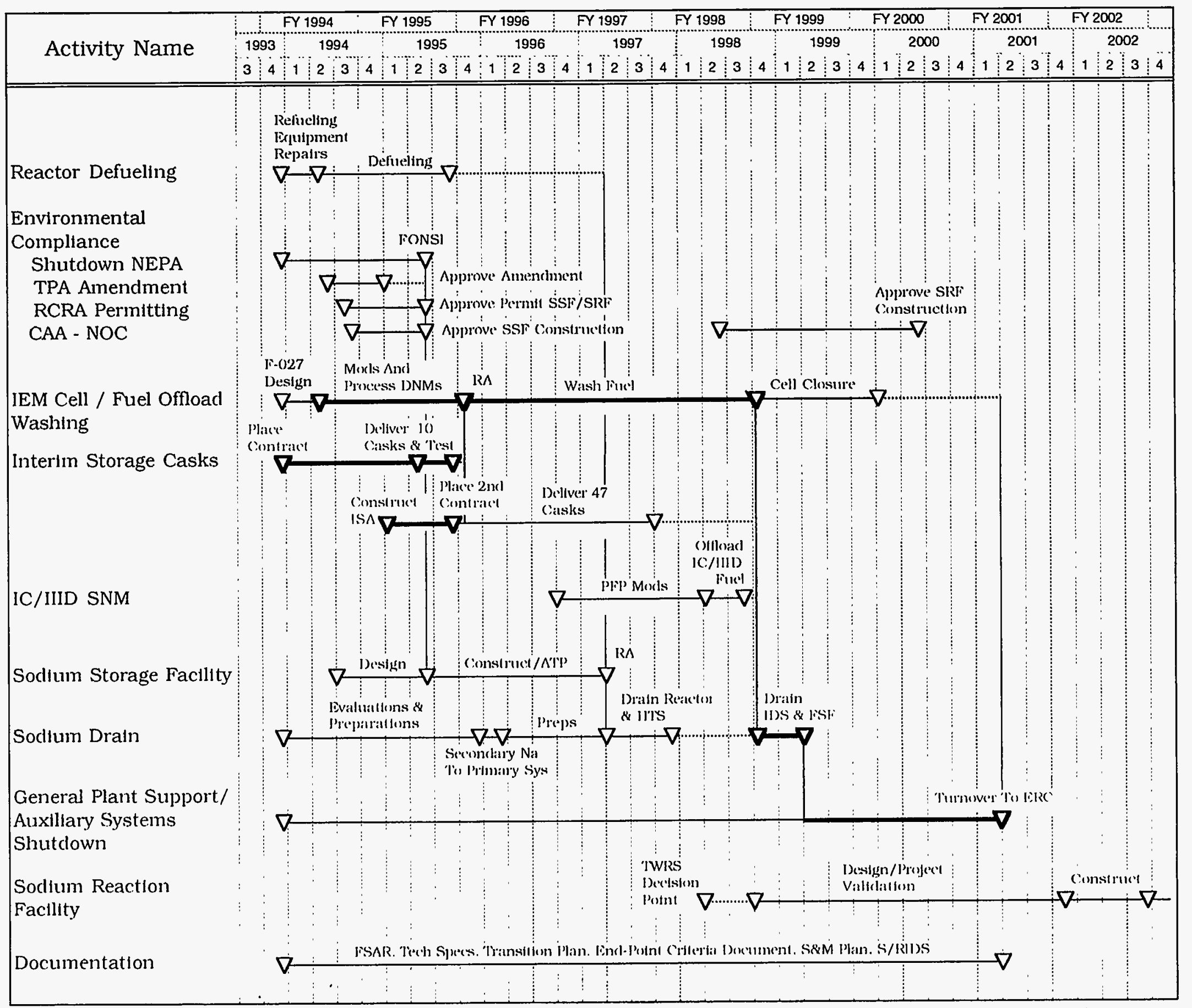

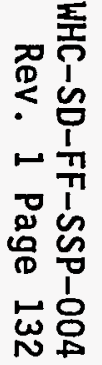

Figure 1. FFTF Transition Project Summary Schedule 


\section{Interim Examination and Maintenance Cell/Fuel Washing}

- Entails modifications to enhance the Interim Examination and Maintenance Cell for washing and offloading fuel (see Section 9.3.1).

- Two delayed neutron monitoring leaking assemblies are disassembled in the Interim Examination and Maintenance Cell (see Section 9.2.4.1).

- A Readiness Assessment is required before initiating fuel offload (washing and placing the fuel in dry storage casks.) (See Sections 9.3.2 and 10.5). Offloading the fuel is critical path.

- Following the fuel offload, the cell is placed in a shutdown condition.

\section{Interim Storage Casks}

- The design/fabrication contract was placed for the first ten casks.

Delivery of the casks are critical path to support fuel offload (see Section 9.3.3).

- After the first cask is satisfactorily tested, a fabrication only contract for an additional 47 casks will be placed. Cask deliveries are spread to reduce annual costs and support the offload schedule. Core Component Containers are also procured.

- The Interim Storage Area is constructed for storage of fuel in the Interim Storage Casks (see Section 9.3.4).

\section{IC/IIID Special Nuclear Material}

- Entails disposition of the Safeguards Category IC/IIID irradiated fuel and IC unirradiated (green) fuel. The latter assumes modifications as necessary for appropriate storage at the Plutonium Finishing Plant facility (see Section 9.2.2 and 9.2.3).

- After this fuel is dispositioned, the FFTF will be downgraded to a Property Protection Area (see Section 14.0).

\section{Sodium Storage/Reaction Facilities}

- The Sodium Storage Facility Functional Design Criteria was approved and the Conceptual Design Report was submitted to RL.

- Assumes accelerated construction of the Sodium Storage Facility, which is dependent upon reprogramming of funds in early Fiscal Year 1995.

- Design and construction of the Sodium Reaction Facility are shown for Project visibility. Project baseline is to defer the Sodium Reaction Facility in support of converting the FFTF sodium to an hydroxide for Tank Waste Remediation Systems (TWRS) appiication. 


\section{Sodium Drain}

- A Readiness Assessment is required before initiating the Reactor and Heat Transport System drain (see Section 10.5).

- As a precursor to the drain (and not shown), the NaK (sodium-potassium eutectic) loops in containment are flushed with sodium (see Section 9.4.3.1).

- The Reactor and Heat Transport System drain are discussed in Sections 9.4.2.1 and 9.4.2.2.

- Following the completion of fuel offload, the Interim Decay Storage vessel and Fuel Storage Facility are drained and their systems deactivated (see Sections 9.4.2.3 and 9.4.2.4).

- Inerting of sodium residuals is discussed in Section 9.4.3.3.

\section{General Plant Support}

- This is a Surveillance and Maintenance activity during deactivation. A high level of plant support is required before sodium drain (see Section 9.6).

\section{Auxiliary Systems Transition}

- Systems wiTl be deactivated for turnover as described in Appendix A-2 in accordance with the Transition End-Point Criteria Document (see Section 7.0).

- Turnover to the Environmental Restoration Contractor and subsequent Tong term surveillance and maintenance are described in Section 9.7.

\section{Key Documentation}

- FFTF Final Safety Analysis Report: Appropriate revisions will be prepared to reflect evolving plant conditions during transition (see Section 10.2).

- FFTF Technical Specifications: Appropriate revisions will be prepared to maintain specifications that provide an accurate, up-to-date safety analysis, based on evolving plant conditions (see Section 10.3).

- FFTF Transition Project Plan: The Plan will be maintained as a living document that will be updated as the FFTF transition progresses in order to provide the current logic/approach and project baseline (see Section 10.1).

- Transition End-Point Criteria Document: The document will define the what actions are required prior to facility turnover to the Environmental Restoration Contractor at the end of the transition period (see Section 7.0). 
- Surveillance and Maintenance Plan: The plan will address the requirements for maintaining the transitioned FFTF in a stable configuration during the long term surveillance and maintenance phase (see Section 9.7).

- Standards/Requirements Identification Document (S/RIDS): A compilation document 7 isting standards and requirements to provide protection of the environment and the health and safety of workers and the public for each DOE facility (see Section 10.6). 
WHC-SD-FF-SSP-004

Rev. I Page 136

This page intentionally left blank. 


\subsection{COSTS}

The FFTF Transition Project costs are shown in Figure 2 (repeated herein). These costs are derived from the Resource Loaded Schedule (Reference 1), and include the workscope of Activity Data Sheets 6640 and 6642 , i.e. . FFTF and FFTF Shutdown Construction respectively. They do not include Activity Data Sheet 6641 , Nuclear Energy Legacies. The costs reflect acceleration of the Sodium Storage Facility and are consistent with the profile in the Fiscal Year 1995 Work Plan and Multi-Year Program Plan (Reference 30).

There are several identified and/or potential productivity improvements that were discussed in earlier sections of the Plan. A compilation of these improvements is included herein.

- Early secondary sodium drain (Section 9.4.2): The \$2.6 million savings will be realized in Fiscal Years 1996 and 1997.

- Increased Core Component Container Loading (Section 9.3.3): A projected $\$ 2.6$ million savings may be realized in Fiscal Years 1995 and/or 1996.

- Sodium Storage Facility (Section 9.4.4.2): The reduced safety class will be evaluated during definitive design. Any cost reduction improvements will be applied in Fiscal Years 1995 and/or 1996.

- Technical Specification reductions (Section 6.2): Reductions are being evaluated and cost reduction improvements will be applied in appropriate fiscal years.

- Reduction in safeguards inventory frequency (Section 14.0): Cost savings of $\$ 134,000$ will be applied in Fiscal Years 1995 through 1997.

Other productivity improvements, including those defined in the Challenge 170 Program, are expected to be identified as the transition activities become more definitive. 
WHC-SD-FF-SSP-004

Rev. I Page 138

This page intentionally left blank. 


\section{FFTF Transition Project - Annual Costs}

(Escalated Dollars)

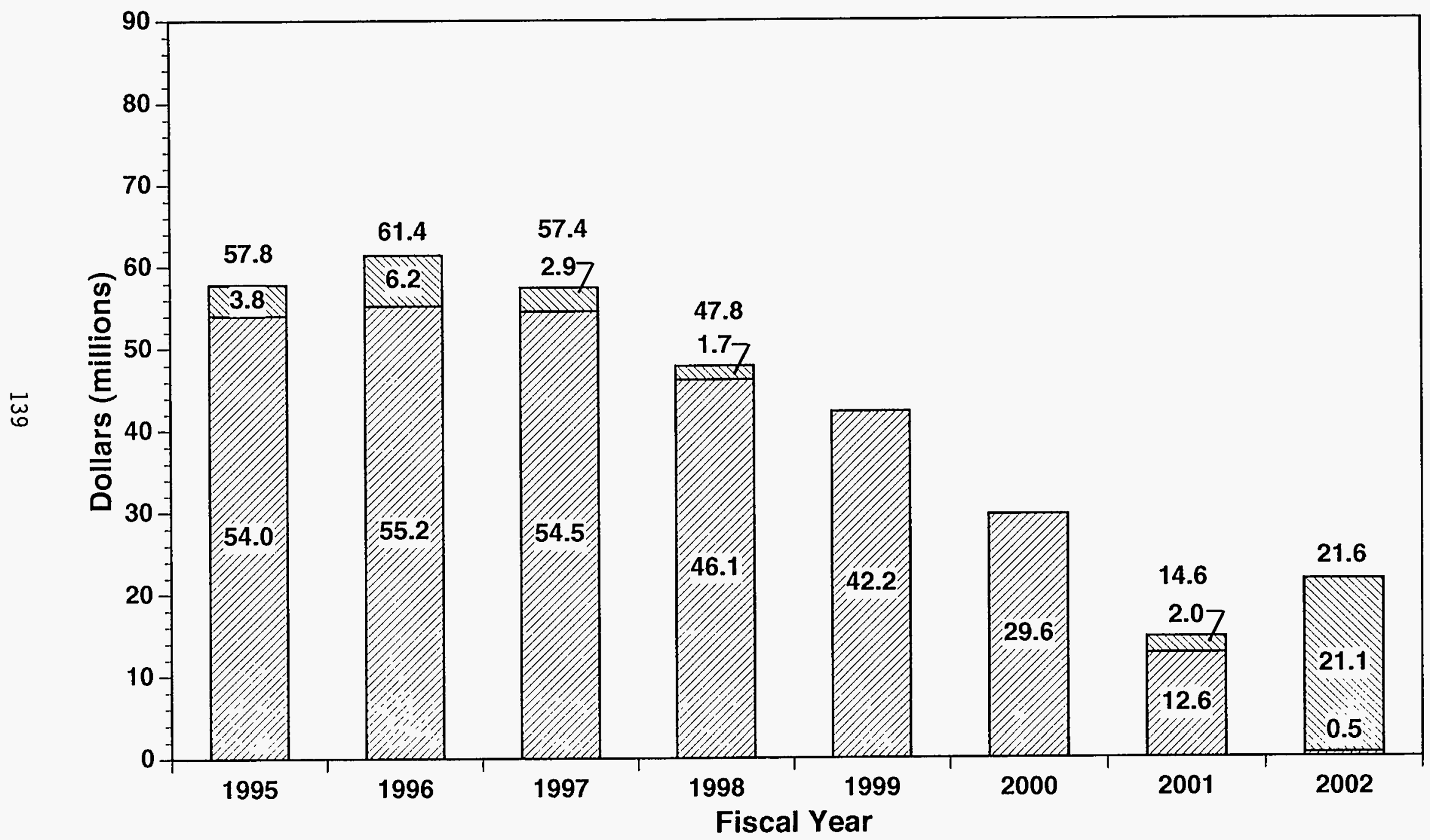

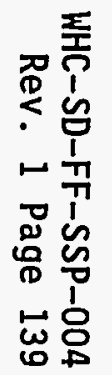

Figure 2. FFTF Transition Project - Annual Costs 


\subsection{STAFFING}

The profile of direct Full Time Equivalent staff that are needed for transition is shown in Figure 23. This profile was derived from the Resource Loaded Schedule, (Reference 1). 
WHC-SD-FF-SSP-004

Rev. I Page 141

This page intentionally left blank. 


\section{FFTF Transition Project - Full Time Equivalent Staff}

(Rev. 1 RLS Direct FTEs for Workscope in ADS 6640 and ADS 6642 )

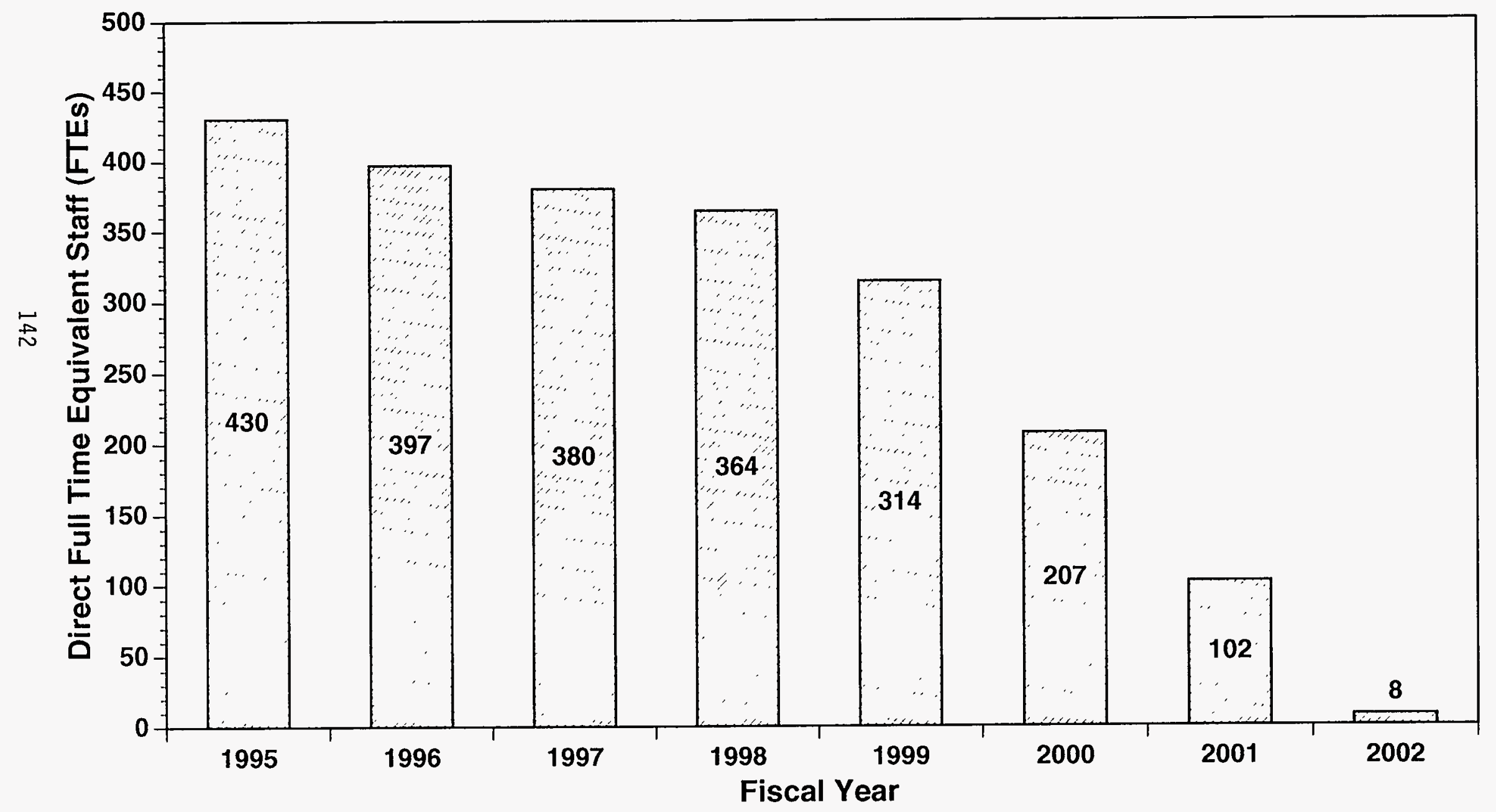

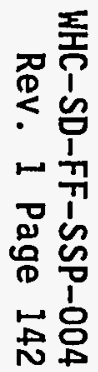

Figure 23. FFTF Transition Project - Fu11-Time Equivalent Staff 


\subsection{REFERENCES}

1. WHC-SD-FF-SSP-050, Rev. 1, "Fast Flux Test Facility Transition Project Resource Loaded Schedule," Westinghouse Hanford Company, October 31, 1994.

2. Letter, R. J. BTiss, WHC, to J. R. Hunter, RL, "Fast Flux Test Facility Cold Standby Program Plan," 9300062B R1, dated March 31, 1993.

3. Letter, H. O'Leary, Secretary of Energy, to Subcommittee on Energy and Hater Development, dated February 5, 1993.

4. Letter, John W. Landis to Hazel R. O'Leary, Secretary of Energy, "Future Use of the United States Department of Energy's Fast Flux Test Facility," dated September 20, 1993.

5. Memorandum, Daniel A. Dreyfus, Acting Director, Office of Nuclear Energy, to John D. Wagoner, Manager, Richland Operations Office, "Commence Fast Flux Test Facility Shutdown (FFTF) Activities," dated December 15, 1993.

6. Letter, J. D. Wagoner, RL, to T. M. Anderson, WHC, "Fast Flux Test Facility (FFTF) Shutdown," OTD:OAF, dated December 15, 1993.

7. WHC-SD-FF-SSP-004, Rev. 0, "Fast Flux Test Facility Shutdown Program Plan," Westinghouse Hanford Company, March 4, 1994.

8. Letter, J. E. Mecca, RL, to A. L. Trego, WHC, "Revised Guidance in the Development of the Fiscal Year Workplan/Multi-Year Program Plan (FYWP/MYPP) for Advanced Reactors Program (ARP), WBS 7.3," OTD:RAA, dated JuTy 29, 1994.

9. Letter, A. J. Rizzo, MACTEC, to J. E. Mecca, RL, "Fast Flux Test Facility (FFTF) Shutdown Program Plan Review," dated April 28, 1994.

10. Letter, J. C. Midgett, WHC, to J. E. Mecca, RL, "Fast Flux Test Facility Shutdown Program Plan Review," 9403032B R1, dated June 24, 1994.

11. Letter, D. J. Swaim, WHC, to J. E. Mecca, RL, "Implementation of DOE $5480.21,5480.22,5480.23$ at FFTF," 9256527, dated September 4, 1992.

12. Letter, J. C. Midgett, WHC, to J. E. Mecca, RL, "Fast Flux Test Facility Hazard Category Evaluation," 9452513, dated Apri1 8, 1994.

13. Document, Washington State Department of Ecology, United States Environmental Protection Agency, United States Department of Energy, "Hanford Federal Facility Agreement and Consent Order," Fourth Amendment, January 1994.

14. Letter, J. C. Midgett, WHC to J. E. Mecca, RL, "Action Description Memorandum: Shutdown of the Fast Flux Test Facility, Hanford Site, Rich1and, Washington," 9450522, dated January 21, 1994. 
15. Letter, J. C. Midgett, WHC, to J. E. Mecca, RL, "Environmenta] Assessment: Shutdown of the Fast Flux Test Facility, Hanford Site, Richland, Washington," 9452321, dated March, 311994.

16. Letter, J. R. Hunter, Assistant Manager for Waste Management, RL, to President, WHC, "National Environmental Policy Act (NEPA) Environmental Assessment (EA) Determination: Shutdown of the Fast Flux Test Facility," OTD:RGH, dated April 15, 1994.

17. Memorandum, T. R. Sheridan, Acting Assistant Manager for Tank Waste Remediation System, to J. E. Mecca, Acting Assistant Manager for Facility Transition, "Use of Fast Flux Test Facility (FFTF) Sodium For The Tank Waste Remediation System (TWRS) Waste Pretreatment Program," dated September 20, 1994.

18. Letter, J. E. Rasmussen, RL, to Ms. Dru Butler, State of Washington Department of Ecology, "Notification of Intent to Request Expansion Under Interim Status for the Fast Flux test Facility (FFTF) Sodium Storage Facility (SSF) and Sodium Reaction Facility (SRF), "dated September 13, 1994.

19. Letter, J. E. Rasmussen, RL, to Ms. Jul ie Atwood, ECOLOGY, "Compliance with the Washington Administrative Code (WAC) and the Uniform Fire Code (UFC) for the Storage of Fast Flux Test Facility (FFTF) Sodium," TPD:RGH, dated August 16, 1994.

20. Letter, M. E. Crist, PNL, to D. L. Nielsen, WHC, "Cultural Resources Review of the FFTF Shutdown Project, HCRC \#94-400-008," dated June 23, 1994.

21. Letter, C. A. Brandt, PNL, to D. L. Nielsen, "Biological Review of the F027-IEM Cel1 Enhancements/Interim Storage Area, the Sodium Storage Facility and the Sodium Reaction Facility (FFTF Shutdown Project) \#94-WHC-140 and \#94-WHC-154," dated May 23, 1994.

22. Document, U.S. Department of Energy Office of Environmental Restoration (EM-40), "Decontamination and Decommissioning Guidance Document," Draft 3, dated January 14, 1994.

23. Letter, J. C. Midgett, WHC, to 0. A. Farabee, RL, "Retention of Sodium Residuals in FFTF at Turnover to Decontamination and Decommissioning," 9456799, dated October 10, 1994.

24. Document, Conceptual Design Report for the Sodium Storage Facility (Fast Flux Test Facility), WHC-SD-FF-CDR-006, Revision 0 [Submitted to RL for approval October 18, 1994].

25. Document, Preliminary Safety Evaluation (PSE) for the Sodium Storage Facility at the Fast Flux Test Facility, WHC-SD-FF-PSE-002, Revision 0 [Released September 30, 1994]. 
26. Letter, R. A. Smith, WHC, to W. S. Chin, RL, "Project 95-L-EXF-028, SubProject 03-F-031 "FFTF Sodium Storage Facility," (Proposed Fiscal Year 1995 Line Item), Request for Project Authorization," 9457251, dated October 24, 1994.

27. Document, Draft Environmental Impact Statement: "Department of Energy Programmatic Spent Nuclear Fuel Management and Idaho National

Engineering Laboratory Environmental Restoration and Waste Management Programs," 2 vols, DOE/EIS/0203-D, U.S. Department of Energy, Idaho Operations Office, 1994.

28. Letter, J. R. Hunter, RL, to President, WHC, "Sale of Clinch River Breeder Reactor Plant (CRBRP) Equipment and Material Inventory," dated January 19, 1993.

29. Letter, J. L. Spracklen, RL, to A. L. Trego, WHC, "Approval of Westinghouse Hanford Company (WHC) deviation to DOE Order 5633.3A, "Control and Accountability of Nuclear Materials," Reduce the Physical Inventory Frequency of the Fast Flux Test Facility (FFTF) Category IC Driver Fuel Assembiies Stored in the Interim Decay Storage (IDS) vesse1," dated August 25, 1994.

30. Letter, J. C. Midgett, WHC, to 0. A. Farabee, RL, "Advanced Reactors Transition Fiscal Year 1995 Multi-Year Program Plan for Work Breakdown Structure 7.3," 94050036 B R2, dated September 22, 1994. 
WHC-SD-FF-SSP-004

Rev. I Page 146

This page intentionally left blank. 
Acronym List

ALARA
ASHE
CFR
DOE
DOE-HQ
FFTF
FONSI
FOTA
HEPA
MOTA
NaK
NEPA
NESHAPS
NFPA
NOC
OSHA
PCB
PIOTA
PLAN
PNC
RAEP
RCRA
RL
S/RIDS
Tri-Party Agreement
TSCA
TWRS
WAC
WHC

As Low As Reasonably Achievable American Society of Mechanical Engineers Code of Federal Regulations U.S. Department of Energy U.S. Department of Energy - Headquarters Fast Flux Test Facility Finding of No Significant Impact Fuel Open Test Assemblies high effiency particulate absolute Materials Open Test Assembly sodium-potassium al loy National Environmental Policy Act of 1969 National Emission Standards for Hazardous Air Pollutants

National Fire Protection Association Notice of Construction Occupational Safety and Health Administration Polychlorinated Biphenyl

Post Irradiation Open Test Assemblies FFTF Transition Project Plan Power Reactor and Nuclear Fuel Development Corporation of Japan

Radioactive Air Emissions Program Resource Conservation and Recovery Act of 1976

U.S. Department of Energy, Richland Operations Office

Standards/Requirements Identification Hanford Federal Facility Agreement and Consent Order

Toxic Substances Control Act of 1976

Tank Waste Remediation System

Washington Administrative Code Westinghouse Hanford Company 
WHC-SD-FF-SSP-004

Rev. I Page 148

This page intentionally left blank. 
WHC-SD-FF-SSP-004

Rev. 1, Page A1-1

\section{Appendix A-1}

\section{Project Plan}


WHC-SD-FF-SSP-004

Rev. 1, Page Al-2

This page intentionally left blank. 
APPENDIX A-1

PROJECT PLAN

FAST FLUX TEST FACILITY TRANSITION PROJECT

Table of Contents

1.0 INTRODUCTION . . . . . . . . . . . . . . . . . 7

2.0 MISSION NEED AND OBJECTIVES . . . . . . . . . . . . . . 9

3.0 TECHNICAL PLAN . . . . . . . . . . . . . . . . . . . 11

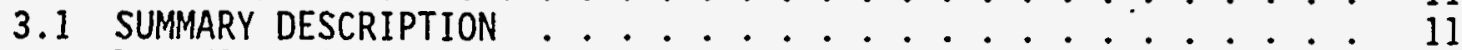

3.2 TECHNICAL APPROACH ...................... . . . 11

3.3 WORK BREAKDOWN STRUCTURE AND RESOURCE LOADED SCHEDULE . . . . 11

4.0 RISK ASSESSMENT . . . . . . . . . . . . . . . . . . 13

4.1 TECHNICAL . . . . . . . . . . . . . . . . . . 13

4.2 SCHEDULE . . . . . . . . . . . . . . . . . 13

4.3 COST . . . . . . . . . . . . . . . . . . . . . . 14

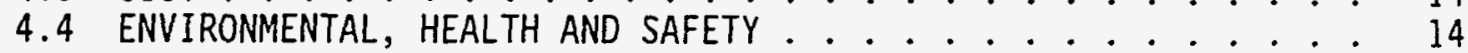

5.0 MANAGEMENT APPROACH . . . . . . . . . . . . . . . . . 25

5.1 MANAGEMENT STRATEGY .................... . . . 25

5.2 ORGANIZATION ........................ . . . . . 25

5.3 MANAGEMENT CONTROL SYSTEM . . . . . . . . . . . . . . . 27

5.3.1 Introduction . . . . . . . . . . . . . . . . . 27

5.3.2 Scope Basel ine Management . . . . . . . . . . . 28

5.3.3 Cost Baseline Management . . . . . . . . . . . 29

5.3.3.1 Cost Estimate Reviews ............ . 29

5.3.3.2 Cost Performance Monitoring .. . . . . . . 30

5.3.3.3 Estimates at Completion ......... 30

5.3.4 Schedule Basel ine Management ... . . . . . . . . 30

5.3.5 Performance Reporting . . . . . . . . . . . . 30

5.3.5.1 Report Content .............. . 31

5.3.5.2 Cost and Schedute Reports . . . . . . . . . 31

5.3.5.3 Report Distribution ........... . 31

5.3.5.4 Review Meetings ............ . 32

5.4 BUDGET, COST AND SCHEDULE PERFORMANCE MEASUREMENT . . . . . . 32

5.5 BASELINE CHANGE CONTROL ................ 35

5.6 PROJECT MANAGEMENT PLANS . . . . . . . . . . . . . . . . . 37

5.7 QUALITY ASSURANCE REQUIREMENTS . . . . . . . . . . . . . 37

5.8 ENVIRONMENTAL DOCUMENTATION . . . . . . . . . . . . . 38

5.9 SAFETY ANALYSIS . . . . . . . . . . . . . . . 38

6.0 ACQUISITION STRATEGY . . . . . . . . . . . . . . . . 39

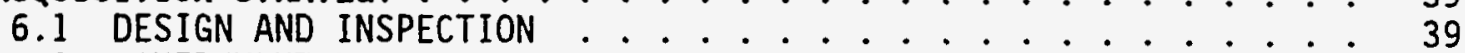

6.2 GOVERNMENT-FURNISHED MATERIAL . . . . . . . . . . . . . 40

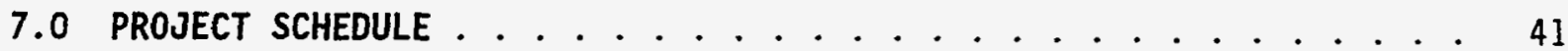


Rev. 1, Page Al-4

8.0 RESOURCES PLAN . . . . . . . . . . . . . . . . . . . . . . . . 43

8.1 FUNDING ALLOCATION . . . . . . . . . . . . . . . 43

8.2 PROJECT STAFFING . . . . . . . . . . . . . . 43

9.0 CONTROLLED ITEMS/BASELINES . . . . . . . . . . . . . . . . 45

9.1 CHANGE CONTROL BOARD .................. 45

9.2 CHANGE CONTROL BOARD OPERATION .............. . . 45

9.2.1 FFTF Change Control Board Chairman ........ . . 45

9.2.2 FFTF Change Control Board Secretary . . . . . . . . . 46

9.2.3 Support Function Members . . . . . . . . . . . . . 46

9.2.4 Change Control Board Meetings . . . . . . . . . 46

9.2.5 Baseline Change Request Priority. . . . . . . . . 47

9.3 BASELINE CHANGE REQUEST . . . . . . . . . . . . . . . . . 47

9.3.1 Change Classifications ............... 48

9.3.2 Change Request Approvals ............. 49

9.3.3 Change Request Distribution ........... 51

10.0 SCHEDULED DECISION POINTS . . . . . . . . . . . . 53

11.0 PROJECT CHARTER ....................... 55

11.1 INTRODUCTION . . . . . . . . . . . . . . . . . . . 55

11.2 PROJECT MANAGEMENT OFFICE LOCATION . . . . . . . . . . . . 56

11.3 MANAGEMENT TEAM . . . . . . . . . . . . . . . . . . . . 56

11.3.1 Operations and Transition Division . . . . . . . . . 56

11.3.2 Project Management Division ........... . 56

11.3.3 FFTF Transition Project ............. . 56

11.3.4 FFTF Transition Project Office ........... 56

11.4 PROJECT MANAGER AUTHORITY \& RESPONSIBILITIES . . . . . . . . 56

11.4.1 Team Building. . . . . . . . . . . . . . . 57

11.4.2 Planning and Baseline Schedule Development . . . . 57

11.4.3 Change Control .............. . 57

11.4.4 Budget and Cost Estimates . . . . . . . . . . 58

11.4 .5 Supporting Sub-Projects ............. . 58

11.4.6 Technical and Regulatory Requirements....... . 58

11.4 .7 Technology ................. . 58

11.4.8 Readiness Assessments . . . . . . . . . . . . . . 59

11.4.9 Turnover of Fuel, Systems, Equipment and Buildings . 59

11.4.10 Project Reports and Records... . . . . . . . . . 60

11.5 SUPPORTING ORGANIZATIONS . . . . . . . . . . . . . . . . . . 60

12.0 REFERENCES . . . . . . . . . . . . . . . . . 61

13.0 ACRONYMS AND ABBREVIATIONS . . . . . . . . . . . . . . 63 


\section{List of Figures}

Figure 3-1 FFTF Transition Project Summary Work Breakdown Structure - . 12 Figure 5-1 FFTF Transition Project Team . . . . . . . . . . . . . . 26

Figure 5-2 Performance Analysis and Reporting Process . . . . . . . . 34

\section{List of Tables}

Table 2-1 Mission of FFTF Transition Project Sub-projects . . . . . 9

Table 4-1 Project Risk Identification, Assessment \& Response . . . . . 15

Table 5-1 FFTF Transition Project Summary Baselines . . . . . . . . . . 27

Table 5-2

Table 5-3

Table 5-4

Table 6-1

Table 8-1

Table 9-1

Table 11-1

FFTF Transition Project Reports .............. . 31

Basel ine Change Classes ................. . 36

Project F-028 FFTF Transition Construction Sub-projects . . . 37

FFTF Transition Project Acquisition Strategy .. . . . . 39

FFTF Transition Project Funding Allocation . . . . . . . . 43

Baseline Change Request Approvals . . . . . . . . . . . . . 50

Table 11-2

FFTF Transition Project Charter Outiine . . . . . . . . . 55

FFTF Transition Project Turnovers ........... . 59 
WHC-SD-FF-SSP-004

Rev. 1, Page A1-6

This page intentionally left blank. 
APPENDIX A-1

\section{PROJECT PLAN \\ FAST FLUX TEST FACILITY TRANSITION PROJECT}

\subsection{INTRODUCTION}

This Project Plan applies to the management of the technical (scope), cost and schedule baselines for the FFTF Transition Project. The Project Plan will be used to measure and assess the effectiveness of the Project. The work scope to which this Project Plan will be applied includes:

1) Project management, planning, control, and reporting.

2) Reactor defueling, fuel washing, and the shutdown of defueling systems and components.

3) Transferring irradiated fuel to interim dry storage casks in the 400 Area.

4) Transferring unirradiated fuel to the Plutonium Finishing Plant.

5) Transferring irradiated, sodium-bonded fuel to the Idaho National Engineering Laboratory.

6) Liquid metal drain and disposition including construction of a Sodium Storage Facility and a Sodium Reaction Facility, radioactive waste disposal and shutdown of liquid metal systems.

7) Shutdown of the support systems.

8) Shutdown of the electrical, instrument and control systems.

9) Surveillance and maintenance which includes all activities needed to maintain safe conditions during the FFTF deactivation in accordance with the applicable DOE Orders.

10) Support function activities such as safety, security, quality assurance, environmental compliance, and external oversight.

This Project Plan is based upon the requirements of the DOE 4700.1 Project Management System procedure (Reference 1) and the WHC-CM-6-2 Project

Management procedure (Reference 11). The key elements include the following:

- Mission Need and Objectives

- Technical Plan

- Risk Assessment

- Management Approach

- Acquisition Strategy

- Project Schedule

- Resources Plan

- Controlled Items/Baselines

- Project Charter 


\section{WHC-SD-FF-SSP-004}

Rev. I, Page A1-8

The following documents will be used to manage all of the FFTF Transition Project activities. All of the documents are "living documents" and will be used in concert with each other throughout the Project life-cycle. They will be modified to reflect the appropriate level of detail as the work scope becomes better defined.

- WHC-SD-FF-SSP-052 Advanced Reactors Transition Fiscal Year (FY) Multi-Year Program Plan (MYPP)

- WHC-SD-FF-SSP-004 FFTF Transition Project Plan (hereafter referred to as the Plan)

- WHC-SD-FF-SSP-050 FFTF Resource Loaded Schedule (RLS) 


\subsection{MISSION NEED AND OBJECTIVES}

The primary mission and objective of the FFTF Transition Project is to transition FFTF to a radiologically and industrially safe shutdown condition. Four new construction projects are required to support the transition activities and are shown in Table 2-1. The mission need, schedule and transition objectives are explained in more detail in Sections $1.0,3.0$ and 9.0 of the Plan. Specific information concerning the manpower, material and schedule requirements is contained in the RLS.

\begin{tabular}{|c|c|l||}
\hline \multicolumn{2}{|c|}{ Table 2-1 Mission of FFTF Transition Project Sub-projects } \\
\hline Project & Description & \multicolumn{1}{c|}{ Purpose } \\
\hline $01-F-029$ & Interim Storage Area & $\begin{array}{l}\text { Construct a fence, install a vehicle } \\
\text { crash barrier and install lighting } \\
\text { around an existing concrete slab in } \\
\text { the 400 Area to store shielded casks } \\
\text { containing cleaned, irradiated fue } .\end{array}$ \\
\hline $02-F-030$ & $\begin{array}{l}\text { Plutonium Finishing } \\
\text { Plant Modifications }\end{array}$ & $\begin{array}{l}\text { Construct a facility or modify an } \\
\text { existing area at the Plutonium } \\
\text { Finishing Plant (PFP) to receive and } \\
\text { store clean, unirradiated FFTF fuel }\end{array}$ \\
\hline $03-F-031$ & Sodium Storage Facility & $\begin{array}{l}\text { Construct a facility adjacent to FFTF } \\
\text { to receive and store sodium drained } \\
\text { from FFTF systems. }\end{array}$ \\
\hline $04-F-032$ & Sodium Reaction Facility & $\begin{array}{l}\text { Construct a facility adjacent to the } \\
\text { Sodium Storage Facility to convert the } \\
\text { sodium to a useable or stable form. }\end{array}$ \\
\hline
\end{tabular}


WHC-SD-FF-SSP-004

Rev. 1, Page A1-10

This page intentionally left blank. 


\subsection{TECHNICAL PLAN}

\subsection{SUMMARY DESCRIPTION}

The activities and work elements for the FFTF Transition Project are described in detail in the Plan and the RLS.

\subsection{TECHNICAL APPROACH}

The technical approach is based upon using existing nuclear reactor and liquid metal process technology to transition FFTF to an industrially and radiologically safe condition. The need for research and development is not expected. For example, the FFTF Transition Project plans to take advantage of the sodium reaction demonstration which will be conducted at the ANL-W Site (EBR-II) in Idaho to avoid that cost.

Technical management will consist of managing the FFTF deactivation activities against approved scope, schedute and cost baselines. Engineering studies, risk assessments, functional design criteria, conceptual designs, codes, standards, and environmental regulations will provide the basis for the design, procurement, construction, and acceptance testing of the new construction work and facility modifications.

The technical expertise of the existing FFTF staff and other WHC resources will be used whenever practical to minimize costs. Offsite technical support, architect-engineers and fixed-price contractors will be used whenever their services are cost effective.

\subsection{WORK BREAKDOWN STRUCTURE AND RESOURCE LOADED SCHEDULE}

The objectives and technical readiness of the FFTF Transition Project and its related activities are described in the Plan. Figure 3-1 shows the general work activities in the form of a Project Summary Work Breakdown Structure (PSWBS). The PSWBS provides the overall framework which displays the products to be produced and the work required to transition FFTF to a safe state. The PSWBS is expanded upon further in the RLS which provides the more detailed Contractor Work Breakdown Structure (CWBS) defining the specifjc results and products to be produced.

The major events, milestones, technical activities, and key decision points for each phase of the Project are shown in the PIan and the RLS. Logic diagrams are provided in the RLS to illustrate the interdependencies of the project elements.

The Project scope, schedule, cost and related milestones are governed by the Advanced Reactors Transition FY 1995 MYPP (Reference 14, WHC-SD-FF-SSP-052). 


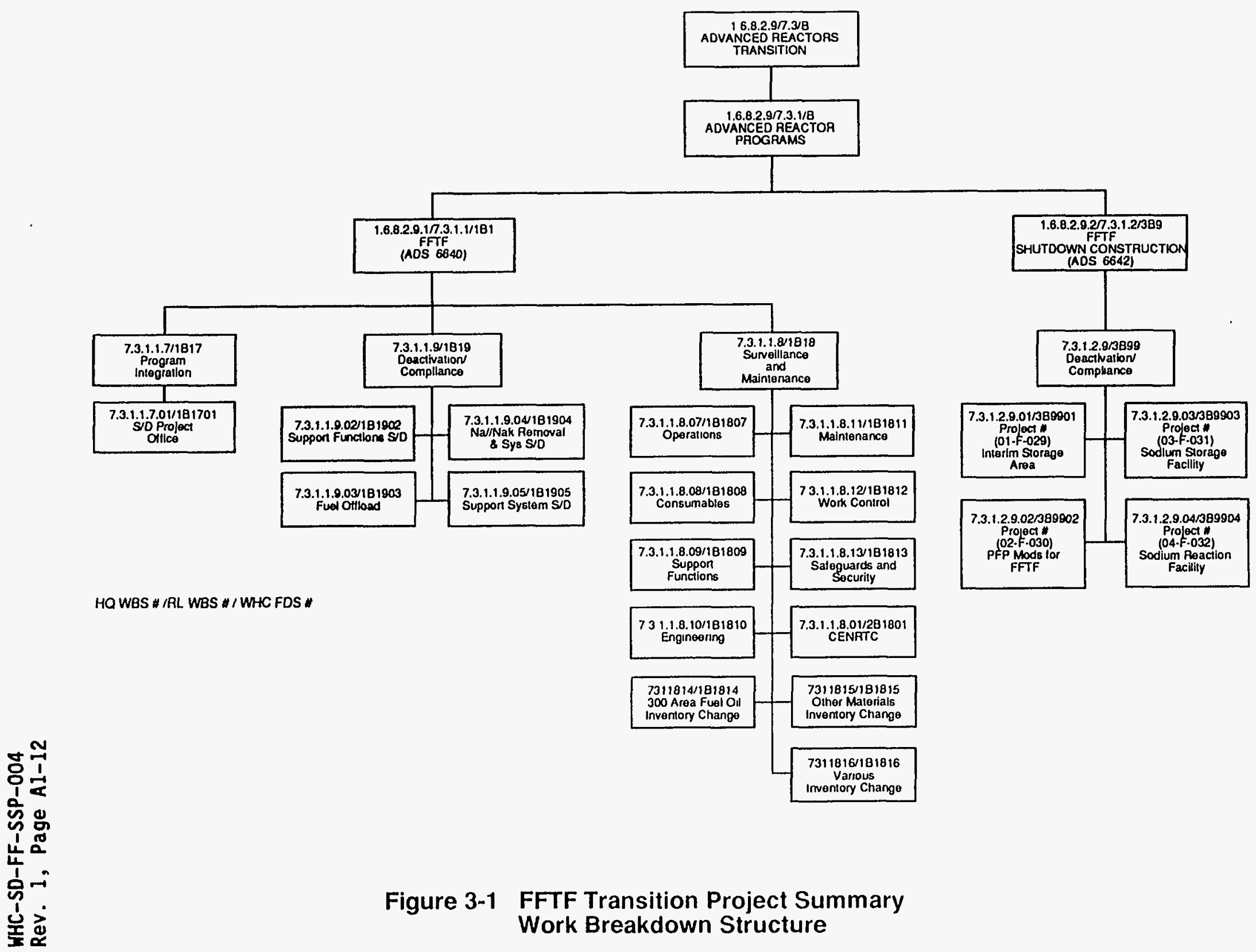




\subsection{RISK ASSESSMENT}

An assessment of the risks associated with each activity and construction project in the FFTF Transition Project is required by Reference 1 (DOE 4700.1). This assessment is shown in Table 4-1 which identifies, assesses and provides the planned responses for the known risks.

It should be noted that the risk assignments, or levels, may change as the Project matures. The consequences of risk typically decrease as the preliminary safety evaluations and the designs for the various project elements are completed. Risk identification, assessment and response is necessary to ensure projects are completed on time and within financial restraints. It is for this reason that the design organizations will identify, assess and provide a risk response as the definitive designs for the major sub-projects are completed.

\subsection{TECHNICAL}

The overall technical risk for the FFTF Transition Project is $10 \mathrm{w}$. It is anticipated that each of the sub-projects will be constructed utilizing standard industrial construction methods. Qualified operating and construction personnel, equipment and proven technology will be used throughout the transition process.

Proven technology and deactivation methods from other nuclear reactor and liquid metal process facilities will be used to reduce risk, improve safety and reduce costs. Although some significant technical challenges are expected (such as accessing the reactor vessel inlet plenum to drain the sodium), these are viewed as engineering development rather than research and development. The risks are considered to be primarily cost and schedule.

It is expected that the consequences of risk and the related costs will be greatly reduced as the Project develops through the initial planning, conceptual and definitive design stages. For example, during the initial planning phase, the Plan was developed by defining and integrating the FFTF system shutdown activities, defueling operations and supporting sub-projects in a logical manner to minimize risk.

Qualified personnel, procedures and equipment will be used to reduce risks associated with the removal of 1 iquid metal sodium and NaK from the FFTF process systems and reacting the material safely.

\subsection{SCHEDULE}

The overall schedule risk is moderate. An intense planning and scheduling effort will be required to achieve the milestone and schedule objectives defined in the Advanced Reactors Transition FY 1995 MYPP (Reference 14, WHC-SD-FF-SSP-052). 
WHC-SD-FF-SSP-004

Rev. 1, Page A1-14

\section{$4.3 \operatorname{COST}$}

The overall cost risk is high and is directly related to the availability of funding. For example, lack of funding to support the construction projects will extend the schedule and related costs for operating and maintaining the FFTF liquid metal process systems. Institutional barriers, budgeting limitations and funding restrictions are historically very difficult to predict.

Funding projections and budget estimates in the Plan and RLS are magnitude values. When the definitive designs for the supporting construction subprojects are completed, more detailed cost estimates will be prepared and the results incorporated into the RLS and Project planning documents.

\subsection{ENVIRONMENTAL, HEALTH AND SAFETY}

The environmental, health and safety risks for the FFTF Transition Project are low. The construction and operation of the sub-projects will comply with the Occupational Safety and Health Act. The personnel at FFTF have a long standing reputation for operating liquid metal and nuclear systems safely. This is expected to continue by maintaining a staff of trained operating and craft personnel who use approved procedures and tested equipment.

Risks to the environment and the health and safety of personnel will be reduced by removing the reactor fuel, removing the bulk of the liquid metal, and removing cooling fluids like ethylene glycol and Mobiltherm during the deactivation process.

Although the technical risk is low, the risk for schedule delays related to environmental issues is high because regulatory agencies historically take considerable time to approve changes, modifications, or projects that have waste or Clean Air Act implications. 


\begin{tabular}{|c|c|c|c|}
\hline \multicolumn{4}{|c|}{ Table 4-1 } \\
\hline $\begin{array}{c}\text { Project } \\
\text { Activity }\end{array}$ & $\begin{array}{c}\text { Risk } \\
\text { Identification } \\
\end{array}$ & $\begin{array}{l}\text { Risk } \\
\text { Level }\end{array}$ & Assessment-Response \\
\hline \multirow[t]{2}{*}{ Fuel offload } & $\begin{array}{l}\text { Schedule and cost risk due } \\
\text { to insufficient number of } \\
\text { trained and qual ified } \\
\text { operators and support } \\
\text { staff. }\end{array}$ & Low & $\begin{array}{l}\text { Assessment Basis: Fuel offload operations have } \\
\text { been completed safely and successfully at the } \\
\text { reactor vessel, Interim Decay Storage vessel and } \\
\text { the Fuel Storage Facility for nearly } 15 \text { years. } \\
\text { Response: Maintain a high level of qualified } \\
\text { personnel, equipment and procedures. Conduct a } \\
\text { Readiness Assessment prior to fuel offloading. } \\
\text { Continue detailed scheduling of fuel handling } \\
\text { operations. }\end{array}$ \\
\hline & $\begin{array}{l}\text { Fuel handling equipment } \\
\text { failures may delay } \\
\text { schedule. }\end{array}$ & Medium & $\begin{array}{l}\text { Assessment Basis: Operating experience with fuel } \\
\text { handling equipment. } \\
\text { Response: Complete upgrades and continue } \\
\text { preventive maintenance work on the fuel handling } \\
\text { equipment to minimize equipment downtime. Build a } \\
50 \% \text { availability factor into the schedule to } \\
\text { account for fuel handling equipment downtime. }\end{array}$ \\
\hline Fuel Washing & $\begin{array}{l}\text { Schedule and cost risk due } \\
\text { to insufficient number of } \\
\text { trained and qualified } \\
\text { operators and support } \\
\text { staff. }\end{array}$ & Low & $\begin{array}{l}\text { Assessment Basis: Fuel washing to remove sodium } \\
\text { has been completed safely and successfully in the } \\
\text { Interim Examination and Maintenance cell for } \\
\text { nearly } 15 \text { years. } \\
\text { Response: Maintain a high level of qualified } \\
\text { personnel, equipment and procedures Continue } \\
\text { detailed scheduling of IEM cell activities. } \\
\text { Provide operator training for the modified rinse } \\
\text { water ion exchange process equipment. Conduct a } \\
\text { Readiness Assessment prior to commencing fuel } \\
\text { washing operations. }\end{array}$ \\
\hline
\end{tabular}




\begin{tabular}{|c|c|c|c|}
\hline $\begin{array}{l}\text { Project } \\
\text { Activity }\end{array}$ & $\begin{array}{c}\text { Risk } \\
\text { Identification }\end{array}$ & $\begin{array}{l}\text { Risk } \\
\text { Level }\end{array}$ & Assessment-Response \\
\hline Fuel Washing & $\begin{array}{l}\text { Fuel washing equipment } \\
\text { failures may delay the } \\
\text { schedule. }\end{array}$ & Medium & $\begin{array}{l}\text { Assessment Basis: Operating experience during } \\
\text { fuel washing operations in IEM Cell. } \\
\text { Response: Schedule and conduct preventive } \\
\text { maintenance work on the fuel washing equipment to } \\
\text { minimize equipment downtime. Build a } 50 \% \\
\text { availability factor into the schedule to account } \\
\text { for fuel washing equipment downtime. }\end{array}$ \\
\hline $\begin{array}{l}\text { Sodium } \\
\text { Draining }\end{array}$ & $\begin{array}{l}\text { Safety, schedule and cost } \\
\text { risk due to insufficient } \\
\text { number of trained and } \\
\text { qualified operators and } \\
\text { support staff. }\end{array}$ & Low & $\begin{array}{l}\text { Assessment Basis: Sodium draining will be } \\
\text { performed in a manner similar to the initial } \\
\text { sodium fill of FFTF. It is mandatory that this } \\
\text { operation be conducted safely. } \\
\text { Response: Prepare procedures and training classes } \\
\text { to support sodium draining. Verify the procedures } \\
\text { and thoroughly train the operators prior to } \\
\text { draining. Conduct a Readiness Assessment prior to } \\
\text { draining sodium from FFTF. }\end{array}$ \\
\hline
\end{tabular}




\begin{tabular}{|c|c|c|c|}
\hline \multicolumn{4}{|c|}{ Table 4-1 Project Risk Identification, Assessment \& Response } \\
\hline $\begin{array}{c}\text { Project } \\
\text { Activity } \\
\end{array}$ & $\begin{array}{c}\text { Risk } \\
\text { Identification } \\
\end{array}$ & $\begin{array}{l}\text { Risk } \\
\text { Level }\end{array}$ & Assessment-Response \\
\hline $\begin{array}{l}\text { Sodium } \\
\text { Draining }\end{array}$ & $\begin{array}{l}\text { It is planned to remove } \\
\text { sodium from the non- } \\
\text { drainable reactor vessel } \\
\text { inlet plenum and the } \\
\text { Interim Decay Storage } \\
\text { (IDS) Core Component Pots } \\
\text { (CCP) using specially } \\
\text { designed hardware. The } \\
\text { installation and operation } \\
\text { of this hardware has not } \\
\text { been performed before. }\end{array}$ & Medium & $\begin{array}{l}\text { Assessment Basis: Developing the methodology and } \\
\text { hardware for accessing the reactor inlet plenum is } \\
\text { probably the greatest technical challenge of the } \\
\text { FFTF Transition Project. Remote drilling of the } \\
\text { reactor internals and removal of sodium from the } \\
\text { inlet plenum is required. Removing sodium from } \\
\text { the IDS CCP's should be somewhat simpler, but } \\
\text { requires accessing each of the CCP's. The risks } \\
\text { are primarily related to cost and schedule due to } \\
\text { unknowns that may be encountered during the } \\
\text { development of the sodium removal methods and } \\
\text { related hardware. } \\
\text { Response: Develop and test the sodium removal } \\
\text { methods and hardware using personnel with } \\
\text { expertise and previous experience in sodium drain } \\
\text { evolutions and hardware design. Assure craft and } \\
\text { operating personnel are thoroughly trained in the } \\
\text { use of the new equipment before installing the } \\
\text { equipment and removing the sodium. }\end{array}$ \\
\hline NaK Draining & $\begin{array}{l}\text { NaK removal is planned to } \\
\text { be performed by connecting } \\
\text { piping from the FFTF } \\
\text { sodium systems to flush } \\
\text { the Nak systems with } \\
\text { sodium. This operation } \\
\text { has not been performed at } \\
\text { FFTF before. }\end{array}$ & Medium & $\begin{array}{l}\text { Assessment Basis: Connecting piping to a system } \\
\text { containing NaK is a medium risk operation. Steps } \\
\text { must be taken to avoid serious accidents due to } \\
\text { the reactive characteristics of NaK. } \\
\text { Response: Prepare the procedures and training } \\
\text { classes to support the NaK flush and drain } \\
\text { operations. Verify the procedures and train the } \\
\text { operators prior to draining. Assure the crafts } \\
\text { and operators are thoroughly trained prior to } \\
\text { connecting piping or flushing systems containing } \\
\text { NaK. Conduct a Readiness Assessment prior to } \\
\text { draining NaK from FFTF. }\end{array}$ \\
\hline
\end{tabular}




\begin{tabular}{|c|c|c|c|}
\hline \multicolumn{4}{|c|}{ Table 4-1 } \\
\hline $\begin{array}{l}\text { Project } \\
\text { Activity }\end{array}$ & $\begin{array}{c}\text { Risk } \\
\text { Identification }\end{array}$ & $\begin{array}{l}\text { Risk } \\
\text { Level }\end{array}$ & Assessment-Response \\
\hline $\begin{array}{l}\text { Surveillance } \\
\& \\
\text { Maintenance }\end{array}$ & $\begin{array}{l}\text { This activity includes the } \\
\text { routine operation and } \\
\text { maintenance of FFTF plant } \\
\text { systems, equipment and } \\
\text { facilities. The major } \\
\text { activity is related to } \\
\text { circulating sodium prior } \\
\text { to fuel offload and sodium } \\
\text { drain operations. This } \\
\text { includes operating and } \\
\text { maintaining inert gas } \\
\text { systems safely. }\end{array}$ & Low & $\begin{array}{l}\text { Assessment Basis: These activities have been } \\
\text { conducted competently with an exceptional degree } \\
\text { of safety for nearly } 15 \text { years. } \\
\text { Response: Maintain high level of qualified } \\
\text { personnel to support the operations and } \\
\text { maintenance of FFTF systems, equipment and } \\
\text { facilities. }\end{array}$ \\
\hline $\begin{array}{l}\text { Interim } \\
\text { Storage } \\
\text { Area }\end{array}$ & $\begin{array}{l}\text { This activity consists of } \\
\text { constructing a fence and } \\
\text { installing lighting around } \\
\text { an existing concrete pad } \\
\text { near FFTF. The pad will } \\
\text { be used during the fuel } \\
\text { offload operations to } \\
\text { store } 57 \text { shielded storage } \\
\text { casks containing washed, } \\
\text { irradiated fuel. Each } \\
\text { loaded cask will weigh } \\
\text { nearly } 60 \text { tons. }\end{array}$ & Low & $\begin{array}{l}\text { Assessment Basis: Fuel handling operations have } \\
\text { been conducted safely at FFTF for nearly } 15 \text { years. } \\
\text { Response: Test and qualify the cask handling } \\
\text { equipment prior to use. Maintain trained and } \\
\text { qualified fuel handling and crafts personnel. } \\
\text { Assure all safeguards and security requirements } \\
\text { are satisfied prior to moving fuel to the ISA. }\end{array}$ \\
\hline
\end{tabular}




\begin{tabular}{|c|c|c|c|}
\hline \multicolumn{4}{|c|}{ Table 4-1 } \\
\hline $\begin{array}{l}\text { Project } \\
\text { Activity }\end{array}$ & $\begin{array}{c}\text { Risk } \\
\text { Identification }\end{array}$ & $\begin{array}{l}\text { Risk } \\
\text { Level }\end{array}$ & Assessment-Response \\
\hline $\begin{array}{l}\text { Plutonium } \\
\text { Finishing } \\
\text { Plant } \\
\text { Modifications }\end{array}$ & $\begin{array}{l}\text { This activity involves } \\
\text { constructing a fuel } \\
\text { storage rack or facility } \\
\text { to permanently store un- } \\
\text { irradiated FFTF fuel } \\
\text { assemblies at the PFP. }\end{array}$ & Low & $\begin{array}{l}\text { Assessment Basis: Projects like the PFP } \\
\text { modifications and fuel handling work have a long } \\
\text { history of being low risk work. } \\
\text { Response: Assure the design for the PFP } \\
\text { modifications can be safely constructed and } \\
\text { operated consistent with criticality control } \\
\text { procedures. Assure the personnel who will be } \\
\text { handling FFTF fuel at PFP are trained and } \\
\text { qualified. Qualify and test the fuel handling } \\
\text { equipment prior to use. }\end{array}$ \\
\hline $\begin{array}{l}\text { Sodium } \\
\text { Storage } \\
\text { Facility } \\
\text { (SSF) }\end{array}$ & $\begin{array}{l}\text { This project consists of } \\
\text { modifying the piping } \\
\text { connections of four large } \\
\text { tanks and removing some } \\
\text { existing internal hardware } \\
\text { in the } 300 \text { Area. The } \\
\text { connection modifications } \\
\text { are necessary to adapt to } \\
\text { the SSF system piping at } \\
\text { FFTF. These Government- } \\
\text { furnished tanks will then } \\
\text { be transported and } \\
\text { installed in the SSF which } \\
\text { is to be constructed } \\
\text { adjacent to FFTF. Risks } \\
\text { include tank inspections, } \\
\text { work in confined spaces, } \\
\text { and those typical of } \\
\text { construction projects. }\end{array}$ & Low & $\begin{array}{l}\text { Assessment Basis: The technology, safety } \\
\text { practices, construction methodology and operating } \\
\text { procedures for sodium storage facilities have been } \\
\text { proven to be of low risk in several liquid metal } \\
\text { reactor facilities. } \\
\text { Response: Design the SSF for safe construction } \\
\text { and operation. Assure the construction and } \\
\text { operational testing procedures are properly } \\
\text { prepared. Assure the personnel who will be } \\
\text { performing tank inspections, constructing the } \\
\text { facility, and operating the facility are properly } \\
\text { trained. Maintain a high level of qualified } \\
\text { personnel to support operation of the SSF. } \\
\text { Conduct a Readiness Assessment prior to } \\
\text { transferring sodium to the SSF. }\end{array}$ \\
\hline
\end{tabular}




\begin{tabular}{|c|c|c|c|}
\hline \multicolumn{4}{|c|}{ Table 4-1 } \\
\hline $\begin{array}{c}\text { Project } \\
\text { Activity }\end{array}$ & $\begin{array}{c}\text { Risk } \\
\text { Identification } \\
\end{array}$ & $\begin{array}{l}\text { Risk } \\
\text { Level } \\
\end{array}$ & Assessment-Response \\
\hline $\begin{array}{l}\text { Sodium } \\
\text { Reaction } \\
\text { Facility } \\
\text { (SRF) }\end{array}$ & $\begin{array}{l}\text { This project constructs a } \\
\text { facility that will receive } \\
\text { molten sodium from the SSF } \\
\text { and convert it into a } \\
\text { sodium hydroxide solution } \\
\text { to be used as feed stock } \\
\text { for the Tank Waste } \\
\text { Remediation System work in } \\
\text { the } 200 \text { Area. The SRF } \\
\text { will be constructed } \\
\text { adjacent the SSF at FFTF. } \\
\text { A schedule risk exists } \\
\text { since it is planned that } \\
\text { the ANL-W Site (EBR-II } \\
\text { Idaho) reaction facility } \\
\text { design will be used here } \\
\text { for reacting sodium which } \\
\text { has been drained from } \\
\text { FFTF. Problems with the } \\
\text { ANL-W reaction process } \\
\text { testing or design could } \\
\text { impact the FFTF schedule. } \\
\text { Design and procedure } \\
\text { controls must be defined. }\end{array}$ & High & $\begin{array}{l}\text { Assessment Basis: FFTF has not been involved } \\
\text { previously in this type of work. The level of } \\
\text { risk will be greatest during SRF operation. } \\
\text { Significant schedule delays may occur if the } \\
\text { funding, design or testing activities for the ANL- } \\
\text { W Site sodium reaction process are delayed. } \\
\text { Response: Maintain close communications with the } \\
\text { ANL-W Site to understand the design, testing and } \\
\text { operating plans for their sodium reaction system. } \\
\text { Send FFTF technical and operating personnel to } \\
\text { ANL-W to become experienced with their process. } \\
\text { Conduct a Readiness Assessment prior to } \\
\text { transferring sodium to the SRF. } \\
\text { Consider contracting the sodium reaction work to } \\
\text { an organization that is experienced, trained and } \\
\text { qualified to do this work. This may include using } \\
\text { the services of a contractor who has operated } \\
\text { other liquid metal reaction facilities and } \\
\text { processes. }\end{array}$ \\
\hline
\end{tabular}




\begin{tabular}{|c|c|c|c|}
\hline \multicolumn{4}{|c|}{ Table 4-1 } \\
\hline $\begin{array}{l}\text { Project } \\
\text { Activity }\end{array}$ & $\begin{array}{c}\text { Risk } \\
\text { Identification }\end{array}$ & $\begin{array}{l}\text { Risk } \\
\text { Level }\end{array}$ & Assessment-Response \\
\hline Costs-Funding & $\begin{array}{l}\text { The funding to support } \\
\text { construction of the } \\
\text { Interim Storage Area and } \\
\text { the design and } \\
\text { construction of the Sodium } \\
\text { Storage Facility is } \\
\text { pending DOE-HQ } \\
\text { authorization. Lack of } \\
\text { funding can delay the } \\
\text { schedule. For example, } \\
\text { capital funding must be } \\
\text { received by January } 2 \text {, } \\
\text { 1995, to achieve the } \\
\text { Multi-year Program Plan } \\
\text { (MYPP) accelerated } \\
\text { milestone to construct and } \\
\text { turnover the SSF by } \\
\text { January } 30 \text {, } 1997 \text {. }\end{array}$ & High & $\begin{array}{l}\text { Assessment: Institutional barriers, budgeting } \\
\text { limitations and funding restrictions have a high } \\
\text { probability of delaying the schedule and } \\
\text { increasing costs due to replanning. In addition, } \\
\text { any schedule extension increases the impact of } \\
\text { risks related to losing experienced and qualified } \\
\text { personnel. } \\
\text { Response: The RLS identifies those activities } \\
\text { that must be funded, and in some cases } \\
\text { accelerated, to complete the FFTF Transition } \\
\text { Project with the least time and cost. Continue to } \\
\text { provide as accurate cost and schedule information } \\
\text { as possible to DOE to justify the minimum required } \\
\text { funding to achieve the milestone and schedule } \\
\text { objectives. }\end{array}$ \\
\hline
\end{tabular}




\begin{tabular}{|c|c|c|c|}
\hline \multicolumn{4}{|c|}{ Table 4-1 } \\
\hline $\begin{array}{l}\text { Project } \\
\text { Activity }\end{array}$ & $\begin{array}{c}\text { Risk } \\
\text { Identification } \\
\end{array}$ & $\begin{array}{l}\text { Risk } \\
\text { Level } \\
\end{array}$ & Assessment-Response \\
\hline $\begin{array}{l}\text { Environmental } \\
\text { Regulatory }\end{array}$ & $\begin{array}{l}\text { The State of Washington } \\
\text { Department of Health (DOH) } \\
\text { has an interest in } \\
\text { assuring that the fuel } \\
\text { offload, sodium storage } \\
\text { and sodium reaction } \\
\text { activities support air } \\
\text { emission regulations. The } \\
\text { removal of sodium \& NaK, } \\
\text { and the eventual reaction, } \\
\text { will reduce the potential } \\
\text { for an environmental } \\
\text { impact. Although the } \\
\text { deactivation activities } \\
\text { and the new construction } \\
\text { projects are not expected } \\
\text { to have any significant } \\
\text { environmental impact, } \\
\text { inadequate communications } \\
\text { with the DoH could delay } \\
\text { completion of the FFTF } \\
\text { Transition Project. }\end{array}$ & High & $\begin{array}{l}\text { Assessment Basis: The fuel offload activity will } \\
\text { be performed using qualified personnel, procedures } \\
\text { and equipment. No environmental impacts are } \\
\text { anticipated for fuel offload. Although no } \\
\text { environmental impacts are expected, the Sodium } \\
\text { Storage and Reaction Facilities are subject to a } \\
\text { preconstruction review and approval by the DOH to } \\
\text { assure air emission requirements continue to be } \\
\text { met. The risk level is shown as high because } \\
\text { regulatory agencies historically take considerable } \\
\text { time to approve modifications or projects that } \\
\text { have waste or Clean Air Act implications. } \\
\text { Response: Assure the DoH is advised of the design } \\
\text { and equipment that will be used to control the } \\
\text { emission of radionuclides from the SSF and SRF. } \\
\text { Provide written Notice of Construction according } \\
\text { to Washington Administrative Code 246-247, } \\
\text { Radiation Protection, Air Emissions. }\end{array}$ \\
\hline
\end{tabular}




\begin{tabular}{|c|c|c|c|}
\hline \multicolumn{4}{|c|}{ Table 4-1 Project Risk Identification, Assessment \& Response } \\
\hline $\begin{array}{l}\text { Project } \\
\text { Activity } \\
\end{array}$ & $\begin{array}{c}\text { Risk } \\
\text { Identification }\end{array}$ & $\begin{array}{l}\text { Risk } \\
\text { Level }\end{array}$ & Assessment-Response \\
\hline $\begin{array}{l}\text { Tri-Party } \\
\text { Agreement }\end{array}$ & $\begin{array}{l}\text { The January } 1994 \text { amendment } \\
\text { to the Tri-Party Agreement } \\
\text { (TPA) requires DOE to } \\
\text { negotiate with the } \\
\text { Washington State } \\
\text { Department of Ecology and } \\
\text { the U. S. Environmental } \\
\text { Protection Agency to } \\
\text { coordinate activities } \\
\text { associated with the } \\
\text { transition of facilities } \\
\text { to a safe, stable and } \\
\text { environmentally sound } \\
\text { condition suitable for } \\
\text { extended surveillance and } \\
\text { maintenance pending final } \\
\text { decommissioning. }\end{array}$ & High & $\begin{array}{l}\text { Assessment Basis: Milestones and target dates } \\
\text { resulting from the TPA negotiations, which began } \\
\text { in July of 1994, could impact the Project and } \\
\text { increase costs. The TPA negotiation process can } \\
\text { cause unexpected changes in the Hanford Site } \\
\text { environmental restoration and transition } \\
\text { activities priorities, which will in turn impact } \\
\text { the funding and schedules for the FFTF Transition } \\
\text { Project. } \\
\text { Response: Develop TPA change packages and } \\
\text { negotiating strategies that support the FFTF } \\
\text { Transition Project in a safe, practical and cost } \\
\text { effective manner. Modify the Advanced Reactors } \\
\text { Transition Multi-Year Program Plan, the Plan and } \\
\text { the RLS to incorporate changes that may be } \\
\text { necessary to support TPA revisions. }\end{array}$ \\
\hline A11 & $\begin{array}{l}\text { Addition of tasks not } \\
\text { related to the project } \\
\text { scope or goals. }\end{array}$ & High & $\begin{array}{l}\text { Assessment Basis: The cost and schedule baselines } \\
\text { are as tight as possible for the known scope. The } \\
\text { addition of administrative tasks such as new DOE } \\
\text { Orders, codification (i.e., rule shifting from DOE } \\
\text { Orders to the Code of Federal Regulations) and } \\
\text { Standards Requirements Identification Documents } \\
\text { (S/RID) with no budget allowance will divert } \\
\text { limited resources. The resulting delay can } \\
\text { decrease the availability of sodium process } \\
\text { technical expertise and result in increased cost, } \\
\text { safety and schedule risks. } \\
\text { Response: Maintain close communications with DOE } \\
\text { to assure the addition of new work scope, } \\
\text { including unfunded work, is minimized during the } \\
\text { FFTF transition process. }\end{array}$ \\
\hline
\end{tabular}




\begin{tabular}{|c|c|c|c|}
\hline \multicolumn{4}{|c|}{ Project Risk Identification, Assessment \& Response } \\
\hline $\begin{array}{l}\text { Project } \\
\text { Activity }\end{array}$ & $\begin{array}{c}\text { Risk } \\
\text { Identification }\end{array}$ & $\begin{array}{l}\text { Risk } \\
\text { Level }\end{array}$ & Assessment-Response \\
\hline A11 & $\begin{array}{l}\text { Reduction of experienced } \\
\text { and qual ified personnel } \\
\text { below necessary levels. }\end{array}$ & High & $\begin{array}{l}\text { Assessment Basis: Following receipt of the } \\
\text { April 1, 1992 Standby Order, the experience level } \\
\text { of the FFTF staff began decreasing. The attrition } \\
\text { accelerated with the December 15, 1993 Shutdown } \\
\text { Order. It is anticipated that the Hanford } \\
\text { Restructuring Plan approved and issued in late } \\
1994 \text { will quicken the attrition of experienced } \\
\text { personnel. It takes time to rebuild } \\
\text { qualification; it may be impossible to restore } \\
\text { experience. } \\
\text { Response: Accelerate the transition schedule } \\
\text { where practical to benefit from the experience of } \\
\text { the present staff while they are available. }\end{array}$ \\
\hline
\end{tabular}
personnel. It takes time to rebuild

qualification; it may be impossible to restore

where practical to benefit from the experience of 


\subsection{MANAGEMENT APPROACH}

This section identifies the major participants and establishes the organizational authority, responsibility, and accountability required to effectively manage the FFTF Transition Project scope, schedule, and cost baselines. Management of these baselines includes the quality assurance, human resource, contractual, procurement, communication, risk, health and safety, regulatory, and environmental elements of the Project.

\subsection{MANAGEMENT STRATEGY}

The deactivation activities will be planned, managed and controlled in compliance with the following procedures:

$\begin{array}{lll}\text { DOE 4700.1 } & \text { Project Management System } & \text { (Reference 1) } \\ \text { RLIP 4700.1A } & \text { Project Management System } & \text { (Reference 5) } \\ \text { WHC-CM-2-5 } & \text { Management Control System } & \text { (Reference 7) }\end{array}$

The deactivation of FFTF will be managed, controlled and reported upon to achieve the cost and schedule goals in the Plan and RLS. A formal change control system will be implemented to manage the scope, schedule and cost baselines. In addition to this Project Plan, a Project-specific Management Plan will be prepared for selected sub-projects. As examples, these include the Plutonium Finishing Plant Modifications Project, the Sodium Storage Facility Project and the Sodium Reaction Facility Project. All scope, schedule and cost changes, including the impact of Tri-Party Agreement negotiations, will be managed by the FFTF Transition Project Change Control Board, which is described in Section 9.0.

\subsection{ORGANIZATION}

The DOE-HQ NE-44 Office of Nuclear Energy requested in Reference 15 that the Manager of RL implement a cost-effective project approach to place FFTF in a radiologically and industrially safe shutdown condition. As a result, a Project team with representatives from several organizations was formed to fulfill the request. The Project team and their focused objective to successfully complete the FFTF Transition Project is illustrated by Figure 5-1. Other stakeholders may be added to the team when needed.

Independent oversight of the transition activities is provided by the U. S. Environmental Protection Agency, and the State of Washington State Departments of Ecology and Health.

The WHC FFTF Transition Project Office is responsible for the overall project management and integrating the activities of the Project team.

The responsibilities of the Project team members are described in Section 11.0 , "Project Charter." 


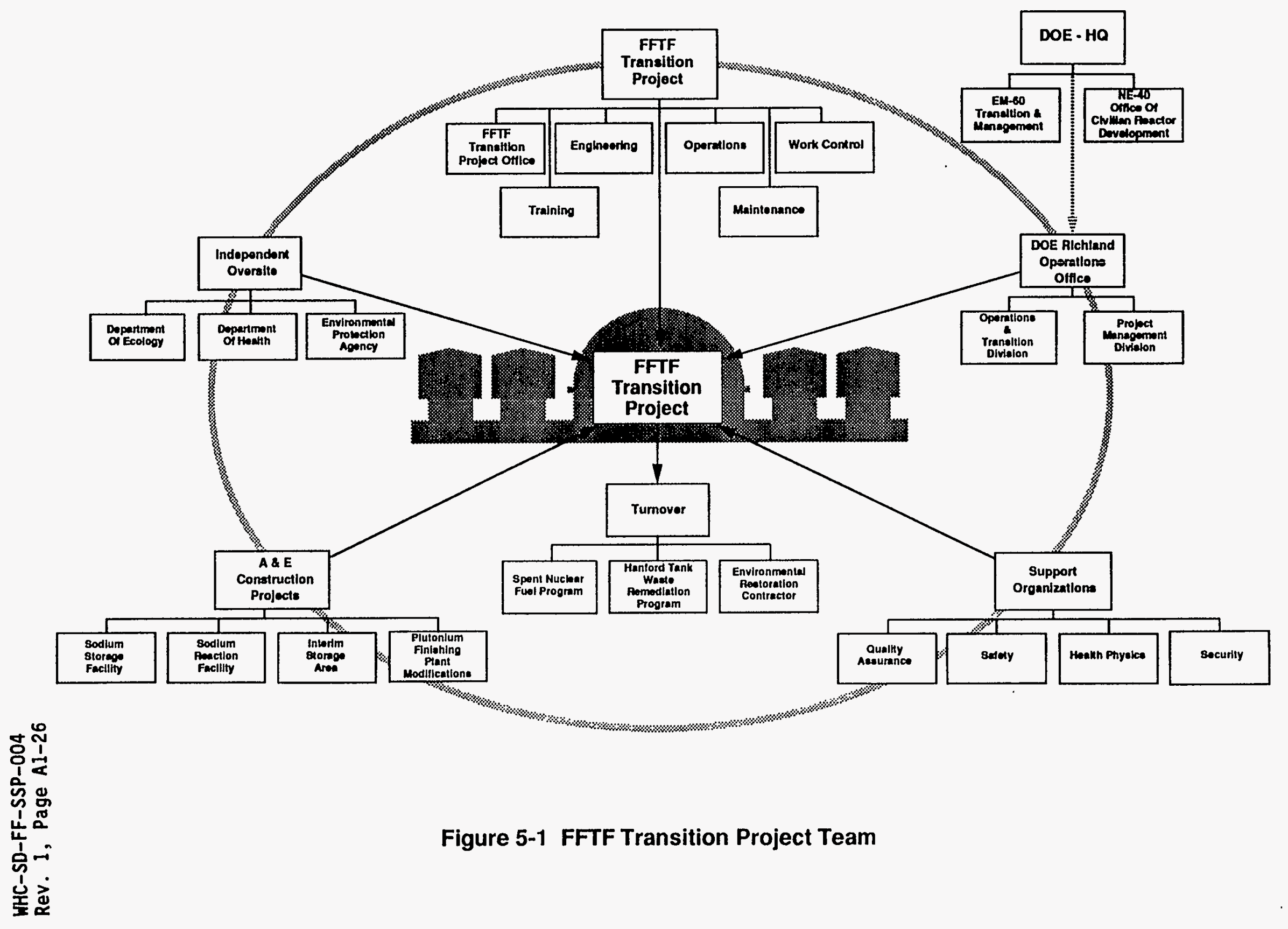




\subsection{MANAGEMENT CONTROL SYSTEM}

\subsubsection{Introduction}

A Management Control System (MCS) consistent with Reference 1 (DOE 4700.1), Reference 5 (RLIP 4700.1A) and Reference 7 (WHC-CM-2-5) will be used to manage the Project baselines effectively. The primary objective is to execute the FFTF Transition Project in a safe, technicaliy sound, timely and costeffective manner. The MCS will be used to establish and control the detailed scope, schedule and cost baselines of the Project.

The summary level baselines are defined by RL. Table 5-1 shows where the baseline information is described.

\begin{tabular}{||l|l||}
\hline \multicolumn{1}{|c|}{ Table 5-1 FFTF Transition Project Summary Baselines } \\
\hline \multicolumn{1}{|c|}{ Description } & \multicolumn{1}{|c|}{ Comments } \\
\hline \hline $\begin{array}{l}\text { Project Summary Work Breakdown } \\
\text { Structure (PSWBS) }\end{array}$ & Provided by Figure 3-1. \\
\hline $\begin{array}{l}\text { Transition Project Summary } \\
\text { Schedule }\end{array}$ & Provided by Plan (Figure 1). \\
\hline $\begin{array}{l}\text { Budget Estimates } \\
\text { Note: The Project scope, schedule, cost and related milestones are governed } \\
\text { by the Advanced Reactors Transition Fiscal Year Multi-Year Program } \\
\text { Plan (Reference 14, WHC-SD-FF-SSP-052). }\end{array}$ \\
\hline
\end{tabular}

The PSWBS has been subdivided into a logical order from which a more detailed Contractor Work Breakdown Structure (CWBS) was prepared. The CWBS is used to develop the detailed scope, schedule and cost baselines which are in the RLS.

The RLS is used to define, budget, schedule, measure, control and manage the Project material and labor resources effectively. Cost and schedule data will be collected, evaluated, and reported by the CWBS cost account and work package elements.

The Project will be controlled against the following baselines:

1) Scope Baseline - defines all activities, including the labor and material resources consumed, and the resulting end products as governed by the Advanced Reactors Transition Fiscal Year MultiYear Program Plan (Reference 14, WHC-SD-FF-SSP-052). This encompasses satisfying all technical, quality, safety, environmental and operating requirements.

2) Cost Baseline - defines all cost-related aspects by WBS cost account and work package element as shown in the Plan and the RLS and as governed by the MYPP (Reference 14). 
WHC-SD-FF-SSP-004

Rev. 1, Page A1-28

3) Schedule Baseline - correlates the time-related aspects of the Project as described in the Plan and restrained by funding, 1 abor and material resources. The MYPP (Reference 14) is the governing schedute.

Modifications or changes to the scope, cost, and schedule baselines and the related milestones will be controlled by the FFTF Transition Project Change Control Board which is described in Section 9.0.

The MCS supports the flow of integrated cost and schedule information from WHC to DOE-RL and DOE-HQ to ensure timely decision making. The MCS will be used by the FFTF Transition Project management team to accomplish the following:

1) Provide a work breakdown structure that defines the Project in a disciplined manner from the overall project level to lower level work packages.

2) Provide scope, schedule and cost information in sufficient detail to measure and report progress toward achieving the planned activities and milestones.

3) Facilitate the evaluation of scope, schedule and cost data to identify trends or problems requiring management intervention.

4) Coordinate the availability of funding to satisfy planned commitments.

All work plans will be evaluated and managed by WHC to make sure: (1) the available funding, labor and material resources support planned work; (2) the work is completed by the scheduled completion dates; and (3) future cost factors like increased labor rates and inflation are considered. This includes continual monitoring and reporting the performance of contractors to identify cost or schedule trends that may cause unfavorable deviations from the Plan and the MYPP (Reference 14).

\subsubsection{Scope Baseline Management}

Management of the design for the scope baseline will be performed at specific points during the design as required by Reference 10 (WHC-CM-6-1, EP 4.I). As the design develops, reviews will be conducted with the results documented to provide assurance that the functional design criteria, safety, quality, environmenta] and operating requirements are satisfied. RL will participate in the design reviews for selected sub-projects, e.g. the Sodium Storage Facility, the Sodium Reaction Facility and the Plutonium Finishing Plant modifications.

As an example, management of the Sodium Storage Facility scope baseline during construction will include monitoring equipment fabrication, building erection, and installation of the storage tanks, piping and equipment. This includes oversight of the on-site inspection contractor's quality assurance activities.

Management of the scope baseline during the test phase will include defining the testing requirements and comparing the test results with the specified design, testing and operating requirements. 


\subsubsection{Cost Baseline Management}

The WHC will manage the cost baseline to ensure that the Project is completed successfully and within the cost and budget estimates. Activity based cost estimates will be prepared following Reference 6 (Office of Waste Management EM-30 cost and Schedule Estimating Guide). The resulting estimates will be used to establish a cost baseline which will be managed throughout the Project life-cycle to minimize changes to the scope, cost and schedule baselines and respond to cost trend information in a timely manner.

\subsubsection{Cost Estimate Reviews}

Thorough reviews of cost estimates, including the system shutdown, defueling and sub-project activities, shall be performed at least annually. The results of these reviews and any corrective action shall be documented. The cost estimate reviews shail assure the following requirements are met:

1) Cost estimate scope is consistent with the PSWBS and a7l approved changes.

2) Cost estimate assumptions are documented. This includes the scope and schedule basis for all FFTF deactivation activities including the construction sub-projects.

3) Cost estimates are performance based and founded upon detailed drawing take-offs whenever practical. This is the preferred method of estimating and shall be done when the definitive design for each sub-project is completed. Performance estimates are bottoms-up, definitive cost estimates and should typically be $\pm 5 \%$ accurate. The cost estimates for manufactured or fabricated items may be supported by vendor quotes.

Parametric estimating techniques may be used when the design details are insufficient to prepare estimates based on actual quantities. Parametric cost estimates are typically $\pm 20 \%$ accurate and are used when the project is not completely defined.

Magnitude cost estimates may be used when the process and products are not defined and there is little information to base estimates upon. Magnitude estimates are typically $\pm 50 \%$ accurate.

4) Minimize the use of cost estimates based upon estimator experience without reference to a known quantities and unit rates.

5) Base labor rates and productivity upon local rates and experience.

6) Assure contingency allowances are properly applied. Contingency allowances are intended to cover unknown or unforseen costs such as minor scope changes, design refinements, changes in market conditions, minor labor rate changes, and work stoppages due to normal weather conditions. Contingency allowances are not expected to cover impacts due to unforeseen items 1 ike prolonged labor strikes, weather disasters, changes in budgets, major scope 
WHC-SD-FF-SSP-004

Rev. 1, Page A1-30

additions, new regulations, or requirements beyond the control of the Project.

Contingency is not assigned to the operating portion of the budget because it has more historical data from which accurate budgets can be estimated. For more information related to the application of contingency to the Project, refer to the RLS.

Cost estimates may be performed by $\mathrm{RL}$, or by independent cost estimating groups working for RL.

\subsubsection{Cost Performance Monitoring}

Cost performance monitoring will include the generation, analysis and reporting of the following information in an objective and timely manner:

1) Cost performance and analysis data. Variances or deviations from the approved thresholds shall be analyzed. A corrective plan to resolve the variances shall be provided with the analysis. The WHC Management Control System (Reference 7, WHC-CM-2-5) shall be used to report this information.

2) Monthly cost performance reports shall be prepared. The cost performance reporting requirements are given in Section 5.3.5.

\subsubsection{Estimates at Completion}

The WHC is responsible for reporting the estimate at completion (EAC) for the Project periodically, or as requested by $\mathrm{RL}$. As a minimum, an updated EAC for each active sub-project will be reported at the Project quarterly meetings. The report shall show the contingency available for the remaining work in each activity or sub-project. The updated EAC shall be based upon current performance and productivity data, an assessment of changed conditions, current pricing data, and supportable forecasts of future conditions.

\subsubsection{Schedule Basel ine Management}

As a minimum, the progress of the FFTF Transition Project will be monitored and reported against the schedule basel ines and milestones each month. The cause and corrective action for all schedule variances will be reported.

\subsubsection{Performance Reporting}

The FFTF Transition Project Office Manager wi11 provide performance reports summarizing the design and construction progress, milestone status, cost status, and the plans to resolve problem areas as required Reference I (DOE 4700.1) and Reference 5 (RLIP 4700.1A). The Project team will use the reports to control the overall Project scope, cost, and schedule baselines. 


\subsubsection{Report Content}

The FFTF Transition Project Office Manager shall report the deactivation activity status monthly and quarterly. The report information shall be obtained from the same data base which supports the day-to-day management of the Project. The following information shall be given in the reports listed in Section 5.3.5.2.

1) Accomplishments and status for each major element or sub-project.

2) Problems and resolutions affecting the scope, cost or schedule baselines.

3) Significant open commitments.

4) Cost performance and contingency status.

5) Schedule status.

Exceptions or problems reported in prior months shall be reported monthly through their resolution.

\subsubsection{Cost and Schedule Reports}

The required cost and schedule reports are 1 isted in Table 5-2.

\begin{tabular}{|c|c|c|}
\hline \multicolumn{3}{|c|}{ Table 5-2 FFTF Transition Project Reports } \\
\hline Name & Frequency & Prepared by \\
\hline Site Management System Report & Monthiy & $\begin{array}{c}\text { Transition Business } \\
\text { Management }\end{array}$ \\
\hline $\begin{array}{l}\text { Deactivation and Shutdown Transition } \\
\text { Status Report }\end{array}$ & Monthiy & FFTF Transition Project \\
\hline Consolidated Progress Report ${ }^{1}$ & Monthly & Project Manager \\
\hline Milestone Schedule and Status Report ${ }^{1}$ & Month7y & Project Manager \\
\hline Monthiy Progress Report ${ }^{1}$ & Monthly & Project Manager \\
\hline \multicolumn{3}{|c|}{$\begin{array}{l}\text { Note 1: Prepared by the wHC Projects Department Manager or Engineer and submitted to the FFTF } \\
\text { Transition Project office Manager, and to the RL Project Management Division. The } \\
\text { format and requirements for these reports are given in Reference } 5 \text { (RLIP } 4700.1 A \text { ). }\end{array}$} \\
\hline
\end{tabular}

\subsubsection{Report Distribution}

Distribution of the reports will follow Reference 5 (RL 4700.1A) and Reference 7 (WHC-CM-2-5). 


\subsubsection{Review Meetings}

The FFTF Transition Project Office Manager has the lead responsibility for the monthly Management Review Meetings (MRM). These meetings are conducted with $\mathrm{RL}$, the Operating Contractor (OC), the Engineering Contractor (EC) and Construction Management (CM) Contractor, or other project participants. The following information will be reported at the meetings:

1) Work status and significant progress.

2) Significant problems and planned corrective actions.

3) Cost and schedule performance status.

4) Cost and schedule trends.

5) Contingency status.

6) Priority efforts for the following three months.

Subsequent meetings will highlight the status and disposition of previously identified problems.

Quarterly review meeting will also be conducted. In addition to the items in the monthly meetings, the quarterly review meeting will include an in-depth review emphasizing significant work accomplishments, concerns, and unresolved problems during the past quarter.

When the responsibility for a project has been assigned to a WHC Projects Department Manager or Engineer, they are responsible for preparing and presenting the monthly and quarterly status information (Section 5.3.5.1) to the RL Project Management Division and to the FFTF Transition Project Office.

\subsection{BUDGET, COST AND SCHEDULE PERFORMANCE MEASUREMENT}

The budget, cost and schedule baselines for the Project have been established in accordance with Reference 7 (WHC-CM-2-5). The major steps in performance measurement and reporting are shown in Figure 5-2 and shall accomplish the following:

1) Provide timely and objective cost and schedule performance data.

2) Track actual progress against the baseline budget estimates and schedule milestones on a monthly basis.

3) Measure cost and schedule progress using earned value techniques.

4) Identify undesirable cost and schedule variances to facilitate management intervention.

5) Develop work-around plans to allay or mitigate unfavorable variances.

6) Initiate cost estimates and budget revisions when cost and schedule variances cannot be corrected within approved funding.

7) Provide cost performance reports (CPR) that integrate all elements of the Project. The CPR will be part of the Site Management 
System (SMS) monthiy report. Earned value progress and changes in the Estimate-At-Completion (EAC) cost will be included in the CPR.

8) Provide a variance analysis by WBS element highlighting situations that exceed the reporting thresholds. The anaiysis shall include incremental and cumulative data and include a statement of the problem and the corrective action taken or planned. The variance thresholds assigned for all variances shall be based on the Budgeted Cost of Work Scheduled (BCWS) as shown below and required by Reference 7 (WHC-CM-2-5, Procedure 3.1). More stringent thresholds can be imposed at the direction of RL, or the WHC FFTF Transition Project Office Manager.

$$
\begin{aligned}
& \text { BCWS }<\$ 500,000= \pm 10 \% \text { and } \pm \$ 10,000 \\
& \text { BCWS > } \$ 500,000= \pm \$ 50,000
\end{aligned}
$$


WHC-SD-FF-SSP-004

Rev. 1, Page A1-34

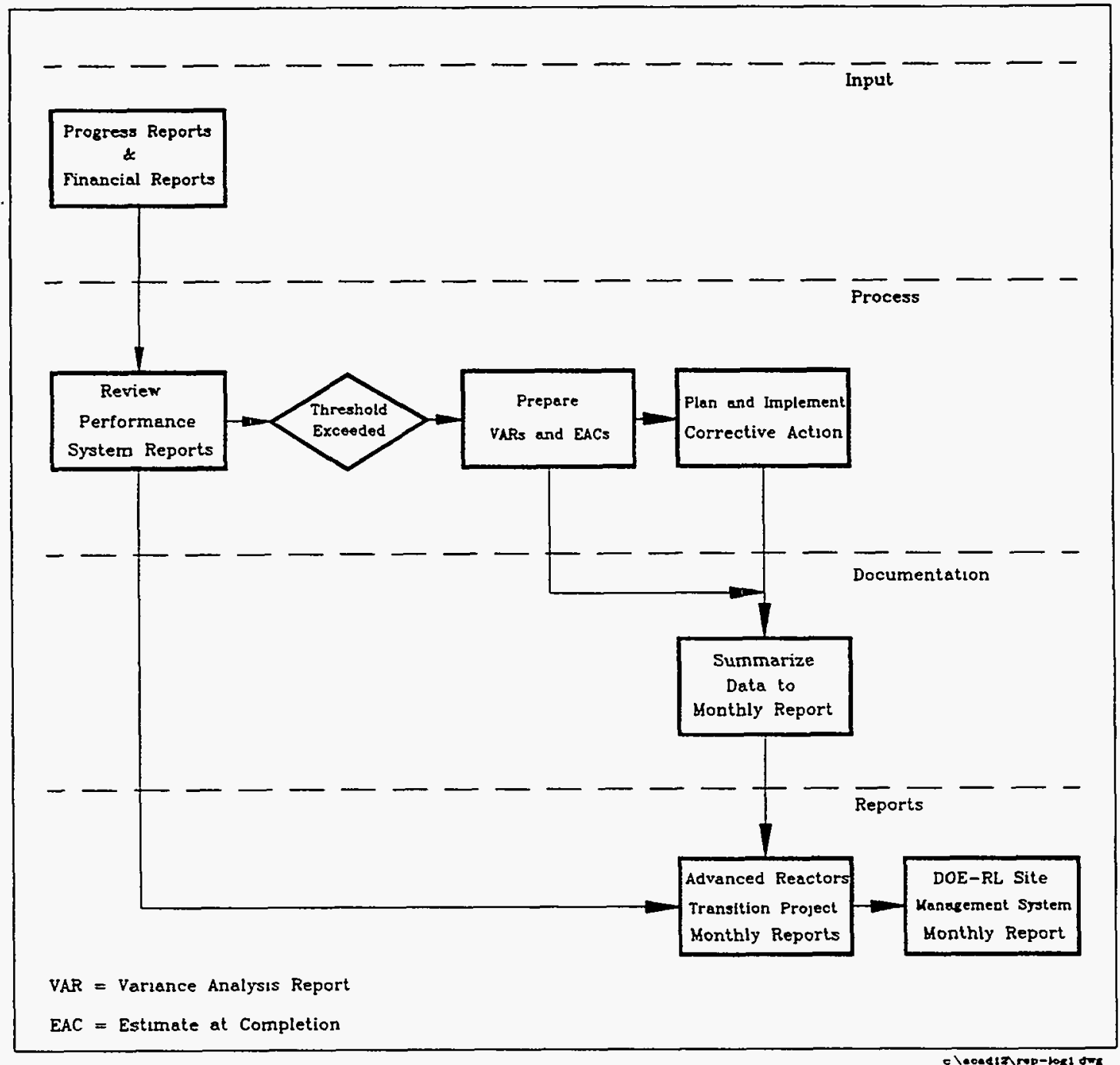

Figure 5-2 Performance Analys is and Reporting Process 


\subsection{BASELINE CHANGE CONTROL}

Changes to the Project cost, schedule and technical baselines are classified as Class I, Class II, or Class III, according to the magnitude of impact. Changes are classified to identify the approval authority. The types of baseline changes and class are shown in Table 5-3.

Although the current DOE-HQ guidance in Reference 1 (DOE 4700.1) refers to Level 0 and Level I as DOE-HQ approval levels, the FFTF Transition Project intends to use the Site Management System terminology in Reference 7 (WHC-CM-2-5), which designates DOE-HQ changes as Class I.

A11 changes to the project schedule, cost and technical baselines will be according to DOE-HQ, RL and WHC Management Control System procedures of Reference 1 (DOE 4700.1), Reference 5 (RLIP 4700.1A), Reference 7 (WHC-CM-2-5, Section 4.1) and Reference II (WHC-CM-6-2, PM 14).

It is not permissible to break a large change into several smaller changes to reduce the classification. Each change shall be identified by a single, stand alone Baseline Change Request.

The approval of RL is required for usage of any contingency when the available contingency is less than $1.4(5 \% \times$ TEC w/o contingency). Funds remaining after completion of a work element may be moved to another work element by the Project Engineer.

The FFTF Transition Project Office Manager is responsible for managing all Change Requests used to control the Project baselines. This includes chairing the FFTF Change Control Board and maintaining the Change Control Log (Section 9.0).

The Plan and the Project-specific Management Plans for the applicable FFTF systems, defueling activities and supporting sub-projects will be reviewed and updated annually to incorporate management decisions, significant changes in scope, and maintain their validity as a project baseline documents. 
WHC-SD-FF-SSP-004

Rev. 1, Page Al-36

\begin{tabular}{|c|c|c|c|}
\hline \multicolumn{4}{|c|}{ Table 5-3 Basel ine Change Classes } \\
\hline Thresholds & Technical & Cost & Schedule \\
\hline $\begin{array}{l}\text { Level I } \\
\text { DOE HQ } \\
\text { (PSO) }\end{array}$ & $\begin{array}{l}\text { Any change in } \\
\text { scope identified } \\
\text { \& approved for HQ } \\
\text { Program Manager/ } \\
\text { Project Manager } \\
\text { Control } \\
\text { Source Document - } \\
\text { DOE HQ's Office } \\
\text { of Waste } \\
\text { Operations (OWO) } \\
\text { Standard } \\
\text { Operating } \\
\text { Practices and } \\
\text { Procedures OWO } \\
5.06\end{array}$ & $\begin{array}{l}\text { Any Change } \geq \$ 5 \\
\text { MiTl ion or } 10 \% \\
\text { TEC, whichever is } \\
\text { less }\end{array}$ & $\begin{array}{l}\text { Level } 1 \mathrm{HQ} \\
\text { Milestones } \geq 2 \\
\text { Months }\end{array}$ \\
\hline $\begin{array}{l}\text { Class I (Level 2) } \\
\text { DOE RL }\end{array}$ & $\begin{array}{l}\text { Any changes to } \\
\text { PSWBS } \\
\text { *Any changes to } \\
\text { Functional Design } \\
\text { Criteria or scope } \\
\text { identified \& } \\
\text { approved for RL } \\
\text { control }\end{array}$ & $\begin{array}{l}\text { Any change }<\$ 5 \\
\text { Million or } \geq \$ 50 \\
\text { Thousand }\end{array}$ & $\begin{array}{l}\text { Any change to } \\
\text { Baseline } \\
\text { Milestones }\end{array}$ \\
\hline $\begin{array}{l}\text { Class II } \\
\text { WHC Project Mgr. }\end{array}$ & $\begin{array}{l}\text { Definitive Design } \\
\text { Media }\end{array}$ & $\begin{array}{l}<\$ 50 K \\
\geq \$ 5 K\end{array}$ & $\begin{array}{l}\text { Level } 3 \\
\text { Milestones on } \\
\text { Project Master } \\
\text { Schedule }<1 \\
\text { Month }\end{array}$ \\
\hline $\begin{array}{l}\text { Class III } \\
\text { Contractor }\end{array}$ & $\begin{array}{l}\text { Changes other } \\
\text { than Class I or } \\
\text { Class II }\end{array}$ & $<\$ 5 K$ & $\begin{array}{l}\text { Level } 4 \\
\text { Milestones } \\
\text { Any change }\end{array}$ \\
\hline
\end{tabular}

PSO = Program Secretarial Officer

PSWBS = Project Summary Work Breakdown Structure

$* \quad=$ RL Program Approval

$<\quad=$ Less than

$\geq \quad=$ Greater than or equal to

$\leq \quad=$ Less than or equal to 


\subsection{PROJECT MANAGEMENT PLANS}

A Project Management Plan shall be prepared for selected sub-projects following the guidance of Reference I (DOE 4700.1), Reference 5 (RLIP 4700.1A) and Reference 11 (WHC-CM-6-2). The PMP is used to manage the design and construction of projects in an efficient and cost effective manner. Table 5-4 shows the construction sub-projects which are planned to support the FFTF Transition Project.

\begin{tabular}{|c|c|c|}
\hline \multicolumn{2}{|c|}{ Table 5-4 } & Project F-028 FFTF Transition Construction Sub-projects \\
\hline Sub-Project & Description & $\begin{array}{c}\text { Project Management } \\
\text { Plan Required }\end{array}$ \\
\hline \hline $01-F-029$ & Interim Storage Area & No \\
\hline $02-F-030$ & Plutonium Finishing Plant Modifications & Yes \\
\hline $03-F-031$ & Sodium Storage Facility & Yes \\
\hline $04-F-032$ & Sodium Reaction Facility & Yes \\
\hline
\end{tabular}

A project-specific PMP will be prepared for each of the sub-projects with the exception of the Interim Storage Area. Because the Interim Storage Area consists of installing an inexpensive fence and lighting configuration around an existing concrete pad, there is no cost benefit in preparing a Project Management Plan. When the conceptual design.for the Plutonium Finishing Plant Modifications is completed, it is possible that the design and construction work may also be relatively simple and not require a PMP.

The PMP for each of the applicable sub-projects shall establish the organizational responsibilities and baseline controls to achieve the technical, safety, environmental, cost and schedule requirements of the Plan. In addition, each PMP shall be based on the Functional Design Criteria and the Conceptual Design Report for each sub-project. The PMP shall be issued before commencing the definitive design of each of the applicable sub-projects. Each PMP shal1 be issued as a separate supporting document to control changes that may be necessary during the sub-project life-cycle.

\subsection{QUALITY ASSURANCE REQUIREMENTS}

To provide the requisite level of quality, the FFTF Transition Project Quality Assurance Program will be in accordance with Reference 3 (DOE 5700.6C) and Reference 4 (10 CFR 830.120). All Quality Assurance activities will follow Reference 8 (WHC-CM-4-2). As examples, a project-specific quality assurance plan will be prepared for Sodium Storage and Sodium Reaction Facility subprojects. 
WHC-SD-FF-SSP-004

Rev. 1, Page Al-38

\subsection{ENVIRONMENTAL DOCUMENTATION}

A major element in the deactivation of FFTF is to comply with the applicable environmental regulations and DOE Orders. The Plan describes how regulatory compliance, including preparation of National Environmental Policy Act (NEPA) documentation, will be achieved to meet the environmental requirements. An environmental requirements checklist has been prepared to determine the permits and approvals applicable to this project.

Site evaluations required under the National Historical Preservation Act and the Endangered Species Act have been completed. Reference 16 provided the Environmental Assessment for the Project.

\subsection{SAFETY ANALYSIS}

The training program and procedures to ensure worker health and safety are described in Section 6.3 of the Plan. The Plan addresses OSHA requirements, implementation of safety elements, safety performance monitoring, fire protection and criticality safety.

Each sub-project will be evaluated for hazard classification and for designation as a nuclear or non-nuclear facility. Appropriate safety documentation will be prepared by WHC in accordance with Reference 2 (DOE 5481.1B) and Reference 9 (WHC-CM-4-46). 


\subsection{ACQUISITION STRATEGY}

\subsection{DESIGN AND INSPECTION}

Design and inspection work for existing FFTF equipment and systems will be provided by WHC. An architect-engineer may be contracted to perform services Tike conceptual design, definitive design, or Title III inspection work when new facilities are required to support the FFTF Transition Project. The acquisition strategy for the major elements of Project is shown in Table 6-1. This information is considered preliminary and may change as the Project becomes better defined. Other acquisition strategies, such as design/build contracts, may be applied to reduce costs or improve the schedule.

\begin{tabular}{|c|c|c|c|}
\hline \multicolumn{4}{|c|}{ Table 6-1 } \\
\hline Activity & Description & Acquisition Contract & Performer \\
\hline $\begin{array}{l}\text { Defueling } \\
\& \\
\text { Fuel Washing }\end{array}$ & $\begin{array}{l}\text { Remove reactor } \\
\text { fuel, remove stored } \\
\text { fuel, and wash } \\
\text { sodium off fue! }\end{array}$ & Cost contract & нHC \\
\hline $\begin{array}{l}\text { Surveillance \& } \\
\text { Maintenance }\end{array}$ & $\begin{array}{l}\text { Surveill ance, } \\
\text { operations and } \\
\text { maintenance of } \\
\text { equipment and } \\
\text { systems }\end{array}$ & Cost contract & WHC \\
\hline $\begin{array}{l}\text { Drain Liquid } \\
\text { Metal systems }\end{array}$ & $\begin{array}{l}\text { Drain sodium to } \\
\text { storage facility }\end{array}$ & Cost contract & WHC \\
\hline $\begin{array}{l}\text { Deactivate } \\
\text { FFTF Systems \& } \\
\text { Equipment }\end{array}$ & $\begin{array}{l}\text { Shutdown fuel } \\
\text { handl ing equipment } \\
\text { and process } \\
\text { systems }\end{array}$ & Cost contract & WHC \\
\hline \multirow{2}{*}{$\begin{array}{l}\text { Project } \\
01-F-029\end{array}$} & \multirow{2}{*}{$\begin{array}{l}\text { Interim Storage } \\
\text { Area }\end{array}$} & Design - cost contract & WHC \\
\hline & & Construction - fixed price contract & $\begin{array}{l}\text { Fixed Price } \\
\text { Contractor }\end{array}$ \\
\hline \multirow{2}{*}{$\begin{array}{l}\text { Project } \\
02-F-030\end{array}$} & \multirow{2}{*}{$\begin{array}{l}\text { PFP Fuel Storage } \\
\text { Modifications }\end{array}$} & Design - cost contract & WHC or A/E \\
\hline & & Construction - cost contract & $\begin{array}{c}\text { Construction Forces } \\
\text { Contractor }\end{array}$ \\
\hline \multirow{2}{*}{$\begin{array}{l}\text { Project } \\
03-F-031\end{array}$} & \multirow{2}{*}{$\begin{array}{l}\text { Sodium } \\
\text { Storage Facility }\end{array}$} & Design - cost contract & A/E \\
\hline & & Construction - fixed price contract & $\begin{array}{c}\text { Fixed Price } \\
\text { Contractor }\end{array}$ \\
\hline \multirow{2}{*}{$\begin{array}{l}\text { Project } \\
04-F-032\end{array}$} & \multirow{2}{*}{$\begin{array}{l}\text { Sodium Reaction } \\
\text { Facility }\end{array}$} & Design - Cost contract & $A / E$ \\
\hline & & Construction - fixed price contract & $\begin{array}{l}\text { Fixed Price } \\
\text { Contractor }\end{array}$ \\
\hline
\end{tabular}




\section{WHC-SD-FF-SSP-004}

Rev. 1, Page A1-40

Construction management services will be provided by the ICF Kaiser Hanford Company (ICF KH). Competitive, fixed-price construction contracts will be awarded to the maximum practical extent. The use of fixed-price incentive fee and cost-plus fixed fee construction contracts is not envisioned.

\subsection{GOVERNMENT-FURNISHED MATERIAL}

Procurement of equipment and materials for the construction projects will be by fixed-price contracts where practical and cost effective. To reduce the cost of the Sodium Storage Facility, the surplus equipment listed below will be furnished by the Government.

1) Three 80,300 gallon tanks

2) One 52,500 gallon tanks

3) Tank level probes

4) Liquid metal process valves

5) Inert gas system process valves

6) Rupture disks

7) Vacuum pump

In addition to the above, one 52,500 gallon tank will be furnished by the Government to reduce the cost of the Sodium Reaction Facility. 


\subsection{PROJECT SCHEDULE}

A summary schedule for the FFTF Transition Project is shown in both the Plan and the RLS. This supports the Advanced Reactors Transition FY 1995 MYPP (Reference 14, WHC-SD-FF-SSP-052). The summary schedule illustrates the relationships between the major activities and milestones like defueling the reactor, draining sodium systems, and designing and constructing projects that are needed to successfully deactivate the FFTF PIant. The RLS provides detailed schedules, which expand upon the Project summary schedule. 
WHC-SD-FF-SSP-004

Rev. 1, Page A1-42

This page intentionaliy left blank. 


\subsection{RESOURCES PLAN}

\subsection{FUNDING ALLOCATION}

The Project is funded with both expense and capital funding. Table 8-1 shows the anticipated allocation of funding for the major elements of the FFTF Transition Project. Specific financial information and budget estimates are given in the RLS (Reference 13) and the Advanced Reactors Transition Fiscal Year Multi-Year Program Plan (Reference 14).

\begin{tabular}{||c|c|c||}
\hline \multicolumn{2}{|c|}{ Table 8-1 FFTF Transition Project Funding Allocation } \\
\hline Activity & \multicolumn{1}{|c||}{ Description } & Funding Type \\
\hline $\begin{array}{c}\text { Transition } \\
\text { Project } \\
\text { Integration }\end{array}$ & Project management and planning & Expense \\
\hline $\begin{array}{c}\text { Deactivation \& } \\
\text { Compliance }\end{array}$ & $\begin{array}{l}\text { Fuel offload, sodium washing } \\
\text { of reactor components, draining liquid } \\
\text { systems and system shutdown }\end{array}$ & Expense \\
\hline $\begin{array}{c}\text { Surveillance \& } \\
\text { Maintenance }\end{array}$ & $\begin{array}{l}\text { Surveillance, operations and maintenance } \\
\text { of equipment and systems, engineering, } \\
\text { work control, support functions }\end{array}$ & Expense \\
\hline Project 01-F-029 & Interim Storage Area & Capital \\
\hline Project 02-F-030 & PFP modifications to store FFTF fuel & Capital \\
\hline Project 03-F-031 & Sodium Storage Facility & Capital \\
\hline Project 04-F-032 & Sodium Reaction Facility & Capital \\
\hline
\end{tabular}

\subsection{PROJECT STAFFING}

Staffing projections to support the FFTF Transition Project are described in the PIan, RLS and the MYPP. 
WHC-SD-FF-SSP-004

Rev. 1, Page Al-44

This page intentionally left blank. 


\subsection{CONTROLLED ITEMS/BASELINES}

\subsection{CHANGE CONTROL BOARD}

The FFTF Change Control Board (CCB) is a customer-established board for the review and disposition of Class I changes to the project scope (technical), cost or schedule baselines. The CCB authority and operation shall follow Reference 7 (WHC-CM-2-5, Change Control Procedure 4.1). The membership of the FFTF CCB shall consist of management representatives, or their designated a]ternates, from the organizations shown below. Others may be added to the membership of the CCB at the direction of the FFTF Transition Project Office Manager or the RL Reactor Programs Branch Manager. As examples, these may include senior management, technical advisors, and consultants.

FFTF Transition Project Office Manager - Chair

FFTF Transition Project Office Planning Manager - Secretary

FFTF Transition Project Director

FFTF Plant Deputy Manager

FFTF Engineering Manager

FFTF Operations Manager

FFTF Work Control Manager

South Office Transition Business Manager

RL Reactor Programs Branch Manager

When new construction sub-projects are undertaken to support the Project, the membership also includes the following:

RL Environmental Projects Manager

RL Project Engineer

WHC Project Manager

WHC Project Engineer

Each CCB member, or their designated alternate, shall be empowered with the authority to make agreements and commitments for the organizations represented.

\subsection{CHANGE CONTROL BOARD OPERATION}

The FFTF CCB is authorized to approve changes to the project baselines within the thresholds defined herein. The FFTF CCB Chairman is responsible for making the final change disposition as noted in the "Disposition" block of the Baseline Change Request (BCR) form as described in Reference 7 (WHC-CM-2-5). The operation of the CCB shall be as follows:

\subsubsection{FFTF Change Control Board Chairman}

1) Preside over the CCB meetings and approve the CCB minutes.

2) Disposition all Class I Baseline Change Requests as the CCB approval authority. 
WHC-SD-FF-SSP-004

Rev. 1, Page A1-46

3) Coordinate actions requiring DOE-HQ and $\mathrm{RL}$ approval including increasing the project total estimated cost (TEC) and changing controlled milestone completion dates or definitions. This includes consulting senior management, or higher level company and customer-related review boards, to obtain their approval before implementing the change.

4) Resolve comments and recommendations concerning the disposition of Change Requests.

\subsubsection{FFTF Change Control Board Secretary}

1) Coordinate the submittal of Change Requests to the CCB.

2) Prepare the meeting agenda and schedule CCB meetings if required (See Section 9.2.4).

3) Distribute the meeting agenda, minutes and Change Requests.

4) Prepare and maintain the Change Control Log which sha11 contain the following information:
a. Change identification number
b. Change title or description
c. Change classification
d. Date originated
e. Date submitted to RL
f. Scope baseline impact
g. Cost baseline impact
h, Schedule baseline impact
i. Disposition status

\subsubsection{Support Function Members}

The CCB may solicit input or advice from support functions like Engineering, Operations, Quality Assurance, Safety, Environmental and Regulatory Compliance, Cost Estimating, Work Control, and Security before acting upon a Change Request. The support function managers perform the following:

1) Review Change Requests prior to submission to the CCB Chairman.

2) Recommend the disposition action for Class I and Class II Change Requests.

3) Review and evaluate Change Requests for technical, cost, schedule, or funding impacts in their area of expertise to assure the impacts are realistically estimated.

\subsubsection{Change Control Board Meetings}

Unless requested by the FFTF Transition Project Office Manager, or the RL Reactor Programs Branch Manager, the CCB is not required to conduct formal meetings. Experience has shown that the CCB can accomplish its 
responsibilities without formal meetings by following the change control process described in Reference 7 (WHC-CM-2-5).

\subsubsection{Basel ine Change Request Priority}

All changes shall be acted upon within the time frame related to the priority of the change. The change priorities are routine, urgent and emergency. The priority is assigned based on the effect of the change on safety, quality, schedule, cost and performance. Each Change Request shall be dispositioned or acted upon within the following time frames:

- Routine - Within seven (7) working days after the Change Request has been distributed for review.

- Urgent - Determined to require an expedited response but does not meet the emergency change criteria.

- Emergency - Within two (2) working days after the Change Request has been submitted. These are usually changes to prevent the cessation of work. They may also be related to safety concerns or unforseen events which could worsen if corrective action is delayed.

Authorization to proceed with the corrective actions for emergencies may be obtained by telephone, electronic mail, or in person. The authority to proceed in this manner resides with the CCB Chairman. In any case, the change action will be taken promptly to ensure the change conditions are implemented in a safe and cost effective manner. The CCB Chairman shall follow-up to ensure any emergency change action is documented.

\subsection{BASELINE CHANGE REQUEST}

The FFTF Transition Project Office Manager shall notify the RL Reactor Programs Branch Manager and the RL Environmental Projects Manager of impending Change Requests. Although informal notification is encouraged, formal notification and approval in the form of a Baseline Change Request is required. In some cases, it may be necessary to present proposed changes to higher level company and customer-related review boards to obtain their approval before implementing the change.

Each Baseline Change Request (BCR) shall include a detailed description of the change, cost estimate, schedule estimate and justification for the recommended course of action. BCR's shall be prepared and executed according to Reference 7 (WHC-CM-2-5). The BCR (54-6100-0633, Site Forms) shall be used for all Class I, II and III changes. This applies to all expense and capital funded elements of the FFTF Transition Project including the new construction subprojects.

To reduce costs, baseline changes for work under the auspices of an ArchitectEngineer can be documented on their own BCR form providing the equivalent information is provided. In any case, all BCR identification or log numbers will be assigned by the FFTF Transition Project Office. 
WHC-SD-FF-SSP-004

Rev. 1, Page Al-48

The cost impact shall be furnished by WBS element and by the fiscal year of the expenditure. The schedule impact shall be based upon the RLS and any impacted milestones in Reference 14 (WHC-SD-FF-SSP-052).

The approval responsibilities for Change Requests are shown in Table 9-1. If it becomes necessary to disapprove a Change Request, the reason for the disapproval shall be stated on the Change Request.

As examples, Change Requests may be needed for one or more of the following:

1) Satisfy design, construction, fabrication, installation, functional or performance requirements.

2) Program Tevel or Project Summary Work Breakdown Structure changes.

3) Revised or new regulatory requirements.

4) Meet safety requirements, or correct potentially hazardous conditions which could injure personnel or damage equipment.

5) Result in significant construction, fabrication, operating, cost or schedule improvements without compromising requirements.

6) Programmatic changes in funding.

7) Achieve a significant cost reduction without adversely affecting the Plan or the RLS.

8) Changes to the master schedule milestone dates and descriptions (TPA, DOE-HQ, and RL).

9) Major changes caused by factors beyond the control of the Project like weather disasters and labor restraints.

10) General and administrative/common support pool rate changes, department overhead rate changes, and service pool rates that impact the Project baselines.

All changes will be reviewed for their impact on compliance with governing documents and regulations (i.e. permitting requirements, DOE commitments, milestones, TPA negotiations and other milestones for environmental compliance).

The following information is intended to give an overview of the Change Request classifications and approval authority. The specific requirements to be followed are given in Reference 7 (WHC-CM-2-5).

\subsubsection{Change Classifications}

Al1 changes to the technical, cost, and schedule baselines shall be processed as Class I or Class II changes. The FFTF CCB will review the class and priority designations of Change Requests to confirm that the designations are appropriate. 
The change classifications are defined as follows:

Class I Changes that impact the following baselines:

\section{Technical Baseline}

- Work Breakdown Structure (WBS) shown in Figure 3-1.

- Functional Design Criteria (FDC).

\section{Cost Baseline}

- Changes to the total estimated cost above established limits.

Schedule Baseline

- Changes to the scheduled completion dates for Project activities shown in the RLS FFTF Transition Project Master Schedule.

- Changes to controlled milestones.

Class II Technical, Cost or Schedule Baselines

- Changes to the technical portions of the Project, such as drawings and specifications, that do not affect the WBS, FDC, schedule, or the total estimated cost above established limits.

- Changes to the cost or schedule baselines that would otherwise be Class III, except that they exceed the lower thresholds for Class II changes.

Class III Changes that do not meet the criteria for Class I or II, and are minor in nature. Class III changes do not impact the technical, cost and schedule baselines.

\subsubsection{Change Request Approvals}

The organizations responsible for approving the Baseline Change Request are identified in Table 9-1. Upon receipt of a Change Request, the approval process can be improved if the FFTF Cost Account Manager and the FFTF Budget Analyst are consulted first.

Class I Acted upon by the CCB upon completion of WHC and ArchitectEngineer $(A-E)$ reviews and recommendations. The $A-E$ may include the ICF Kaiser Hanford Company (ICF KH), or another A-E. In some cases, the change classification may necessitate a review and approval by a higher level company, or customer-established change control board.

Class II Acted upon by WHC and the A-E project managers upon completion of their reviews and resolution of their comments.

Class III Acted upon by the A-E or WHC. 


\begin{tabular}{|c|c|c|}
\hline \multicolumn{3}{|c|}{ Table 9-1 Basel ine Change Request Approvals } \\
\hline \multicolumn{3}{|c|}{\begin{tabular}{|c|c|} 
Change Class & Approved by \\
\end{tabular}} \\
\hline$I$ & & $\begin{array}{l}\text { - Architect-Engineer } \\
\text { - WHC Project Manager } \\
\text { - FFTF Cost Account Manager } \\
\text { - South Office Transition Business Manger } \\
\text { - FFTF Change Control Board Chairman } \\
\text { (FFTF Transition Project Office Manager) } \\
\text { - FFTF Activity Manager } \\
\text { (FFTF Plant Deputy Manager) } \\
\text { - RL Reactor Programs Branch } \\
\text { - RL Environmental Projects Branch } \\
\end{array}$ \\
\hline II & & $\begin{array}{l}\text { - Architect-Engineer }{ }^{1} \\
\text { - WHC Project Manager } \\
\text { - FFTF Cost Account Manager } \\
\text { - South Office Transition Business Manger } \\
\text { - FFTF Transition Project Office Manager } \\
\text { (CCB Chairman) } \\
\text { - FFTF Activity Manager } \\
\text { (FFTF Plant Deputy Manager) }\end{array}$ \\
\hline III & & $\begin{array}{l}\text { - Architect-Engineer' } \\
\text { - WHC Project Manager } \\
\text { - FFTF Cost Account Manager } \\
\text { - South Office Transition Business Manger }\end{array}$ \\
\hline \multicolumn{3}{|l|}{ Notes: } \\
\hline th & \multicolumn{2}{|c|}{$\begin{array}{l}\text { A-E prepares Change Requests related to the design and construction of sub-projects } \\
\text { that support the FFIF Transition Project. }\end{array}$} \\
\hline wh & \multicolumn{2}{|c|}{$\begin{array}{l}\text { WHC Project Manager (Project Engineer) approves Change Requests related to the } \\
\text { construction sub-projects. }\end{array}$} \\
\hline $\mathrm{Tr}_{\mathrm{AC}}$ & \multicolumn{2}{|c|}{$\begin{array}{l}\text { Transition Business Manager approves Change Requests after review by FFTF cost } \\
\text { Account Manager and FFTF Budget Analyst. }\end{array}$} \\
\hline $\begin{array}{l}\mathrm{RL} \\
\mathrm{CC} \\
\mathrm{Pr}\end{array}$ & \multicolumn{2}{|c|}{$\begin{array}{l}\text { RL Environmental Projects Branch Chief approves Change Requests related to the } \\
\text { construction sub-projects, unless delegated to the RL Environmental Projects Branch } \\
\text { Project Engineer. }\end{array}$} \\
\hline $\begin{array}{l}\mathrm{Re} \\
\mathrm{ar}\end{array}$ & \multicolumn{2}{|c|}{$\begin{array}{l}\text { Refer to Table } 5.3 \text { for the technical, cost and schedute thresholds for Class I, II } \\
\text { and III Change Requests. }\end{array}$} \\
\hline
\end{tabular}




\subsubsection{Change Request Distribution}

The CCB Secretary shall distribute all Baseline Change Requests and the Change Control Log to the affected organizations including the following:

FFTF Transition Project office

RL Reactor Programs Branch Manager

RL Environmental Projects Manager

WHC Project Engineer

FFTF Cost Account Manager

FFTF Work Control

South Office Transition Business Manager 
WHC-SD-FF-SSP-004

Rev. 1, Page A1-52

This page intentionally left blank. 


\subsection{SCHEDULED DECISION POINTS}

Milestones for the new construction sub-projects have been established in the approved MYPP (Reference 14) and are defined in the RLS as follows:

- Key decision 0, Approval to begin Conceptual Designa

- Key decision 1, Approval to begin Title I Detailed Design ${ }^{b}$

- Key decision 2, Approval to begin Title II Detailed Design

- Key decision 3, Approvar to begin Construction ${ }^{2}$

- Key decision 4, Approval to begin Operation/Production

a RL approval of the Functional Design Criteria satisfies this decision.

b Key decision 1 and 2 may occur at the same time if cost effective.

c Notice to Proceed satisfies this decision.

d Readiness Assessment (RA) approval satisfies this decision. 
WHC-SD-FF-SSP-004

Rev. 1, Page A1-54

This page intentionally left blank. 


\subsection{PROJECT CHARTER}

\subsection{INTRODUCTION}

This Project Charter assigns the responsibility for planning, directing, and monitoring the Project activities to the FFTF Transition Project Office. Reference 15 directed that the transition to shutdown be performed in a radiologically safe, industrially safe and cost-effective manner using a project approach. The FFTF Transition Project office is accountable for fulfilling this charter. The responsibility ends at turnover when the accountability is formaity transferred to others. The following turnovers are planned.

1) Turnover irradiated nuclear fuel to the Spent Nuclear Fuel Program.

2) Turnover unirradiated nuclear fuel to the Plutonium Finishing Plant.

3) Turnover FFTF systems, equipment and buildings to the Environmental Restoration Contractor (ERC - Referred to as the Hanford Surplus Facilities Program in Revision 0 of the Plan).

This Project Charter delineates the management authority, responsibility, and accountability for the FFTF Transition Project. The Project Charter has been prepared to satisfy Reference 1 (DOE 4700.1A), Reference 5 (RLIP 4700.1A) and Reference 11 (WHC-CM-6-2). It establishes the operational management

relationships between $\mathrm{DOE}-\mathrm{HQ}, \mathrm{RL}$ and the contractor organizations responsible for the successful implementation and completion of the FFTF Transition

Project. An outline for the Project Charter is given in Table 11-1.

\begin{tabular}{||l|l|}
\hline \multicolumn{1}{|c|}{ Table 11-1 FFTF Transition Project Charter Outline } \\
\hline \multicolumn{1}{|c|}{ Description } & \multicolumn{1}{|c|}{ Information Source } \\
\hline \hline Purpose and Objectives (Scope) & Plan - Section 3.0 \\
\hline Cost Estimate \& Funding & $\begin{array}{l}\text { P7 an - Section 18.0 } \\
\text { RLS - Section 6.0 (WHC-SD-SSP-050) } \\
\text { MYPP - Reference 14 (WHC-SD-SSP-052) }\end{array}$ \\
\hline $\begin{array}{l}\text { Schedule \& Resources } \\
\text { Rlan - Section 17.0 } \\
\text { RLS - Reference 13 (WHC-SD-SSP-050) }\end{array}$ \\
\hline $\begin{array}{l}\text { Management Approach } \\
\text { Plan - Appendix A-1, Section 5.0 }\end{array}$ \\
\hline $\begin{array}{l}\text { Operational Management } \\
\text { Relationships }\end{array}$ & Project Charter \\
\hline $\begin{array}{l}\text { Project Manager Authority \& } \\
\text { Responsibilities }\end{array}$ & Project Charter \\
\hline $\begin{array}{l}\text { Supporting Organization } \\
\text { Responsibilities }\end{array}$ & Project Charter \\
\hline
\end{tabular}


WHC-SD-FF-SSP-004

Rev. 1, Page A1-56

\subsection{PROJECT MANAGEMENT OFFICE LOCATION}

Richland Operations Office, Richland, Washington

\subsection{MANAGEMENT TEAM}

The primary objective of the FFTF Transition Project management team is to transition FFTF to a radiologically and industrially safe shutdown condition. The members of the management team are shown in Figure 5-1. Others may be included at the direction of the FFTF Transition Project Office Manager or the RL Reactor Programs Branch Chief.

\subsubsection{Operations and Transition Division}

0. A. Farabee, Acting Director Operations and Transition Division

R. M. Almquist, Acting Chief

Reactor Programs Branch

\subsubsection{Project Management Division}

R. M. Hiegel, Acting Director

Project Management Division - RL

R. M. Hiegel, Chief

Environmental Projects Branch - RL

\subsubsection{FFTF Transition Project}

J. C. Midgett, Director

FFTF Transition Project

\subsubsection{FFTF Transition Project Office}

Sol Guttenberg, Manager

FFTF Transition Project Office

\subsection{PROJECT MANAGER AUTHORITY \& RESPONSIBILITIES}

The FFTF Transition Project Office has the lead responsibility to transition FFTF to a radiologically and industrially safe condition for turnover to the Environmental Restoration Contractor (ERC). The ERC will be responsible for long term surveillance preparatory to final decontamination and decommissioning. The FFTF Transition Project Office is also responsible for turning over the irradiated reactor fuel to the WHC Spent Nuclear Fuel Program and the unirradiated fuel to the Plutonium Finishing Plant.

The FFTF Transition Project Office Manager is responsible for overall control of the project, including cost and schedule control. This includes planning related to the obtaining the funding for the construction sub-projects. The Project Manager shall implement the Site Management System, which uses basel ine management and change control procedures for organizing, planning, monitoring and controlling the Project scope, schedule, and costs. 
The Transition Project Office Manager's authority and responsibilities include:

\subsubsection{Team Building}

Maintain a strong team relationship among several key stakehoiders. As examples, these include FFTF Operations, Engineering, Work Control, Safety, Quality Assurance, Regulatory, Projects, and Senior Management; ArchitectEngineers; Procurement; Contracting; and Federal and State Government personnel. Integrate the activities of these groups to achieve the milestone and cost performance objectives safely.

\subsubsection{Planning and Baseline Schedule Development}

1) Plan, direct and monitor the FFTF transition and turnover program activities. This includes assuring that the labor and material resources needed for the defueling, fuel washing, fuel disposal, sodium drain and storage, and sodium reaction process activities are planned and conducted in a safe and cost effective manner.

2) Establish milestones which support the transition schedule including DOE and TPA requirements.

3) Provide the Work Breakdown Structure, logic diagrams, and upper tier schedules to establish baselines for the preparation of supporting resource loaded schedules and cost estimates.

Assure the RLS supports the objective to safely and permanently deactivate FFTF on time and within budget.

4) Anticipate problems that may impact the schedule and expedite the resolution of problems promptly to minimize schedule impacts.

5) Update the PIan and RLS whenever required to reflect changes in project scope, schedule or funding.

6) Maximize the use of fixed-price contractors to complete the Project activities. This includes out-source procurement and private-sector contracting whenever cost effective.

\subsubsection{Change Control}

1) Approve all Change Requests that impact the Project cost and schedule baselines.

2) Establish a Change Control Board which includes the customer and WHC management. Serve as the board chairman. 
WHC-SD-FF-SSP-004

Rev. 1, Page A1-58

\subsubsection{Budget and Cost Estimates}

1) Prepare cost estimates to justify budgets and support financial planning.

2) Prepare and submit financial planning documents such as the Multiyear Program Plan, Activity Data Sheets and Project Authorization documents.

\subsubsection{Supporting Sub-Projects}

1) Assure the conceptual planning, definitive design, budgets and construction of the sub-projects support the successful completion of the FFTF Transition Project. Examples of the sub-projects include:

$\begin{array}{ll}\text { 01-F-029 } & \text { Interim Storage Area } \\ 02-\mathrm{F}-030 & \text { PFP Modifications for FFTF Fue } \\ 03-\mathrm{F}-031 & \text { Sodium Storage Facility } \\ 04-\mathrm{F}-032 & \text { Sodium Reaction Facility }\end{array}$

2) Assure all comments concerning the safety, design and operational readiness of the supporting sub-projects are resolved.

\subsubsection{Technical and Regulatory Requirements}

1) Re-define Technical Specification requirements consistent with the orderly deactivation of FFTF systems, equipment and facilities.

2) Assure the applicable codes, orders, regulations and procedures are implemented.

3) Serve as the central interface point with the State and Federal Government agencies, and with the company regulatory and environmental stakeholders. Coordinate the resolution of environmental permitting and regulatory issues.

4) Review and approve project technical documentation.

\subsubsection{Technology}

1) Serve as the central technology coordinating group for the application of sodium processing and reaction technology to reduce costs and enhance the effectiveness of the Transition Project.

2) Maintain active liaison with liquid metal reactor facilities, both domestic and foreign, so that lessons learned at other

deactivation sites may be applied. 


\subsubsection{Readiness Assessments}

Manage the conduct of Readiness Assessments (RA) for the following activities:
1) Fuel Washing
2) Fuel Storage
3) Sodium Draining and Storage
4) Sodium Reaction

\subsubsection{Turnover of Fuel, Systems, Equipment and Buildings}

As the shutdown and deactivation activities are completed, the FFTF reactor fuel, systems, equipment and buildings will be formally turned over to other organizations as shown in Table 11-2.

\begin{tabular}{|c|c|c|}
\hline FFTF Cost Account Manager & Turnover Responsibility & Receiving Function \\
\hline Operations Manager & $\begin{array}{l}\text { FFTF Plant buildings, } \\
\text { systems and equipment }\end{array}$ & $\begin{array}{l}\text { Environmental } \\
\text { Restoration } \\
\text { Contractor }\end{array}$ \\
\hline Fuel Offload Manager & Irradiated reactor fuel & $\begin{array}{l}\text { WHC Spent } \\
\text { Fuel Program }\end{array}$ \\
\hline Fuel offload Manager & Unirradiated reactor fuel & $\begin{array}{c}\text { Plutonium } \\
\text { Finishing Plant } \\
\end{array}$ \\
\hline Fuel Offload Manager & $\begin{array}{l}\text { Reactor fuel handling } \\
\text { systems and equipment }\end{array}$ & $\begin{array}{c}\text { Environmental } \\
\text { Restoration } \\
\text { Contractor } \\
\end{array}$ \\
\hline Operations Manager & $\begin{array}{l}\text { Sodium Storage Facility } \\
\text { and Sodium Reaction } \\
\text { Facility }\end{array}$ & $\begin{array}{c}\text { Environmental } \\
\text { Restoration } \\
\text { Contractor } \\
\end{array}$ \\
\hline $\begin{array}{l}\text { Operations Manager } \\
\text { or } \\
\text { Sodium Reaction Facility } \\
\text { Operating Contractor }\end{array}$ & $\begin{array}{l}\text { Products produced in the } \\
\text { Sodium Reaction Facility } \\
\text { that are suitable for feed } \\
\text { chemicals for cleanup and } \\
\text { remediation of Hanford } \\
\text { liquid waste }\end{array}$ & $\begin{array}{l}\text { Tank Waste } \\
\text { Remediation } \\
\text { Program }\end{array}$ \\
\hline
\end{tabular}

The responsibilities of the managers who support the turnover process include:

1) Oversee definition of the criteria for turnover of the FFTF reactor fuel, systems, equipment and buildings.

2) Assure all personnel who will become responsible for turned over FFTF fuel, systems, equipment and buildings are properly trained before the turnover or transfer of responsibility occurs. 
Rev. 1, Page Al-60

3) PI an and manage the turnover of irradiated FFTF reactor fuel to the Spent Nuclear Fuel Program for storage and surveillance.

4) Plan and manage the turnover of unirradiated FFTF reactor fuel to the Plutonium Finishing Plant for storage and surveillance.

5) PI an and manage the turnover of FFTF systems, equipment and buildings to the Environmental Restoration Contractor (ERC). This includes the Sodium Storage and Sodium Reaction Facilities. The ERC will be responsible for the long term surveillance preparatory to final decontamination and decommissioning.

\subsubsection{Project Reports and Records}

1) Measure and report the performance of the Project using earned value and variance analysis techniques as described in Reference 7 (WHC-CM-2-5).

2) Establish and maintain the FFTF Transition Project files and records for all deactivation construction sub-project activities.

\subsection{SUPPORTING ORGANIZATIONS}

The FFTF departments and related organizations which support the FFTF Transition Project are 7 isted below. Their functional responsibilities will generally follow Reference 12 (WHC-CM-6-14).

FFTF Engineering

FFTF Maintenance

FFTF Operations

FFTF Training

FFTF Transition Project Office

FFTF Work Control

Quality Assurance

Environmental \& Regulatory

Safeguards \& Security

Safety 


\subsection{REFERENCES}

NOTE: The latest revisions of the following references apply.

1. DOE Order 4700.1 Project Management System, U.S. Department of Energy, Washington, D.C.

2. DOE Order 5481.1B Safety Ana7ysis and Review System, U. S. Department of Energy, Washington D. C.

3. DOE Order 5700.6C Quality Assurance, U. S. Department of Energy, Washington D. C.

4. 10 CFR 830.120 Quality Assurance Requirements, U. S. Department of Energy, Washington D. C.

5. RLIP 4700.1A Project Management System, U.S. Department of Energy, Richland Operations Office, Richland, Washington.

6. No Doc Number Cost and Schedule Estimating Guide, Office of Waste Management, U. S. Department of Energy, Washington $D$. C.

7. WHC-CM-2-5

Management Control System, Hestinghouse Hanford Company, Richland, Washington.

8. WHC-CM-4-2

Qualjty Assurance Program, Westinghouse Hanford Company, Richland, Washington.

9. WHC-CM-4-46

Nonreactor Facility Safety Analysis Manual, Westinghouse Hanford Company, Richland, Washington.

10. WHC-CM-6-1 Standard Engineering Practices, Westinghouse Hanford Company, Richland, Washington.

11. WHC-CM-6-2 Project Management, Westinghouse Hanford Company, Richland, Washington.

12. WHC-CM-6-14 FFTF Plant Policy Manual, Westinghouse Hanford Company, Richland, Washington.

13. WHC-SD-FF-SSP-050 Fast Flux Test Faci7ity Shutdown Project Resource Loaded Schedule, Westinghouse Hanford Company, Richland, Washington.

14. WHC-SD-FF-SSP-052 Advanced Reactors Transition Fiscal Year 1995 MultiYear Program P7an WBS 7.3, Westinghouse Hanford Company, Richland, Washington. 
WHC-SD-FF-SSP-004

Rev. 1, Page A1-62

15. Letter

Daniel A Dreyfus, DOE-HQ, to John D. Wagoner, RL, Commence Fast Flux Test Facility Shutdown (FFTF) Activities, December 15, 1993.

16. Letter

J. C. Midgett, WHC, to J. E. Mecca, RL, Environmental Assessment: Shutdown of the Fast Flux Test Facility, Hanford Site, Richland, Washington, 9452321.2, dated September 201994. 
WHC-SD-FF-SSP-004

Rev. 1, Page A1-63

\subsection{ACRONYMS AND ABBREVIATIONS}

\begin{tabular}{|c|c|}
\hline $\begin{array}{l}\text { A-E } \\
\text { AI } \\
\text { ALARA } \\
\text { AME } \\
\text { AMW } \\
\text { ANSI } \\
\text { ASME } \\
\text { BCR } \\
\text { BCWS } \\
\text { CAA } \\
\text { CAM } \\
\text { CCB } \\
\text { CCP } \\
\text { CENRTC } \\
\text { CERCLA } \\
\text { CF } \\
\text { CM } \\
\text { CPR } \\
\text { CQA } \\
\text { CWBS } \\
\text { D\&D } \\
\text { DOE } \\
\text { DOE-HQ } \\
\text { DOE-RL } \\
\text { DOH } \\
\text { EA } \\
\text { EAC } \\
\text { EBR-II } \\
\text { EC } \\
\text { ECC } \\
\text { ECOlog } \\
\text { EM } \\
\text { EM-60 } \\
\text { ENB } \\
\text { EPA } \\
\text { ERC } \\
\text { FTC } \\
\text { FFTF } \\
\text { FY } \\
\text { ICF KH } \\
\text { IDS } \\
\text { IEM } \\
\text { ISA } \\
\text { MCS } \\
\text { MRM } \\
\text { MY } \\
\text { MYPP } \\
\text { NaK } \\
\text { NE-40 } \\
\text { NEPA }\end{array}$ & $\begin{array}{l}\text { Architect-Engineer } \\
\text { Acceptance Inspection } \\
\text { as low as reasonably achievable } \\
\text { Assistant Manager for Environmental Management } \\
\text { Assistant Manager for Waste Management } \\
\text { American National Standards Institute } \\
\text { American Society of Mechanical Engineers } \\
\text { Baseline Change Request } \\
\text { Budgeted Cost of Work Scheduled } \\
\text { Clean Air Act } \\
\text { Cost Account Manager } \\
\text { Change Control Board } \\
\text { Core Component Pot } \\
\text { capital equipment not related to construction } \\
\text { Comprehensive Environmental Response Compensation and Liability } \\
\text { Construction Forces } \\
\text { Construction Management } \\
\text { Cost Performance Report } \\
\text { Construction Quality Assurance } \\
\text { Contractor Work Breakdown Structure } \\
\text { decontamination and decommissioning } \\
\text { U.S. Department of Energy } \\
\text { U.S. Department of Energy-Headquarters } \\
\text { U.S. Department of Energy, Richland Operations Office } \\
\text { Department of Health, State of Washington } \\
\text { environmental assessment } \\
\text { Estimate at Completion } \\
\text { Experimental Breeder Reactor-II, Idaho Falls, Idaho } \\
\text { Engineering Contractor } \\
\text { Engineer Constructor Contractor } \\
\text { Department of Ecology, State of Washington } \\
\text { Office of Environmental Restoration and Waste Management } \\
\text { Office of Facility Transition \& Environmental Management } \\
\text { Environmental Projects Branch } \\
\text { U.S. Environmental Protection Agency } \\
\text { Environmental Restoration Contractor } \\
\text { Functional Design Criteria } \\
\text { Fast Flux Test Facility } \\
\text { Fiscal Year } \\
\text { ICF Kaiser Hanford Company } \\
\text { Interim Decay Storage } \\
\text { Interim Examination \& Maintenance Cell } \\
\text { Interim Storage Area } \\
\text { Management Control System } \\
\text { Management Review Meeting } \\
\text { Mutti-Year } \\
\text { Multi-Year Program Plan } \\
\text { sodium and potassium eutectic alloy } \\
\text { Facilities Division Office of Nuclear Energy } \\
\text { National Environmental Policy Act }\end{array}$ \\
\hline
\end{tabular}




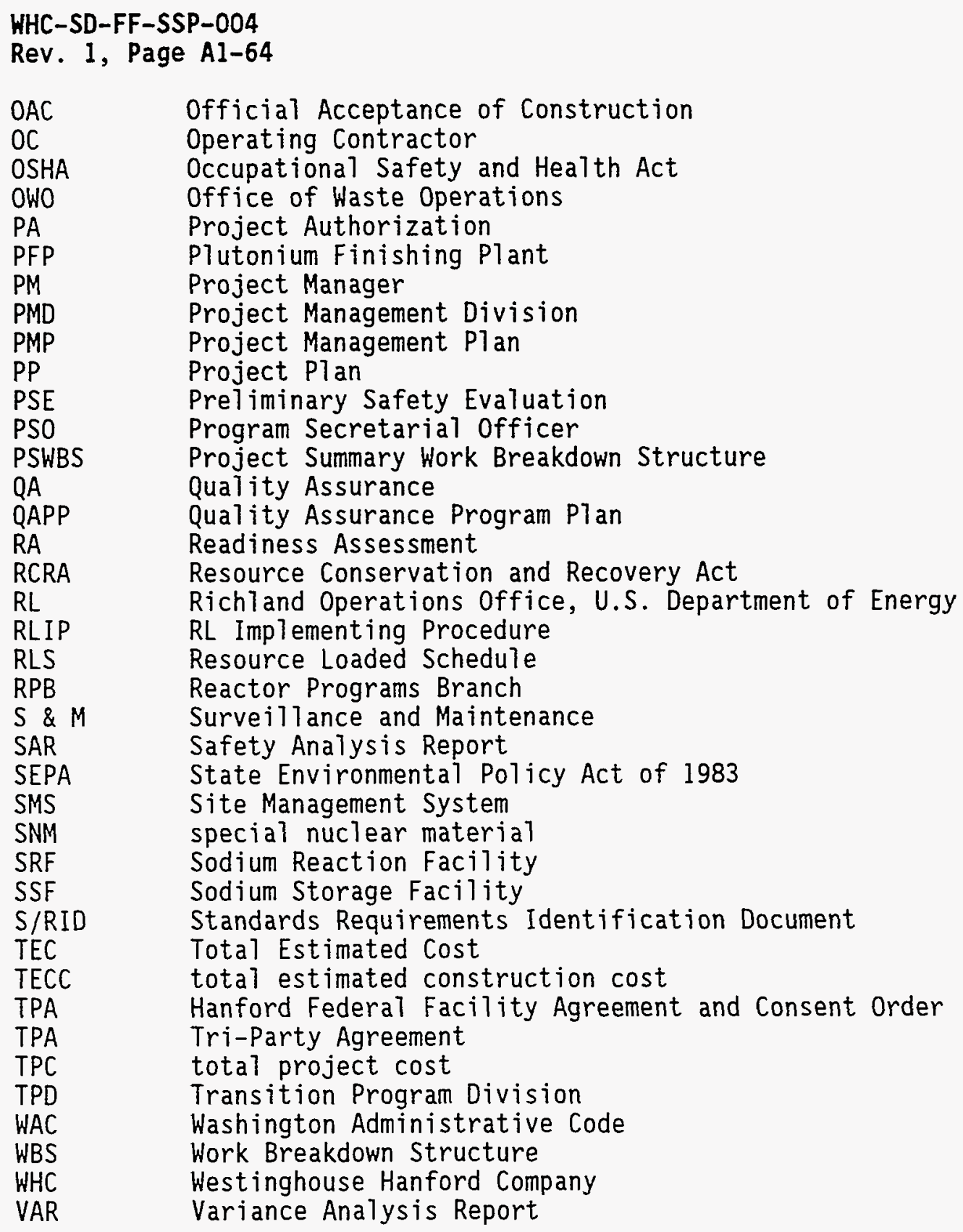


Appendix A-2

FFTF Status at Completion of Transition Phase 
WHC-SD-FF-SSP-004

Rev. 1, Page A2-1a

This page intentionally left blank. 


\section{APPENDIX A-2}

\section{FFTF STATUS AT COMPLETION OF TRANSITION PHASE}

\subsection{FFTF SYSTEMS}

The plant systems will be configured to meet the evolving specific criteria that is generated for final turnover to the Environmental Restoration Contractor. The systems are divided into two groups; those systems that will remain available for operation and those which will be permanently shutdown. The systems or portions thereof that will remain available for operation include fire water pumps, sanitary water pumps, lighting, ventilation, nitrogen, and the supporting electrical systems. Appropriate spare parts inventory will be retained for these systems. All other systems will be shutdown and de-energized.

System Shutdown Plans were prepared to describe how each system would be deactivated and the necessary allocation of resources and time. These estimates provided the bases for development of the Resource Loaded Schedule. Some modifications to systems remaining in operation will be required and the shut down of many systems will occur in stages. The conditions described in the following sections reflect a summary of the final shutdown status at the time of turnover to the Environmental Restoration Contractor. The referenced System Shutdown Plans provide added detail of time-phased partial shutdowns, modifications, and turnover status.

\section{I.1 SYSTEMS REMAINING AVAILABLE FOR OPERATION}

\section{$11 \mathrm{~A} \quad 115 \mathrm{KV}$ BPA Electrical Yard 451B and 13.8KV Transmission Lines}

This system provides all electrical power from the BPA electrical grid to the 400 area including FFTF. This electrical substation $451 B$ is owned and maintained by BPA. It will remain in operation supplying power to all facilities within the 400 area including that portion needed to provide surveillance of FFTF. This system will continue to supply electrical power to substation $451 \mathrm{~A}$ and the main transformer $X-1$ that feeds FFTF.

The one breaker (C5X4) in electrical substation $451 \mathrm{~B}$ that feeds $13.8 \mathrm{KV}$ backup power to FFTF will be shutdown.

Reference: WHC-SD-FF-SSP-006

$11 \mathrm{~B} 115 \mathrm{KV} / 13.8 \mathrm{KV}$ Transformers, Electrical Yard 451A and Station Ground Grid

This electrical substation $451 \mathrm{~A}$ provides the main preferred $13.8 \mathrm{KV}$ electrical power to FFTF. The $X-1$ transformer will remain operating to provide $13.8 \mathrm{KV}$ power to four $13.8 \mathrm{KV} / 480 \mathrm{VAC}$ transformers through switchgear $\mathrm{H}-4$ and $\mathrm{H}-5$. Two of these transformers are outside the plant and two are inside the plant. The 
two transformers outside are needed to supply power to the fire protection system and sanitary water for the 400 area. The two transformers inside the plant will remain in operation to the extent they are needed to support surveillance of the plant.

Reference: WHC-SD-FF-SSP-006

\section{$12 \mathrm{~B} \quad \underline{13.8 \mathrm{KV} \text { System }}$}

This system distributes the main electrical power $13.8 \mathrm{KV}$ through out the plant to transformers that reduce it to 480VAC. The major portion of this system will be shutdown. In the electrical substation $451 \mathrm{~A}$ two of the three 13.8KV switches on the output side of $X-1$ will be opened and remain in $p 1$ ace as spares. The third switch will continue to provide $13.8 \mathrm{KV}$ power to the system that is now referred to as the emergency electrical system, switchgear $\mathrm{H}-4$ and $\mathrm{H}-5$. This system will be used as the power distribution system within the plant to maintain those systems needed for surveillance. This system will no longer be an emergency system, since the diesel and gas turbine generators will be shutdown. All of the PCB transformers in the normal and emergency systems will be removed and properly disposed of in accordance with all Federal and State laws.

Reference: WHC-SD-FF-SSP-007

\section{$12 \mathrm{D} 480$ Normal Volt AC Load Centers}

This system distributes and provides electrical protection for the 480VAC power system going to electrical equipment such as electrical breaker panels, motor control centers, lighting load centers and directiy to large equipment. Al1 the 480VAC load centers in the normal power system will be shut down.

Reference: WHC-SD-FF-SSP-007

\section{$12 E \quad 480$ Volt AC Emergency Load Centers}

This system distributes and provides electrical protection for the 480VAC power system going to safety related equipment that is fed from electrical breaker panels, motor control centers, lighting load centers and directly to large equipment. These load centers have back up emergency power sources from two diesel generators and one gas turbine generator. These backup generators will be shutdown. The 480VAC load centers in the emergency power system will continue to be used to supply power to those loads needed to support the surveillance of FFTF, however they will no longer be emergency power load centers.

Reference: WHC-SD-FF-SSP-007 


\section{$12 F \quad$ Lighting}

Lighting from the normal power system will be shutdown. Lighting from the system that is now referred to as the emergency power system will remain on to provide minimal lighting to the plant for surveillance tours. This lighting will include exit sign iighting throughout FFTF.

Reference: WHC-SD-FF-SSP-007

\section{$12 G$ Low Voltage AC Systems Regulated and Non-requiated}

This system provides low voltage 120 VAC power from a reducing transformer and breaker panels to individual loads including lighting, instruments, and control panels. The low voltage power systems in the normal power system will be completely shutdown. The low voltage power systems now referred to as the emergency power system will remain on to the extent needed to support surveillance. Any loads needed to support surveillance from the normal power system will be moved to the system now referred to as the emergency power system.

Reference: $\quad W H C-S D-F F-S S P-007$

\section{$12 \mathrm{~K} \quad 480$ Volt Motor Control Centers}

This system provides electrical protection and start/stop control function for motor loads. The motor control centers in the normal power system will be completely shutdown. The motor control centers in the system now referred to as the emergency power system will remain in operation only to the extent needed to provide power to motor loads such as ventilation fans to support surveillance.

Reference: WHC-SD-FF-SSP-007

\section{L Freeze and Cathodic Protection}

This system includes trace heating of outside water, fuel $0 i 1$, and service air piping and cathodic protection to underground fuel oil tanks and piping. All others will be secured following drainage of the associated piping and removal of the underground tanks.

Reference: $\quad W H C-S D-F F-S S P-007$

\section{Fuel Storage Facility (FSF) Electrical - ALL}

This system receives power from the 45IB switchyard and provides power to all FSF systems. It will remain in operation only to the extent needed to support surveillance.

Reference: WHC-SD-FF-SSP-007 


\section{A FFTF and FSF Communications System}

This system provides in plant telephone, radio, and paging capabilities. The majority of the system will be shutdown. This includes the PAIC and PAX subsystems (unless operation of the PAX system is required to keep the Public Address system operational). The radio subsystem will remain in service to provide damage control communications, primarily with the Fire Department. A single GTE line will be active in the Control Room to allow contacting the Emergency Organization if a need arises.

Reference: WHC-SD-FF-SSP-009

\section{Support Buildings and Structures}

Lead shielding (bricks, etc.) not retained in its original configuration will be excessed.

Reference: WHC-SD-FF-SSP-010

\section{Control Panels Outside RCB}

Only those control panels necessary to support ventilation or fire and sanitary water system operation will remain available for operation.

Reference: WHC-SD-FF-SSP-010

\section{A Well Water System}

This system collects and stores well water for sanitary and fire water supplies throughout the 400 Area. It will remain in service to insure that a supply of fire water exists. The water will still be chlorinated to continue to provide drinking water in the facilities which remain occupied following the shutdown of the Liquid Metal Reactor activities in the 400 Area.

Reference: WHC-SD-FF-SSP-011

\section{B Sanitary Water System}

This system pumps and distributes chlorinated sanitary water throughout the 400 Area. It will remain in service as required to support any occupied buildings. Modifications will be incorporated to isolate water supply 1 ines to deactivated portions of the 400 Area. It is assumed that FMEF, MASF and 400 Area office buildings will be turned over to other DOE programs. Therefore, FMEF, MASF and their support facilities will require this system to be in operation.

Reference: WHC-SD-FF-SSP-011 


\section{H Process and Sanitary Drain System}

This system will remain in service as required to support any occupied buildings. It is assumed that FMEF, MASF and 400 Area office buildings will be turned over to other DOE programs. Therefore, FMEF, MASF and their support facilities will require this system to be in operation. The FFTF Plant building complex and DHX sump pumps will be secured, but remain in an operable condition so that pumping can be performed, if necessary. Open drains will be capped for varmint control. Buildings with H\&V secured will have all water systems isolated/drained to prevent freezing damage.

Reference: WHC-SD-FF-SSP-014

\section{$25 A \quad$ RCB H\&V System}

This system provides fresh air, cooling, and pressure control for the containment building atmosphere and includes redundant supply and exhaust units, recirculation coolers, associated distribution ducts, and HEPA filtering capability. Portions of the system will be available during the D\&D Surveillance and Monitoring period to provide ventilation to meet safety requirements.

Reference: WHC-SD-FF-SSP-022

\section{A Fire Protection Water Supply}

This system includes three water storage tanks, one electric pump, and two diesel pumps. It will remain in service providing water to the hydrants outside of the FFTF plant and buildings. The electric pump and one diesel pump will remain in service to provide backup pumping capability in the event that site power is lost. ATI FFTF and Fuel Storage Facility above ground risers will be isolated at the yard post-indicating-valve and drained.

Reference: WHC-SD-FF-SSP-025

260 Fire Alarm and Detection System - FFTF and FSF

When no longer required to meet property and fire protection requirements, all but one of the fire detection and alarm panels will be shutdown and

deenergized. The backup batteries will be disconnected, removed and recycled. Panel C1359 will need to remain in service to provide fire detection and alarm for buildings 481 and $481 \mathrm{~A}$ and the Fire Protection and Sanitary Water Systems, $26 \mathrm{~A}$ and $23 \mathrm{~B}$.

Reference: WHC-SD-FF-SSP-025 


\section{$27 \mathrm{~A}$ Reactor Containment Vessel}

The domed containment vessel will remain in place. The Equipment Air Lock (EqAL) will have the inner door open and the control system de-energized and vented. The control system will be left in a condition permitting reactivation using a portable air compressor and power source to facilitate opening the other door if the need arises. The Personnel and Emergency Air Locks will have both doors operable. Lead shielding (brick, etc.) not retained in its original configuration will be excessed.

Reference: WHC-SD-FF-SSP-026

\section{Control Panels for RCB}

Only those control panels necessary to support ventilation system operation will remain available for operation.

Reference: WHC-SD-FF-SSP-026

\section{$82 A$ Argon Supply and Distribution System}

This system stores liquid argon and distributes argon gas throughout the plant for reactor and secondary system cover gas, refueling machines, IEM Cell atmosphere and other auxiliary liquid metal systems. It will be converted to provide a static nitrogen blanket on the drained liquid metal systems. One dewar will contain liquid nitrogen with pressure and level indication. The required portions of the argon distribution system will remain in service. The rest of the system will be vented to atmosphere. The vendor owned storage dewars that are no longer required will be returned.

Reference: WHC-SD-FF-SSP-034

\section{$822 \quad$ FSF Argon System}

This system stores liquid argon and distributes it for FSF storage vesse? cover gas and NaK expansion tank cover gas. It will be converted to provide a static nitrogen blanket on the drained i iquid metal systems. Either the FSF dewar will be maintained with liquid nitrogen or the FSF distribution system will be cross-connected with the plant system so only one dewar will be required.

Reference: WHC-SD-FF-SSP-034

\section{A Annunciator Systems - FFTF and FSF}

The local control panel annunciators associated with the equipment that remains available for operation will also remain available for operation, if needed. The $\mathrm{C}-636$ and control room subsystems will be secured.

Reference: WHC-SD-FF-SSP-041 


\section{A Process Radiation Monitoring}

This system provides continuous air monitoring and particulate filter monitoring for all gaseous effluent paths. These systems will be deactivated but some will remain available for operation. Monitors will be available, but will require testing prior to use. Air emissions standards and environmental monitoring needs will require some units to be operable depending on the potential release of radionuclides during the surveillance period and during final disposition activities. The specific equipment that will remain available for operation will be determined at the time of turnover to the Environmental Restoration Contractor, based on the radiological status of the plant at that time. A portion of this system has already been deactivated for FFTF Standby.

Reference: WHC-SD-FF-SSP-045

96B Area Radiation Monitoring (and 96Z, FSF Radiation Monitoring System)

This system provides continuous monitoring and alarm capability for generai plant areas. These systems will be deactivated, but some will remain available for operation to support the Environmental Restoration Contractor's radiation monitoring requirements. They will have power available, but will require testing prior to use. The specific equipment that will remain available for operation will be determined at the time of turnover to the Environmental Restoration Contractor based on the radiological status of the plant at that time. A portion of this system has already been deactivated for FFTF Standby.

Reference: WHC-SD-FF-SSP-045

\subsection{SYSTEMS THAT WILL BE SHUT DOWN TO THE ENVIRONMENTAL RESTORATION CONTRACTOR'S REQUIREMENTS}

\section{$12 \mathrm{~A} \quad 125$ Volt DC IE System}

This system provides uninterruptible power to safety systems required for public protection and is qualified per IEEE Standard 308. When shutdown activities progress to where these safety systems are no longer required, the IE regulations will no longer appiy to this system. A portion of this system will be relocated outside the plant to continue supplying DC control power to the switchgear from the former emergency system that will continue in operation.

Reference: WHC-SD-FF-SSP-007 


\section{$12 \mathrm{C} \quad 2.4 \mathrm{KV}$ System}

This system consists of $13.8 \mathrm{KV}$ to $2.4 \mathrm{KV}$ transformers and switchgear for electrical protection and distribution. The system provides electrical power to the MHTS pumps, DHX fans, primary CRDM MG-set, and the Ex-containment Chilled Water Chillers. This system will be completely shutdown.

Reference: WHC-SD-FF-SSP-007

\section{$12 \mathrm{H}$ Emergency Diesel and Turbine Generators}

This equipment provides on-site emergency power generation to loads that are important for plant equipment protection during reactor operation in case of a loss of all off-site power sources. The diesel generators will be secured and a 17 support fluids drained to eliminate the potential for fire from the fuel and oil systems. The Gas Turbine Generator and its systems will be secured in a like manner. Disposition of the ethylene glycol, fuel, and oil will be accomplished per regulations.

Reference: WHC-SD-FF-SSP-008 and -048

\section{J Zero Time Outage - 120 Volt AC System}

This system provides uninterruptible power to safety systems required for public protection and is qualified per IEEE Standard 308. When shutdown activities progress to where these safety systems are no longer required, the Zero Time Outage will be completely de-energized.

Reference: WHC-SD-FF-SSP-007

\section{$12 M \quad$ Non-IE 125 VDC Battery System}

This system provides 125 VDC power for operation of all normal switchgear breakers and protective relays. This system will be completely shutdown and the batteries excessed or disposed of in accordance with appropriate regulations.

Reference: WHC-SD-FF-SSP-007

\section{$21 \mathrm{~B}$ Cranes and Hoists Outside RCB}

All cranes will be deactivated. No preventative maintenance will be performed. Spare parts will be retained.

Reference: WHC-SD-FF-SSP-010

\section{FSF Land Improvements and Building Structures}

The structures will remain intact, but inactive.

Reference: WHC-SD-FF-SSP-010 


\section{C Cooling Tower System}

This system uses evaporative cooling to provide a final heat sink for cooling of auxiliary systems. It will be shutdown and de-energized. The tower sumps will be drained and cleaned to acceptable environmental standards. Treatment and analysis chemicals will be depleted or excessed.

Reference: WHC-SD-FF-SSP-012

\section{D Cooling Water Systems}

This system circulates an ethylene-glycol solution to transfer heat from auxiliary systems to the cooling towers. These auxiliary systems include the In-containment and Ex-containment chilled water systems, Mobiltherm system, air compressors, RAPS and CAPS compressors, and MHTS pump liquid rheostats. It will be shutdown and de-energized. Disposition of the ethylene-glycol and the pump lubricating oil will be accomplished per regulations.

Reference: WHC-SD-FF-SSP-012

\section{F Ex-Containment Chilled Water System}

This system uses refrigeration units to transfer heat from an ethylene-g7ycol chilled water solution to the cooling water system. The chilled water is circulated throughout the plant to cool the sodium removal system and H\&V units outside of the containment building. It will be shutdown and deenergized. Disposition of the ethylene-giycol, refrigerant and the chiller and pump lubricating oil will be accomplished per regulations.

Reference: WHC-SD-FF-SSP-013

\section{G In-Containment Chilled Water System}

This system uses refrigeration units to transfer heat from an ethylene-glycol chilled water solution to the cooling water system. The chilled water is circulated throughout the containment building as well as HTS-South to c001 inert gas coolers and containment atmosphere recirculation coolers. It will be shutdown and de-energized. Disposition of the ethylene-glycol, refrigerant and the chiller and pump lubricating oil will be accomplished per regulations.

Reference: WHC-SD-FF-SSP-013

\section{J Instrument Air System}

This system provides compressed, dried air primarily for plant instrumentation and remotely operated valves. It will be de-energized and depressurized. The freeze protection for this piping will be secured.

Reference: WHC-SD-FF-SSP-015 


\section{L Diesel Fuel System to Diesel Generators}

These systems will be secured and all oil drained and flushed to acceptabie environmental standards. The storage tanks will be drained and removed from the ground. Disposition of the fuel oil will be accomplished per regulations.

Reference: WHC-SD-FF-SSP-016

\section{$23 \mathrm{M}$ Fuel 0 il to $\mathrm{DHX}$ Heaters}

These systems will be secured and 211 oil drained and flushed to acceptable environmental standards. The storage tanks will be drained and removed from the ground. Disposition of the fuel oil will be accomplished per regulations. The freeze protection for this piping will be secured.

Reference: WHC-SD-FF-SSP-017

23P Service Air (utility and breathing)

The system will be depressurized and all freeze protection de-energized.

Reference: WHC-SD-FF-SSP-015

23R Demineralized Water System

This system uses resin beds to treat sanitary water and provide demineralized water to the MHTS pump liquid rheostats and the sodium removal system. It will be drained and de-energized. The purification beds will be returned to the vendor. All freeze protection will be de-energized.

Reference: WHC-SD-FF-SSP-018

\section{S Mobiltherm System}

This system circulates an oil referred to as Mobiltherm to transfer heat from the IDS and primary cold trap NaK cooling systems to the cooling water system. It will be secured and drained. Disposition of the Mobiltherm and pump lubricating oil will be accomplished per regulations.

Reference: WHC-SD-FF-SSP-019

$23 Y$ FSF Auxiliary Systems

This system consists of the sanitary water and drains of FSF. It will be drained and any freeze protection de-energized.

Reference: WHC-SD-FF-SSP-020 


\section{$23 Z$ FSF Chilled Water System}

This system uses a refrigeration unit to chill an ethylene glycol solution which then cools the FSF vessel vault cooling system. It will be secured and de-energized. Disposition of the ethylene glycol, refrigerant and lubricating oil will be accomplished per regulations.

Reference: WHC-SD-FF-SSP-013

\section{$24 \mathrm{~A}$ Radioactive Liquid Waste System}

The system stores and provides transfer capability for liquid waste, primarily from the sodium removal system. The system and the traps will be drained and flushed. The water will be sent to the 200 Areas for disposal.

Reference: WHC-SD-FF-SSP-02I

\section{B Oxygen Monitoring}

This system consists of oxygen monitors and alarm capability for all general plant access areas with a potential for an inert atmosphere. They will be deenergized and the sensor heads removed and excessed or disposed of in accordance with applicable regulations.

Reference: WHC-SD-FF-SSP-023

\section{D Control Building and AEB East H\&V System}

This ventilation system provides fresh air, cooling, heating, and pressure control for the control building and $A E B$ East and includes ail supply and exhaust units, heaters, recirculation coolers, distribution ducts and HEPA filtering capability for the Survey Area East. It also includes the Life Support System for Control Room Habitability. The system will be shutdown and de-energized.

Reference: WHC-SD-FF-SSP-022

\section{E RSB and AEB West H\&V System}

This ventilation system provides fresh air, cooling, and heating for the RSB and $A E B$ West and includes all supply and exhaust units, heaters, recirculation coolers, and distribution ducts. The system will be shutdown and deenergized.

Reference: WHC-SD-FF-SSP-022 


\section{F HTS and DHX Building H\&V System}

This ventilation system provides fresh air, cooling, and heating for all HTS and DHX buildings and includes all supply and exhaust units, heaters, recirculation coolers and distribution ducts. It also provides HEPA filtering capability for the primary cover gas sampling cells in HTS-South. The system will be shutdown and de-energized.

Reference: WHC-SD-FF-SSP-022

\section{$25 \mathrm{G} \quad$ CLS H\&V System}

This ventilation system provides fresh air, cooling, and heating for all cells containing secondary closed loop system equipment and includes all supply and exhaust units, heaters, recirculation coolers and distribution ducts. This system will be secured.

Reference: WHC-SD-FF-SSP-022

\section{H RAPS and CAPS H\&V System}

This system provides ventilation and cooling to the normally closed cells containing the RAPS and CAPS systems and the radioactive liquid waste system. It will be shutdown and de-energized.

Reference: WHC-SD-FF-SSP-022

\section{J Reactor Head Compartment/Cavity Gas Cooling System}

This system interfaces with the In-containment Chilled Water system to provide air cooling to the reactor head compartment and nitrogen cooling to the reactor cavity, CRDMs, LLFMs, and Center Island. It will be shutdown and deenergized. The cells and piping will be vented to atmosphere.

Reference: WHC-SD-FF-SSP-024

\section{K IDS vessel and Tank Cell Gas Cooling System}

This system interfaces with the In-containment Chilled Water system to provide nitrogen cooling for the IDS vessel cell and other auxiliary liquid metal systems. It will be shutdown and de-energized. The cells and piping will be vented to atmosphere.

Reference: WHC-SD-FF-SSP-024 


\section{L Closed Loop Gas Cooling System}

This system interfaces with the In-containment Chilled Water system to provide nitrogen cooling for the cells containing closed loop components and piping as well as the in-containment portion of the primary sodium sampling system. It will be shutdown and de-energized. The cells and piping will be vented to atmosphere.

Reference: WHC-SD-FF-SSP-024

\section{M HTS Gas Cooling System}

This system interfaces with the In-containment Chilled Water system to provide nitrogen cooling for the cells containing primary MHTS components and piping. It will be shutdown and de-energized. The cells and piping will be vented to atmosphere.

Reference: WHC-SD-FF-SSP-024

25N IEM Cell and Fuel Subassembly Gas Cooling System

This system interfaces with the In-containment Chilled Water system to provide argon cooling for the IEM cell and its fuel subassembly cooling system. It wi 77 be shutdown and de-energized. The cells and piping will be vented to atmosphere.

Reference: WHC-SD-FF-SSP-024

\section{W Meteorological System}

The system will be shutdown and de-energized.

Reference: None

\section{X FSF Building H\&V}

This ventilation system provides fresh air, cooling, and heating for FSF and includes all supply and exhaust units, heaters, recirculation coolers and distribution ducts. The system will be shutdown and de-energized.

Reference: WHC-SD-FF-SSP-022

\section{$25 Y$ FSF Oxygen Monitoring}

The oxygen monitors will be de-energized and the sensor heads removed and excessed or disposed of in accordance with applicable regulations.

Reference: WHC-SD-FF-SSP-023 


\section{$252 \quad$ FSF Vault Cooling}

This system provides air cooling to the FSF vessel vault. It will be shutdown and de-energized.

Reference: WHC-SD-FF-SSP-022

\section{B Fire Protection Sprinkler System - FFTF and FSF}

This system will be isolated and drained. Disposition of the propylene-glycol and AFFF will be processed according to regulations. The sprinkler system can only be taken out of service when the plant is officially recognized as having no real property replacement value.

Reference: WHC-SD-FF-SSP-025

\section{C Fire Protection Gas System - FFTF and FSF}

This system provides automatic halon fire suppression for rooms containing computer equipment and nitrogen flooding capability for rooms containing secondary sodium. The nitrogen flooding system will be secured and vented to atmosphere. The halon systems will be shutdown and deenergized when they are no longer required to meet property and fire protection requirements. The halon bottles will be removed and disposed of per Letter, Managed Phaseout of Halon Fixed Fire Suppression Systems, dated June 3, 1993, R.A. Holten Director Quality, Safety and Health Programs Division, U.S. Department of Energy, to President Westinghouse Hanford Company.

Reference: WHC-SD-FF-SSP-025

\section{$\underline{27 B} \quad$ RCB Polar Crane}

The crane will be deactivated. No preventative maintenance will be performed. Spare parts will be retained.

Reference: WHC-SD-FF-SSP-026

\section{$27 \mathrm{E}$ Reactor Containment Building Inert Cells}

The cells will be vented to atmosphere via the flanged ports through which the volumes are de-inerted.

Reference: WHC-SD-FF-SSP-026

\section{$27 \mathrm{M}$ Containment Margins}

This system provides containment atmosphere sampling and scrubbing capability to mitigate the effects of a severe accident. It will be secured and deenergized. The system gas cylinders will be returned to the stores system for re-issue.

Reference: WHC-SD-FF-SSP-027 


\section{A Reactor Internals}

This system consists of the in core assemblies, instrument trees, core structural components and shielding. It will be secured from the standpoint of its operation as a system in the FFTF plant. The irradiated fuel will be removed. The instrument trees will remain in place on the reactor head to seal the reactor vessel and limit leakage of the nitrogen blanket. They will be rotated to the removal position, if possibie. The MOTA gloveboxes will be decontaminated and removed with the sweep gas capped and the gas bottles removed.

Reference: WHC-SD-FF-SSP-028

\section{$31 \mathrm{~B}$ Control Rod Drive Mechanisms (CRDM)}

This system consists of the motor assemblies above the reactor vessel used to move the control rods. It will be secured and de-energized with the absorber assemblies disconnected. The head mounted components will be configured to seal the reactor vessel and limit leakage of the nitrogen blanket.

Reference: WHC-SD-FF-SSP-028

\section{A Reactor Enclosure}

The reactor cavity will be vented via its inert gas cooling system. The system will be secured in all other respects. Disposal of depleted uranium shielding will be evaluated for final disposition.

Reference: WHC-SD-FF-SSP-029

\section{A In-Vessel Handling Machine (IVHM)}

These three machines perform fuel handling within the reactor vessel by moving fuel assemblies between the core and the in-vessel storage modules. The controls and drive mechanisms are mounted on the reactor vessel head with the handling mechanism within the vessel. They will be secured and de-energized. A11 reactor head mounted equipment wi11 remain in place. The IVHM's will be configured to seal the reactor vessel and limit leakage of the nitrogen blanket.

Reference: WHC-SD-FF-SSP-030

\section{C Core Component Handling and Storage}

This system includes the handling machines (CLEM and BLTC), the installed storage facilities, and associated interface equipment used to perform all ex-vessel fuel handling. All movable refueling machines and handling equipment will be secured and de-energized. The smaller fuel handling 
components (Solid Waste Cask, Shielded Cell Transfer Container, Plug Handling Fixtures, Floor Valves, and Floor Valve Adapters) that have internal contamination will be disassembled into modules that will fit into the large Hanford concrete burial boxes.

Reference: WHC-SD-FF-SSP-030

\section{D IEM Cel1 and Sodium Removal System}

This system is a shielded, hot-cell that provides remote sodium washing, disassembly, and examination of irradiated core components. It will be secured and de-energized. The argon atmosphere will be vented through a HEPA filter. The master-slave portion of the manipulators will be removed and the ports configured to provide an effective, long-term seal to prevent contamination spread. Other cell penetrations will be evaluated to ensure no seal degradation will occur during the surveillance period. The sodium removal system will be flushed with water which will be disposed of via the liquid radioactive waste system prior to its shutdown. Removable lead shielding (bricks, etc.) will be excessed.

Reference: WHC-SD-FF-SSP-031

\section{$412 \quad$ FSF Fuel Handling}

This system consists of the refueling equipment that enables transfer of core components to and from the FSF vesse1. The FSF PHF will be disassembled into modules that will fit into the large Hanford concrete burial boxes. These modules will be sealed with bolted-on covers that will contain the

contamination. They will be loaded into the burial boxes at FFTF and shipped to the 200 Area for burial.

Reference: WHC-SD-FF-SSP-030

\section{A Segmented Maintenance Cask}

Component Removal/Installation Equipment

Cask and Handling Equipment

Component Disassembly/Assembly Equipment

Repair Tooling and Equipment

Those components that are not contaminated and can be released will be excessed. Any components that have internal contamination will be disassembled into modules that will fit into the large Hanford concrete burial boxes. These modules will be sealed with bolted-on covers that will contain the contamination. They will be loaded into the burial boxes at FFTF and shipped to the 200 Area for burial.

Reference: None 


\section{A HTS Primary Coolant System}

The primary reactor core coolant system consists of three coolant loops each with a main sodium pump, support systems and sodium piping. The system will be secured and de-energized. The sodium will be drained and residuals maintained under a nitrogen blanket. The pump couplings will be removed and the shafts will be capped to limit nitrogen Teakage. Disposition of the pump lubricating oil will be accomplished per regulations.

\section{Reference: HHC-SD-FF-SSP-032}

\section{B HTS Secondary Coolant System}

The secondary coolant system consists of three coolant loops, isolated from the radioactive primary coolant loops by the IHXs, each with a main sodium pump, support systems and sodium piping. The system will be secured and deenergized. The sodium will be drained and residuals will be maintained under a nitrogen blanket. The pump couplings will be removed and the shafts will be capped to limit nitrogen leakage. Disposition of the pump lubricating oil will be accomplished per regulations.

Reference: $\quad W H C-S D-F F-S S P-032$

\section{C HTS Dump Heat Exchanger System}

This system provides the final heat sink for reactor core cooling by removing heat from the secondary coolant system with twelve sodium to air heat exchangers. It consists of main cooling fans, control dampers, structural components and oit fired preheaters to maintain sodium temperatures during reactor refueling. The system will be secured and de-energized. The sodium will be drained and residuals will be maintained under a nitrogen blanket. Disposition of the fan lubricating oil and preheater fuel oil will be accomplished per regulations.

Reference: WHC-SD-FF-SSP-032

61A Closed Loop \#2 Primary Coolant System

61B Closed Loop \#2 Secondary Coolant System

61C Closed Loop \#2 DHX System

61D Closed Loop \#2 CLIRA

$61 \mathrm{C}$ Closed Loop \#1 Primary Coolant System

$61 \mathrm{~F}$ Closed Loop \#1 Secondary Coolant System

61G Closed Loop \#1 DHX System

61H Closed Loop \#1 CLIRA

These systems were intended to provide cooling systems for in-reactor experiments that were isolated from the main reactor cooling systems. equipment was installed, but the systems were never completed and are currently abandoned in place. Other than completion of closeout documentation, these systems are already in their final end point condition.

Reference: None 


\section{Sodium Receiving and UnToading System}

This system provided sodium fill capability for the primary and secondary cooling systems and is currently inactive. It will be used during sodium draining and then will be secured and de-energized.

Reference: WHC-SD-FF-SSP-033

\section{B Reactor Primary Sodium Processing}

This system provides primary sodium purification by circulating primary sodium through a cold trap and returns it to the reactor vessel to maintain vessel level. It will be secured and de-energized. The primary cold trap is highly radioactive and cannot be drained so it will be frozen and left in place for final D\&D.

Reference: WHC-SD-FF-SSP-033

\section{C IDS and Primary Sodium Storage/Processing}

This system provides IDS and stored primary sodium purification by circulating sodium through a cold trap. It will be secured and de-energized. The sodium will be drained and residuals will be maintained under a nitrogen blanket. The IDS cold trap cannot be drained and it is located in the same cell as the highly radioactive primary cold trap. It will therefore be frozen and left in place for final D\&D.

Reference: WHC-SD-FF-SSP-033

810 NaK IDS Cooling System

This system cools the IDS sodium to remove decay heat and transfers this heat to the Mobiltherm system. It will be secured and de-energized. The NaK will be flushed into the bulk sodium using molten sodium and then the system will be drained to the extent possible and frozen.

Reference: WHC-SD-FF-SSP-033

\section{E NaK Cold Trap Cooling System}

This system cools the primary system cold trap and transfers this heat to the Mobiltherm system. It will be secured and de-energized. The NaK will be flushed into the bulk sodium using molten sodium and then the system will be drained to the extent possible and frozen.

Reference: WHC-SD-FF-SSP-033 


\section{F Reactor Secondary Sodium Processing}

This system provides secondary sodium purification by circulating secondary sodium through a cold trap, one per loop. It will be secured and deenergized. The sodium will be drained and residuals will be maintained under a nitrogen blanket. The secondary cold traps cannot be drained so they will be frozen and left in place for final D\&D.

\section{Reference: WHC-SD-FF-SSP-033}

\section{Y FSF Sodium Purification}

The system provides FSF sodium purification by circulating FSF sodium through a cold trap and provides auxiliary heat input, if required, to maintain bulk sodium temperature. It will be secured and de-energized. The sodium will be drained and residuals will be maintained under a nitrogen blanket. The FSF cold trap cannot be drained so it will be frozen and left in place for final D\&D.

Reference: WHC-SD-FF-SSP-033

\section{FSF NaK Heat Transfer}

This system cools the FSF storage vessel sodium by natural circulation of two NaK loops from the vessel to two natural draft air to NaK heat exchangers. Only one of the loops has ever been operated. This loop will be secured, deenergize, and the NaK drained and disposed of in the bulk sodium.

Reference: WHC-SD-FF-SSP-033

\section{D Cel1 Atmosphere Processing System (CAPS)}

This system collects and processes the nitrogen gas from the inerted cells in the containment building and other miscellaneous process gases. It provides a vacuum for cell pressure control and can process any radionuclides in the gas by cryogenic charcoal delay beds. It will be secured and de-energized. The cold box charcoal beds will remain in place. In some cases, the system may be vented through a HEPA filter. Other portions will be adequately capped or sealed to prevent contamination spread.

Reference: WHC-SD-FF-SSP-034

\section{$82 E$ Radioactive Argon Processing System (RAPS)}

This system collects and processes the radioactive reactor cover gas. It provides a vacuum for reactor pressure control and processes the radionuclides in the gas by cryogenic charcoal delay beds. It will be secured and de-energized. The cold box charcoal beds will remain in place. The system will be capped or sealed to prevent contamination spread.

Reference: WHC-SD-FF-SSP-034 


\section{G Nitrogen Supply and Distribution System}

This system stores liquid nitrogen and distributes it throughout the plant for in-containment inerted cells, pneumatic valve operation, RAPS and CAPS cryogenic cold box cooling and other auxiliary systems. It will be secured and vented to atmosphere. The vendor owned storage dewars will be returned.

Reference: WHC-SD-FF-SSP-034

\section{J Vacuum System}

This system was used, in conjunction with the argon supply system, to reduce the oxygen content of sodium piping to acceptable levels prior to sodium fill. It will be secured and vented. Selected portable vacuum pumping units will be transferred for use in the sodium storage and reaction facilities.

Reference: WHC-SD-FF-SSP-034

82L Nitrogen Atmosphere Sampling/Analysis

This system samples the inerted cell atmospheres for oxygen and radioactivity. It has been deactivated for FFTF Standby. Other than completion of closeout documentation, this system is in its final end point condition.

Reference: WHC-SD-FF-SSP-034

\section{N IEM Cell Argon Purification System}

This system processes the argon atmosphere of the IEM Cell to remove oxygen and moisture. It will be secured and de-energized. The oxygen removal desiccant will be removed and disposed of in accordance with applicable regulations.

Reference: HHC-SD-FF-SSP-034

\section{$82 Y \quad$ FSF Nitrogen System}

The system will be secured and vented to atmosphere.

Reference: WHC-SD-FF-SSP-034

\section{A HTS Primary Sodium Sampling/Monitoring}

This system provides sampling capability and continuous monitoring of primary sodium gross impurity levels. It will be secured and de-energized. The sodium in the HTS-South sample loop is currently frozen for FFTF Standby, but will be melted prior to primary sodium system drain. The sodium will be drained and residuals will be maintained under a nitrogen blanket. The primary cesium trap, which is highly radioactive, cannot be drained so it will be frozen and left in place for final D\&D.

Reference: WHC-SD-FF-SSP-035 


\section{C HTS Secondary Sodium Sampling/Monitoring}

This system provided sampling capability and continuous monitoring of secondary sodium gross impurity levels. It will be secured and de-energized. The sodium will be drained and residuals will be maintained under a nitrogen blanket.

Reference: WHC-SD-FF-SSP-035

\section{B \& 85D CLS Primary and Secondary Sodium Samp7ing/Monitoring}

These systems provided sampling capability for the closed loop sodium. The closed loop systems were never completed, so these systems are currentiy abandoned in place. Other than completion of closeout documentation, the systems are in their final end point condition.

Reference: WHC-SD-FF-SSP-035

\section{E Argon Cover Gas Sampling and Monitoring}

This system provides sampling, continuous reactor cover gas monitoring for impurities, and distributes cover gas to the fuel failure monitoring system. It has been deactivated for FFTF Standby. The system will be capped or sealed to prevent contamination spread.

Reference: WHC-SD-FF-SSP-035

857 FSF Sodium Sampling

This system provides sampling capability and continuous monitoring of FSF sodium gross impurity ievels. It will be secured and de-energized. The sodium will be drained and residuals will be maintained under a nitrogen blanket.

Reference: WHC-SD-FF-SSP-035

\section{A HTS Flow control System}

This system controls main sodium coolant pump speed to control rate of flow. It will be secured and de-energized. The liquid rheostats will be drained and flushed.

Reference: WHC-SD-FF-SSP-036

90B HTS DHX Control System

This system controls DHX fan speed and damper position to control DHX out let temperatures. It has been deactivated for FFTF Standby. Other than completion of closeout documentation, this system is in its final end point condition.

Reference: WHC-SD-FF-SSP-036 
$\underline{90 C}$ Reactor Flux Control System

This system controls control rod position for automatic reactor power control. It has been deactivated for FFTF Standby. Other than completion of closeout documentation, this system is in its final end point condition.

Reference: WHC-SD-FF-SSP-036

\section{D Reactor Plant Control Panels}

This system houses the components of the flow, DHX and flux control systems in the control room. It will be secured and de-energized.

Reference: WHC-SD-FF-SSP-036

\section{A PDS Computer. Peripherals, and CRT Displays}

This system provides continuous monitoring and recording of various plant parameters. It also performs calculations for determination of core characteristics and optimization of plant operation. It will be secured and de-energized. The computer equipment will be deployed by other DOE missions, excessed or abandoned in place.

Reference: WHC-SD-FF-SSP-037

\section{C PDS Multiplexer}

This system is the interface between the incoming plant instrumentation and the main PDS computer. It will be secured and de-energized. The computer equipment will be deployed by other DOE missions, excessed or abandoned in place.

Reference: WHC-SD-FF-SSP-037

\section{D EDS/DAS - Experimenters DATA System/Data Acquisition System}

This system provides continuous monitoring and recording of various plant parameters of importance to specific experiments. It has been deactivated for FFTF Standby. Other than completion of closeout documentation, this system is in its final end point condition. The computer equipment will be deployed by other DOE missions, excessed or abandoned in place.

Reference: WHC-SD-FF-SSP-038

\section{E EDS/CALC - Experimenters Data System Calculational Computer}

This system performs calculations using data from the EDS/DAS system by using programs specific to certain experiments. It has been deactivated for FFTF Standby. Other than completion of closeout documentation, this system is in 
its final end point condition. The computer equipment will be deployed by other DOE missions, excessed or abandoned in place.

Reference: WHC-SD-FF-SSP-038

\section{Reactor and Vessel Instrumentation (FTRIA)}

This system provides monitoring of individual core assembly and reactor vessel parameters. It will be secured and de-energized. The in-reactor sensors will remain in place.

Reference: WHC-SD-FF-SSP-039

\section{B Sodium Piping Trace Heat and Controls}

This system provided initial preheat of sodium piping prior to fill and continues to provide temperature control for sodium filled piping using electric heaters and proportional controllers. It will be secured and deenergized after the associated sodium system is drained.

Reference: WHC-SD-FF-SSP-042

\section{C Seismic Monitoring}

This system provides monitoring and recording of seismic activity. It will be secured and de-energized.

Reference: WHC-SD-FF-SSP-026

93D Na Leak Detection and Alarm System

This system provides for early indication of sodium leakage using contact leak detectors and sodium aerosol detectors. It will be secured and de-energized.

Reference: WHC-SD-FF-SSP-040

\section{FSF Trace Heating and Controls}

This system provided initial preheat of sodium piping prior to fill and continues to provide temperature control for sodium filled piping using electric heaters and proportional controllers. It will be secured and deenergized after the FSF sodium is drained.

Reference: WHC-SD-FF-SSP-042

\section{$94 \mathrm{~A}$ Fuel Failure Monitoring System}

This system provides for early detection of fuel failure by continuousiy monitoring the reactor cover gas for fission gas and is capable of sampling the cover gas for tag gases to locate the core assembly that is leaking. It 
also monitors the primary sodium piping for neutrons emitted from fission fragments. It has been deactivated for FFTF Standby. Other than completion of closeout documentation, this system is in its final end point condition. The liquid nitrogen system will be drained and vented.

Reference: WHC-SD-FF-SSP-043

\section{A Flux Monitoring System}

This system uses neutron detectors to provide indication of reactor power and subcritical reactivity. The system will be secured and de-energized.

Reference: WHC-SD-FF-SSP-044

\section{Information Systems}

This system supports equipment data base and work control functions. The system will be secured and de-energized following completion of all deactivation activities. The computer equipment will be deployed by other DOE missions, excessed or abandoned in place.

Reference: None

99A Plant Protection System

This system consists of the electronics that automatically scram the reactor in case of unsafe plant conditions. It will be secured and de-energized. The secondary Plant Protection System was deactivated for FFTF Standby. The primary Plant Protection System will be deactivated in conjunction with the Containment Isolation System (System 99B).

Reference: WHC-SD-FF-SSP-046

\section{B Containment Isolation System}

This system consists of the electronics that automatically seal the containment building on detection of high radiation in the containment exhaust duct. It will be secured and de-energized.

Reference: WHC-SD-FF-SSP-046

\subsection{FFTF PLANT BUILDINGS}

The buildings will be left in a state where all hazardous material and radiological contamination has been either removed or contained to a point that it cannot be inadvertently disturbed. All areas with surface contamination (e.g., the IEM Cell, the sodium removal system cell, and other cells that may be contaminated during shutdown activities) will be decontaminated to levels that prevent re-suspension or migration or the area will be sealed or vented through filters. All of these areas are currently in 
cells with installed sealing systems, so sealing these areas will be the preferred option. All loose hazardous material, such as lead or friable asbestos, will be removed and disposed of. Building roofs will be maintained and upgraded to ensure roof integrity for at least five years after turnover to the Environmental Restoration Contractor. All facility penetrations that do not communicate with a closed system will be sealed against foul weather and animal intrusions.

The following is a list of 400 Area buildings that house FFTF systems and to which these requirements apply:

BUILDING

405

$491 E, S, W$

$408 A, B, C$

403

4717

462lE, W

483

484

4721

4703

\section{DESCRIPTION}

Containment building - reactor vessel, primary heat transport system, interim decay storage vessel, and refueling equipment.

Heat Transport System buildings - secondary heat transport systems and support equipment.

Dump Heat Exchanger buildings - DHX's, sodium preheaters and support equipment.

Fuel Storage Facility - fuel storage vessel, refueling and support equipment.

Reactor Service Building - support equipment such as chillers, air compressors, sodium removal system, etc.

Auxiliary Equipment Buildings East and West electrical systems and diesel generators.

Cooling Water Pad - cooling water towers and pumps.

Chilled Water Building - chillers and chilled water pumps.

Turbine generator and electrical switchgear.

Control Building

\subsection{SHUTDOWN PROGRAM LOGIC DIAGRAM}

The following major activities will define the process of placing the FFTF systems in a deactivated status. Refer to Figure 1 for a logic diagram of these activities. The milestones identified are a function of the completion of the tasks and not a calendar date. Once a key event has been performed, the systems providing support for that activity will be shutdown. These 
groups are detailed on Table Al. The groups are defined based on current assumptions for the fuel washing sequence, sodium drain sequence and deletion of the requirement for containment integrity. Therefore, the system groups may change slightly as the shutdown progresses. The major shutdown activities are:

- All fuel is removed from the reactor vessel and placed in IDS or FSF. At this point conditions are established to begin shutdown of major systems and commencing HTS sodium drain.

- Sodium from the three secondary HTS loops is transferred to the in-plant sodium drain tanks (T-42, T-43 and T-44). Note that the secondary sides of the IHXs will continue to contain sodium. This will permit shutdown of most of the secondary HTS support systems although some portions will remain available for later offloading of T-44 and the IHXs.

- Following completion of the Sodium Storage Facility, the sodium remaining in T-44 and the secondary sides of the IHXs is transferred to the SSF. The remainder of the secondary HTS support systems can then be shut down.

- The remaining in-plant sodium tanks (T-42 and T-43) inventories are transferred to the SSF and the primary HTS sodium is then drained and transferred permitting the shutdown of the primary HTS support systems.

- Washing of all fuel from the FSF vessel is completed in the IEM Cell. The FSF fuel handling equipment and heat removal systems can be shutdown at this point.

- The sodium is removed from FSF permitting the shutdown of its support systems.

- Washing of all fuel from the IDS vessel is completed in the IEM Cell permitting the shutdown of all fuel handling equipment, provided that all fuel has already been removed from FSF.

- The sodium is discharged from IDS permitting the shutdown of its support systems.

- After all fuel and other sodium wetted components have been washed, the IEM $\mathrm{Ce}] \mathrm{l}$ and its support systems may be shutdown.

- The remainder of plant support systems may be shutdown after all major shutdown activities have been completed. The facility is then turned over to the Environmental Restoration Contractor for surveillance and maintenance. 


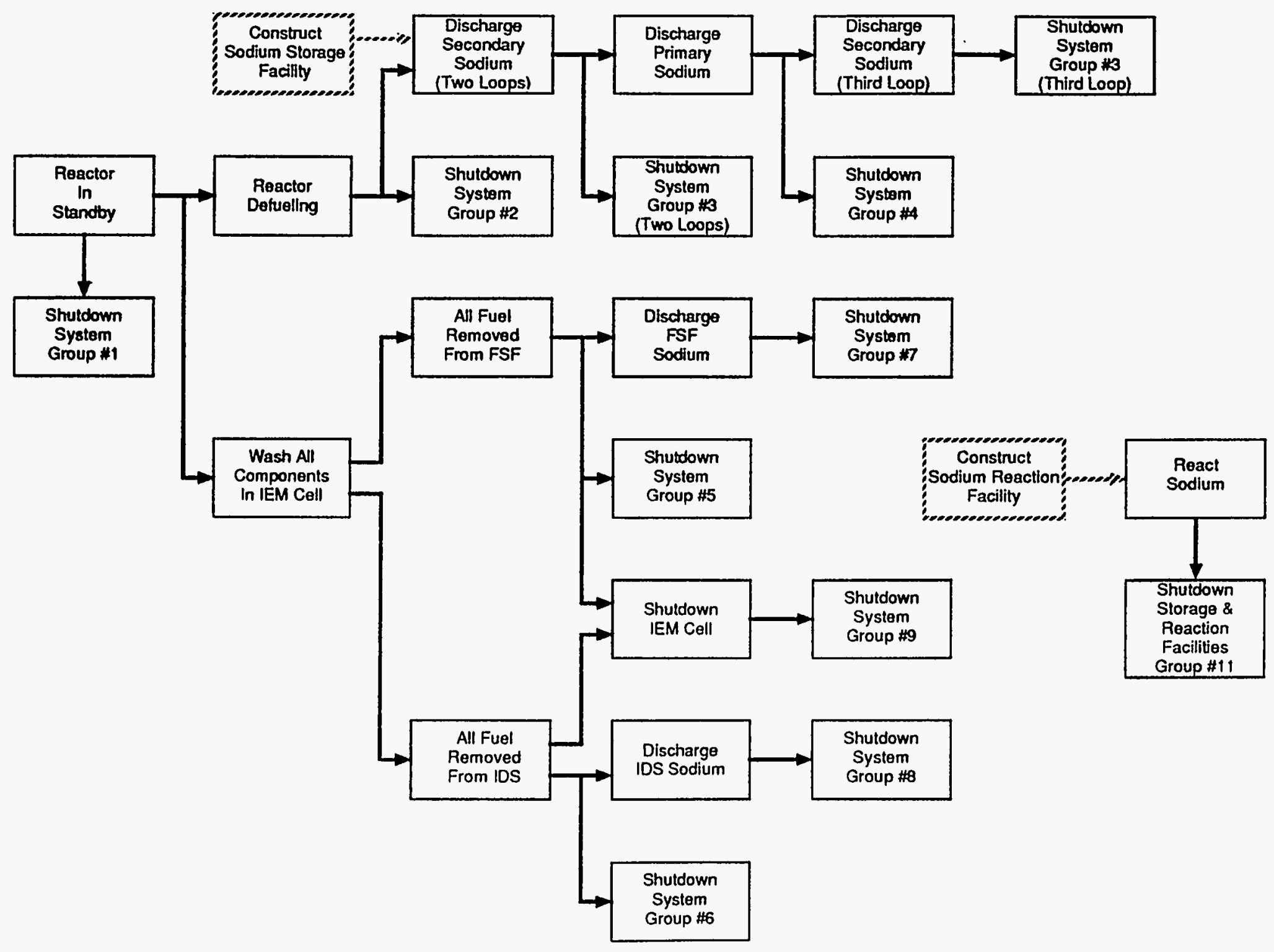

Figure 1. Shutdown Program Logic Diagram 


\section{TABLE A1}

\section{SHUTDOWN SYSTEM GROUPS}

Group 0: Systems Shutdown During Operation (Inactive Systems)

61A Closed Loop \#2 Primary Coolant System

$61 \mathrm{~B}$ Closed Loop \#2 Secondary Coolant System

61C Closed Loop \#2 DHX System

610 Closed Loop \#2 CLIRA

$61 \mathrm{C}$ Closed Loop \#1 Primary Coolant System

$61 F$ Closed Loop \#1 Secondary Coolant System

6IG Closed Loop \#1 DHX System

$61 \mathrm{H}$ Closed Loop \#1 CLIRA

85B CLS Primary Sodium Sampling/Monitoring

85D CLS Secondary Sodium Sampling System

Group 1: Systems Shutdown for FFTF Standby

$12 \mathrm{~J}$ Zero Time Outage - 120 Volt AC System

$12 \mathrm{H}$ Emergency Diesel and Turbine Generators (Diesels only)

23L Diesel Fuel System to Diesel Generators

$25 \mathrm{~A}$ Containment H\&V System (Partial)

250 Control BIdg and AEB-E H\&V System (Partial)

$25 E \quad R S B$ and AEB-W H\&V System (Partial)

$25 \mathrm{~F}$ HTS and DHX Building H\&V System (Partial)

27M Containment Margins

82E Radioactive Argon Processing System (RAPS)

82L Nitrogen Atmosphere Sampling/Analysis

85E Argon Cover Gas Sampling and Monitoring

90B HTS DHX Control System (Fans, Dampers, Gates)

90C Reactor Flux Control System

91A PDS Computer, Peripherals, and CRT Displays

91C PDS Multiplexer

91D EDS/DAS - Experimenters DATA System/Data Acquisition System

$91 E$ EDS/CALC Experimenters Data System Calculational Computer, LPMA Experimenters (Room 404) Computer Equipment

94A Fuel Failure Monitoring System

99A Plant Protection System

99B Containment Isolation System

36A Fusion MOTA GTovebox and Controls

Group 2: Systems Shutdown After Fuel Removed from the Reactor Vessel

$12 A 125$ Volt IE DC System

$31 \mathrm{~A}$ Reactor Internals

31B Control Rod Drive Mechanisms (CRDM)

$41 \mathrm{~A}$ In-Vessel Handling Machine (IVHM)

92 Reactor and Vessel Instrumentation (FTRIA)

95A Flux Monitoring System 
Group 3: Systems Shutdown After Secondary Sodium Drain

\section{C 2.4KV System}

23M Fuel 0 i1 to DHX Heaters

5IB HTS Secondary Coolant System

51C HTS Dump Heat Exchanger System (Tube Bundles and Enclosure)

81F Reactor Secondary Sodium Processing

85C HTS Secondary Sodium Sampling System

90A HTS Flow control System

90D Reactor Plant Control Panels

Group 4: Systems Shutdown After Primary Sodium Drain

$12 \mathrm{H}$ Emergency Diesel and Turbine Generators (remainder)

$12 M$ Non-1E 125 VDC Battery System

23S Mobi7therm System

25J Reactor Head Compartment/Cavity Gas Cooling System

25L Closed Loop Gas Cooling System

25M HTS Gas Cooling System

26B AFFF System

$32 \mathrm{~A}$ Reactor Enclosure

$51 \mathrm{~A}$ HTS Primary Cool ant System

81B Reactor Primary Sodium Processing

81E NaK Cold Trap Cooling System

85A HTS Primary Sodium Sampling/Monitoring

93B Sodium Piping Trace Heat and Controls (a11 except IDS)

93D Na Leak Detection and Alarm System (ali except IDS)

Group 5: Systems Shutdown After All Fuel is Removed from FSF

41 Solid Waste Transfer Pit

412 FSF Fuel Handling

812 FSF NaK Heat Transfer*

$82 Y$ FSF Nitrogen System

Group 6: Systems Shutdown After All Fuel is Removed from IDS

41C Core Component Handling and Storage

Group 7: Systems Shutdown After FSF Sodium Drain

23Y FSF Auxiliary Systems

232 FSF Chilled Water System

$25 Y$ FSF Oxygen Monitoring

$25 Z$ FSF Vault Cooling

$81 Y$ FSF Sodium Purification

$85 Z$ FSF Sodium Samp ing

$93 Z$ FSF Trace Heating and Controls

* NaK can be removed before fuel removal. 
Group 8: Systems Shutdown After IDS Sodium Drain

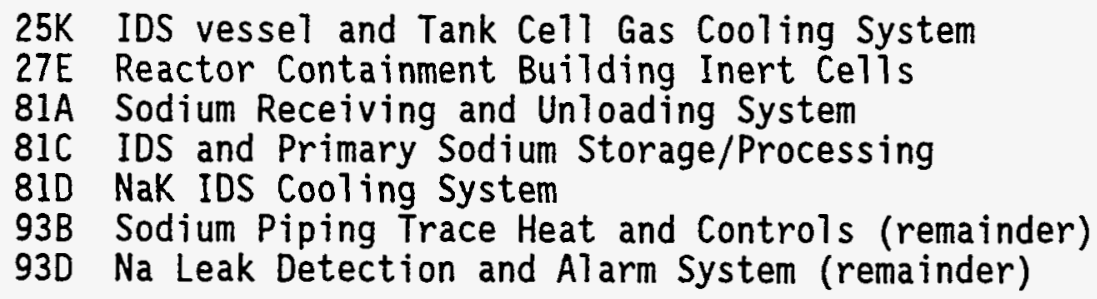

\section{Group 9: Systems Required for IEM Cell Support}

23R Demineralized Water System

25N IEM Ce11 and fuel Subassemb7y Gas Cooling System

41D IEM Cell and Sodium Removal System

44A Segmented Maintenance Cask Component Removal/Installation Equipment Cask and Handling Equipment Component Disassembiy/Assembly Equipment Repair Tooling and Equipment

82N IEM Cell Argon Purification System

Group 10: Final Systems Shutdown

23C Cooling Tower System

230 Cooling Water systems

23F Ex-Containment Chilled Water System

23G In-Containment Chilled Water System

23J Instrument Air System

23P Service Air (utility and breathing)

24A Radioactive Liquid Waste System

25A Containment H\&V System (Remainder)

25B Oxygen Monitoring

$25 D$ Control Bldg and AEB-E H\&V System (Remainder)

25E RSB and AEB-W H\&V System (Remainder)

$25 \mathrm{~F}$ HTS and DHX Building H\&V System (Remainder)

25H RAPS and CAPS H\&V System

25W Meteorological System

26A Fire Protection Water Supply (Partial)

26B Fire Protection Sprinkler Systems

26C Fire Protection Gas Systems

$26 D$ Fire Detection and Alarm Systems

27B RCB Polar Crane

82D Cell Atmosphere Processing System (CAPS)

$82 G$ Nitrogen Supply and Distribution System

$82 \mathrm{~J}$ Vacuum System

$93 \mathrm{C}$ Seismic Monitoring 
Group 11: Bulk Sodium Conversion

98 Information Systems

Sodium Storage Facility

Sodium Reactor Facility

Ancillary Systems/Equipment 
WHC-SD-FF-SSP-004

Rev. 1, Page A2-33

This page intentionally left blank. 
WHC-SD-FF-SSP-004

Rev. 1, Page A3-1

Appendix A-3

Environmental Restoration Contractor Turnover Criteria 
WHC-SD-FF-SSP-004

Rev. 1, Page A3-2

This page intentionally left blank. 
From: $\quad 100$ Area Projects

Phone: $373-1184 \times 5-55$

$85000-94-0003$

Date: January 27, 1994

Subject: FAST FLUX TEST FACILITY DEACTIVATION CRITERIA FOR ACCEPTANCE BY 100 AREA PROJECTS FOR DECONTAMINATION AND DECOMMISSIONING

To:

J. C. Midgett

cc:
T. M. Burke

R. G. Egge

O. A. Farabee

P. W. Griffin

G. B. Griffin

S. Guttenberg

R. K. Hulvey

E. J. Krejci

E. F. Loika

P. D. Mix

M. R. Morton

J. E. Parker

J. B. Waldo

R. A. Winship

MCH File/LB
N2-53

N2-01

T7-05

N1-39

$\times 5-55$

N2-34

N2-53

$\mathrm{N2}-33$

$\mathrm{N} 1-72$

N2-51

H6-29

$\times 5-55$

NI -71

N2 -57

A3-30

In a follow-up to our meeting with you and your staff on January 10, 1994, relative to deactivation of the Fast Flux Test Facility (FFTF) area facilities and the applicable acceptance criteria for these facilities to be transferred to the 100 Area Projects (100AP) for decontamination and decommissioning, the 100AP is forwarding the subject information for your use. The proposed criteria is what $100 \mathrm{AP}$ belleves will put the FFTF facilities in the best condition until they are decommissioned. However, as you know, the DOE EM-60 and EM-40 organizations will have the final approval for transfer and acceptance.

If 100AP can be of further assistance in this process, please call me at 373-1184 or Mr. Dick Minship at 376-5768.

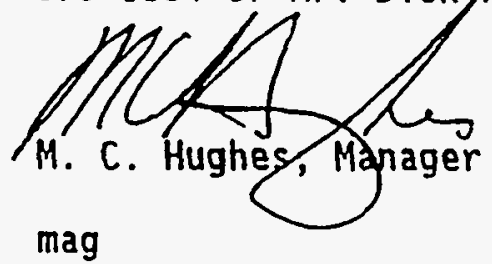

Attachment 


\section{DECONTAMINATION AND DECOMMISSIONING (D\&D) FACILITY ACCEPTANCE. CRITERIA FOR THE FAST FLUX TEST FACILITY (FFTF) AREA FACILITIES.}

The following information provides guidance relative to the acceptance criteria for the eventual transfer of the Fast Flux Test Facility (FFTF) area into the 100 Area Projects (100AP) Program for the purpose of decommissioning. These guidelines are derived from the basic facility transition requirements specified in the DRAFT DOE ORDER 58XX.XX. Iransition of Facilities To The Office of Environmental Restoration and Haste Management, August 27, 1992. These acceptance criteria were designed such that the FFTF area facilities could be maintained in a surveillance and maintenance (S\&M) mode for up to 20 to 25 years before final decommissioning.

Although the following criteria are intended to represent guidelines for transferring facilities from FFTF to 100AP for D\&D, it is expected they will be implemented as suggested unless changes are requested, negotiated, and agreed upon between $100 A P$ and FFTF.

Following is a list of FFTF area facilities that should be completed in accordance with the generic stabilization conditions.

BUILDING NUMBER

$491 E, S, W$

$408 \mathrm{~A}, \mathrm{~B}, \mathrm{C}$

403

4717

4621 E, W

484

481

$481 \mathrm{~A}$

4721

\section{DESCRIPTION}

Containment, main heat transport system piping, reactor vessel, interim decay storage vessel

Secondary heat transport system pumps, piping, support equipment.

Dump heat exchanger buildings, secondary heat transfer heat exchanger, piping, support equipment.

Fuel storage facility, spent fuel, fuel storage vessel, support systems.

Reactor service building, auxiliary support equipment.

Auxiliary equipment east, west building, electrical switchgear, misc. electrical motors and controls.

Cooling water pad, cooling towers and misc. equipment.

Chill water buildings, chillers, misc. equipment.

Fire/sanitary water pump house

Fire/sanitary water pump house

Turbine generator building, electrical switchgear. 
Interim storage area

(No Number)
Interim storage area for above-ground spent fuel casks.

\section{A. Generic Conditions for Facility Transfer to 100 AP}

1. Deactivation of the facility shall be accomplished to the extent that future surveillance inspections will not be required on a frequency of more than once each quarter.

2. Complete the deactivation check sheets for each facility or group of facilities signed off by the responsible personnel performing the actual work and the overview organization with management's approval signatures.

3. Record all deactivation activities in the deactivation log books and reports.

4. Finalize and close out any existing occurrence reports, off-normal occurrence reports, unusual occurrence reports, and/or any other out-ofstandard condition reports in accordance with applicable management requirements and procedures (MRP).

5. The FFTF area Safety Analysis Report or Interim Safety Bases and Plant Emergency Procedures shall be reviewed and updated for activation/ shutdown status in accordance with applicable MRPs.

6. Complete a risk assessment on all the FFTF area facilities and prepare a report on the findings.

7. Assure that certified vendor information, equipment maintenance standards, equipment operating procedures, records, prints, as-builts, photographs, etc., are available in an indexed file and in good up-todate order.

8. Review with 100AP any existing environmental and/or other applicable permits associated with the facilities to determine the status and applicability for maintaining them.

9. Develop an S\&M Plan for guidance to 100AP on future requirements to maintain the facilities in a safe, stable condition until final decommissioning.

10. Assure, where applicable, full compliance with WHC-CM-1-6, WHC Radiological Control Manual, especially as it pertains to radiological posting. This should be accomplished by having Health Physics perform 
an operational safety assessment, followed by operations correcting all noted discrepancies.

11. Decontaminate and release all permanent radiation zones or reduce the surface contamination levels to prevent re-suspension and/or migration of loose contamination in accordance with Health Physics direction, or, with concurrence of 100AP, seal the area.

12. Decontaminate and release all temporary radiation zones inside and outside of facilities or, with the concurrence of 100AP, seal the area.

13. Install a continuous air monitoring system to a level required by the Health Physics organization.

14. Reduce physical areas requiring radiation monitoring to a level required by the Health Physics organization.

15. Facilities criticality monitoring and alarm systems shall be deactivated and tagged out of service following a determination that no reactor fuel exist in the facilities that would contribute to a nuclear criticality excursion.

16. Identify the required environmental monitoring systems and maintain in serviceable condition.

17. Identify any seal pits, dry or wet, and assure that their radiological status is documented and available on file.

18. Clean, drain, and/or remove heels from all tanks, vessels, drums, etc., or, with concurrence of 100AP, leave in place and sample and analyze for radionuclides and hazardous materials in accordance with applicable state and federal regulations. See item B-3 for further details.

19. Assure that final radiological status surveys are available on file for all facilities and for associated process equipment, drains, sumps, and handling equipment.

20. Collect and dispose of all hazardous materials used for deactivation and cleanup work in accordance with established procedures.

21. Remove from facilities all unattached hazardous material (i.e., loose friable asbestos, lead, mercury, etc.,) and dispose of in accordance with established procedures.

22. Locate, identify, and quantify all hazardous material which is attached/ contained and cannot be removed without going into a D\&D mode and record as part of the shutdown/deactivation file.

23. Remove or stabilize loose or damaged asbestos in and around the facilities. 
24. Remove all emergency lighting from the facilities and dispose of A3-7 associated batteries in accordance with applicable procedures.

25. Deactivate, environmentally seal, and tag air supply and exhaust systems, where appropriate.

26. Isolate all liquid effluent flow routes to disposal sites by sealing or capping at the facilities and screening off the outlet end of the discharge pipes for varmint control.

27. Close off all appropriate facility penetrations, i.e., louvers, pipe openings, vent pipes, etc., to prevent bird, animai, and weather intrusions.

28. Adequately close off all systems that were open to facilitate deactivation and could present a radiological and/or an industrial safety problem if left open.

29. Centralize, where applicable, the electrical services left for S\&M activities to one location (i.e., lighting circuits that are required for S\&M).

30. Reduce or eliminate the electrical and water supply services to the facilities in accordance with the requirements of the S\&M plan. Remove and excess all tools and equipment.

31. Assure that there is documentation available on file showing that zero energy checks were made on all electrical circuits that were deenergized.

32. Reduce or eliminate year-round fire protection systems in accordance with the Fire Protection Group.

33. Repair all known facilities roof leaks and/or deteriorated roof panels to ensure roof integrity for at least five years.

34. Deactivate all crane systems with documentation on file as to the type, weight, and class of fluids used in the system so as to aid in any future startups. Also include files that relate to preventative maintenance information.

35. Deactivate, isolate, and tag the buildings steam system.

36. Remove and excess all office furniture.

37. Remove and excess all tools and equipment.

38. Remove all janitorial supplies from facilities

39. Perform good housekeeping in all zones and areas in and around the facilities. 
40. Lock from the inside all doors to the facilities except those required for entrance by S\&M crews. Turn over to 100AP any keys needed for entrance as part of the access and key control procedures. Record all deactivation activities in the deactivation log books and reports.

41. Install liquid level and monitoring equipment in vessels, ion exchange vaults, or sumps that have the potential to receive significant liquid effluents from building leaks, consolidation of flushing solutions or storm water.

42. Provide a file on the operating history of and the spare parts list for plant equipment that is required to be left operational in support of the S\&M activities. This equipment shall not produce any liquid effluent discharges.

43. Repair the containment crane to a state such that it can be utilized during D\&D efforts.

B. In addition to the generic conditions that should be met to transfer FFTF facilities to the 100AP D\&D Program, the following specific conditions are also required for the Transfer of the 403, 405, 408-A, $-B,-C, 491-E,-S,-H$ buildings and the interim storage spent fuel cask pad.

1. Meet the conditions specified in section $A$ above.

2. Determine that all unirradiated and irradiated fuel assemblies have been removed from the above buildings and cask pad. Documented evidence must be available for review that shows all locations where fuel assemblies were handled, stored, and irradiated were thoroughly examined, i.e., reactor core, fuel charge/discharge areas, wet storage areas, shipping and storage areas, etc.

3. Insure that no reactive sodium metal is left in these buildings. Orain and remove all sodium heels from tanks, vessels, piping, sumps, etc. that are/were used for storage/ containment of sodium. This is to assure that no reactive sodium metal is left in these facilities. This requirement also includes any stored equipment which is out of service.

4. Blank the piping systems at the appropriate locations after they have been flushed, cleaned, drained, and heels removed. Enter in the deactivation logbook a record of the blanks installed. A photographic record of the internal vessels should be made where applicable/practical.

$1 / 26 / 94$ 


\section{Appendix A-4}

\section{FFTF Irradiated Non-Fuel Core}

Components Disposition Study 
WHC-SD-FF-SSP-004

Rev. I, Page A4-2

This page intentionally left blank. 
From: $\quad$ FFTF Facility Transition

18300-HDL-001

Phone: 6-4221 N2-53

Date: January 7, 1993

Subject: FFTF IRRADIATED NON-FUEL CORE COMPONENTS DISPOSITION STUDY

To:
J. H. Daughtry
N2-32
N2-34
G. B. Griffin
E. F. Loika
N2-51
D. M. Lucoff
$\mathrm{N} 1-36$
cC: R. A. Almquist A6-55
J. M. Escamillo A6-55
0 . A. Farabee $\quad A 6-55$
S. Guttenberg N2-53
S. W. Hiller
N2-33

D. J. Swaim

$N 2-51$

J. E. Truax

N2-33

J. B. Waldo

N2-57

A. E. Waltar

$\mathrm{HO}-32$

R. W. Kolowith

N2-53

H. D. Lenkersdorfer

$\mathrm{N2}-53$

J. L. Marshal1

$\mathrm{N2}-02$

R. B. Packard

N2-53

Reference: Letter, D. J. Swaim, HHC, to J. E. Mecca, RL, "Sodium Removal Location for FFTF Fuel," 9257150, dated September 28, 1992.

\section{EXECUTIVE SUMMARY}

The Fast Flux Test Facility (FFTF) contains irradiated non-fuel core components (control rods, reflectors, characterizers, experiments, in-core shim assemblies, gas expansion modules (GEMS), and material test assemblies) resulting from plant operation. These core components are irradiated and sodium wetted in a manner similar to the Reactor Vessel internals including the In-Vessel Handling Machines (IVHMs) and Instrument Trees (ITs).

The study conducted herein evaluated the disposition of the subject non-fuel core components, in the event of an FFTF shutdown, and concluded that this hardware should be placed and stored in the Reactor Vessel pending ultimate disposition consistent with the Reactor Vessel and its internals. This evaluation is summarized in the Attachment. Based on the associated cost savings, waste minimization and schedular enhancement, this approach will be used as the project position for planning purposes.

\section{INTRODUCTION}

The original plans for disposition of FFTF irradiated non-fuel core components that had reached "end of life," consistent with long-term operation of the facility, included removal from the Reactor Vessel to insodium storage in the Interim Decay Storage (IDS) Vessel or the Fuel Storage Facility (FSF), removal from in-sodium storage and transport to the Maintenance and Storage Facility (MASF), removal of the residual sodium in the Smal1 Diameter Cleaning Vessel (SDCV), loading into Disposable Solid Waste Casks (DSWCs), and disposal in the 200 Area. Removal of these 
irradiated core components from in-sodium storage was necessary to maintain or extend adequate in-sodium storage capacity for spent fuel. A Part A/Part $B$ Resource Conservation and Recovery Act (RCRA) permit application was submitted for MASF in November, 1985, for treatment (by washing) of the sodium residuals from these waste core components prior to their disposal. MASF currently has interim status under RCRA for this operation. This continues to be the logical path if the FFTF receives a long term mission.

If the FFTF were to receive a shutdown directive from its current standby status, two options exist for the disposition of this hardware:

Option 1: Remove residual sodium and dispose of the irradiated non-fuel core components; or,

Option 2: Store the irradiated non-fuel core components in the Reactor Vessel for disposition with other irradiated components at a later date.

The purpose of this Position Paper is to pursue these two shutdown options and formulate a preferred strategy. In so doing, it is necessary to develop the inter-relationship between the disposition of irradiated fuel and irradiated non-fuel components.

\section{IRRADIATED FUEL DISPOSITION FOR THE SHUTDOHN SCENARIO}

The core components in the reactor core are dependent on each other to maintain a vertical position. If too many of these assemblies are removed, the adjacent remaining core components would tilt from vertical precluding grappling with the IVHM. Consequently, as each assembly is removed, another core component must be installed in its place to maintain the core configuration. The initial group of non-fuel core components were installed in the reactor core by hand prior to Reactor Vessel sodium fill. At the same time, Simulated Core Assemblies (SCAs) were installed in that part of the core that would receive actual fuel assemblies or control rods after sodium fill. During initial fuel load, the SCAs were replaced with fuel assemblies using the IVHMs. The residual sodium was removed from the SCAs and the components were placed in storage.

During reactor defueling at shutdown, as each fueled core component is removed from the core, one of the SCAs or a non-fuel core component would be inserted in its place to maintain the core configuration. Currently, there are 63 Driver Fuel Assemblies (DFAs) and 16 fueled experiments in the core. There are also 46 DFAs and one fueled experiment in In-Vessel Storage (IVS). Core components in IVS are held in the vertical position without adjacent core components and therefore, they can be removed without replacement. 
If a shutdown order were received in CY-93 without restarting the reactor, all of the fuel in the Reactor Vessel would have decay heat levels less than $1.4 \mathrm{KW}$ and could be moved to the FSF or IDS without any further decay period. Decay heat is limited to less than 250 watts per fuel assembly in both the Core Component Container (CCC) and the Interim Storage Cask (ISC); consequently, an additional decay period in the FSF or IDS would be required for some fuel prior to sodium removal and cask storage. There are also a small number of Safeguard Category IC and IIID fuel assemblies that are stored in sodium. These constitute assemblies that have never been irradiated in the reactor core, have been irradiated for only a short period of time, or have decayed sufficiently to no longer be self-protecting from a Safeguard standpoint. These assemblies will remain in-situ until appropriate storage facilities are made available.

A recently conducted study selected the IEM Cell and the RSB Cask Loading Station (CLS) as the preferred fuel washing and storage cask loading locations in the event of an FFTF shutdown directive (see Reference), contingent upon formal DOE concurrence. (However, if a long-term mission is assigned to FFTF, MASF will remain the designated sodium removal location to minimize IEM Celi congestion and enhance mission success.) Fuel offload washing in the IEM Cell could commence as soon as Interim Storage Casks (ISCs) and the Interim Storage Area (ISA) are available for storage and following some minor modifications to the RSB CLS and the IEM Cell sodium removal system.

\section{OPTION 1: REMOVE SODIUM AND DISPOSE OF IRRADIATED NON-FUEL CORE COMPONENTS}

The designs of the core component nozzles and various core positions in the FFTF provide for mechanical discrimination to preclude incorrect loading (e.g., the 2-inch diameter discriminator post on an outer DFA preclude its insertion in any Row 1-5 inner DFA position). If this option were

implemented, all 199 positions of the reactor core would require replacement with SCAs designed to fit the various core position configurations.

The irradiated non-fuel core components, would be processed through the IEM Cell in a manner similar to the fuel. A total of 220 units would be loaded into 37 DSWCs and transported to the 200 Area for disposal. This washing activity would require compliance with RCRA. The 199 SCAs in the reactor core would become contaminated but not activated. As additional waste, they would be dispositioned along with the Reactor Vessel internals, IVHMs, ITs, etc., at a later date. 
WHC-SD-FF-SSP-004

Rev. 1, Page A4-6

J. H. Daughtry, et al.

$18300-\mathrm{HDL}-001$

Page 4

January 7, 1993

\section{OPTION 2: STORE THE IRRADIATED NON-FUEL CORE COMPONENTS IH THE REACTOR VESSEL}

Irradiated fuel removed from the Reactor Vessel would be replaced with irradiated non-fuel core components located in IDS or FSF wherever their discriminator posts are compatible with the specific core position. This includes 30 reflectors that can be placed in Row 6, 18 other irradiated nonfuel core components that can be stored in Rows 1-5, and a 1157 positions in IVS. The remaining core positions would be filled with the SCAs used in initial fuel load. At this time, 221 FFTF irradiated non-fuel core components exist in the FFTF irradiated non-fuel core component inventory. One of these, a Materials Open Test Assembly (MOTA) would be processed through the IEM Cell as part of the experiment load. Of the remaining 220 irradiated non-fuel core components, 165 would be placed in core positions that would accept their discriminator posts. The remaining irradiated nonfuel core components would be placed in 55 of the 57 positions in IVS. A total of 34 SCAs would be required to fill the remaining core positions. Consequently, all existing FFTF irradiated non-fuel core components can be centrally stored in the Reactor Vessel as the fuel is removed.

At the completion of reactor offload, the irradiated fuel would be in the FSF and IDS and the irradiated non-fuel core components would be in the Reactor Vessel. The latter would remain in the Reactor Vessel and be dispositioned with vessel internals, IVHMs, ITs, etc., at a later date. It is recognized that the non-fuel core components would increase the radiation level in the reactor vessel; however, it is not expected to significantly affect this final disposition. Waste minimization would be achieved by using the irradiated non-fuel core components already in sodium storage in place of SCAs.

\section{COST AND SCHEDULE COMPARISON}

Removing the residual sodium from the existing 220 irradiated non-fuel core components in the IEM Cell will increase the system usage by over fifty percent. This would extend the overall IEM Cell shutdown schedule by approximately 1.5 years.

The operational cost of maintaining the process systems, transfer equipment and plant personnel for this additional period, coupled with the costs of casks and disposal, would add an estimated $\$ 30-40 M$ to shutdown, with no obvious technical benefit. 
J. H. Daughtry, et al.

18300-HDL-001

Page 5

January 7, 1993

\section{CONCLUSION}

It is concluded that, for both technical and programmatic considerations, retaining the irradiated non-fuel core components in the Reactor Vessel following shutdown is clearly the preferred alternative. This approach will be used as the project position for planning purposes.

\section{$H$. $D$. Lenkersdorfer}

FFTF Facility Transition

bgs

Attachment 1

CONCURRENCE

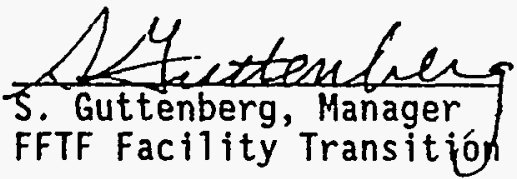

APPROVAL

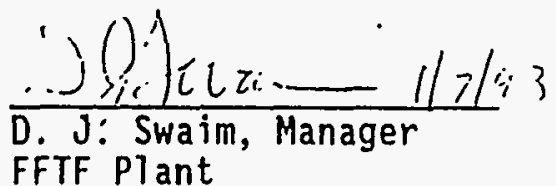




\section{ATTACHMENT}

\section{SUMMARY TABLE}

EFIF IRRADIATED NON-FUEL CORE COMPONENT DISPOSITION OPTIONS

\begin{tabular}{|l|c|c|}
\hline & $\begin{array}{c}\text { OPTION 1 } \\
\text { CLEAN \& DISPOSE OF NON- } \\
\text { FUEL CORE COMPONENTS }\end{array}$ & $\begin{array}{c}\text { OPTION 2 } \\
\text { STORE NON-FUEL CORE } \\
\text { COMPONENTS IN REACTOR } \\
\text { VESSEL }\end{array}$ \\
\hline $\begin{array}{l}\text { DISPOSABLE SOLID HASTE } \\
\text { CASKS REQUIRED }\end{array}$ & 34 & 0 \\
\hline $\begin{array}{l}\text { CORE COMPONENT } \\
\text { CONTAINERS REQUIRED }\end{array}$ & 34 & 0 \\
\hline $\begin{array}{l}\text { IEM CELL HASTE } \\
\text { GENERATED }\end{array}$ & YES & NO \\
\hline $\begin{array}{l}\text { IEM CELL RCRA PERMIT } \\
\text { REQUIRED }\end{array}$ & YES & NO \\
\hline $\begin{array}{l}\text { LOCATION OF IRRADIATED } \\
\text { NON-FUEL CORE COMP }\end{array}$ & 200 AREA DISPOSAL SITE & REACTOR VESSEL \\
\hline SCAS REQUIRED & 199 & 34 \\
\hline NEH SCAS REQUIRED & YES & NO \\
\hline $\begin{array}{l}\text { ADDITIONAL IEM CELL } \\
\text { PROCESSING TIME }\end{array}$ & 1.5 YEARS & NONE \\
\hline ADDITIONAL COST & $\$ 30-40$ MILLION & NONE \\
\hline
\end{tabular}




\section{Appendix A-5}

\section{FFTF Reactor Defueling Plan}


WHC-SD-FF-SSP-004

Rev. 1, Page A5-2

This page intentionally left blank. 


\section{APPENDIX A-5}

\section{FFTF REACTOR DEFUELING PLAN}

The purpose of this evaluation is to determine the estimated time to defuel the reactor. This study will also layout some of the constraints and issues to defuel the reactor vessel and place within the reactor vessel (core and IVSM) all sodium wetted, irradiated non-fuel core components currently in FFTF inventory for long-term storage and/or disposal.

Assumptions (or actual conditions as of 2-16-94):

(1) 17 modified MTAs (1" discriminator post) are available for installation into IDS.

(2) All fuel will be removed from the core:

60 DFAs

14 Fueled Experiments

(3) Core locations by row (fueled rows only):

91 locations:

1 in row 1

6 in row 2 (two required to be left vacant - 1202 and 3202)

12 in row 3 (three with control rods)

18 in row 4

24 in row 5 (six with control rods)

30 in row 6

(4) A11 fuel will be removed from IVSM:

40 DFAs

2 fueled experiments

(5) Durations for component transfers:

100\% AVAILABILITY TIMES:

- 1 day ( 24 hours) to transfer component between IDS and FSF

- 1 day (24 hours) to receive and transfer MTA into IDS

- H day ( 8 hours) to exchange components between reactor and IDS

- 3 days (72 hours) to replace a center island test position

(6) Limitations:

- $40 \mathrm{~kW}$ for IVHM handling - not a constraint

- $7 \mathrm{~kW}$ (operational) for CLEM handling - not a constraint

- $1.4 \mathrm{~kW}$ for BLTC handling - not a constraint

- $155 \mathrm{~kW}$ for IDS - not a constraint

- $50 \mathrm{~kW}$ for FSF - not a constraint 
(7) The quantity of fueled components being transferred to FSF will not require the operation of the FSF NaK loops as the total inventory of fueled assemblies will be less than $50 \mathrm{~kW}$ by December 1994 (based on last reactor operation to March 19, 1992).

(8) All components are less than $1.4 \mathrm{~kW}$ after February 1993.

(9) IDS decay heat is $\approx 13 \mathrm{~kW}$.

(10) FSF decay heat is $\approx 24 \mathrm{~kW}$.

(11) IVS decay heat is $\approx 11 \mathrm{~kW}$.

(12) There are 32 green and three low dose-rate fuel assemblies (Category IC) in IDS.

(13) All irradiated (high dose-rate) fueled components will remain in FSF or IDS until long-term storage is available (not available at this time).

(14) All Category IC components will remain in IDS until a program has been put into place to remove the Category IC components from IDS, wash them of sodium, and place them into a long-term storage container - possibly something simitar to the RRSC.

(15) CLEM drip pot changeout is required for every 50 transfers

- 3 days for changeout

(16) BLTC drip cup changeout is required for every 15 transfers

- 3 days for changeout

(17) Craft support needed for port opening/closing

- Monday through Friday day shift only

- Manpower - one Health Physics Technician, one Rigging Person-InCharge, two Riggers, one Crane Operator

(18) Operators and Health Physics Technicians are available 24 hours a day, seven days a week.

(19) Staffing limitations are assumed allowing only two major defueling activities to occur at any one time (one Health Physics Technician, two Refuelers, one Refueling Engineer).

(20) Refueling port opening or closing times.

- FTP - 2 days

- IDS - 1 day

- FSF - 1 day 
(21) The new MTAs will have their discriminator post bobbins removed so they can be inserted into any standard core location. This changes their discriminator post from a 2" diameter to a 1" diameter.

(22) The non-fuel Material Test Assemblies HMO60 and HM061 were not designed for handling by the IVHM, therefore, they will not be inserted into the reactor vessel, but will remain in FSF.

(23) This offload will not require opening of the 3 sealed rows at FSF that were sealed due to criticality concerns. The currently available locations at FSF are sufficient to support this defueling.

(24) To accommodate the defuel ing effort and to also not require the loading of additional unirradiated components, the defueling will need to allow for additional non-adjacent vacancies. This would require a change to the FFTF FSAR of the current seven vacancy limit. These positions would be selected so as to ensure the control rods remain in the 9 control rod core locations and to a7so leave core locations 1202 and 3202 empty.

(25) Locations 1202 and 3202 were requested to be left vacant as they provide vessel access very near to the center and can be accessed through the standard Center Island spoolpiece at the vessel head penetration. Location 2202 has vessel instrumentation at the head penetration and the Instrument Tree in that sector covers the 2202 core location. However, 2202 and several other core locations will be left vacant to accommodate the core defueling.

(26) The VOTA and IRTA assemblies are the only 40 foot, irradiated test assemblies that can be reinserted into the vessel (i.e., all of the MOTAs do not have ducts installed). The VOTA uses all standard SCE equipment and should therefore be reinserted. The IRTA is non-standard and therefore may require substitution of a non-fuel assembly and a PIOTA if the IRTA tooling cannot be obtained.

(27) There are 30 non-fuel, irradiated Open Test Assemblies (OTAs) currentiy stored in the reactor vessel, IDS, TACS and the IEM Cell. Eight of these will be reinserted into the reactor vessel and are listed in the Confirmed Core Map (Above Core Component Map, CM.DEFUEL.2), the remaining 22 OTAs will remain in IDS, TACS and the IEM Celi until a final disposition is determined. 
Inventory Summary - Pre-Defueling:

\section{- Reactor Vessel}

199 total core positions

57 total IVSM positions

120 fueled components in the reactor vessel

Core : 74 fueled components

IVS : 46 fueled components

127 non-fueled components in the reactor vessel

Core : 125 non-fueled components

IVS : 2 non-fueled components

- Interim Decay Storage (IDS)

112 positions available in IDS for CCPS

- 5 locations w/o CCPS

- I CCP with a pedestal

- 2 CCPs currently empty

- 3 components awaiting PIE

-35 components that await Shutdown Phase 2 processing

68 locations available for offload

90 fueled components in IDS

78 driver fuel assemblies

12 fueled experiments

16 non-fueled components in IDS

5 control rods

4 CRFS

5 Reflectors

2 Test Assemblies

- Fuel Storage Facility (FSF)

160 fueled components in FSF

4 fueled characterizes

69 driver fuel assemblies

49 fueled experiments

38 Ident $69 \mathrm{~s}$

79 non-fueled components in FSF

7 non-fuel characterizes

16 control rods

3 no-fuel test

3 ICSAS

6 GEMS

44 Reflectors 
Inventory Summary - Post-Defueling:

- Reactor Vessel

199 total core positions

57 total IVSM positions

No fueled components in the reactor vessel

236 non-fueled components in the reactor vessel

Core : 181 non-fueled components

IVS : 55 non-fueled components

- Interim Decay Storage (IDS)

112 fueled components in IDS

- Fuel Storage Facility (FSF)

258 fueled components in FSF

2 non-fueled components in FSF 


\section{DEFUELING TIME ESTIMATE}

STEP 1: Transfers between IDS and FSF - 1:

A) BLTC offload of 42 components from IDS to FSF

BLTC return 30 components from FSF to IDS:

[(42 components) ( 1 day/transfer)] + [(2 FSF port openings) (1 day/port opening) $]+[$ ( 2 FSF port closings) (1 day/port closing) $]+[$ (1 IDS port closings) (1 day/port closing) $]+[$ (1 IDS port openings)( 1 day/port opening $)]+[(42$ transfers $) /(15$ transfers/dripcup changeout) ( 3 days/changeout)]

\section{$=55$ days}

STEP 2: Receive \& Load MTAS/SCAS into IDS:

- 7 fresh, non-fuel components loaded into IDS

(7 MTA) (1 day/transfer) $+[$ ( 3 cCCS port openings) + ( 3 CCCS port closings)] (1 day)

$$
=23 \text { days }
$$

\section{STEP 3: Perform Defueling of Sector 1}

- CLEM transfers 23 components from IDS to Reactor core

- CLEM transfers 26 components from Reactor to IDS

- CLEM transfers 19 components from IDS to IVS

- CLEM transfers 19 components from IVS to IDS

- Includes defueling of 4 center Is land locations

[(47 CLEM transfers) (\% days/transfer) + (1 FTP port openings + 1 FTP port closing) (2 days/port) + (1 CLEM drip pot changeout) ( 3 days / changeout) + (1 IDS port openings) (1 day/port opening) + (4 center island positions)(3 days) + (2 CLEM grapple exchanges) (2 days)]

$$
=40 \text { days }
$$


STEP 4: Transfers between IDS and FSF - 2:

A) BLTC offload of 54 components from IDS to FSF

BLTC return 44 components from FSF to IDS:

[(54 components) (1 day/transfer)] + [(3 FSF port openings) ( 1 day/port opening) $]+[$ ( 3 FSF port closings) (1 day/port closing $)]+[(1$ IDS port closings) (1 day/port closing) $]+[$ (1 IDS port openings) (1 day/port opening $)]+[(54$ transfers $) /(15$ transfers/dripcup

changeout) ( 3 days/changeout) ]

$$
\text { = } 73 \text { days }
$$

STEP 5: Perform Defueling of Sector 2

- CLEM transfers 14 components from IDS to Reactor (core \& IVS)

- CLEM transfers 18 components from Reactor to IDS

- CLEM transfers 15 components from IDS to IVS

- CLEM transfers 18 components from IVS to IDS

[(36 CLEM transfers) (1/3 days/transfer) + (1 FTP port openings + 1 FTP port closing) (2 days/port) + ( 1 CLEM drip pot changeout) ( 3 days / changeout) + (1 IDS port openings)(1 day/port opening)]

$$
=44 \text { days }
$$

STEP 6: Transfers between IDS and FSF - 3:

A) BLTC offload of 17 components from IDS to FSF BLTC return 10 components from FSF to IDS:

[(17 components) (1 day/transfer) $]+[$ (2 FSF port openings) ( 1 day/port opening $)]+[(2 \mathrm{FSF}$ port closings) (1 day/port closing) $]+[$ (1 IDS port closings)(1 day/port closing)] $+[$ (1 IDS port openings)(1 day/port opening $)]+[(17$ transfers $) /(15$ transfers/dripcup changeout) ( 3 days/changeout) ]

26 days 
WHC-SD-FF-SSP-004

Rev. 1, Page A5-10

\section{STEP 7: Perform Defueling of Sector 3}

- CLEM transfers 19 components from IDS to Reactor (core \& IVS)

- CLEM transfers 25 components from Reactor to IDS

- CLEM transfers 19 components from IDS to IVS

- CLEM transfers 19 components from IVS to IDS

- Includes defueling of 3 center Island locations

[(44 CLEM transfers) (') days/transfer) + (1 FTP port openings +1 FTP port closing) (2 days/port) + (1 CLEM drip pot changeout) ( 3 days / changeout) + (1 IDS port openings)(1 day/port opening) + (3 center island positions)( 3 days) + (1 CLEM grapple exchanges)(2 days)]

$$
=34 \text { days }
$$

STEP 8: Final IVS/IDS/FSF Transfers to Complete Core Defueling:

A) BLTC offload of 16 components from IDS to FSF BLTC return 6 components from FSF to IDS

B) CLEM transfers 6 components from IDS to Reactor (core \& IVS)

C) CLEM transfers 6 components from Reactor to IDS

[(16 components) (1 day/transfer)] + [(2 FSF port openings) ( 1 day/port opening $)]+[(2$ FSF port closings) (] day/port closing) $]+[(1$ IDS port closings) (1 day/port closing) $]+$ [(1 IDS port openings)(1 day/port opening $)]+[(16$ transfers $) /(15$ transfers/dripcup changeout) ( 3 days/changeout) $]+[$ [ 6 CLEM transfers) (\% days/transfer) + (2 FTP port closings) (2 days/port closing)]

$$
=31 \text { days }
$$

TOTAL TIME TO DEFUEL CORE and IVSM:

- STEP 1 Offload/load IDS - 1

- STEP 2 Load MTA into IDS

- STEP 3 Core Defuel - Sector 1

- STEP 4 Offload/load IDS - 2

- STEP 5 Core Defuel - Sector 2

- STEP 6

- STEP 7

- STEP 8
Offload/load IDS - 3

Core Defuel - Sector 3

Final IVS/IDS/FSF Transfers
55 days

23 days

40 days

73 days

44 days

26 days

34 days

31 days 